\title{
ATMOSPHERIC PROFILING USING THE LIDAR TECHNIQUE
}

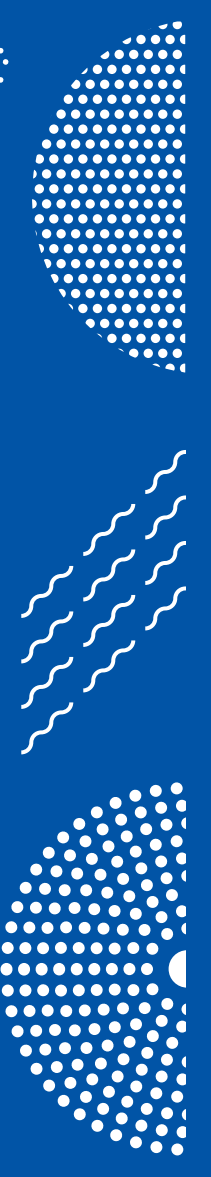

MARIA FILIOGLOU 
FINNISH METEOROLOGICAL INSTITUTE CONTRIBUTIONS

No. 166

\title{
ATMOSPHERIC PROFILING USING THE LIDAR TECHNIQUE
}

\author{
Maria Filioglou \\ Finnish Meteorological Institute \\ Atmospheric Research Centre of Eastern Finland \\ Kuopio, Finland \\ 2020
}

Academic dissertation

To be presented by the permission of the Faculty of Science and Forestry for public examination through video connection at the University of Eastern Finland, Kuopio, on June 17, 2020, at 12 o'clock noon 
ISBN 978-952-336-109-6 (paperback)

ISBN 978-952-336-110-2 (pdf)

ISSN 0782-6117

Edita Prima Oy

Helsinki 2020 


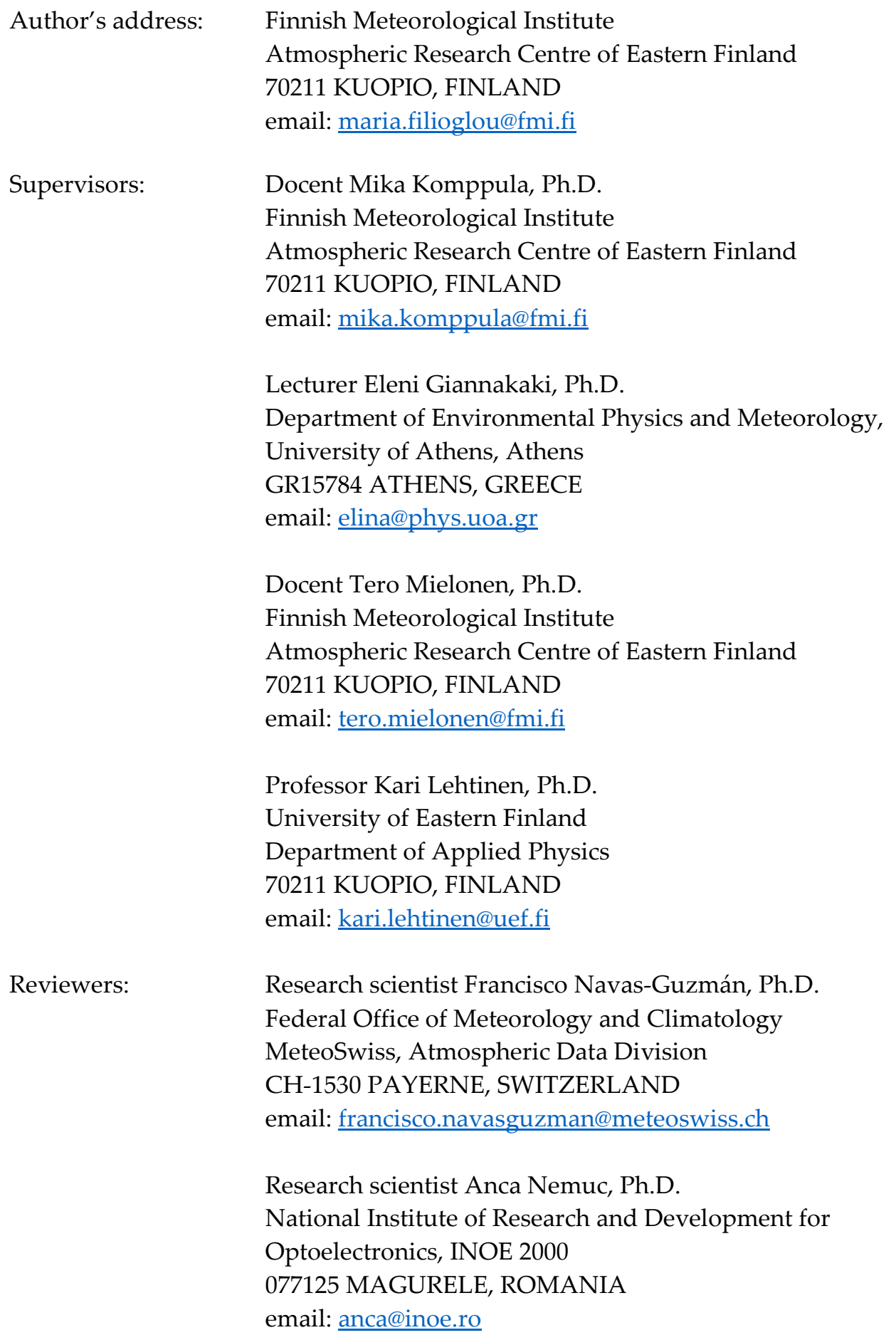


Opponent: $\quad$ Research scientist Franco Marenco, Ph.D.

Met Office

EX1 3PB EXETER, UNITED KINGDOM

email: franco.marenco@metoffice.gov.uk 
Published by Finnish Meteorological Institute

Erik Palménin aukio 1, P.O. Box 503

FIN-00101 Helsinki, Finland
Series title, number, and report code of publication

Finnish Meteorological Institute Contributions, 166, FMI-CONT-166

Date: May 2020

Author(s)

\section{Maria Filioglou}

\section{Title}

\section{Atmospheric profiling using the lidar technique}

\section{Abstract}

Atmospheric aerosol particles absorb and scatter solar radiation, altering directly the radiation balance. Indirectly, these particles have a complex interplay in cloud formation, affecting cloud reflectivity and cloud lifetime. Apart from the climatic effects, atmospheric particles pose negative health effects and they reduce visibility with adverse effects in road traffic and aviation safety.

To improve the understanding of the aerosol effect on climate four different studies have been conducted. The main instrument utilized to retrieve vertical profiles of the aerosols was a multi-wavelength Polly ${ }^{\mathrm{XT}}$ lidar. The hygroscopic effect of the aerosol particles in the retrieved optical properties which is relevant to cloud studies can be assessed using the water vapor capabilities of the lidar. Lidar water vapor retrieval requires initial calibration. An evaluation of the different lidar water vapor signal calibration techniques was performed to quantify the uncertainty in the retrieved water vapor profiles. Moreover, two measurement campaigns were held in Finland and the United Arab Emirates in order to characterize the properties of understudied aerosol types (pollen and Arabian dust). Lastly, the effectiveness of the different aerosol types to the formation of ice, water, or mixedphase clouds in the Arctic was determined using a synergy of a spaceborne lidar (CALIOP) and a cloud radar (CloudSat).

The study on water vapor showed that accurate water vapor retrievals are subject to the calibration factor. Operational on-site radiosondes are the best option, but robust retrievals are possible using data from the nearest radiosonde site or modelled data. Satellite-derived water vapor profiles performed the poorest, yet they could serve as an option in the absence of better information. The analysis of the pollen observations showed that the classification of various pollen types is possible, although challenging. Characterization requires shape information from at minimum two linear particle depolarization wavelengths, as well as external information such as airmass backward trajectories to ensure that other non-spherical aerosol particles such as dust are not present over the measurement site. Regarding the Arabian dust optical properties, it was found that this aerosol type exhibits different optical properties, specifically concerning the lidar ratios, than the dust originating from the Saharan region. Consequently, the universal lidar ratio of $55 \mathrm{sr}$ currently used in lidar-based applications may lead to biases for dust originating from the Arabian Peninsula. The Arctic study on aerosol-cloud interactions showed that higher aerosol load was associated with higher occurrence of mixed-phase clouds. On the contrary, moderate association was found with varying the aerosol type. Nevertheless, meteorology outweighed the aerosol load importance over less stable atmospheric conditions, for example, over open ocean.

Publishing unit

Finnish Meteorological Institute, Atmospheric Research Centre of Eastern Finland

Classification (UDC)

$528.8 .042,528.8 .044 .6,532.243,551.521 .3$

$551.501 .86,52-64,54-138$

\section{Keywords}

Remote sensing, aerosols, clouds, satellite, measurements

ISSN and series title

0782-6117 Finnish Meteorological Institute Contributions

\begin{tabular}{lll}
\hline ISBN & Language & Pages \\
$978-952-336-109-6$ (paperback) & English & 158
\end{tabular}

978-952-336-110-2 (pdf) 
Julkaisija

IImatieteen laitos

Erik Palménin aukio 1

PL 503, 00101 Helsinki
Julkaisun sarja, numero ja raporttikoodi

Finnish Meteorological Institute Contributions, 166, FMI-CONT-166

Päiväys

Toukokuu 2020

Tekijä(t)

Maria Filioglou

Nimeke

IImakehän luotaaminen lidar-tekniikalla

\section{Tiivistelmä}

Tässä väitöskirjassa tutkittiin ilmakehän pienhiukkasten ominaisuuksia ja niiden vaikutusta pilviin hyödyntämällä useiden kaukokartoitusmenetelmien synergiaa. Tutkimuksessa käytettiin pääasiassa PollyXT-lidar-mittalaitetta. Tutkimus jakautui kolmeen kokonaisuuteen: 1) Arvioitiin eri kalibrointimenetelmien aiheuttamaa epävarmuutta lidar-mittauksiin pohjautuvissa vesihöyryprofiileissa. 2) Määritettiin Suomessa ja Yhdistyneissä arabiemiirikunnissa tehtyjen mittausten avulla siitepölyn ja aavikkopölyn optiset ominaisuudet. 3) Selvitettiin miten erilaiset pienhiukkastyypit vaikuttavat erityyppisten pilvien muodostumiseen Arktisella alueella hyödyntämällä satelliittipohjaisia lidar- (CALIOP) ja tutkahavaintoja (CloudSat).

Vesihöyrytutkimus osoitti, että tarkat lidar-havainnot vesihöyrystä vaativat tarkan kalibroinnin muiden mittausten avulla. Parhaaseen tulokseen päästään käyttämällä radioluotauksia samalta asemalta mutta niiden puuttuessa voidaan käyttää myös radioluotauksia lähiseudulta tai mallinnettuja vesihyöryprofiileja. Heikoin tulos saatiin satelliittihavaintoja käyttämällä, mutta niistäkin on apua parempien tietolähteiden puuttuessa. Siitepölymittaukset osoittavat, että siitepölytyyppien tunnistaminen lidar-mittausten avulla saatavien optisten ominaisuuksien perusteella on mahdollista, vaikkakin haastavaa. Tyyppien tunnistamiseksi mittauksista täytyy saada tietoa hiukkasten muodosta, koosta sekä kyvystä absorboida valoa. Lisäksi pitää varmistaa, että havaintoja eivät ole häirinneet muut ei-pallomaiset hiukkaset, kuten aavikkopöly, käyttämällä tietoa ilmamassojen kulkureiteistä. Mittaukset Arabian niemimaan aavikkopölystä paljastivat, että sen optiset ominaisuudet poikkeavat Saharan pölystä, etenkin lidarsuhteen osalta. Täten lidar-mittausten analyyseissa usein käytetty lidarsuhde aavikkopölylle ei vastaa Arabian niemimaan aavikkopölyä. Tutkimus pienhiukkasten ja pilvien vuorovaikutuksesta Arktisella alueella osoitti, että pienhiukkasten määrän kasvaessa pilvet, jotka sisältävät sekä vettä että jäätä, lisääntyvät. Pienhiukkastyypin vaikutus pilviin oli huomattavasti pienempi. Sen sijaan ilmakehän ollessa epävakaa, esimerkiksi avomeren päällä, pilvien ominaisuudet riippuivat enemmän ilmakehän virtauksista kuin pienhiukkasten pitoisuudesta tai tyypistä.

Julkaisijayksikkö

IImatieteen laitos, Itä-Suomen ilmatieteellinen tutkimuskeskus

Luokitus (UDK)

$528.8 .042,528.8 .044 .6,532.243,551.521 .3$

$551.501 .86,52-64,54-138$
Asiasanat

Kaukokartoitus, aerosolit, pilvet, satelliitit, mittausmenetelmät

ISSN and series title

0782-6117 Finnish Meteorological Institute Contribution

ISBN

978-952-336-109-6 (nidottu)

978-952-336-110-2 (pdf)

$\begin{array}{ll}\text { Kieli } & \text { Sivumäärä } \\ \text { Englanti } & 158\end{array}$

Kieli

158 


\section{Acknowledgements}

The work presented in this dissertation has been carried out at the Atmospheric Research Centre of Eastern Finland in Kuopio at the Finnish Meteorological Institute. I am grateful to research Professor Sami Romakkaniemi for the opportunity to work in Kuopio and for all the consultation and encouragement given throughout this thesis. I could not imagine any better support all these years.

I also express my gratitude to my four supervisors: Doc. Mika Komppula for giving me the opportunity to work in challenging yet interesting research projects and field campaigns all around the world. Thank you for trusting me to find my own solutions. Doc. Eleni Giannakaki for the very relevant comments that pushed me to try harder; Doc. Tero Mielonen for always having the time to discuss my concerns and research-related issues, despite the myriad times I've knocked his office door! It must not have been always very pleasant, and I am grateful for all the support; Prof. Kari Lehtinen for trusting me and being available every time I reached out to him.

I wish to thank the preliminary examiners, Dr. Anca Nemuc and Dr. Francisco Navas-Guzmán for critically reviewing this thesis and for their valuable comments and Dr. Franco Marenco for agreeing to be my opponent. I am also very thankful to Dr. Eimear M. Dunne for all the advices on scientific writing and for proofreading some of the papers in this dissertation. It has been an enjoyment to spend my office years at Kuopio with you. My thanks also go to the members of FMI Kuopio Unit. It has been refreshing to spend coffee breaks and share all kinds of things with you inside and outside the workplace.

Finally, my warmest thanks to my friends, my partner and my family for supporting me all these years. It would have been a lot harder without all of you.

\section{Maria Filioglou}

Helsinki, 2020 



\section{CONTENTS}

List of original publications .......................................................................11

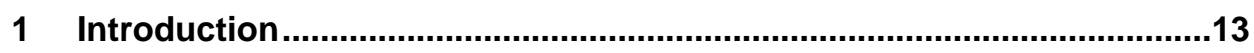

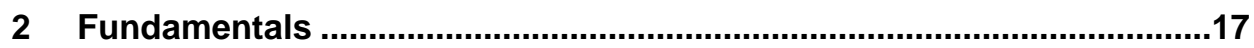

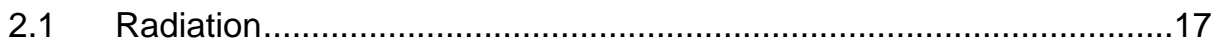

$2.2 \quad$ Atmospheric aerosol particles .....................................................21

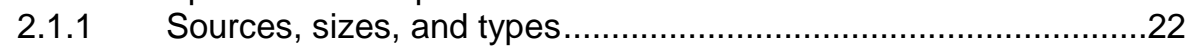

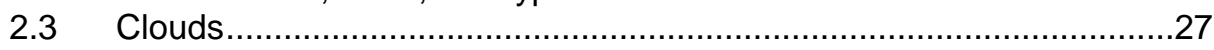

2.4 Radiative forcing by aerosols and clouds ............................................30

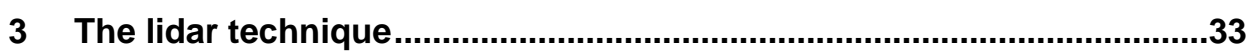

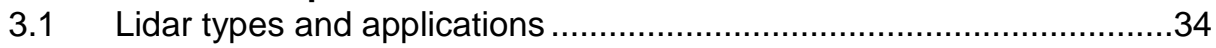

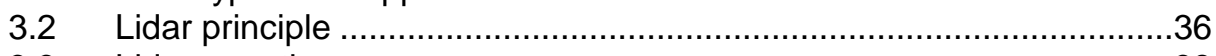

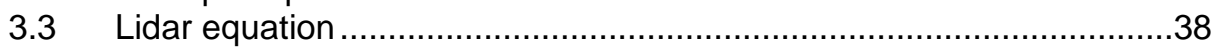

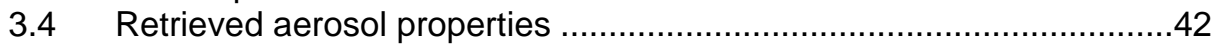

3.4.1 Optical properties....................................................................

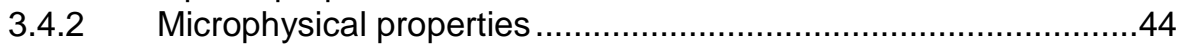

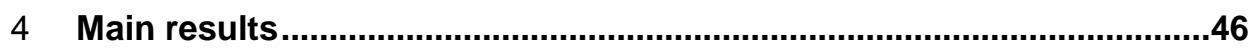

4.1 Water vapor mixing ratio and its link to atmospheric particles .............46

4.2 Optical properties of pollen particles …………………………..........48

4.3 Optical properties of Arabian dust .......................................................51

4.4 Importance of atmospheric particles in low-level Arctic clouds ..............54

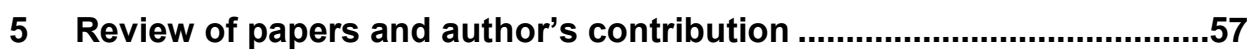

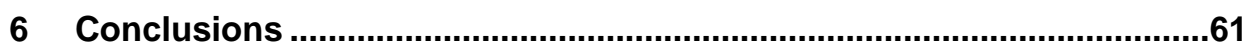

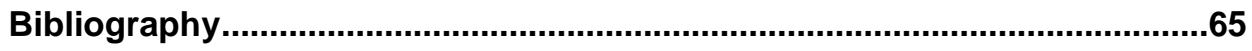





\section{List of original publications}

This thesis is based on research presented in the following articles, referred to by the Roman numerals I-IV. Throughout the thesis, the papers will be referred to by these numerals.

I Filioglou M, Nikandrova A, Niemelä S, Baars H, Mielonen T, Leskinen A, Brus D, Romakkaniemi S, Giannakaki E, Komppula M. (2017). Profiling water vapor mixing ratios in Finland by means of a Raman lidar, a satellite and a model. Atmospheric Measurement Techniques, 10: 4303-4316, https://doi.org/10.5194/amt-10-4303-2017.

II Bohlmann S, Shang X, Giannakaki E, Filioglou M, Saarto A, Romakkaniemi S, Komppula M. (2019). Detection and characterization of birch pollen in the atmosphere using a multi-wavelength Raman polarization lidar and Hirst-type pollen sampler in Finland. Atmospheric Chemistry and Physics. 19: 14559-14569, https://doi.org/10.5194/acp-19-14559-2019.

III Filioglou M, Giannakaki E, Backman J, Kesti J, Hirsikko A, Engelmann R, O'Connor E, Leskinen J. T. T, Shang X, Korhonen H, Lihavainen H, Romakkaniemi S, and Komppula M. (2020). Optical and geometrical aerosol particle properties over the United Arab Emirates, Atmospheric Chemistry and Physics Discussion, https://doi.org/10.5194/acp-2020-133.

IV Filioglou M, Mielonen T, Balis D, Giannakaki E, Arola A, Kokkola H, Komppula M, Romakkaniemi S. (2019). Aerosol effect on the cloud phase of low-level clouds over the Arctic. Journal of Geophysical Research: Atmospheres, 124: 7886-7899, https://doi.org/10.1029/2018JD030088. 


\section{Introduction}

The atmosphere, from the Greek words ' $\alpha \tau \mu$ ós' and ' $\sigma \varphi \alpha i ́ \rho \alpha$ ' meaning vapor and sphere, respectively, was introduced as a scientific term during the $17^{\text {th }}$ century (Martin, 2015). It comprises the stratified layer or the set of stratified layers of gases surrounding a body (e.g. planet), maintaining their place by the gravity of that same body. The Earth's atmosphere consists of five layers. From bottom to top, the troposphere (up to $12 \mathrm{~km}$ in altitude, on average), the stratosphere $(12-50 \mathrm{~km})$, the mesosphere $(50-85 \mathrm{~km})$, the thermosphere $(85-1000 \mathrm{~km})$ and the exosphere $(>1000 \mathrm{~km})$. Undoubtedly, the Earth's atmosphere is the primary regulator of energy in the Earth enabling life on it. The energy budget of incoming shortwave radiation from the Sun and outgoing longwave radiation from the Earth involves the exchange of energy between the Earth's surface, the top of the atmosphere and the atmosphere in between (Hansen et al., 2005). Within the Earth's atmospheric layers, gases and solid or liquid particles co-exist and interact dynamically. From these atmospheric components, aerosol particles, clouds and water vapor are of great interest as they participate in the energy transfer in the atmosphere and impact air quality and climate (Boucher et al., 2013; Lohmann \& Feichter, 2005; McCormick \& Ludwig, 1967; Twomey, 1974). Atmospheric aerosol particles, clouds, and water vapor are presently linked with a plethora of uncertainties arising from limited knowledge on their spatial, temporal, as well as microphysical and optical properties. These knowledge gaps in turn, become the bottleneck for reliable and accurate projections of weather and climate change (Boucher et al., 2013; Stevens \& Feingold, 2009). Therefore, continuous monitoring of the optical and physical properties of aerosol particles, clouds, and water vapor are critical to facilitate accurate weather and climate predictions.

Atmospheric aerosols are minute solid or/and liquid particles suspended in the air (Hinds, 1998). Their origin, anthropogenic or natural, determine their initial physicochemical properties such as size, chemical composition (type) and shape. Upon emission to the atmosphere, aerosol particles interact with other atmospheric components and alter their chemical composition and physical properties (Fuzzi et al., 2015). These determine their atmospheric residence time, influence on the formation and properties of clouds (Carslaw et al., 2013) and upon interaction with radiation their optical properties. Unlike the main atmospheric gases, which are equally distributed around the globe, aerosol particles are highly variable both in time and space. This variability results from their shorter lifetime (from a few days to a few weeks in the troposphere) combined with the uneven geographical distribution of the aerosol sources. These sources are vastly heterogeneous in size, type and emission height (from point sources such as factories and cars to massive water bodies and occasional volcanic eruptions), resulting to the emission and formation of a wide 
range of particle sizes (from $1 \mathrm{~nm}$ to several tens of micrometres). Under favourable atmospheric conditions, aerosol particles can be long-range transported from a place to another altering, not only the local, but also the regional and global climate. Moreover, different atmospheric particles exhibit different optical properties which are not fully known (Bond \& Bergstrom, 2006). To this end certain aerosol particle types such as pollen and dust originating from different sources are still underdetermined.

Clouds are the visible evidence of atmospheric processes linking aerosol particles with water vapor and local meteorological conditions. Clouds consist of water droplets, ice crystals or both, and depending on their geolocation and altitude in the atmosphere exhibit contrasting net radiative effects (Ramanathan et al., 1989). This implies that clouds can both warm and cool down the Earth's surface (Hartmann et al., 1992). Typically, low-level clouds cool the Earth's surface by reflecting shortwave radiation while high-level thin clouds trap the longwave radiation on Earth's surface, warming it up (Lynch, 1996). Despite this general trend, more recent studies have shown that low-level clouds located in the Arctic have a warming effect (Cronin \& Tziperman, 2015; Shupe \& Intrieri, 2004) and thick cirrus clouds pose a cooling effect (Hartmann et al., 1992). Therefore, their spatial distribution and physical properties are of great importance. Clouds also redistribute energy from the equator towards the poles and they are an essential part of the hydrological cycle through the process of precipitation. Changes in their spatiotemporal distribution or abundance can potentially outweigh any other factor associated with climate change. Under favourable meteorological conditions, clouds form through homogeneous and heterogeneous nucleation pathways. In homogeneous nucleation, the phase transition, for example from water to ice realizes without the presence of a foreign substance. On the contrary, the heterogeneous nucleation pathway requires the pre-existence of aerosol particles which act as ice nuclei particles (INPs) in ice and mixed-phase clouds or cloud condensation nuclei (CCN) in water clouds. The CCNs serve as nucleating sites upon which water vapor can condense and INP enables other aerosol particles, water vapor or droplets to collide and freeze, facilitating the cloud formation. Different aerosol types with their various range of sizes, optical and microphysical characteristics and mass abundance affect the cloud lifetime, precipitation, and physical cloud properties in various ways. However, the relative importance of aerosols compared to changes in meteorology is still unclear. CCN properties of different chemical components are quite well known, but INP ones not. Previous studies have shown that certain aerosol particles are more efficient to serve as ice nuclei than others (Atkinson et al., 2013; DeMott et al., 2003; Kanji et al., 2017) but their importance under real atmospheric conditions is debatable (Ansmann et al., 2009; Li et al., 2017; Zamora et al., 2018; Zhang et al., 2015). To this end, the aforementioned aerosol effects in climate through cloud processing compile the greatest source of uncertainty in climate estimates (IPCC Fifth Assessment Report, Seinfeld et al., 2016). 
As emphasized, observations of aerosol and cloud properties are needed to reduce current climatic uncertainties. Based on the measuring technique, observations can be separated into two major categories. The first category considers in-situ measurements of the atmospheric components. In-situ observations cover all techniques having physical contact with the observed target. However, such measurements are not representative for the whole atmosphere since the spatial coverage is poor over remote areas (e.g. over oceans) and no vertical information is provided as the observations refer only to the exact point of the measurement (excluding radio soundings). The second category is remote sensing in which information about the target is acquired at some distance. The information about the atmospheric component under study is based on the interaction of the target with electromagnetic radiation. There are two types of remote sensing instruments: passive and active. Active remote sensors emit their own electromagnetic radiation to illuminate the target they observe, and passive sensors utilize radiation emitted by the target itself or reflected from the target or a source other than the instrument (e.g. the Sun or the Moon). Active remote sensing techniques, such as cloud radars (radio detection and ranging) and elastic or Raman lidars (light detection and ranging), have been increasingly employed in atmospheric research to monitor the spatial and temporal evolution of water vapor and several cloud- and aerosol-related quantities with high accuracy (Weitkamp, 2005). Lidars can retrieve ambient aerosol particle and cloud properties continuously with a high vertical/temporal resolution of a few meters/seconds, under almost all atmospheric conditions (except rain and thick clouds). They also have the capability to retrieve the sphericity of the targets, a measure of the shape of particles, which assist the overall interpretation of the observations. Lidar systems are most sensitive to aerosol particles and optically thin clouds, but the detection is limited under optically thick liquid-containing clouds. On the contrary, cloud radars can penetrate optically thick clouds which makes the lidar-radar synergy a powerful tool to study aerosol-cloud interactions. Applications of these instruments alone and synergistically at ground-based or satellite-based platforms provide solid grounds to study the geometrical, optical, and microphysical properties of aerosol particles and clouds and the interactions of these in local and global scale.

This doctoral dissertation consists of 4 original papers. In each, we have exploited the capabilities of multi-wavelength elastic and Raman lidars, as well as synergies with cloud radars to study aerosol optical properties and their interaction with clouds. The main objectives of the thesis were: 1) to evaluate the robustness of Raman lidar retrievals in terms of water vapor mixing ratios, a parameter that can be used to calculate the amount of water vapor in the atmosphere. Profiles of water vapor can be utilized to study the hydration rate of aerosol particles (Paper I). 2) To address the aerosol optical properties of understudied aerosol types, specifically, pollen and Ara- 
bian dust to improve the aerosol classification retrievals and advanced methodologies used in lidar applications (Paper II \& III). 3) To use satellite-based elastic lidar and cloud radar measurements to study regional aerosol properties and their effect on cloud formation (Paper IV). One important factor in cloud formation is the amount of water vapor (Paper I). Large particles like dust and pollen can act as CCN or INP (Paper II \& III), and even affect the cloud phase (Paper IV). All these objectives have implications, directly and indirectly, on the climate uncertainties addressed earlier and they work synergistically towards a better understanding of the aerosols and their role in climate change. Below we summarize the objectives in the form of research questions.

Q1: What is the best alternative to calibrate a ground-based lidar for water vapor observations in the absence of co-located radiosondes? Can Raman lidars be confidently used for long-term and precise observations of water vapor profiles?

Q2: Can we recognize and characterize different pollen types based on their characteristic optical signature using elastic, polarization and Raman lidars? Which of the optical properties are crucial for such characterization?

Q3: What are the optical properties of Arabian dust and how do they compare with other dust optical properties from different regions?

Q4: How do different aerosol types and their mass abundance affect the thermodynamic phase of the clouds in the pristine environment of the Arctic?

The thesis is organized as follows. The theoretical background of radiation, aerosols and clouds and their connection to climate is described in Section 2. Section 3 includes a brief history of the development of the lidar technique, the methodology and quantities that elastic, polarization, and Raman lidars measure, as well as applications of these. The main results of the original papers included in this thesis is found in Section 4, and the paper review and author's contribution can be found in Section 5. Concluding remarks are given in Section 6. 


\section{Fundamentals}

Active remote instruments such as lidars and radars use electromagnetic radiation to observe aerosol particles and clouds. Here, a short introduction to what is radiation and how the physical and chemical properties of these atmospheric components together with the radiation facilitate their detection and classification is presented (Sect. 2.1). The most relevant aerosol types are presented in Section 2.2 and cloud properties in Section 2.3. Lastly, the importance of aerosols and clouds and their link to climate is found in Section 2.4 .

\subsection{Radiation}

Electromagnetic radiation (EMR) is a form of energy that propagates through space as waves, traveling in packets of energy called photons. EMR consists of a spectrum with variable wavelengths (denoted with $\lambda$ ) and travels through the air with the speed of light $\left(2.997 \times 10^{8} \mathrm{~m} / \mathrm{s}\right)$. The wavelength is the distance between two successive wave crests or troughs and determines the energy of a photon (Fig. 1). The shorter the wavelength, the higher the frequency of the electromagnetic wave, and the greater the energy of the waveform. From shorter to longer wavelengths: gamma rays, $\mathrm{x}$-rays, ultraviolet, visible, infrared, microwaves and radio waves constitute the electromagnetic spectrum (Fig. 1). The visible light is a tiny region of the EMR spectrum $(0.4-0.7 \mu \mathrm{m})$, yet it defines our perception of the world as human eyes are sensitive at these wavelengths. Life on this planet have been evolved to have their best sensitivity to the visible light. EMR is emitted by any object having temperature greater than absolute zero $\left(-273.15^{\circ} \mathrm{C}\right)$. This practically means that the Sun, the Earth, and the atmosphere having extremely different temperatures from each other radiate at different electromagnetic spectra. The Sun, for example, emits shortwave radiation; the maximum intensity of the emitted energy is around $0.5 \mu \mathrm{m}$ at the top of the atmosphere and the energy distribution is skewed to the shorter wavelengths, meaning that about half of the energy is in the visible wavelengths below $0.7 \mu \mathrm{m}$. The Earth emits longwave radiation at a peak wavelength of about $10 \mu \mathrm{m}$ and its intensity is orders of magnitude lower than that of the Sun.

Energy transfer in the atmosphere is accomplished through EMR. Not all the shortwave radiation from the Sun is transmitted all the way to the Earth. Some of the wavelengths reach the Earth's surface while others are partly or fully filtered out by the atmosphere (Fig. 1). For example, the ozone layer located in the stratosphere absorbs most of the solar ultraviolet radiation, while in the troposphere, aerosol particles and clouds interact with radiation both by absorbing and reflecting it. Then, the 
Earth absorbs the remaining shortwave radiation and emits it back to the atmosphere. Overall, the atmosphere regulates this transfer of energy. The amount of energy reaching the Earth and the amount of energy escaping from the Earth, i.e. the radiative balance, ultimately controls the climate of the Earth and it is critical in ecosystems functionality. An imbalanced radiation budget forces the components of the climate system to adjust and eventually pose warmer/cooler surface temperatures over time reaching a new energy balance (equilibrium).

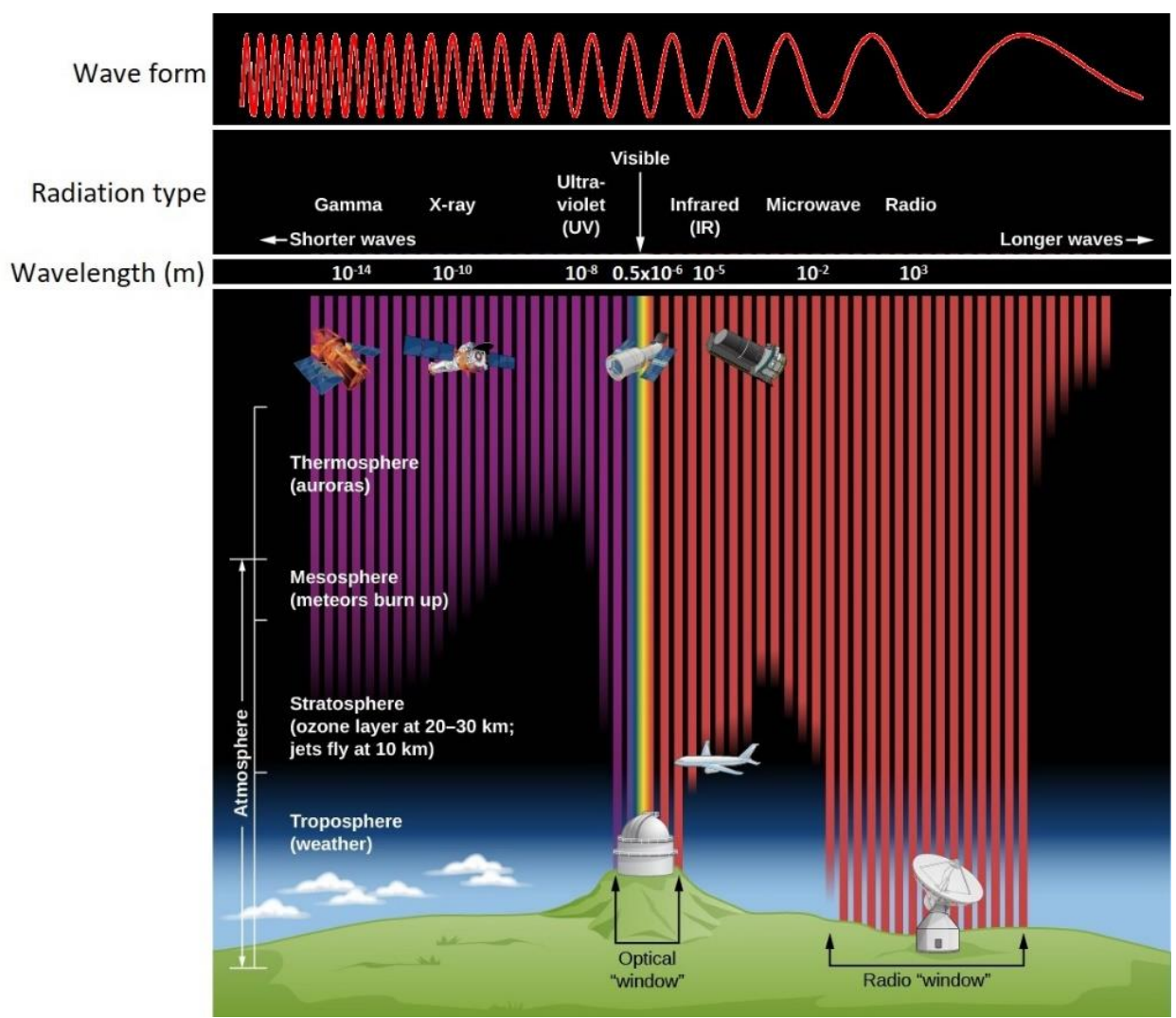

Figure 1. Range of electromagnetic spectrum and interaction with the Earth's atmosphere. As shown in the uppermost part, the smaller the wavelength the more frequent the wave form is. The ability of certain wavelengths to penetrate the Earth's atmosphere from space is shown with vertical lines. Credit: STScl/JHU/NASA.

As mentioned, EMR interacts with ozone molecules, aerosol particles and many other atmospheric components. The form of interaction between radiation and matter depends on the size, shape, and chemical composition of the component, as well as the wavelength of the incident radiation. There are three main processes affecting 
the propagation of radiation through the atmosphere: absorption, emission, and scattering. Eventually, these processes reduce the amount of radiation propagating through the atmosphere. In real conditions, rarely a single wavelength strikes a molecule or an aerosol particle. Instead, radiation of various incident wavelengths head towards a target. When this occurs, molecules and particles may selectively absorb or scatter radiation at certain wavelengths. Lidars use such properties to measure, for example, the water vapor in the atmosphere (see Sect. 3). The selection of the emitted wavelength together with the size of the targets are the two decisive parameters for the observation of the various atmospheric components.

When a photon is absorbed by a molecule, it ceases to exist, and its energy is transferred to the molecule. This energy can be transferred to vibrational, rotational, electronic, or translational forms which combined are called the internal energy of the molecule. The above energies are quantized and in absorption the energy transfer occurs only when the energy of the incident photon exactly matches the energy difference between two energy states in the molecule. In this case, the incident radiation becomes part of the internal energy of the molecule positioning the molecule to a higher energy level (excited state). As a result of absorption, atmospheric components increase their internal energy which further increases their temperature. In emission, molecules that are excited decay to lower energy levels by emitting radiation (e.g. fluorescence). Therefore, emission increases the outgoing radiation at certain wavelengths and absorption reduces it. When the incident radiation is less than the energy difference between two levels in the molecule for it to be absorbed, scattering can occur. In scattering, the electrons within the molecule are perturbed at the same frequency as the incident wave. As a result, the electrons within the molecule are momentary separated, inducing a dipole moment. The scattered light is the result of emitted EMR induced by this dipole. There are two different scattering processes depending whether the molecule returns to its original state or not upon scattering the radiation: elastic and inelastic. Elastic scattering is when the scattered radiation has the same wavelength as the incident radiation and (almost) no energy loss has occurred. Therefore, the molecule returns to the initial energy state upon emission of EMR. Correspondingly, in inelastic and particularly in Raman scattering, the wavelength is shifted between the incident and scattered radiation as the induced dipole is adjusted by molecular motions like vibrational or rotational (Raman \& Krishnan, 1928). In this case, the initial and final energy states are different. There is a variety of rotational/vibrational excitation states which leads to several bands of Raman radiation (Wandinger, 2005). The scattered Raman radiation is characteristic of the molecule which allows temperature determination of the molecule.

Scattering is highly dependent on the size parameter, $x=\pi \mathrm{nr} / \lambda$, which is a function of the particle radius $r$, the incident wavelength $(\lambda)$, and the refractive index, $n$, (defined by the chemical composition of the molecule, hereafter scatterer). There are 
three regions depending on the size parameter which defines the scattering properties (Fig. 2).

Firstly, when the size of the particle is much smaller than the wavelength of the incident radiation, the scattering is considered as Rayleigh or molecular scattering in which the optical properties of the scattered particles can be predicted by the socalled Rayleigh theory (Strutt, 1871). As almost 99\% of the Earth's atmosphere consists of molecules of nitrogen and oxygen (very small compared to both solar and terrestrial radiations), this type of elastic scattering is the most dominant in the upper atmosphere. Moreover, Rayleigh scattering exhibits a strong wavelength dependence. The wavelength dependence of the scattered intensity is proportional to $\lambda^{-4}$, meaning that shorter wavelengths are more efficiently scattered than longer wavelengths. For example, the sky appears blue because molecules in the air scatter blue light from the Sun almost 10 times more than red light.

Secondly, when the particle is comparable in size with the wavelength of the incident radiation, the scattering is better described by Mie theory (Mie, 1908). Although, Mie theory covers the Rayleigh region, it is optimally used for particles whose sizes are comparable to the wavelength of the radiation, or larger. The scattering intensity in this case varies strongly with the wavelength and can therefore be used to identify atmospheric particles. Nevertheless, dissimilar to the Rayleigh scattering in which the radiation is scattered similarly, in Mie scattering the scattered radiation is angular dependent. The scattering angle is the angle between the incident and scattering directions. In Mie scattering, the scattering intensity distribution is weighted in the forward direction $\left(0^{\circ}\right)$. This implies that more light is scattered forward than backwards $\left(180^{\circ}\right)$. Mie calculations assume that the particles are spherically shaped, but that is not the case for all atmospheric particles. The assumption of perfect spheres to retrieve optical properties for irregularly shaped particles increase the errors and impair forecast accuracies, producing potentially misleading results (Kylling et al., 2014). Therefore, Mie theory is often a rough approximation in the case of large and non-spherical particles such as dust and ice crystals where different approaches are more appropriate (Redmond et al., 2010). Rayleigh theory also considers the particles to be spherically shaped but due to their small size compared to that of the wavelength of the incident radiation the errors can be neglected.

Thirdly, when the size of the particle is much bigger than the wavelength of the incident radiation, the scattering is non-selective, and the light propagation is better described by geometric (or ray) optics. Geometric optics is not widely used in atmospheric research, but some applications have been reported (e.g. Hulley \& Pavlis, 2007). 


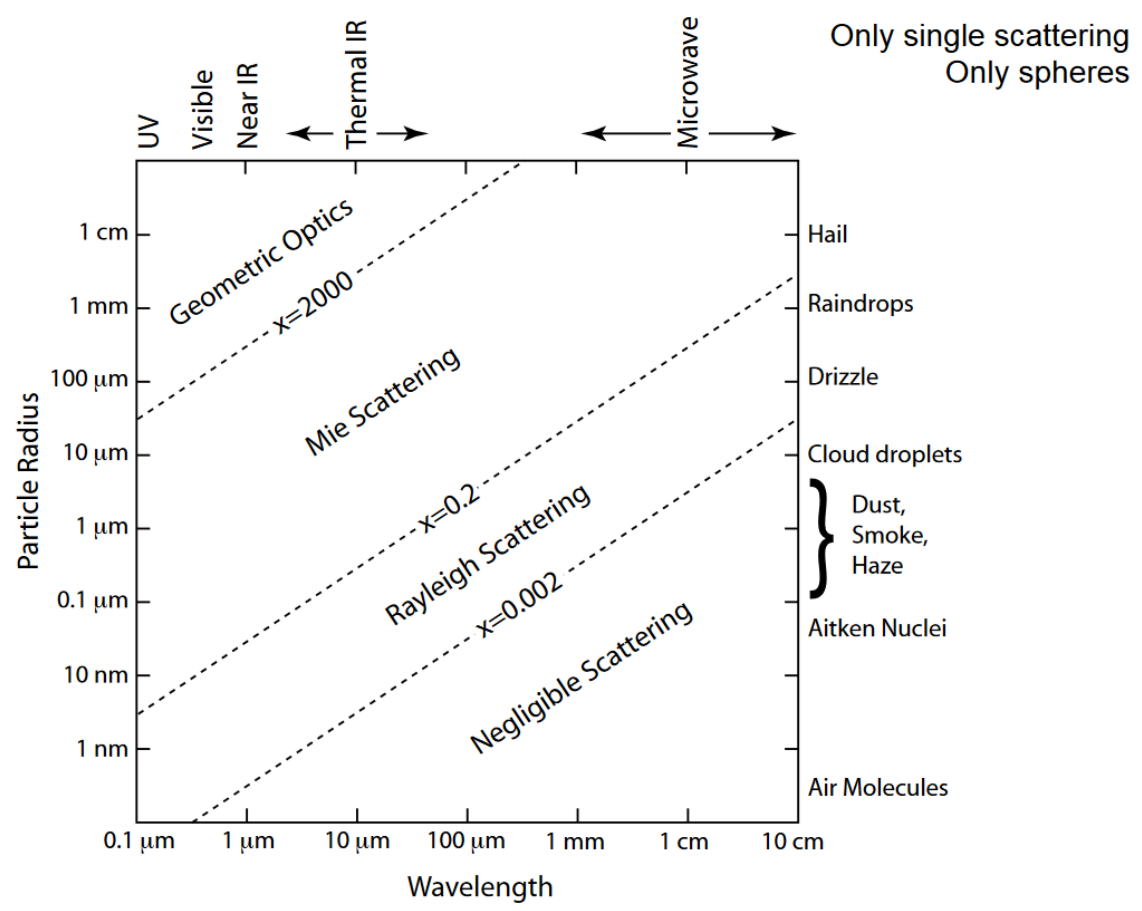

Figure 2. Wavelength dependence of incident radiation and particle radius for various atmospheric components assuming spherically shaped particles.

Credit: Dr. Luca Lelli (http://www.iup.uni- 21remen.de/ luca/?download=01_LL_VO.pdf).

\subsection{Atmospheric aerosol particles}

Aerosol particles are an essential component in the atmospheric EMR interactions along with clouds and atmospheric gases like water vapor. These atmospheric components are present everywhere in the atmosphere with number concentrations from few particles per $\mathrm{cm}^{3}$ in remote areas up to $10^{6}$ particles per $\mathrm{cm}^{3}$ in heavily polluted urban areas. Nearly $90 \%$ of the aerosol mass in the atmosphere comes from sea-salt and dust aerosol particles (Textor et al., 2006). Though less abundant, anthropogenic aerosols can often dominate the air over urban and industrial areas. Globally, the annual anthropogenic emissions amount to over $110000 \mathrm{Gg}$ considering particles below $10 \mu \mathrm{m}$ (Klimont et al., 2017). Most of the atmospheric particles are located in the lowest part of the atmosphere (troposphere) but aerosol layers higher up in the stratosphere can also be found. Their distribution in time is also highly variable and typically a sample of air consists of several chemical species with various sizes and shapes as the result of the many heterogeneous aerosol sources and atmospheric processes. This high variability makes the quantification of global distributions of the different aerosol species challenging. 


\subsubsection{Sources, sizes, and types}

Various classifications are used to describe atmospheric aerosol particles. As already mentioned in the introduction, atmospheric particles may arise from natural sources such as windblown dust, pollen, plant fragments, sea salt, sea spray, volcanic emissions, and so on, or anthropogenic sources which are linked to human activities (fuel combustion, industrial processes, transportation, agricultural activities, domestic uses, etc.). Aerosol particles can be also classified as primary or secondary; primary aerosols are introduced directly from the source and secondary aerosols are formed through gas-to-particle conversion. Once dispersed, aerosol particles change their mixing state (external or internal), chemical, as well as physical properties (Fuzzi et al., 2015). In the absence of chemical or physical processes, particles stay externally mixed, i.e. they are chemically distinct particles. However, this is highly unlike in the atmosphere where different chemical compounds may condense on the particles and particles randomly collide with each other forming aggregates (coagulation). Altogether, these processes lead to chemically more alike compounds, i.e. they become internally mixed. Therefore, tracking back to their primary source or secondary formation pathway, which can be either of natural or anthropogenic origin, is rather difficult. Therefore, aerosol particle populations in the atmosphere are a mixture of both primary and secondary aerosols originating from either natural or anthropogenic sources.

The aforementioned processes, along with the relative humidity of the environment that the particles reside in, affect their size and shape which in turn determines their optical properties, ability to participate in cloud formation and finally the atmospheric lifetime. Atmospheric particles can range from few nanometres $(\mathrm{nm})$ to tens of micrometres $(\mu \mathrm{m})$ in diameter within an air sample. Their size distribution is divided, typically, into two distinct modes. Particles with diameters $<2 \mu \mathrm{m}$ are considered as fine mode particles whereas coarse mode particles are those with diameters $>2 \mu \mathrm{m}$ (Seinfeld \& Pandis, 2016). The fine mode is further divided into accumulation $(0.1-2 \mu \mathrm{m})$, Aitken or nuclei mode $(0.01-0.1 \mu \mathrm{m})$ and nucleation mode $(<0.01$ $\mu \mathrm{m}$ ) consisting of ultra-fine particles (Fig. 3). All these modes are formed by different mechanisms which, eventually, assist the interpretation of the health effects of a certain particle size or classification according to their origin or even their ability to form clouds (CCN/INP) and their interaction with radiation. In general, coarse mode particles, mostly natural/primary particles, are formed by mechanical processes such as wind or erosion (windblown dust, sea spray, pollen grains, etc.); whereas fine particles are usually formed by condensation of secondary particles from the gas phase or by coagulation and water condensation of small primary particles. While the number distribution is dominated by small-sized particles (nucleation and Aitken mode), at most regions the volume or mass distribution is dominated by the accumulation and coarse modes. 


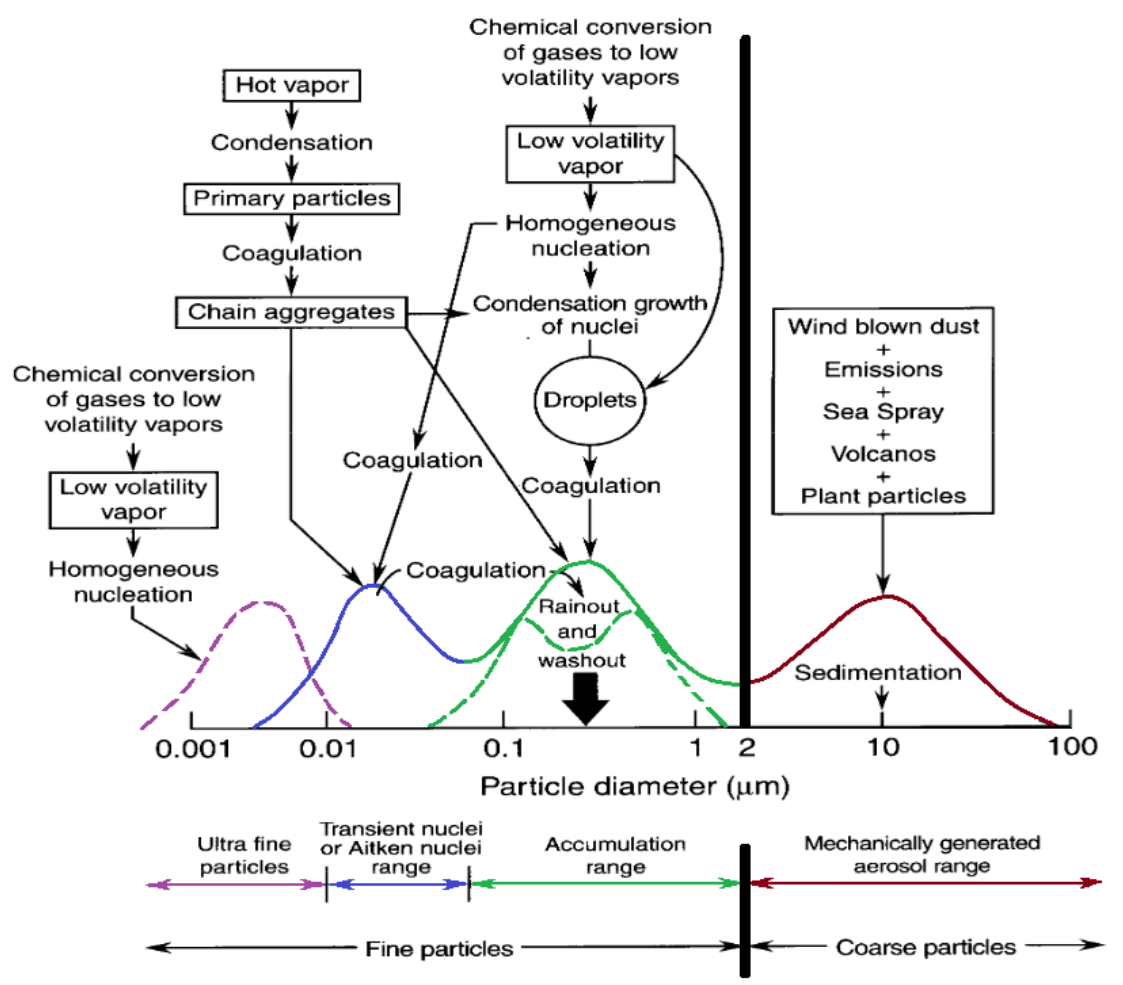

Figure 3. Schematic of an idealized atmospheric aerosol size distribution showing four modes. Current knowledge is shown by dashed lines on top of the original hypothesis (solid lines). The figure has been adapted by Finlayson-Pitts \& Pitts, (2000).

It is evident by now that aerosol populations in an air sample are neither of a single chemical specie nor of a specific size. However, it is critical to classify the aerosol particles in order to establish connections between the aerosol sources and their climatic and health impacts, enabling the development of adequate policies. Because of the various measurement techniques (in situ vs. remote sensing) and the use of climate models in atmospheric science, this aerosol classification is quite diverse. For example, in situ instruments normally measure aerosol populations in terms of number and mass size distributions. On the contrary, climate models categorize the aerosols both by their size distribution and chemical composition. In active remote sensing, the aerosol classification schemes are a type-specific set of mean optical properties relating the multi-wavelength aerosol scattering and polarization properties to the aerosol sources (e.g. Groß et al., 2011; Müller et al., 2007; Omar et al., 2009; Tesche et al., 2011).

The key aerosol compounds are sulphates, organic carbon, black carbon, nitrates, mineral dust, and sea salt. In practice, atmospheric aerosols are a mixture of these 
compounds and many more. The lidar-specific aerosol typing methodologies classify the atmospheric particles by the relative contribution of the different compounds mentioned above while additional information can assist the aerosol typing (e.g. the use of airmass backward trajectories). Among the different aerosol types, marine aerosols, mineral dust, pollen, and a brief introduction to other aerosol types are discussed further below. We should mention here that more aerosol particle types exist; these primarily depend on the classification approach used in different algorithms (Nicolae et al., 2018; Papagiannopoulos et al., 2018). An example of an aerosol classification scheme used in satellite-based lidar observations from CALIPSO can be found in Paper IV.

\section{Marine aerosols}

Marine aerosols can be formed both from primary and secondary processes. Primary marine aerosols consist of sea-spray aerosols (a combination of inorganic sea-salt with varying fractions of organic matter) arising from the interaction of wind stress at the surface of the ocean (Dadashazar et al., 2017; Gantt \& Meskhidze, 2013). Even though sea-salt contributes to only about $10 \%$ of the total number distribution of marine aerosols, it dominates both the surface area and volume size distributions (Wex et al., 2016). This is because sea-salt consists of coarse particles. Moreover, organic matter alone is present more at the fine mode rather than the coarse mode, and its contribution to the fine mode mass depends on the oceanic yearly biological activity with higher contribution during summertime (Cavalli et al., 2004). Secondary marine aerosols (SMA) consist both of inorganic and organic aerosols. SMA are primarily non-sea-salt sulphate formed by oxidation of organosulfur gases to e.g. dimethyl sulphide (DMS) which can transform to sulphate aerosols. Another secondary path formation is particle formation through iodine oxides. Both SMA paths are equally probable at different times due to different plankton species and/or plankton life cycle (O'Dowd \& de Leeuw, 2007).

More than $70 \%$ of the Earth's surface is covered by sea water. Therefore, particle emissions from the marine environment are one of the most abundant (about $17000 \mathrm{Tg}$ per year, Textor et al., 2006). Due to the large particle diameter of sea-salt, they are quickly removed from the atmosphere through deposition resulting to an atmospheric loading of about 7.5 Tg (Textor et al., 2006). Marine particles are usually spherical in shape at $\mathrm{RH}>70 \%$, but under dry atmospheric conditions their shape becomes cube-like (Wise et al., 2005). Haarig et al. (2017) studied the shape of marine particles using lidar observations, specifically sea-salt particles, under both wet and very dry conditions and they found that lidars can track and classify marine particles under any $\mathrm{RH}$ conditions as their shape can be used as an indicator. 


\section{Mineral dust}

Mineral dust is also one of the most mass abundant aerosol types found in the atmosphere (Kok et al., 2017). Annually, about $2000 \mathrm{Tg}$ of dust particles are emitted into the atmosphere (Textor et al., 2006), although this amount can be highly variable (Evan et al., 2014; Huneeus et al., 2011). The atmospheric loading is estimated to be almost $20 \mathrm{Tg}$ (Textor et al., 2006). Besides the natural sources, human activities such as soil disturbance in agricultural areas have also a significant influence on dust emissions (Prospero et al., 2002; Rodríguez et al., 2011). Quantitatively, the anthropogenic contribution of mineral dust accounts for 30 to $60 \%$ of the total dust burden (Ginoux et al., 2012; Webb \& Pierre, 2018). The particle sizes of mineral dust vary greatly over space and time and currently, dust size distributions are poorly understood (Reid et al., 2003). The lifetime of coarse particles is heavily limited by its size yet, a recent study report that dust with particle diameters above $5 \mu \mathrm{m}$ does not settle as quickly as predicted in climate models (Adebiyi \& Kok, 2020).

Mineral dust particles are emitted from arid and semi-arid regions such as the Saharan and Arabian deserts (Laurent et al., 2008; Yu et al., 2015). In fact, North Africa is the major contributor of mineral dust in the atmosphere (50-70\%) followed by deserts in Middle East (about $10 \%$ ). Although these particles are emitted locally and lifted up in the atmosphere, due to thermal lows, unstable conditions, and human activities, they can be transported over thousands of kilometres away from the sources (e.g. Prospero \& Mayol-Bracero, 2013), affecting ecosystems, public health, aviation and climate which will be looked into more detail in Section 2.4.

Dust particles are of various chemical composition. They are a mixture of many minerals, mainly clays, calcite, quartz, feldspars and iron oxides that constitute the Earth's crust (Di Biagio et al., 2017; Walter \& Theodore, 1979; Nowak et al., 2018; Querry, 1987; Sokolik \& Toon, 1999). The chemical composition of dust and their size can vary substantially from a place to another (Järvinen et al., 2016; Müller et al., 2007; Schuster et al., 2012; Shin et al., 2018). Therefore, dust optical properties are not fixed. Finally, mineral dust particles are non-spherical with irregular shapes and substantial surface heterogeneity (Wagner et al., 2012; Wiegner et al., 2009; Winker et al., 2010). Their non-spherical property is exploited in the lidar technique for the detection and classification of the dust aerosol layers in the atmosphere, since not many atmospheric particles exhibit this property (some pollen types, volcanic aerosols, and ice crystals). In Paper III, we retrieved the Arabian dust optical properties, including the degree of depolarization (a measure of particle sphericity), using a one-year of lidar observations in a desert site at the United Arab Emirates and compared it to those of Saharan originated dust. 
Pollen

Atmospheric pollen is a biogenic particle emitted in large quantities by terrestrial vegetation for reproduction (Bennett, 1990). These, mainly anemophilous (wind-dispersed) pollen particles and fragments of those, are coarse particles with diameters which range up to $150 \mu \mathrm{m}$ (Emberlin, 2008). The production and emission of pollen particles are closely linked to meteorological and climatological factors such as wind, relative humidity, phenology and soil moisture (Sofiev, 2017; Weber, 2003). Different vegetation types have different pollination periods, releasing pulses of pollen particles into the atmosphere at varying times during the year. Naturally, some overlapping exists. Upon release in the atmosphere, pollen grains can be transported even thousands of kilometres away from the sources (Sofiev et al., 2006) and can potentially change their physicochemical properties in the presence of other atmospheric pollutants (Sénéchal et al., 2015). Atmospheric pollen has a decisive role in public health as it is a well-known allergen and further alters visibility and climate. This type of aerosol particle appears to be near-spherical to irregular in shape, depending on the pollen type (Cao et al., 2010). In Paper II, we observed the shape of two atmospheric pollen types using the depolarization capabilities of a ground-based lidar system.

\section{Other aerosol types}

Atmospheric chemistry is complex and some aerosol types such as anthropogenic and biomass burning (smoke) aerosols are a mixture of many chemical compounds. In these cases, the relative contribution of the different compounds is either facilitated with source appointment which, to some extent, helps the classification. Organic aerosols, sulphates, nitrates, black and organic carbon are usually found in the aforementioned aerosol types.

Organic aerosols originate primarily from vegetation and micro-organisms and combustion of fuels (fossil and bio-), as well as open biomass burning (forest fires). Secondary formation occurs through gas-phase oxidation of parent organic species which partition themselves between the gas and aerosol phase. Most organic aerosols cool the Earth's atmosphere (scatter solar radiation) and their contribution to fine particles accounts to as high as $90 \%$ in tropical forest areas (Kanakidou et al., 2005). Black carbon (BC) is produced primary from the incomplete high-temperature combustion of fuels (fossil and bio-) and biomass. Naturally, combustion is never complete (i.e., partial oxidization to $\mathrm{CO}_{2}$ ), releasing various gases, organic carbon (OC) and $\mathrm{BC}$. The amount of $\mathrm{BC}$ to $\mathrm{OC}$ depends on the burning material.

Inorganic aerosols such as sulphates and nitrates have both anthropogenic and natural origins and they consist of fine particles. Sources of sulphate aerosols start as emissions from burning fossil fuels, volcanic eruptions, or oceans. Sulphate particles 
form via gas-to-particle conversion from the oxidation of sulphur dioxide. Typical sources for nitrate aerosols are the oceans, biomass burning, industrial processes, as well as lightning. Nitrate aerosols are chemically formed in the atmosphere from ammonia and nitric acid. Sulphate and nitrate aerosol particles pose a cooling effect as they reflect nearly all radiation they encounter.

Anthropogenic and open biomass burning aerosols (smoke) are the main sources of carbon particles into the atmosphere. Apart from the anthropogenic contribution, biomass burning aerosols present natural origins too. These aerosol types are a mixture of chemical compounds inferring varying climate impacts due to their complex chemical and optical properties. For example, primary anthropogenic aerosols are mainly composed of OC and BC from fossil fuels. Secondary aerosol particles are mainly composed of organics, sulphates and nitrates emitted e.g. in power plants or traffic and industrial activities. Anthropogenic aerosols are near spherically shaped.

Vegetation and peat fires (open Biomass burning) release large amounts of aerosol particles and gases in the atmosphere. Biomass burning aerosols are of fine mode but the size distribution is rather variable and depends on the physical and chemical processing in the smoke plume (Janhäll et al., 2010; J S Reid et al., 2005). Biomass burning produces mainly carbonaceous particles. Their composition is mostly of OC and BC while other substances such as inorganic traces of sulphates, nitrates, inorganic nutrients and metals account for approximately $10 \%$ of the particle mass (Cachier et al., 1995). The amount and size of these particles are highly variable and depend on the vegetation type, duration of flaming versus smouldering, the ambient environment, and secondary reactions in the atmosphere. Therefore, the optical properties of biomass burning aerosols are also affected. For example, biomass burning aerosols from forest and peat fires have larger particle sizes and scatter more solar radiation than those from grass and shrub fires. Atmospheric aging has also a considerable effect on these aerosols. When long-range transported, biomass burning aerosols abate their absorbing efficiency (Nicolae et al., 2013) complicating climatic impact calculations. Biomass burning aerosols are spherical to nearly-spherical in shape (Gialitaki et al., 2020) and their shape is transforming to more spherical while aging and coating of the BC particles (Baars et al., 2019).

\subsection{Clouds}

Clouds are a key part in the hydrological cycle and strongly modulate Earth's radiative balance. Their radiative, optical, and microphysical properties are critical for the holistic interpretation of the Earth's climate and its possible response to changes. The radiative properties depend on the altitude and location of the clouds. In the troposphere, clouds are classified according to their altitude as low-level (up 
to $2 \mathrm{~km})$, mid-level (2-7 km) and high-level (7-12 km). Typically, low-level clouds reflect solar radiation forming a shield for the surface below posing a cooling effect and high-level clouds have a warming effect. These relationships can be reversed depending on the physical size of the cloud and its location compared to the underlying surface (ice covered, snow or land). Regarding their physical size, clouds appear stratified, i.e. not vertically developed but rather spread out horizontally (stratus), or convective, i.e. formed by convection.

Satellite-based observations suggest that clouds cover more than $60 \%$ of the planet. Globally, clouds are not distributed uniformly, neither vertically nor horizontally. Regarding their vertical extent, cloud tops over tropics are substantially higher than cloud tops over the poles (1-2 km higher) extending the troposphere higher up compared to Polar Regions. Cloud cover over the tropics is also higher by 10 to $20 \%$ due to the enhanced evaporation caused by the solar radiation which is the maximum at this region. Regarding their spatial distribution, oceans are more frequently covered with clouds than land (Hahn et al., 1984). Clouds over ocean also reside at about $1 \mathrm{~km}$ lower than clouds over land.

A key parameter behind the clouds' interaction with radiation and further their climatic impacts is their thermodynamic phase. Clouds consist of water droplets, ice crystals or both, light enough to float in the air. The thermodynamic phase of a cloud is driven both by the meteorology and the ability of the aerosols to act as CCN/INP. There are two types of clouds considering the thermodynamic phase: ice and liquid-containing. In all cases, clouds start forming when the air becomes saturated, i.e. the relative humidity against liquid water or ice exceeds $100 \%$. As the saturation point (air contains the maximum amount of water vapor) is a function of temperature and pressure, it varies from place to place and from time to time. For example, at $20{ }^{\circ} \mathrm{C}$ air can hold $0.33 \mathrm{~g}$ of water vapor per $\mathrm{kg}$ of dry air compared to $+30{ }^{\circ} \mathrm{C}$ which is up to $26.3 \mathrm{~g} / \mathrm{kg}$. At both situations, the relative humidity against liquid water is $100 \%$ and under favourable atmospheric conditions clouds can form.

\section{Liquid-containing clouds}

Liquid-containing clouds can consist entirely of water droplets or a mixture of supercooled-liquid water and ice (mixed-phase). Warm water clouds typically form in the lower troposphere when the ambient temperature is above $0{ }^{\circ} \mathrm{C}$ and require soluble aerosol particles to serve as CCNs upon which water vapor will condense onto. Aerosol particles respond to changes in humidity in different ways. Above certain relative humidity, hydrophilic particles deliquesce forming a tiny liquid drop, which further grows with increasing RH. When RH exceeds $100 \%$ some of particles might reach their critical size, allowing spontaneous growth into cloud droplets (activation of the particles). Their growth with increasing relative humidity is primarily a function of their size, and secondarily of their chemical composition, and mixing 
state. Growth of water droplets by condensation in a cooling air parcel increases their droplet radius $(10-30 \mu \mathrm{m})$ eventually, further coalescence and collision produces large rain droplets $(200-1000 \mu \mathrm{m})$ which leads to precipitation.

Water clouds may also consist of supercooled-liquid water. We think that typically water freezes below $0{ }^{\circ} \mathrm{C}$, but this is not entirely correct. In the atmosphere, small water droplets can remain in the liquid phase even at ambient temperatures below $-40{ }^{\circ} \mathrm{C}$ (Kim et al., 2017). This supercooled liquid water is possible due to the absence of impurities in the droplet itself (such as dust particles). Previous studies have reported that supercooled-liquid water can exist in the temperature range from about $-40{ }^{\circ} \mathrm{C}$ to $0{ }^{\circ} \mathrm{C}$ (Findeisen, 1942) and can pose adverse effects in aviation safety (Cober \& Isaac, 2002).

Supercooled-liquid water is found in mixed-phase clouds. Mixed-phase clouds have been observed in the temperature range between $-40{ }^{\circ} \mathrm{C}$ to $0{ }^{\circ} \mathrm{C}$ where both ice and supercooled-liquid water co-exists. In fact, a mixed-phase cloud is a three-phase system consisting of water vapour, liquid droplets, and ice particles. These clouds are thermodynamically unstable and should quickly dissipate. In the presence of ice crystals and supercooled-liquid water droplets and given that there is sufficient water content, ice crystals will grow by vapour deposition at the expense of liquid drops that would lose their mass by evaporation (Bergeron, 1935; Findeisen, 1942; Wegener, 1912). This is feasible as the equilibrium water vapour pressure with respect to ice is less than with respect to liquid at the same subfreezing temperature. The equilibrium vapor pressure is the main property that determines the evaporation rate of the liquid or ice. Observational studies have found that relative humidity in these clouds is close to saturation over water which enhances the above theory (Korolev \& Isaac, 2003). Nevertheless, mixed-phase clouds in the Arctic are found to be persistent (Intrieri et al., 2002; Shupe et al., 2005). It has been proposed that the longevity of the Arctic mixed-phase clouds is possible due to high CCN concentrations (Stevens et al., 2018) which suppress ice formation (Norgren et al., 2018). The level of understanding of mixed-phase clouds is rather low because of their complicated structure, dynamics, and aerosol-cloud interactions. In Paper IV we have linked the cloud top temperature in mixed-phase clouds with different aerosol types found in the vicinity of those. We found strong correlation of the mixed-phase occurrence to the aerosol load in which polluted mixed-phase clouds occurred more frequent than less polluted ones.

\section{Ice clouds}

The processes involved in ice particle formation are far more complicated and less understood than for water droplets. Ice clouds are made of ice crystals. Typically, ice can be formed when the ambient temperature falls below $0{ }^{\circ} \mathrm{C}$. Then, ice crystals 
can form either by a) freezing of cloud droplets (liquid to ice) or by b) deposition of water vapor to the solid phase (vapor to ice). In both cases, the formation of ice crystals in the atmosphere follow two ice nucleation pathways: homogeneous and heterogeneous (Cantrell \& Heymsfield, 2005). Homogeneous ice nucleation occurs without the aid of an aerosol particle to act as INP and heterogeneous ice nucleation involves the aid of insoluble aerosol particles to serve as INP. In practice, homogeneous nucleation materializes only through the first case, freezing of a liquid drop, as homogeneous deposition requires conditions which never occur in the atmosphere. Furthermore, this ice formation mechanism is more probable when the ambient temperature is below $-40^{\circ} \mathrm{C}$. Regarding the second ice formation pathway, there are four different heterogeneous freezing modes: deposition nucleation, condensation, immersion and contact freezing (Pruppacher \& Klett, 2010). These ice heterogeneous nucleation mechanisms are not equally efficient. For example, deposition ice nucleation dominates at temperatures below $-30^{\circ} \mathrm{C}$ (Phillips et al., 2008).

The heterogeneous ice nucleation mechanisms are currently associated, among others, with uncertainties related to the ability of aerosol particles to form ice. Different aerosol types exhibit different ability to serve as INPs given to their differences in chemical composition. For example, In Paper III, we studied the Arabian dust properties. Dust is considered the main contributor of INP, especially in the northern hemisphere, which along with biogenic particles (e.g. pollen) can act as INP already at temperatures between -10 and $-20^{\circ} \mathrm{C}$ (Atkinson et al., 2013). Nevertheless, atmospheric processes (aging) often modify the surface of aerosol particles therefore their ice nucleation ability can be decreased or increased depending on the coating material on the particle (Augustin-Bauditz et al., 2014; Kanji et al., 2017; Sullivan et al., 2010). In Paper IV, we correlated the cloud phase and the aerosol type in the vicinity of that cloud and found moderate discrepancies between ice clouds and aerosol type. Moreover, free-tropospheric smoke particles were mostly associated with mixedphase clouds rather than ice clouds which is contradictory as BC is considered as INP. Recent studies question the BC efficiency (Ullrich et al., 2017; VergaraTemprado et al., 2018) and airborne measurements correlate the presence of smoke particles to a reduction of $\sim 50 \%$ in the cloud droplet radii (Zamora et al., 2016), supporting the less efficient glaciation due to higher droplet number concentration.

\subsection{Radiative forcing by aerosols and clouds}

Presently, the influence of given climatic factor in the climate is expressed through radiative forcing $(R F)$. The $\mathrm{RF}$ is the net change in the energy balance of the Earth system due to some imposed perturbation (IPCC Fifth Assessment Report, Seinfeld et al., 2016). Climate forcings are factors that potentially change the Earth's 
radiative balance. When a climate forcing results in greater incoming energy than outgoing energy, the planet warms up (positive RF). Conversely, if outgoing energy is greater than incoming energy, the planet cools down (negative RF). The climatic drivers can be either natural, such as changes in Earth's orbital cycle, changes in Solar irradiance, and volcanic eruptions or human-induced such as emission of greenhouse gases, aerosol particles and changes in land use. Since 1750, humaninduced climate drivers have been increasing, and currently their effect dominate the natural climate drivers. The changes in greenhouse gases, aerosol particles, clouds and land use have resulted in a total anthropogenic RF of 2.29 (1.13 to 3.33 indicating $95 \%$ confidence) $\mathrm{W} \mathrm{m}^{-2}$, therefore the Earth receives more energy than releases back to space. Because of this, the global average surface temperature on Earth has risen about $0.9^{\circ} \mathrm{C}$ since the late $19^{\text {th }}$ century.

Climate drivers can also trigger feedbacks intensifying or weakening the original forcing. An example can be observed in Polar Regions. During the past decades, the Earth has been warming rapidly and the strongest increase in temperature has been observed over Arctic regions. Consequently, the annual Arctic sea ice extent decrease rate is currently $12.85 \%$ per decade (IPCC Fifth Assessment Report, Seinfeld et al., 2016). This gradually reduces the surface albedo over the Arctic sea which in turn traps more heat enhancing the melting of the ice. Permafrost is also affected by the higher surface temperatures further releasing greenhouse gases due to deglaciation. Both amplification mechanisms influence cloud properties which in turn regulate surface radiative fluxes (Vavrus, 2004).

Atmospheric aerosols impact the energy transfer both directly and indirectly. The direct effect of the aerosols occurs when an aerosol layer in the atmosphere absorbs or scatters radiation. The total anthropogenic RF of the aerosols due to this amounts to -0.27 (-0.77 to 0.23) $\mathrm{W} \mathrm{m}^{-2}$ (IPCC Fifth Assessment Report, Seinfeld et al., 2016). Thus, on average aerosol particles have a negative radiative forcing, cooling the climate. Nevertheless, individual aerosol types exhibit contrasting RF effects. For example, mineral dust, sulphates, nitrates, and organic aerosols pose a cooling effect whereas $\mathrm{BC}$ and brown carbon (BrC) - an organic type of carbon- have a warming effect. In fact, BC has an estimated anthropogenic RF of $0.4 \mathrm{~W} \mathrm{~m}^{-2}$ (IPCC Fifth Assessment Report, Seinfeld et al., 2016), and therefore is the second strongest anthropogenic contributor (after $\mathrm{CO}_{2}$ which has a global mean of $1.68 \mathrm{~W} \mathrm{~m}^{-2}$ ) to climate forcing. In addition to scattering or absorbing radiation, aerosols alter the albedo of surfaces when deposited. Bright surfaces, such as sea ice and snow, reflect radiation and cool the climate whereas, darker surfaces, such as the ocean absorb solar radiation resulting to opposite effect. Therefore, the darkening of snow-covered areas due to $\mathrm{BC}$ and $\mathrm{BrC}$ deposition has been found to introduce an additional small positive forcing for the specific compounds. Particularly in the Arctic, aerosols from biomass burning and anthropogenic pollution facilitate the melting of the ice. Therefore, the 
direct aerosol effect is highly heterogeneous since the concentration of atmospheric particles are localized. On top of that, atmospheric processing (aging) changes their scattering/absorption ability of the presented aerosols. For example, coated BC enhances its absorption efficiency (Luo et al., 2018) even when coated with non-absorbing aerosol particles such as sulphates, organics and nitrates (Fierce et al., 2016 and references therein). Furthermore, internally mixed OC suppresses the ability of marine aerosols to grow with increasing $\mathrm{RH}$ which lowers its cooling effect and their ability to act as CCN (Randles et al., 2004). Moreover, freshly emitted mineral dust is considered insoluble yet, several studies have revealed that long-range transported dust can acquire significant soluble coatings like sea-salt and sulphates resulting in hygroscopicity enhancements and its CCN activity.

The importance of clouds in the radiative balance is also well perceived since they reflect, on average, $25 \%$ of the incoming radiation. Of this, the relative contribution of low-level clouds is $90 \%$, while high-level clouds form the rest $10 \%$. The above associations are also important considering the aerosol indirect effect. Indirectly, aerosol particles can modify cloud microphysical processes by changing their radiative properties, amount, and lifetime. The indirect effect of aerosols through cloud adjustments amounts to a RF value of -0.55 (-1.33 to -0.06$) \mathrm{W} \mathrm{m}^{-2}$ (IPCC Fifth Assessment Report, Seinfeld et al., 2016). The total aerosol effect in the atmosphere, including cloud adjustments, offsets a substantial portion of the RF from well-mixed greenhouse gases. Nevertheless, the current scientific understanding of the aerosol indirect effect is low. The estimated error of the indirect effect is linked with uncertainties in aerosol-cloud interactions such as the efficiency of cloud ice nucleation pathways which depends on the chemical and microphysical properties of the various aerosol types. In these processes, aerosols act as CCN/INP with various contributions depending on the aerosol type (Kanji et al., 2017). 


\section{The lidar technique}

Animal echolocation, or bio-sonar (sound navigation and ranging), is the oldest known variation of modern active remote sensing evolved in nature millions of years ago (e.g. Boonman et al., 2014; Tsagkogeorga et al., 2013). The three-dimensional view of the surrounding area allows animals to navigate, communicate, and even find their prey. It wasn't before 1904 when similar systems started to develop by humans, initially for military purposes (Battan, 1973; Little, 1969; Synge, 1930). Radar technology evolved first, followed by sonar, sodar (sonic detection and ranging) and lidar. All share the same operation principle deviating at the wavelength at which they operate, giving a plethora of applications in today's society.

Lidar has a long rich history where early developments trace back to the 1930s. In 1930, long before the laser invention, Edward. H. Synge proposed measuring upper air density profiles by determining the scattering intensity using an array of searchlight beams (Synge, 1930; Tuve et al., 1935). The first observations were made seven years later by Hulburt, (1937), a US Naval scientist, where traces of the searchlight beams were captured at a sensitive photographic film after long exposure. The film had recorded light from as high as $28 \mathrm{~km}$ in altitude. A year later, Johnson et al. (1939) extended the observations up to $40 \mathrm{~km}$ in altitude. Later in 1938, the first cloud base height measurements were performed using light pulses (Bureau, 1946). The first height-resolved upper air observations were made by Elterman, (1951 and 1954), by scanning the receiver field of view of a distant telescope along the searchlight beam. Almost two decades later after Synge's idea, Middleton \& Spilhaus, (1953) introduced the term lidar, i.e., a system in which height resolution is actively deduced by collocating the transmitter (light emission) and receiver (signal detection).

Despite the innovative idea of using searchlight beams, it wasn't before the early 1960s and the invention of the laser and Q-switching techniques (Mainman, 1960; McClung \& Hellwarth, 1962; Schawlow \& Townes, 1958) until lidar technology started to rapidly develop, together with technological advancements in the optical components and photodetectors. The first lidar based atmospheric research is recorded by Fiocco \& Smullin, (1963) where scattered light, presumably from dust particles, was detected along the beam pathway in the upper atmosphere. Ligda in 1963 introduced a whole new era for lidars as they aimed for the detection of particles and clouds in the lower atmosphere (Ligda, 1963). In 1981, Nd:YAG (neodymium-doped yttrium aluminium garnet; $\left.\mathrm{Nd}: \mathrm{Y}_{3} \mathrm{Al}_{5} \mathrm{O}_{12}\right)$ and other solid state lasers replaced the former ruby lasers as the light source (Chanin \& Hauchecorne, 1981). 


\subsection{Lidar types and applications}

Various lidar instruments have been developed since the 60s, giving a wide range of applications (Neff, 2018). Nowadays, lidar applications go beyond atmospheric research. Topography (Bufton et al., 1991), agriculture (Weiss \& Biber, 2011), biology (Lefsky et al., 2002), forestry (Dubayah \& Drake, 2000), geology (Jordan et al., 2005), law enforcement (Mandava et al., 2018), transportation (Xu et al., 2019), 2019), air traffic control (Salerno et al., 2008), archaeology (Masini \& Lasaponara, 2013), green energy (Suomalainen et al., 2017), and even gaming (McCormack et al., 2015) are just a few of the myriad applications developed. Selectively, lidars serve as an excellent tool for 2D and 3D mapping in topographic and image applications such as digital elevation maps of the Earth and other planets, crop mapping and categorization, soil recognition, planning archaeological excavations, tumour recognition, etc. Due to the high spatial and temporal resolution, lidars can determine obstacles with an accuracy of $\pm 2 \mathrm{~cm}$ making them an excellent tool for obstacle detection in autonomous vehicles, collision avoidance, and parking allocation, increasing road safety. In the field of law enforcement, lidars track a vehicle's speed (speed guns), record accidents and crime scenes (Terpstra et al., 2019; Tredinnick et al., 2019).

The applications in the atmospheric science focus on measurements of atmospheric gases, aerosol particles, clouds, wind and temperature, as well as concentrations of metal atoms and ions (Comerón et al., 2017). These observations can be made from lidars located on the ground (ground-based), on board of a satellite (satellite or spaceborne) as well as on an aircraft (airborne) (McCormick, 2005). There are 5 basic lidar techniques which depend on the interaction between the emitted radiation and the atmospheric constituents (Weitkamp, 2005): Elastic and inelastic (Raman) lidars, differential absorption lidars (DIAL), resonance fluorescence lidars, and Doppler lidars (Wandinger, 2005). The first two lidar techniques have been used in this dissertation but all five will be shortly introduced for their applications. In general, the wavelengths of radiation used in the aforementioned techniques depend on the application and range from about $250 \mathrm{~nm}$ to $11 \mu \mathrm{m}$. Figure 4 presents the lidar types based on the interaction of the observed components with light and their corresponding applications in the atmosphere.

Elastic lidars are the simplest form of lidars and they deliver vertical information about the presence and location of aerosol and cloud layers in the atmosphere, but they can also estimate the visibility (Pantazis et al., 2018). The term elastic corresponds to the elastic scattering (see Section 2) by which the emitted wavelength from the laser source remains unchanged after interaction with the target.

In addition to the above mentioned quantities, inelastic or Raman lidars are used to measure also temperature and atmospheric gases such as water vapor (Behrendt et al., 2002; Behrendt, 2005; Whiteman et al., 1992). The advantage over elastic lidars 
is that the assumptions in the retrievals are minimized giving robust results and possibility to observe more optical properties (see Section 3.4). On the downside, Raman lidars are usually limited to night-time observations as the intensity of the Raman scattered electromagnetic radiation is orders of magnitude lower than the intensity of the elastic scattering and during daytime the solar radiation limit the detection of these signals. Nevertheless, daytime Raman operation is possible with an adequate lidar setup (Renaut et al., 1980; de Tomasi et al., 1999).

Differential absorption lidars, hereafter DIALs, are used for the detection of atmospheric gases such as $\mathrm{H}_{2} \mathrm{O}$ (water vapor), $\mathrm{O}_{3}, \mathrm{NO}_{2}, \mathrm{NO}, \mathrm{N}_{2} \mathrm{O}, \mathrm{SO}_{2}, \mathrm{CH}_{4}, \mathrm{HCl}, \mathrm{NH}_{4}$, and temperature (Bösenberg, 2005; Gimmestad, 2005). The detection principle lies in the fact that every gas absorbs electromagnetic radiation differently at different wavelengths, creating a signature that can be quantified with laboratory measurements. DIALs emit two wavelengths from two different laser sources, one of which is absorbed by the gas more strongly than the other, which enables the detection and characterization of the amount and physical properties of these components in the atmosphere. Despite the wide measurement capabilities, elastic scattering by atmospheric aerosols interfere DIAL measurements. As a result, it is almost impossible to define atmospheric gas concentrations under enhanced aerosol loading. A combination of Raman and DIAL techniques has also been proposed to tackle this effect so that Raman shifted radiation from nitrogen or/and oxygen is separately detected. Therefore, the aerosol extinction coefficients can be determined, and the aerosol contribution can be subtracted.

Resonance fluorescence lidar is adequate for monitoring, among others, atoms and ions in the mesosphere (Abo, 2005). In resonance fluorescence the frequency (wavelength) of the incident radiation coincides with the natural frequency of the atom, ion, or molecule, and emission happens at the same or longer wavelength. A laser source is used, and the detection of the scattered radiation is performed at an adequate wavelength specific for the atmospheric component.

Finally, Doppler lidars measure turbulence and wind in the lower atmosphere with applications in weather and wind energy production (Werner, 2005). The aerosol particles are considered ideal for tracking winds. Doppler lidars emit electromagnetic radiation, usually at $1.5 \mu \mathrm{m}$ wavelength, into the atmosphere. As the aerosol particles move from point A to B, they scatter light. Because the particles are moving while scattering, it is conceived by the receiver as frequency shift, therefore the particle velocity (or wind) can be calculated using the Doppler effect equations. 

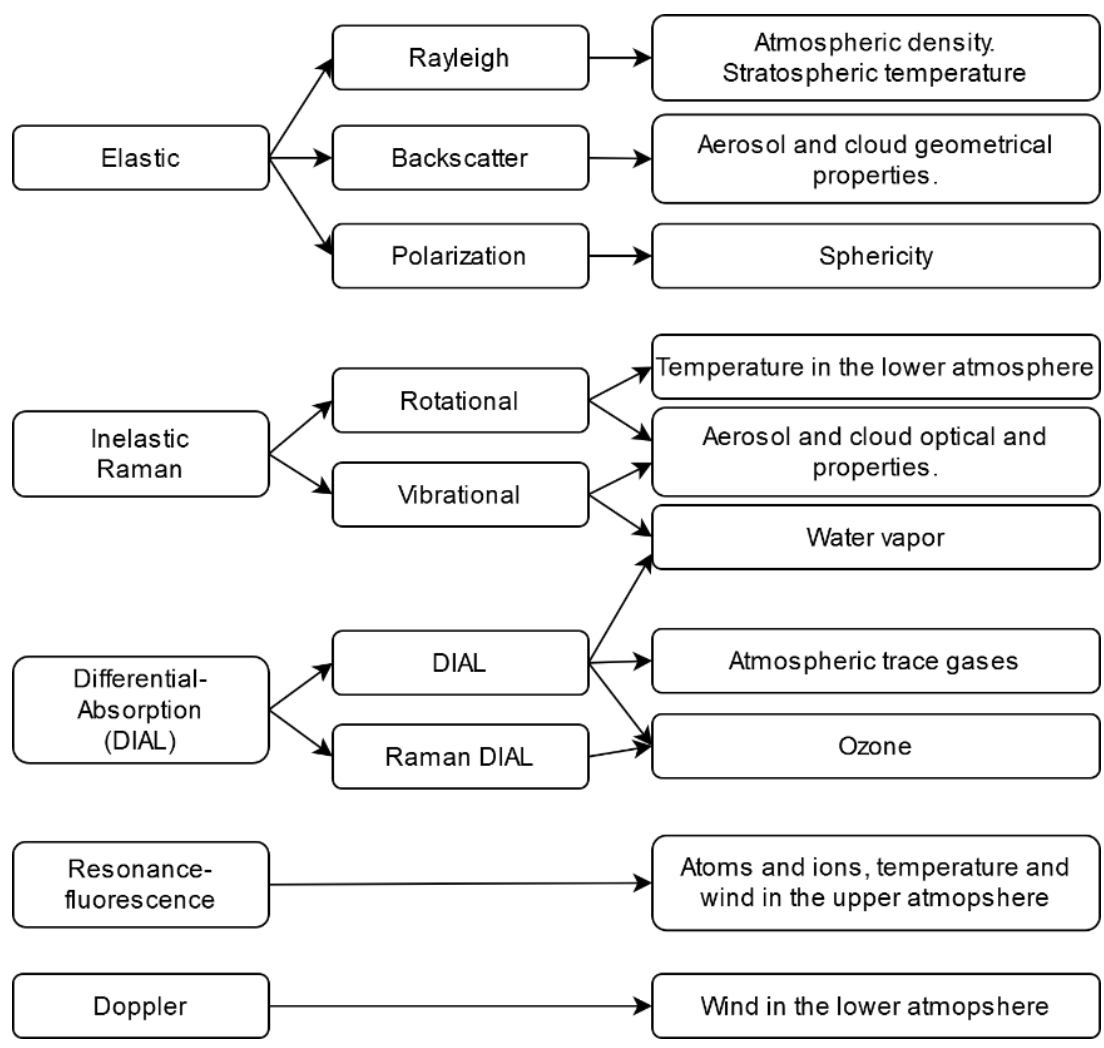

Figure 4. Different types and the corresponding main applications. Atmospheric pollutants refer to gases and particles in the atmosphere

\subsection{Lidar principle}

Active remote sensing instruments use their own radiation source. In lidars, a laser generates short light pulses which can be absorbed or scattered upon interaction with the atmospheric gas molecule and aerosol particles. Then, the instrument detects the electromagnetic radiation scattered in the backward direction, and an estimation of the vertical distribution and the type of the scatterer can be derived. The temporal lag between the emission of the laser pulse and the reception of the scattered light corresponds to the distance of the scatterer from the instrument. Thus, the two major components of a lidar instrument are the transmitter and the receiver.

The transmitter consists of a laser source, nowadays high-power excimers or $\mathrm{Nd}$ :YAG lasers. I will focus on Nd:YAG lasers as these lasers are widely used in ground based networks and satellite based lidars such as the European Aerosol Research Lidar Network (EARLINET), the Latin American Lidar Network (LALINET) 
and the Cloud-Aerosol Lidar and Infrared Pathfinder Satellite Observation (CALIPSO) satellite (Guerrero-Rascado et al., 2016; Hunt et al., 2009; Pappalardo et al., 2014). The primary emission of Nd:YAG lasers is in the infrared spectral region at $1064 \mathrm{~nm}$. Frequency doubling, tripling or quadrupling is used to convert the primary radiation to 532, 355 and $266 \mathrm{~nm}$ wavelengths. Depending on the lidar system, a beam expander can be placed before the beam is directed to the atmosphere. Beam expanders reduce the divergence of the laser beam by increasing the size of the beam diameter. Although lasers produce highly collimated beams of about $1 \mathrm{mrad}$, further decrement is required for narrow lidar field of views. The narrow field of view is necessary to suppress background light and increase the signal to noise ratio. For example, in PollyXT lidar systems (Althausen et al., 2009; Engelmann et al., 2016) used in this work the laser beam is expanded almost 6.5 times, from $7 \mathrm{~mm}$ before the beam expander to $45 \mathrm{~mm}$ in diameter after it.

The receiver consists of three subsystems. A telescope collects the backscattered radiation and further directs it to the optical analysing and data acquisition units. The telescope's properties such as the focal length and diameter define the field of view of the instrument. The telescope's properties in conjunction with the location where the laser beam exits the instrument define the 'blind' region of the instrument or the so-called overlap region. Two possible configurations exist depending on the laser beam location, coaxial and biaxial. Coaxial systems use the same aperture therefore the overlap effect is almost absent. However, such systems are difficult to construct, and they come with certain limitations (Nicolae et al., 2008). In the more commonly used systems, the laser beam exits from the side of the receiver telescope. Since the beam gradually enters the field of view of the telescope, it needs some distance to be fully imaged by the telescope. This effect needs to be considered in the retrieval of the aerosol optical properties for distances near the instrument. More complex lidars use a second smaller telescope with adequate geometry to reduce the overlap region as close as possible to the instrument (Engelmann et al., 2016), increasing the usefulness of the retrieved optical properties at lower altitudes. Eventually the light captured by the telescope is directed with the use of mirrors and beam splitters to the optical analysing and data acquisition units. At this point the radiation is not monochromatic (single wavelength). Within the optical analysing system, the light is spectrally separated using interference filters. These filters transmit light in a certain passband around the wavelength of interest and restrain light outside the transmission band. Interference filters are usually located before the detection units. The detection of the photons realizes through photomultiplier tubes (PMTs) and avalanche photodiodes (APDs), depending on the wavelength of interest. The simplest lidar setup has a single detector which gives the opportunity to detect one wavelength, but many detectors are usually arranged in a lidar setup for better characterizing the atmospheric constituents (multi-wavelength lidars). Essentially, the detectors convert the 
backscattered radiation into an electrical signal. The signal is then amplified, digitized, and recorded for further processing. The number of received photons (intensity of electrical signal) at fixed time intervals gives the range resolved density of scatterers (Kovalev \& Eichinger, 2004).

\subsection{Lidar equation}

In its simplest form, an elastic lidar emits radiation at a single wavelength and detects the backscattered radiation at the same wavelength. The backscatter radiation refers to the backward direction of the scattered radiation detected by the lidar at $180^{\circ}$ compared to the incident. Usually, lidar systems generate radiation in multiple wavelengths, typically at 1064, 532 and $355 \mathrm{~nm}$. The number of detected elastic or/and inelastic wavelengths depends on the lidar capabilities. An elastic lidar signal can be expressed through Eq. 3.1.

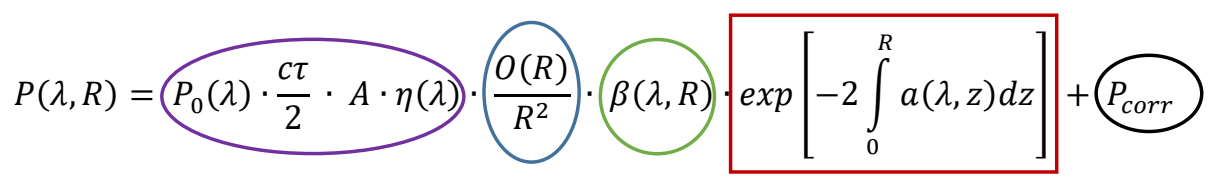

Where, $\mathrm{P}$ is the measured signal power at wavelength, $\lambda$, and distance, $\mathrm{R}$, from the instrument. $P_{0}$ is the average power of a single laser pulse. The products of the speed of light, c, and the temporal pulse length, $\tau$, are divided by a factor of two to account for the effective (spatial) pulse. The backscattered light received at an instant time corresponds to a scattering volume rather than a single point. The length of the scattering volume is the effective pulse length (Fig. 5). The area of the telescope is denoted with $A$ and $\eta$ is the wavelength-dependent total system efficiency. The term $\mathrm{O}(\mathrm{R})$ refers to the overlap function. This parameter is 0 close to the instrument and becomes 1 when the laser beam is fully imaged to the receiver's field of view (biaxial setup). The $\mathrm{R}^{2}$ is the aftereffect of the receiver's telescope area and makes up the lidar's perception angle for light scattered at distance R. The volume backscatter coefficient, $\beta$, describes the amount of light scattered backwards, i.e., towards the receiver. The backscatter coefficient is the result of all types of scatterers in the atmosphere including air molecules and aerosol particles. Finally, the volume extinction coefficient, $\alpha$, results from the absorption and scattering of light by air molecules and particles. It is counted twice due to the two-way transmission from the instrument to some distance $\mathrm{R}$ and back (Fig. 5). 


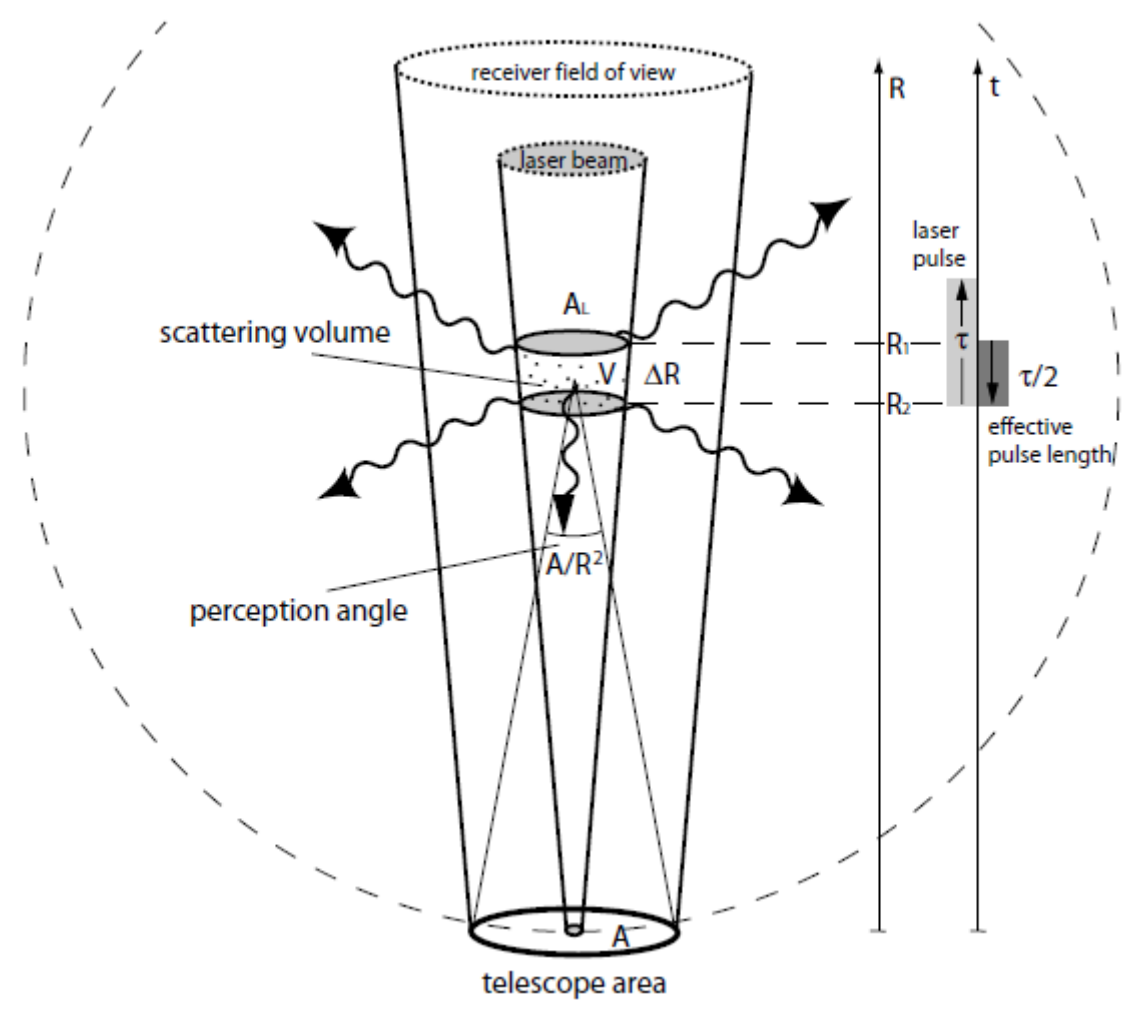

Figure 5: Illustration of the lidar geometry (coaxial). Image from Weitkamp, (2005).

The lidar equation (Eq. 3.1) can be grouped into five factors as circled. The first one (purple) is the system factor that summarizes the range-independent parameters of the lidar system. The system factor incudes the optical efficiency of all elements the light passes when transmitted and received, as well as the efficiency of the detectors. Such elements are optical components used for directing the laser beam into the atmosphere and back into the detectors. For example, non-ideal optical surfaces and optical coatings on beamsplitter cubes and mirrors and the quantum efficiency of the photomultipliers at a given wavelength are some of these components. The second one (blue) is the geometric factor as explained earlier. These first two factors are determined by the lidar setup and can be fully characterized (Wandinger \& Ansmann, 2002). The third factor (green) is the volume backscatter coefficient. As mentioned, this factor has the contribution both form air molecules and aerosol particles and determines the strength of the received signal. The transmission term (red), expressed through the extinction coefficient, accounts for the losses of light on the way from the lidar to the scattering volume and back. Both, $\beta$ and $\alpha$ are wavelength dependent 
parameters and they are the two unknowns and most desired parameters in the lidar equation. Finally, the last term (black) stands for signal corrections. These can be corrections due to background noise interference in the received signal or corrections regarding multiple scattering effects (Wandinger et al., 2010 \& 1998; Wang et al., 2004). Multiple scattering is the phenomenon wherein photons scattered from the incident radiation are re-scattered from neighbouring particles prior to reaching the instrument detector. This effect falsely adds up to the received signal. Usually, multiple scattering correction is omitted for the study of aerosol particles, but this is not the case during strong aerosol events and clouds where the concentration of particles and droplets/crystals is much higher.

Additionally, to the elastic wavelength detection, Raman lidar systems record the inelastically scattered radiation from nitrogen molecules. The shifted wavelength is characteristic of the scattering molecule. For example, for a stimulation wavelength at 355 or $532 \mathrm{~nm}$ which is the case for the vast majority of elastic lidars, the detection is performed at 387 and $607 \mathrm{~nm}$, respectively. The lidar equation concerning the inelastic scattering at the Raman wavelength, $\lambda_{\mathrm{Ra}}$, is described by Equation 3.2. Dissimilar to the elastic equation, here the transmission term accounts for light extinction at the emitted wavelength, $\lambda$, on the way to the scattering volume and at the shifted wavelength, $\lambda_{\mathrm{Ra}}$, on the way back to the lidar. The backscatter coefficient corresponds to the vibrational-rotational scattering of the nitrogen molecules only.

$$
P\left(\lambda_{R a}, R\right)=P_{0}(\lambda) \cdot \frac{c \tau}{2} \cdot A \cdot \eta\left(\lambda_{R a}\right) \cdot \frac{O(R)}{R^{2}} \cdot \beta\left(\lambda_{R a}, R\right) \cdot \exp \left[-\int_{0}^{R} a(\lambda, z)+a\left(\lambda_{R a}, z\right) d z\right]
$$

Both lidar equations include molecular and aerosol particle contributions. Therefore, the molecular contribution must be removed from the measured total signal before aerosol optical properties can be analysed. The molecular properties are well-determined and can be therefore calculated knowing the number density of the molecules, their scattering cross-section, and the phase function for the scattering angle in backward direction (Bucholtz, 1995). Usually, temperature and pressure profiles are available for the determination of the number density (e.g. through radiosondes or standard atmosphere). In the case of elastic lidars, the equation contains two unknown physical quantities, the volume backscatter and extinction coefficients of the particles. Since it is not possible to derive both parameters having only one equation, an assumption about their possible relationship is necessary. The lidar ratio, i.e. the extinction to backscatter ratio, is a critical parameter for the retrieval of aerosol properties from elastic lidar observations and can introduce more than $20 \%$ error in the retrieved aerosol profiles (Böckmann et al., 2004; Sasano et al., 1985). After assumption of the lidar ratio, the backscatter coefficient can be determined by inversion 
methods proposed by Klett, Fernald and Sasano (Fernald, 1984; Klett, 1981; Sasano \& Nakane, 1984) or iteratively (Girolamo et al., 1999). On the contrary, Raman lidar observations allow independent estimations of the aerosol backscatter and extinction profiles without uncertain assumptions (Ansmann et al., 1992 \& 1990).

\section{Polarization measurements}

The electromagnetic radiation is a vector of the electric and magnetic fields. An intrinsic property of the electric field is that any instance in space it shows some orientation. This orientation can be linear, rotating, or random, yielding linearly, rotating or randomly polarized radiation. Elastic lidars use this fundamental property by polarizing linearly the outgoing radiation. Upon interaction with the atmospheric components, part of the beam loses this orientation. The detection of the depolarized radiation is then performed at two orthogonal polarization planes, parallel and perpendicular when compared to the incident plane (Murayama et al., 1999). The linear particle depolarization ratio, i.e. the depolarization with respect to linearly polarized emitted light, depends on the atmospheric scatterer where non spherical aerosol particles pose stronger depolarization than spherical aerosol particles (Behrendt et al., 2002; Tesche et al., 2011). This information is valuable in atmospheric measurements as particles come in many different shapes (Pal \& Carswell, 1973; Schotland et al., 1971). Polarization lidars can classify the aerosol types based on their shape (Groß et al., 2011 \& 2015; Sugimoto et al., 2002) which gives the possibility to further calculate the share of spherical to non-spherical contribution in the lidar signal (Tesche et al., 2009). In Papers II and III, we used the polarization capability of a multi-wavelength lidar to study the degree of depolarization causes by pollen and Arabian dust particles. However, the optical components in the emission and receiving units can lead to large systematic errors in the retrieved polarization ratio (Belegante et al., 2018; Freudenthaler, 2016). For a well-designed lidar system these errors can be minimized yet a previous study has found up to $10 \%$ of systematic error in the presence of depolarizing particles which can exceed $100 \%$ in the molecular area (Bravo-Aranda et al., 2016).

The polarization detection capability of lidars is useful for one more reason. Mattis et al. (2009) demonstrated that in the presence of depolarizing scatterers in the atmosphere, the receiver can be affected with a systematic error caused by polarization-dependent receiver transmission configuration. In the same study, a correction methodology is proposed in the measured signals using the depolarization channel which can lead to as high as $20 \%$ more accurate backscatter retrievals. Therefore, a well-designed system to avoid systematic errors due to non-ideal optical elements and frequent quality assurance tests is needed to minimize the effect in the retrieved linear particle depolarization ratio profile. 
Water vapor mixing ratio measurements

Water vapor mixing ratio measurements are performed by detecting two Raman signals (Ansmann et al., 1992; Whiteman et al., 1992). One of which is the return signal from a reference atmospheric gas such as nitrogen and the other one is from the atmospheric gas of interest e.g. water vapor or any other gas with sufficient concentration. Typically, the Raman lidar technique uses the inelastic backscatter from nitrogen and water vapor at $387 \mathrm{~nm} 407 \mathrm{~nm}$, respectively (Whiteman, 2003). The inelastic signals from $607 \mathrm{~nm}$ and $660 \mathrm{~nm}$ are also an option. The ratio of the above returned signals, which can be expressed through Equation 3.2 after rearrangements, is proportional to the mixing ratio of water vapor, i.e. the ratio of the mass of water vapor to the mass of dry air in a given volume. Thus, water vapor mixing ratios derived from lidars require a calibration constant to adjust the signal ratio to meaningful values. The calibration constant can be determined in many ways where most commonly a reference system is used for calibrating the lidar water vapor mixing ratio (Foth et al., 2015; Navas-Guzmán et al., 2014). In Paper I, we evaluate the calibration factor from several different reference methods and appoint alternatives depending on the availability of these at the lidar location.

Measurements of water vapor mixing ratio in the atmosphere can be used to further derive RH (Mattis et al., 2002; Navas-Guzmán et al., 2014; Ristori et al., 2005). The optical properties of the atmospheric particles strongly depend on $\mathrm{RH}$ values (Navas-Guzmán et al., 2019), therefore it can be used to track changes in the physical properties of the atmospheric particles (Haarig et al., 2017).

\subsection{Retrieved aerosol properties}

\subsubsection{Optical properties}

The determination of the particle extinction and backscatter coefficients using the lidar technique derives a handful of optical properties (Table 1). These optical properties can be divided into two categories. Extensive optical properties which depend both on the nature (composition and shape) and the amount of the atmospheric aerosol particles or clouds in the atmosphere, and intensive properties which depend only on the nature of the atmospheric component. The intensive properties can be used in multi-parametric relationships in the automatic aerosol and cloud classification (Kim et al., 2018; Müller et al., 2007; Nicolae et al., 2018).

\section{Extensive properties}

The backscatter and extinction coefficients are two extensive properties which have been already discussed. All lidars have a detection limit above which they can observe aerosol and cloud layers in the atmosphere. The detection limit is a function 
of the nature and concentration of the scatterers. For example, the lidar instrument on board CALIPSO satellite has a detection limit of $2-4 \times 10^{-4} \mathrm{~km}^{-1} \mathrm{sr}^{-1}$ backscatter in the troposphere (Powell et al., 2009; Winker et al., 2010). The undetected weak aerosol and cloud layers in the atmosphere introduce underestimations of the aerosol and cloud burden in comparison studies of optical properties (Kacenelenbogen et al., 2014; Toth et al., 2018), as well as in calculations of radiative transfer (Thorsen et al., 2017).

Another extensive property is the Aerosol optical depth (AOD). The AOD is a measure of the total aerosol extinction (Liou, 2002). The AOD is commonly used as an estimate of the amount of aerosol particles in the atmosphere, although it also depends on the optical properties of the aerosol. In the lidar technique, the parameter can be calculated by integrating the extinction coefficient profile from the surface up to the maximum possible measurement height range.

\section{Intensive properties}

An impressive effort has been made by the lidar community all around the world to define the intensive optical properties of pure aerosol types. Nicolae et al. (2018) summarize the up-to-date knowledge for the aerosol properties observed with elastic and Raman lidar systems. Cloud related optical properties have been reported by Weitkamp, (2005), Yorks et al., (2011), Voudouri et al., (2019) and references therein. Explicitly, the intensive properties involve the following parameters:

Lidar ratio $(L R)$ is the extinction to backscatter ratio. The molecular LR is range independent and well defined and can be therefore calculated. On the contrary, the particle LR can fluctuate with altitude as it depends on the size, shape, humidity, and chemical composition of the particles which is not constant throughout the atmospheric column. For example, dust particles at $532 \mathrm{~nm}$ wavelength have values between 30-60 sr compared to marine aerosols whose range is between 15 and $30 \mathrm{sr}$ (Nicolae et al., 2018).

Angström exponent $(\AA)$ describes the spectral dependence of the AOD (Ångström, 1929; Ansmann \& Müller, 2005). It requires the performance of optical measurements of at least two wavelengths while additional wavelengths provide more detailed characterization of the observed atmospheric components (Baars, 2011). The $\AA$ is a rough measure of the size of the atmospheric components. Typical values range between 0 to 3. Small particles correspond to large $\AA$ values and large particles to small $\AA$ values. For example, dust and marine particles show $\AA$ values lower than 1 indicating the presence of coarse mode particles in the atmosphere (Eck et al., 1999; Schuster et al., 2006). 
Linear particle depolarization ratio $\left(\delta_{p}\right)$ is a measure of sphericity of the atmospheric components. The degree of the depolarization is a function of the amount, size, refractive index and shape of the particles. The values generally range from 0 to $45 \%$, so that irregularly shaped particles such as ice crystals, volcanic and desert dust introduce $\delta_{p}$ larger than 25\% (Groß et al., 2011; Müller et al., 2007; Sassen, 2005). Moreover, the shape of atmospheric particles, therefore the $\delta_{\mathrm{p}}$ is affected by the hydration rate of the atmospheric particles (humid or dry), their lifetime (aged or fresh), as well as their physical composition (water or ice) (Ansmann et al., 2009; GranadosMuñoz et al., 2015). Beyond aerosol classification, $\delta_{\mathrm{p}}$ is useful parameter in the retrieval of microphysical aerosol properties.

Table 1. Optical properties derived with a lidar instrument.

\begin{tabular}{|c|c|}
\hline Parameter & Units \\
\hline \multicolumn{2}{|l|}{ Extensive properties } \\
\hline Backscatter coefficient & $\mathrm{Mm}^{-1} \mathrm{sr}^{-1}$ \\
\hline Extinction coefficient & $\mathrm{Mm}^{-1}$ \\
\hline Aerosol Optical Depth (AOD) & - \\
\hline $\begin{array}{l}\text { Water Vapor Mixing ratio } \\
\text { (WVMR) }\end{array}$ & $\mathrm{g} \mathrm{kg}^{-1}$ \\
\hline \multicolumn{2}{|l|}{ Intensive properties } \\
\hline Lidar ratio (LR) & sr \\
\hline 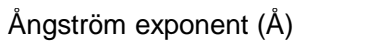 & - \\
\hline $\begin{array}{l}\text { Linear particle depolarization } \\
\text { ratio }\left(\delta_{p}\right)\end{array}$ & $\%$ \\
\hline
\end{tabular}

\subsubsection{Microphysical properties}

The transition from lidar derived aerosol particle optical properties to microphysical properties is challenging due to the lack of adequate light-scattering models. The lidar-derived optical properties obtained from a single scattering angle $\left(180^{\circ}\right)$ is too low to determine all the microphysical properties such as the effective radius, shape, refractive indices, single scattering albedo, size distribution and concentration of the particles. Therefore, inversion methods have been developed (Gasteiger et al., 2011; Müller et al., 1999; Osterloh et al., 2013; Veselovskii et al., 2002 \& 2004). The mathematical inverse problem is ill-posed in which the desired microphysical property derives after several iterations and therefore different solutions instead of a unique one, introducing large uncertainties in the retrieved microphysical properties 
(Papayannis et al., 2012; Pérez-Ramirez et al., 2013), thus regularization and constraints are necessary. The basic input is a $3 \beta+2 \alpha$ (or $3+2$ ) dataset, i.e. the three available backscatter coefficients at 1064, 532 and $355 \mathrm{~nm}$ and the two extinction coefficients at 532 and $355 \mathrm{~nm}$. This configuration works rather well in the case of spherical particles (e.g. Balis et al., 2010) but extensions have been developed to non-spherical particles for more accurate calculations (Müller et al., 2016; Veselovskii et al., 2010). A widely used light scattering model for non-spherical particles assumes that the particles are spheroids in shape (Dubovik et al., 2006). Veselovskii et al. (2010) implemented this model to lidar retrievals assuming aerosols to be a mixture of spheres and randomly oriented spheroids with a size-independent shape distribution. However, the approach of spheroid like particles in lidar applications is rather restricted (Müller et al., 2010 \& 2012). Tesche et al. (2019) demonstrated that in the case of non-spherical particles, additional information of linear particle depolarization measurements $(3+2+1)$ improve the retrieved microphysical properties but the advantage of more depolarization channels $(3+2+X)$ is limited by the use of the nonideal light scattering model which assumes non spherical particles to have spheroid like shape (Dubovik et al., 2006). Nonetheless, new light scattering models have been developed presenting more realistic particle geometries (Kahnert et al., 2016; Nousiainen \& Kandler, 2015). Synergistically, new light scattering models and novel lidar systems able to detect the atmospheric dust particle orientation (Tsekeri et al., 2019) could overwrite current lidar setups.

Cloud microphysical relevant parameters such as CCN and INP number concentrations can be also estimated by means of lidar observations (Andreae, 2009; Ghan et al., 2006; Mamouri \& Ansmann, 2017 \& 2016 \& 2015; Tan et al., 2019). To this end, these calculations are accompanied with large uncertainties linked to both lidar related retrieval errors and errors introduced by the methodologies themselves (Ansmann et al., 2019; Tan et al., 2019). In fact, uncertainties to the retrieved CCN number concentration amounts to 50-200\% and regarding the INP number concentrations up to a factor of 3 higher than CCN retrievals, has been determined (Ansmann et al., 2019). Predominately, the errors are linked to insufficient knowledge of the aerosol particle types and their corresponding physical properties, chemical properties, and coating effects due to aging in the atmosphere. 


\section{Main results}

This chapter presents a synopsis of the main results and the relationship between Papers I to IV. For detailed results, kindly refer to the original publications included in the supplementary material.

\subsection{Water vapor mixing ratio and its link to atmospheric particles}

In Paper I, we retrieved profiles of water vapor mixing ratio (WVMR) in the troposphere using a ground based PollyXT Raman lidar (Althausen et al., 2009; Engelmann et al., 2016). Lidar WVMR profiles require calibration and this calibration is valid until further changes are applied to the receiver's channels involved in the WVMR retrieval (see Section 3.3). Typically, WVMR profiles from co located radiosondes (RS) are used to adjust the uncalibrated lidar WVMR data. As we propose in Paper I, in the absence of collocated RS, a few alternative methods can be used for the calibration (Fig. 6).
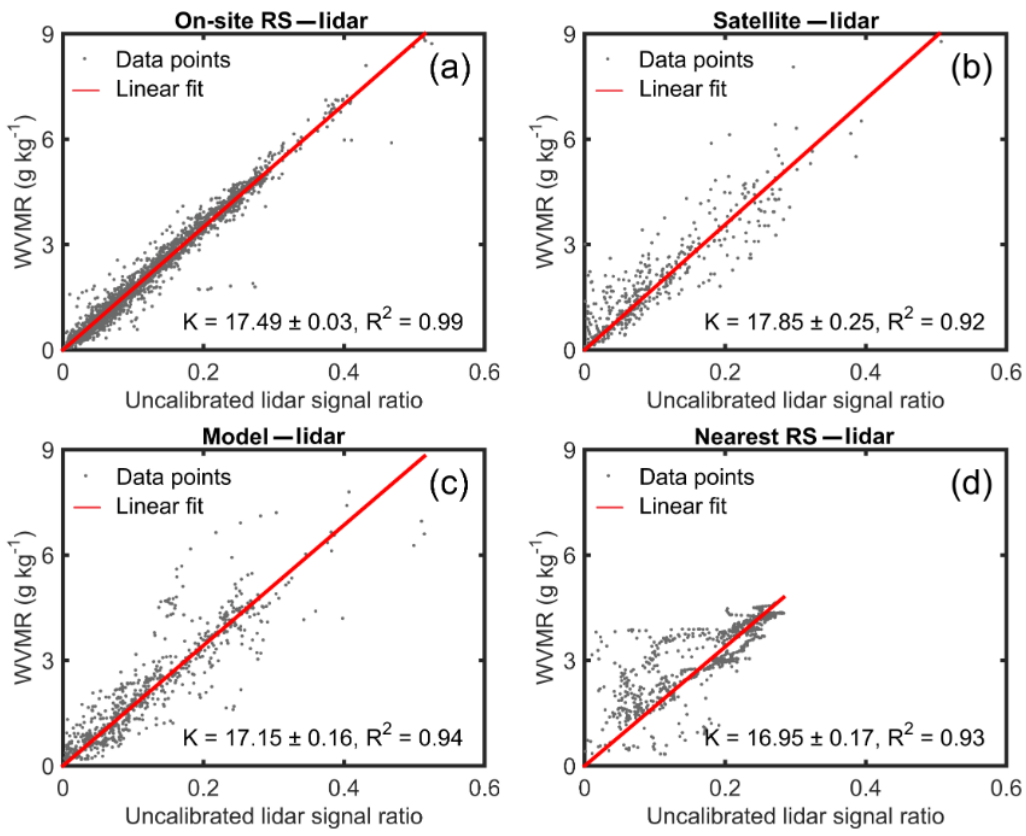

Figure 6. Overall calibration factor between the lidar and (a) on-site RS (b) the satellite, (c) the model and (d) the nearest RS. Data points are marked as grey dots and the regression as red line. The calibration factor is also shown for each method along with the standard deviation at the bottom of each panel. 
In this study, we used the regression method for the determination of the calibration factor. The principle is to perform a linear regression between the uncalibrated WVMR lidar signal and the known WVMR from the RS or any other reference instrument (England et al., 1992). The slope of the regression is the desired calibration factor. As another option, a set of calibration factors can be calculated from individual cases and then an average factor is retrieved. We concluded that it is preferable to use a combined regression method for the retrieval of the calibration factor instead of individual cases as they can have an impact on the derived factor inferring large bias in the WVMR profile. The inter comparisons between the on-site RS and the rest, showed that the NWP (Numerical Weather Prediction) model and the nearest available RS (almost $100 \mathrm{~km}$ away from the site in this case) were an effective alternative when no RS was available on site. In fact, in the lowest few kilometres, the model represented the shape of atmospheric WVMR layers more accurately than the nearest RS. Therefore, the use of the nearest RS which is typically what is available over the site is limited. Nonstable atmospheric conditions can lead to inadequate vertical representation of water vapor; for example, when there is enough time lag between the RS and the lidar measurement and when PBL activity is not constant, for example, between day and night. The WVMR from the satellite resulted in the highest discrepancies when compared to on site RS. The discrepancies are attributed to the worse spatial and poorer vertical resolution in the satellite data. We also proposed a more effective method when comparing satellite WVMR profiles to ground based ones. Instead of using the closest footprint to the point of interest, the use of trajectories to find the most suitable footprint is preferred. We found better agreement between the RS, the lidar and the satellite when applying this technique as described in the paper.

Accurate WVMR profiles can be used to study the hydration of atmospheric particles. For example, in Paper III we studied the aerosol properties over a dusty region. The observations were conducted in the United Arab Emirates under the OASIS (Optimization of Aerosol Seeding In rain enhancement Strategies) project. The project aimed towards a more robust knowledge of the efficiency of the aerosol particles to act as CCN/INP. With less than $100 \mathrm{~mm}$ of annual rainfall (Wehbe et al., 2017), precipitation enhancement techniques such as cloud seeding (French et al., 2018) have been implemented to tackle water shortages in the region. This approach requires accurate understanding of local/regional meteorology, detailed characterization of the background aerosol particles and their efficiency to act as CCN/INP, and the complex interplay between aerosols, clouds, and meteorology. One of the critical parameters is when and where cloud seeding should take place. By using WVMR profiles and further deriving the RH profiles we were able to observe dry layers in the atmosphere and calculate statistics for these isolated dry layers (Fig. 7). Dry layers 
have very low $\mathrm{RH}$ values compared to the surrounding air which has direct implications in cloud seeding. If cloud seeding has been successfully done and a cloud has been formed then under favourable atmospheric conditions, precipitation falls out from the bottom of the cloud. In the presence of isolated dry layers, this precipitation quickly evaporates or sublimates before reaching the ground. Thus, the effectiveness of cloud seeding is linked, among others, to the presence of dry layers. During the one-year campaign, we found that dry layers were present most of the time above the measurement site, showing higher frequency during the winter months (more than $60 \%$ of the time). The average altitude that these layers reside is at $5 \mathrm{~km}$ on average and their geometrical depth is about $1 \mathrm{~km}$.

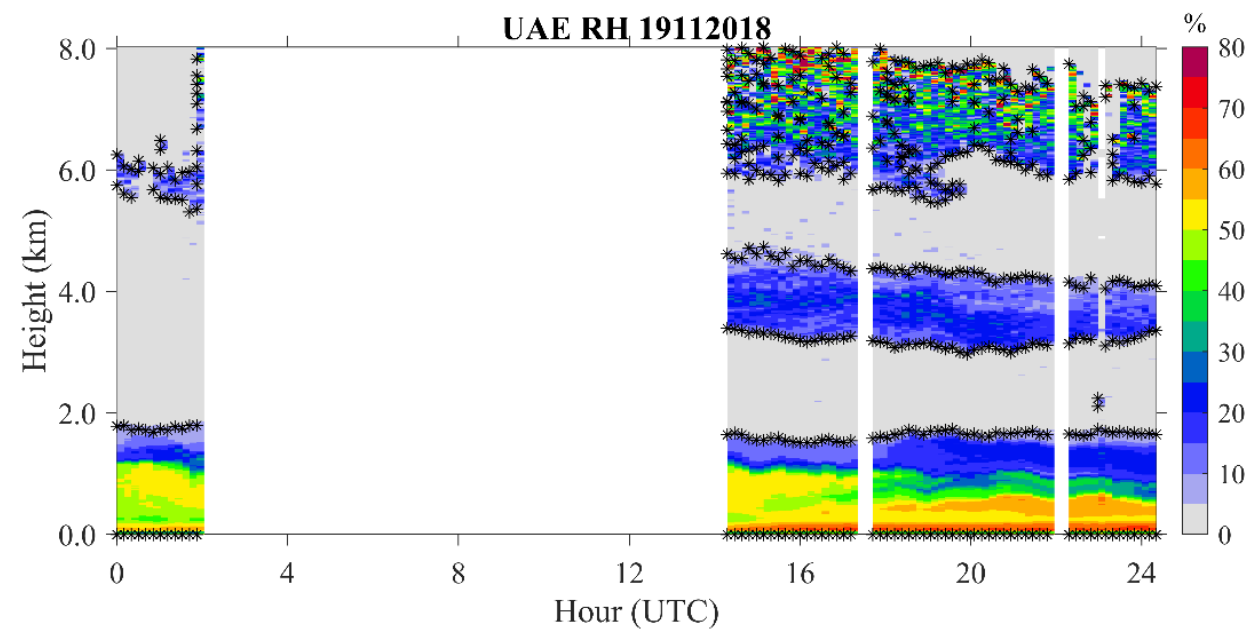

Figure 7. Example of dry layers at UAE measurement size during OASIS campaign. Diurnal $\mathrm{RH}$ profiles retrieved by a PollyXT Raman lidar at $19^{\text {th }}$ of November 2019. The asterisks show top and bottom of the detected layers. The retrieval is limited to nighttime observations hence from around 3 until 15 UTC the data gap is shown with white color (see Section 3).

\subsection{Optical properties of pollen particles}

In Paper II, we explored the capabilities of ground-based multi-wavelength Raman lidars to retrieve optical properties of atmospheric pollen particles. Despite the allergenic effects of pollen, current lidar aerosol classification schemes do not include a pollen aerosol particle category as there is still no comprehensive and validated characterization of their atmospheric optical properties. In this study, we focused on birch and mixtures of birch and spruce pollen, taking advantage of the distinct pollination periods of these pollen types in the rural lidar site of Vehmasmäki in Kuopio, 
Finland. Figure 9 shows a case study of lidar-derived optical properties and meteorological conditions where both birch and spruce pollen was measured in ground-level.

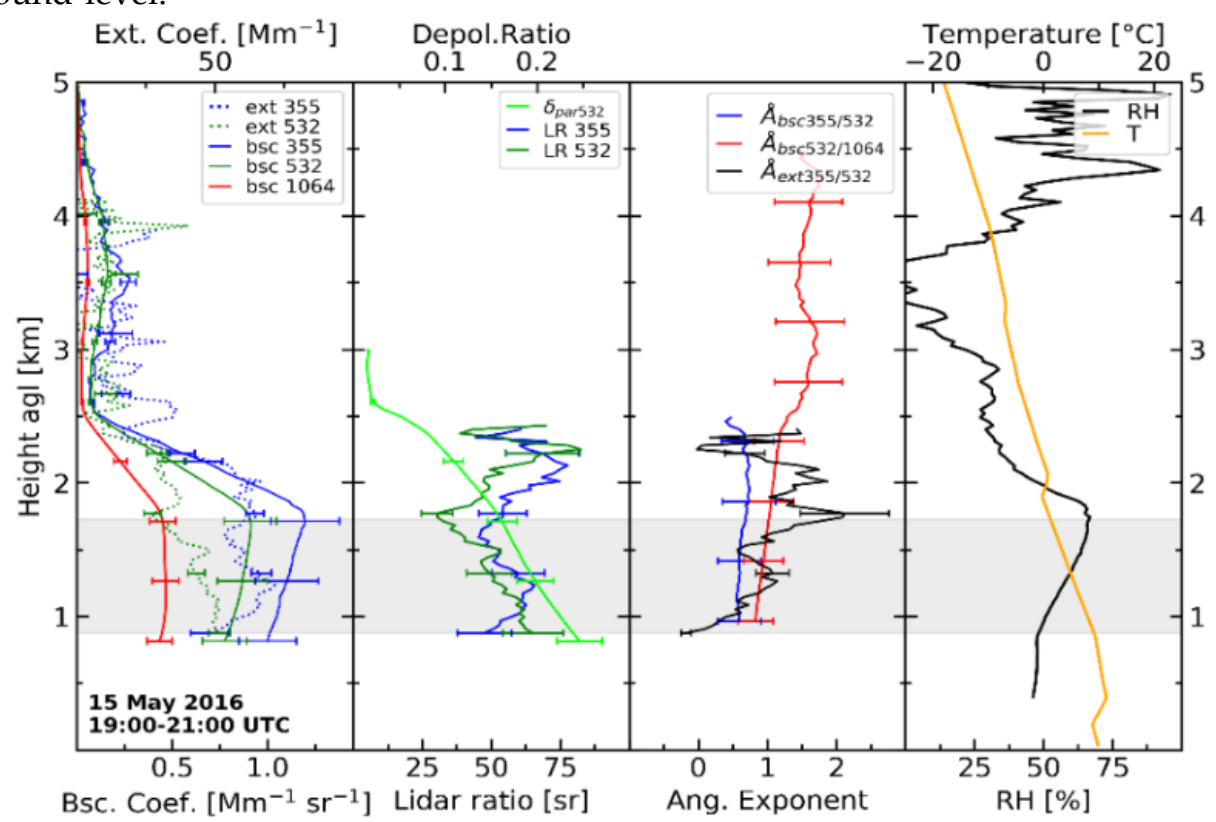

Figure 9. Example of lidar optical properties during a birch-spruce event. From left to right: Backscatter coefficient (Bsc. Coef.) and extinction coefficient (Ext. Coef.), lidar ratio (Lidar ratio) and linear depolarization ratio (Depol. Ratio), Angstrom exponents (A), relative humidity $(\mathrm{RH})$ ad temperature. The available wavelengths are marked for each optical parameter in each panel.

Using a Hirst-type volumetric air sampler (Hirst, 1952), we were able to measure the pollen type and concentration near the ground and further link this information to the lidar observations. In the first period (5 to 9 of May 2016), high concentrations of birch pollen were measured in-situ with a maximum pollen concentration of 3700 grains per $\mathrm{m}^{3}$. During the second period (12 to 15 of May 2016), birch was still the dominant type in the collected samples, but a significant contribution of spruce was also evident. These two pollen types exhibit different shapes (near spherical versus non spherical) and therefore lidar derived optical properties resulted in contrasting values (Table 2). The retrieved pollen LRs are characteristic for dust and dust-smoke mixtures (Tesche et al., 2011), hence the characterization of pollen particles using the LR alone is rather problematic. On the contrary, $\delta_{p}$ values of $10 \%$ and $26 \%$ for birch and mixture or birch and spruce pollen, respectively, can be used in aerosol classification schemes. Nonetheless, these values fall in the same range of dust and biomass burning aerosol mixtures or dust mixtures with marine contribution (Groß et al., 
2011). As a result, pollen is currently misclassified as dusty mixtures in automatic aerosol classification schemes (e.g. Omar et al., 2009). Thus, to separate pollen from other aerosol types a minimum of two depolarization wavelengths must be available as well as, backward air mass trajectories and dust and biomass-burning aerosol sources must be considered from auxiliary methods.

Table 2. Lidar ratio (LR) and linear particle depolarization ratio $(\delta p)$ for birch and birch-spruce mixture at $532 \mathrm{~nm}$ wavelength.

\begin{tabular}{c|c|c} 
Pollen type & LR (sr) & $\boldsymbol{\delta}_{\mathbf{p}}(\%)$ \\
\hline Birch & $52 \pm 12$ & $10 \pm 6$ \\
\hline Spruce contaminated & $62 \pm 10$ & $26 \pm 7$
\end{tabular}

Paper II shows the potential of ground-based lidar measurements to detect pollen in the atmosphere. Nevertheless, there are several challenges which need to be addressed in order to improve the characterization of optical properties of airborne pollen. Currently, the contribution of pollen to other aerosol particles, such as anthropogenic pollution, has not been separated using well known methodologies (Tesche et al., 2009). This implies that the pure extensive properties of birch and spruce particles have not been fully defined. Moreover, laboratory studies on birch and spruce have reported much higher $\delta_{p}$ values than in the present study. This can be attributed to three reasons. The first reason is that laboratory measurements study pollen optical properties in dry conditions in contrast to lidar observations which are subject to ambient RH. For example, it has been shown that dry birch pollen particles become less spherical causing depolarization. The second reason can be related to pollen orientation. Previous studies have shown that pollen particles exhibit certain orientation when airborne. Thus, the non-spherical pollen particles and therefore the observed $\delta_{\mathrm{p}}$ can be sensitive to the viewing angle; in the case of laboratory measurements such thing might have not been considered. Currently, theoretical optical properties of pollen particles under ambient conditions from scattering simulations do not exist. The third reason can be related with aging in the atmosphere. Big particles are likely to collect smaller ones and can potentially change their initial shape. Although this is not so likely in our relatively clean conditions. 


\subsection{Optical properties of Arabian dust}

In Paper III, we retrieved aerosol particle properties in an understudied dusty region over the United Arab Emirates (UAE) using a ground-based multi-wavelength Polly ${ }^{\mathrm{XT}}$ Raman lidar (Engelmann et al., 2016). The night-time lidar observations from the year-long campaign revealed frequent multiple aerosol particle layer structures over the site (Fig. 10). Only in $10 \%$ of the cases, a single aerosol layer was present. Two (30\%), three $(29 \%)$ or even more simultaneous layers $(31 \%)$ were more common. These multiple aerosol particle layers resulted from gravitational waves generated by the sea breeze passing over the mountains and stratifying the atmosphere over the measurement site. Because of this stratification, isolated dry layers were present in the atmosphere as discussed in Section 4.1.

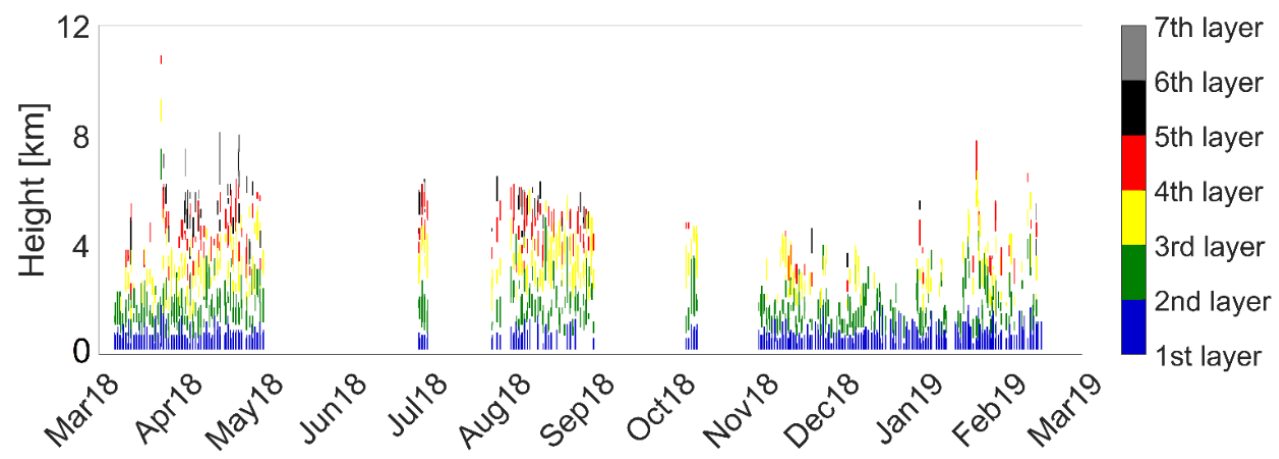

Figure 10. Night-time geometrical boundaries of the aerosol layers observed between $6^{\text {th }}$ March 2018 and $14^{\text {th }}$ February 2019 at the measurement site in UAE. The color indicates the number of aerosol layers in the atmosphere. The gaps in the dataset seen from May to August and between September and November were due to instrumental complications.

Apart from the geometrical aerosol properties, we have also retrieved the AOD and further calculated the contribution of boundary layer (BL) and free-tropospheric (FT) aerosols to the total AOD. The mean AOD amounts to $0.37 \pm 0.12$ and $0.21 \pm 0.11$ at 355 and $532 \mathrm{~nm}$, respectively, with higher values occurring during the summer months and lower values during the winter months. The contribution of FT aerosol layers to the total AOD was usually greater than that of the BL. Nevertheless, this behaviour was reversed from November to February. The lower total layer AODs during these months resulted from either the absence of multiple FT layers, or the lower surface wind speeds. We should mention here that, although the AOD values refer to night-time observations, on average the intra-day variation in the region is moderate (Arola et al., 2013; Eck et al., 2008), and therefore the aforementioned values are valid also during daytime. 
The climatological values of the aerosol optical properties and their relevance to the vertical domain are presented in Figure 11. Due to the lower (on average) aerosol load, the $\beta$ and $\alpha$-coefficients decreased with increasing altitude. In contrast, almost constant LRs up to $5 \mathrm{~km}$ propose rather similar aerosol mixtures. Interestingly, $\delta_{\mathrm{p}}$ at $532 \mathrm{~nm}$ wavelength increased or remained constant with altitude excluding aerosol layers above $5 \mathrm{~km}$. This behaviour was also seen at $355 \mathrm{~nm}$ wavelength up to $2 \mathrm{~km}$. The most plausible explanation is that up to $2 \mathrm{~km}$, the night-time residual layers contain mixtures of mineral dust and anthropogenic pollution or/and marine aerosols resulting to lower linear particle depolarization values. Hygroscopicity effects were rejected since the mean relative humidity of these aerosol layers was much less than $60 \%$ for $82 \%$ of the cases.
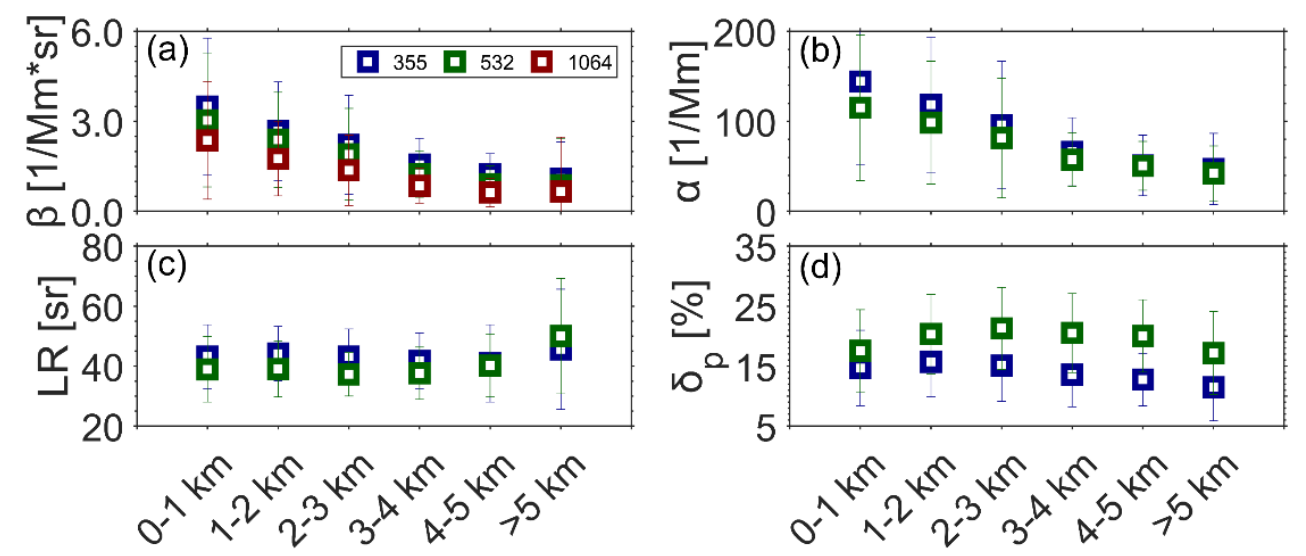

Figure 11. Height-dependent aerosol properties for 0-1, 1-2, 2-3, 3-4 and $>5 \mathrm{~km}$ altitude. (a) Backscatter coefficient at $355 \mathrm{~nm}$ (blue), $532 \mathrm{~nm}$ (green) and $1064 \mathrm{~nm}$ (red). (b) Extinction coefficient at $355 \mathrm{~nm}$ and $532 \mathrm{~nm}$. (c) Lidar ratio at $355 \mathrm{~nm}$ and $532 \mathrm{~nm}$. (d) Linear particle depolarization ratio at $355 \mathrm{~nm}$ and $532 \mathrm{~nm}$.

Lastly, we have explored the pure Arabian dust optical properties. This aerosol type exhibits different optical properties than dust originating from Saharan or Asian deserts yet there are currently only four previous lidar studies from the area. The table below summarizes the Arabian dust optical properties as retrieved from this study and all the previous ones (Table 3). Examining the reasons behind the different LR values in Arabian compared to African dust, previous studies linked the optical behaviour to the chemical composition of the dust particles. In fact, Schuster et al. (2012) showed that the LR behaviour of dust is subject to the percentage of illite in the soil. The content of illite, i.e a K-rich argillaceous component of sedimentary rock, in the dust determines the real refractive index. The real refractive index influences strongly the lidar ratio, an aerosol type parameter. Thus, it is expected that different 
dust types would exhibit different optical characteristics depending on their mineralogical composition. For example, high content of illite in Saharan soil (up to $35-40 \%$ ) results in somewhat higher real refractive index values than that of Arabian dust. To confirm the connection, we have collected dust samples from the area around the measurement site and performed elemental analysis. The fraction of $\mathrm{K}$ rich argillaceous component of sedimentary rocks was well below $5.5 \%$ in the collected dust samples, supporting previous theories.

Implications of these findings propose that a universal lidar ratio of $55 \mathrm{sr}$ for dust aerosol particles, as currently used, leads to biased retrievals in ceretain regions. For example, in satellite or ground-based extinction or aerosol typing retrievals as well as separation methods of a lidar signal to its aerosol components. In turn, all the aforementioned products are usually the basic input for advanced methodologies such as the retrieval of CCN/INP concentrations from lidar observations.

Table 3: Aerosol particle properties of the Arabian dust and comparison to previous studies. Both 355 and 532nm wavelengths are reported in terms of their lidar ratio (LR), linear particle depolarization $\left(\delta_{p}\right)$ and Ångström exponent from the extinction (AE) at 355/532. The mean and standard deviation is shown for each optical property, if available, and the numbers in the brackets show the range of values reported for each parameter.

\begin{tabular}{c|c|c|c|c|c} 
Property & $\begin{array}{c}\text { LR } \\
\mathbf{3 5 5 n m} \\
{[\mathbf{s r}]}\end{array}$ & $\begin{array}{c}\mathbf{L R} \\
\mathbf{5 3 2 n m} \\
{[\mathbf{s r}]}\end{array}$ & $\begin{array}{c}\mathbf{3 5 5 n \mathbf { n }} \\
{[\%]}\end{array}$ & $\begin{array}{c}\boldsymbol{\delta}_{\mathbf{p}} \\
\mathbf{5 3 2 n m} \\
{[\%]}\end{array}$ & $\begin{array}{c}\mathbf{A E} \\
\mathbf{3 5 5} / \mathbf{5 3 2}\end{array}$ \\
\hline Müller et al. (2007) & $38 \pm 5$ & $38 \pm 5$ & - & - & $0.6 \pm 0.3$ \\
\hline Mamouri et al. (2013) & - & $\begin{array}{c}34 \pm 7 \\
\text { to } \\
39 \pm 5\end{array}$ & - & - & - \\
\hline Nisantzi et al. (2015) & - & $\begin{array}{c}41 \pm 4 \\
(33-48)\end{array}$ & - & - & - \\
\hline Hofer et al. (2017) & $42 \pm 3$ & $36 \pm 2$ & $18 \pm 2$ & $31 \pm 1$ & $0.4 \pm 0.2$ \\
\hline This study & $\begin{array}{c}45 \pm 5 \\
(35-55)\end{array}$ & $\begin{array}{c}42 \pm 5 \\
(34-54)\end{array}$ & $\begin{array}{c}25 \pm 2 \\
(22-32)\end{array}$ & $\begin{array}{c}31 \pm 2 \\
(28-35)\end{array}$ & $\begin{array}{c}0.3 \pm 0.2 \\
(0.0-0.7)\end{array}$
\end{tabular}




\subsection{Importance of atmospheric particles in low-level Arctic clouds}

In Paper IV, we focused on aerosol cloud interactions using a synergy of satellite based elastic lidar and cloud radar over the Arctic. Three years of CALIOP (CloudAerosol Lidar with Orthogonal Polarization) onboard CALIPSO (Cloud-Aerosol Lidar and Infrared Pathfinder Satellite Observation) and CloudSat observations were combined to quantify how strongly different aerosol types and their corresponding aerosol load affect the cloud phase in low-level clouds over the Arctic. Low-level clouds in the Arctic are very frequent and as already mentioned in the introduction they pose an opposite radiative effect compared to mid-latitude low-level clouds. The liquid-containing cloud fraction is rather high in the Arctic (Fig. 12) and especially mixed-phase clouds are persistent and dominate in the temperature region between -10 and $-25^{\circ} \mathrm{C}$, over water and ice clouds (Fig. 13). The longevity of mixed phase clouds is controlled, among others, by the ambient aerosol concentration and thus their ability to serve as CCN and INP.

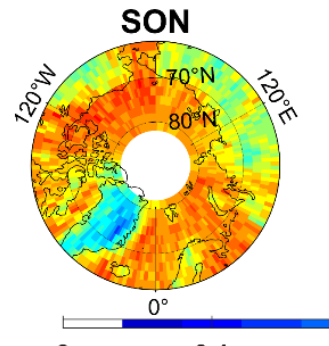

0.1

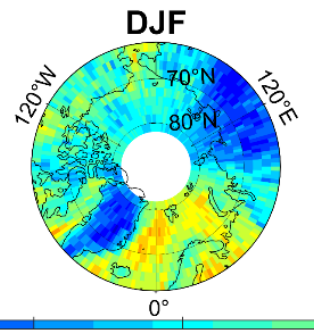

0.2

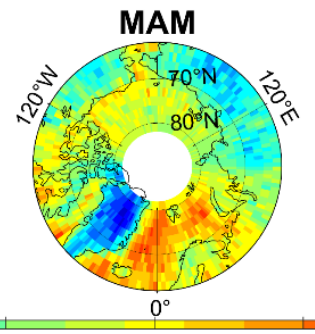

0.5

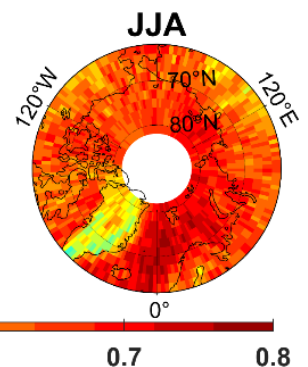

0.7

0.8

Figure 12. Seasonal relative cloud phase occurrence of liquid-containing clouds in the Arctic.
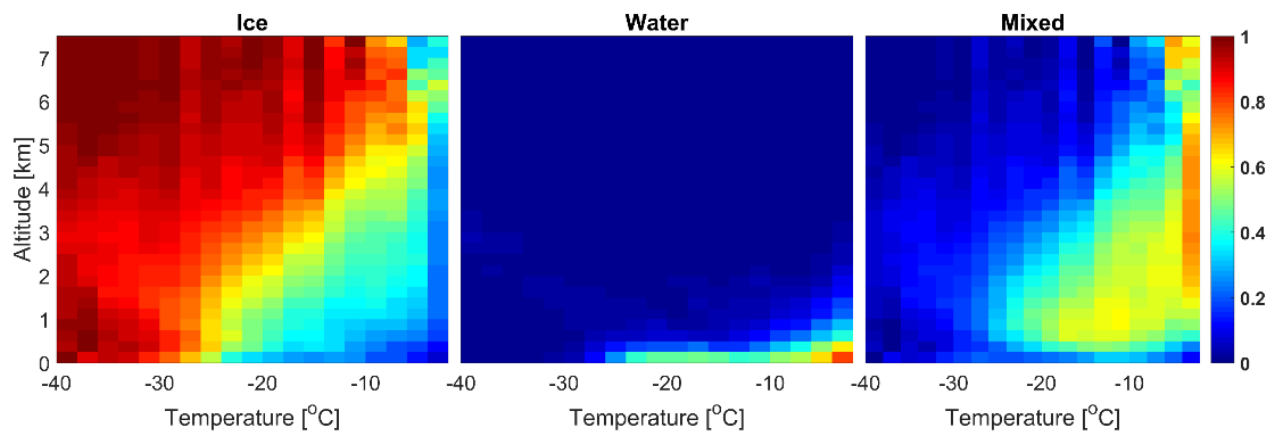

Figure 13. Vertical relative cloud phase occurrence for ice, water and mixed-phase clouds in the Arctic. 
Figure 14 links the cloud top temperature (CTT) at the three thermodynamic cloud phases with the aerosol load of different aerosol particles, where the rest aerosol category includes marine, continental, and elevated smoke aerosols and dust category includes mineral dust and polluted dust. The aerosol categorization was made according to the AOD at $532 \mathrm{~nm}$ of the aerosol layers. AOD with less than 0.10 was considered as low concentration and those with AOD $>0.25$ as high. Figure 14 suggests that depending on the aerosol load, the temperature at which a cloud completely glaciates can vary by up to $6-10^{\circ} \mathrm{C}$. In the same figure, we observe that the ice RCPOs for both aerosol categories, dust and rest, show similar behaviour under the same AOD constraint, therefore aerosol type independent. Moreover, more mixed-phase clouds were associated with the high aerosol load, which supports recent studies associating the longevity of the Arctic mixed-phase clouds with higher CCN concentrations (Norgren et al., 2018).
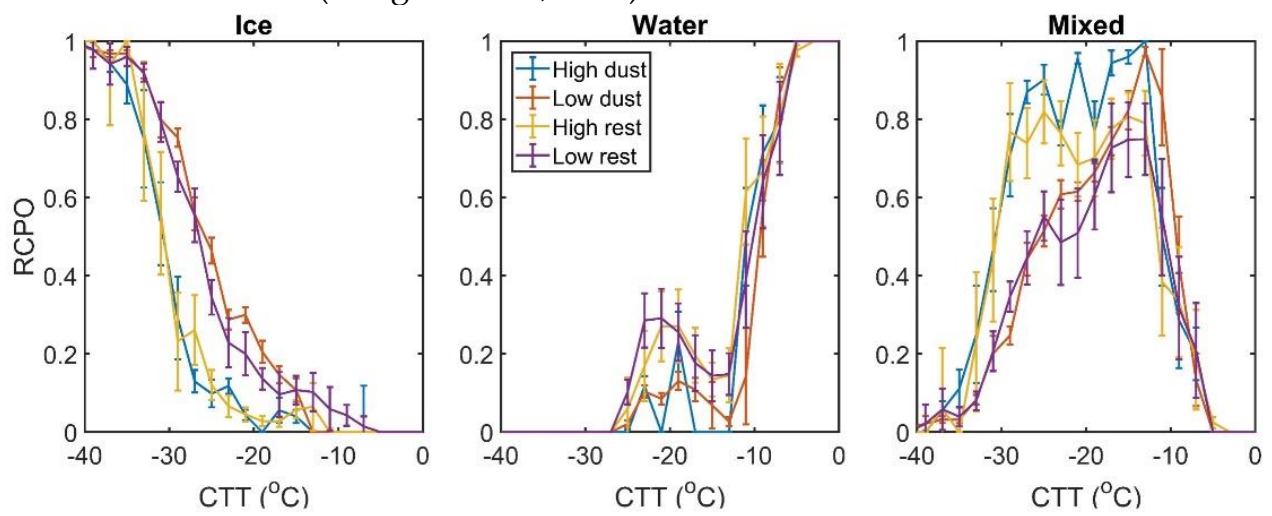

Figure 14. Relative cloud phase occurrence (RCPO) for each thermodynamic phase and their relationship with the cloud top temperature (CTT) associated with different aerosol particles. Two aerosol type categories are shown: Dust and Rest, where Rest includes marine, continental, and elevated smoke aerosols. An aerosol optical depth (AOD) constrain has been applied to the data. Aerosol layers with AOD values higher that 0.25 were considered as high $A O D$ cases and aerosol layers with AOD less than 0.1 were considered as low AOD cases, respectively.

In addition to the aerosol load effect, we further investigated the impact of the different aerosol types. Figure 15 links the cloud top temperature (CTT) at the three thermodynamic cloud phases with marine, continental, dust, and elevated smoke (ES) aerosol particles. Overall, the different aerosol types exhibit similar relationships for the ice phase. However, a $4{ }^{\circ} \mathrm{C}$ difference between ES and dust related ice clouds at $50 \%$ of relative cloud phase occurrence (RCPO) suggests ice formation in warmer temperatures in the presence of dust particles. Nevertheless, identical behaviour was 
observed for continental aerosol particles. A plausible explanation is that in the pristine Arctic environment continental aerosol mixtures already contain sufficient INPs for ice formation. In addition, the satellite derived aerosol classification scheme is not fool proof and can likely narrow the temperature gap among them. For example, diamond dust is often misclassified as dust (D) or polluted dust (PD) (Di Biagio et al., 2018). Additionally, Arctic aerosols are likely coated with sulfuric acid (Girard et al., 2013) due to long-range transportation and aging in the atmosphere. Aerosols coated with such material are less effective INPs (Sullivan et al., 2010). Regardless, assigning a single factor to the difference between the different aerosol types is rather impossible. The temperature differences between the aerosol types in Figure 15 are within the temperature uncertainty range, and no solid conclusion cannot be made.
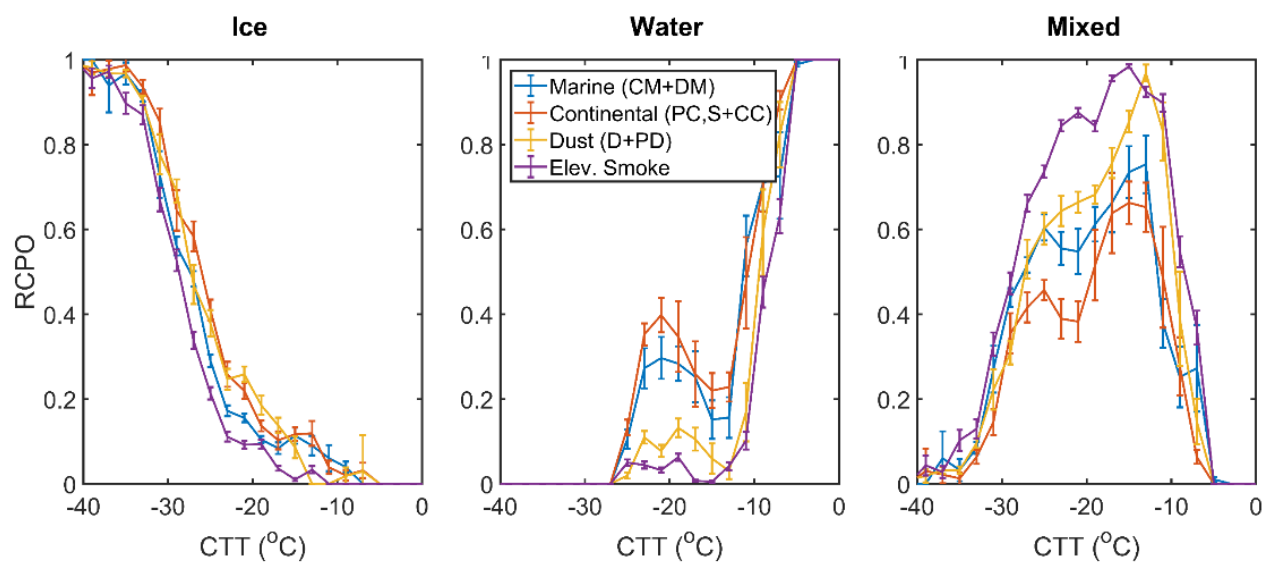

Figure 15. Relative cloud phase occurrence (RCPO) for each thermodynamic phase and their relationship with the cloud top temperature (CTT) associated with marine (clean marine $[\mathrm{CM}]$ and dusty marine [DM]), continental (polluted continental [PC], smoke [S], and clean continental [CC]), dust (dust [D] and polluted dust [PD]) and elevated smoke (Elev. smoke) aerosol particles.

To confirm that the observed aerosol effects are not an outcome of changing meteorological conditions, we explored if atmospheric stability or aerosol relative humidity (RH) differ for the different aerosol categories at different sub-regions. The findings suggest a complex inter-play between meteorology, aerosol load, and aerosol type under certain conditions. It was evident that over North Atlantic and Barents Sea the CTT discrepancies among the aerosol types and aerosol loads were diminished. The open ocean and the lower atmospheric stability in this region were certainly the driving factors for cloud formation. On the contrary, the aerosol load outweighed both meteorology and aerosol type over the rest Arctic regions. 


\section{Review of papers and author's contribution}

The author alone is responsible for writing this introductory part of the thesis. The publications selected in this dissertation are original research papers on water vapor mixing ratios, optical and geometrical aerosol particle properties and aerosol-cloud interactions using a multi-wavelength elastic, polarization and/or Raman lidar with water vapor capabilities.

Paper I Filioglou M, Nikandrova A, Niemelä S, Baars H, Mielonen T, Leskinen A, Brus D, Romakkaniemi S, Giannakaki E, Komppula M. (2017). Profiling water vapor mixing ratios in Finland by means of a Raman lidar, a satellite and a model. Atmospheric Measurement Techniques, 10: 43034316, https://doi.org/10.5194/amt-10-4303-2017.

Overview: we present tropospheric water vapor mixing ratio profiles observed with a ground-based Raman lidar during three field campaigns held in Finland. In the absence of co-located radiosondes, we evaluate the possibility to calibrate the lidar water vapor mixing ratio profiles using information descended from satellite, numerical weather prediction (NWP) and the nearest radio sounding data located further away from the lidar location. We found that Raman lidar water vapor mixing ratios compare well with the on-site radio sounding providing accurately the aforementioned parameter. We also propose that the second-best option for the lidar water vapor calibration are the nearest available radiosondes or the NWP model. Furthermore, we present a 4-year seasonal analysis of vertical water vapor for one of the sites that the lidar instrument permanently resides, enabling long-term observations of water vapor. Lastly, we evaluate the seasonal performance of NWP model and lidar water vapor mixing ratio observations and assign reasons behind this discrepancy.

Author's contribution: The author was responsible for conceptualizing and finalizing the methodology together with the supervisors. The author also collected the lidar observations and launched part of the radio soundings on the measurement site. Moreover, the author performed the data analysis and wrote the manuscript. 
Paper II Bohlmann S, Shang X, Giannakaki E, Filioglou M, Saarto A, Romakkaniemi S, Komppula M. (2019). Detection and characterization of birch pollen in the atmosphere using a multi-wavelength Raman polarization lidar and Hirst-type pollen sampler in Finland. Atmospheric Chemistry and Physics. 19: 14559-14569, https://doi.org/10.5194/acp-1914559-2019.

Overview: we investigate pollen optical properties retrieved from a multi-wavelength Raman lidar. For the characterization of the pollen type, we use a Hirst-type volumetric air sampler. We found that pollen can be detected using an elastic/Raman lidar and in particular different pollen types can be distinguished with the polarization capabilities of the lidar. We focus on two pollen types, birch and combination of birch and spruce, and further examine their differences in the retrieved optical properties such as the lidar ratio and linear particle depolarization ratio. The linear particle depolarization ratio of pollen can be used for the identification of the different pollen types in the atmosphere, nevertheless, this parameter alone is not enough for the pollen classification. Currently pollen is misclassified as dusty mixtures in aerosol classification schemes as it exhibits similar optical properties to other aerosol types.

Author's contribution: the author collected part of the Burkard samples and was responsible for the lidar observations. Moreover, the author contributed to the scientific discussion.

Paper III Filioglou M, Giannakaki E, Backman J, Kesti J, Hirsikko A, Engelmann R, O'Connor E, Leskinen J. T. T, Shang X, Korhonen H, Lihavainen H, Romakkaniemi S, and Komppula M. (2020). Optical and geometrical aerosol particle properties over the United Arab Emirates, Atmospheric Chemistry and Physics Discussion, https://doi.org/10.5194/acp-2020-133.

Overview: we present one-year of aerosol geometrical and optical properties over a dusty region in the United Arab Emirates using a ground-based multi-wavelength Raman lidar. We retrieve the aerosol geometrical and optical depth of these layers and further calculate the contribution of boundary layer aerosols to the total aerosol optical depth. Apart from the general optical properties in the region which is a mixture of dust with anthropogenic and marine contribution, we 
further derive pure Arabian dust optical properties. This underdetermined aerosol type exhibits different optical properties than dust originating from Saharan or Asian deserts. Lastly, we correlate these differences with geochemical characteristics by collecting and analysing soil from the area. The findings suggest lidar ratios for Arabian dust are somewhat lower than dust originating form Saharan area. Moreover, Arabian dust can be distinguished using lidar observations from other dust types, for more accurate aerosol classification.

Author's contribution: The author was responsible for conceptualizing and finalizing the methodology together with the supervisors. The author was also responsible for the lidar observations and collected the dust samples. Moreover, the author performed the data analysis and wrote the manuscript.

Paper IV Filioglou M, Mielonen T, Balis D, Giannakaki E, Arola A, Kokkola H, Komppula M, Romakkaniemi S. (2019). Aerosol effect on the cloud phase of low-level clouds over the Arctic. Journal of Geophysical Research: Atmospheres, 124: 7886-7899, https://doi.org/10.1029/2018JD030088.

Overview: we focus on aerosol cloud interactions using a synergy of satellite based elastic lidar and cloud radar over the Arctic. We present how different aerosol types affect the cloud top temperature in low-level Arctic clouds. We further investigate whether the changes in the cloud top temperature are correlated more strongly with the aerosol type or the aerosol load. We report that aerosol load drives the cloud phase compared to the different aerosol types in the Arctic. We also examine the validity of the aforementioned conclusions by revealing spatial patterns in the Arctic where meteorology, for example over open ocean compared to ice covered areas, outweighs the aerosol effect, both type and load.

Author's contribution: The author was responsible for conceptualizing and finalizing the methodology together with the supervisors. The author performed the data analysis and wrote the manuscript. 


\section{CONCLUSIONS}

Remote sensing techniques provide a powerful tool for the observation of particles, gases, and clouds in the atmosphere. Lidars along with cloud radars are the two fundamental instruments in atmospheric research for the profiling of the atmosphere. The aim of this dissertation was to study undetermined atmospheric aerosol particles using elastic and Raman lidars and further link the aerosol optical properties to cloud formation through a lidar-radar synergy. In this section. I will reflect on the objectives set at the beginning of the thesis (what was done) and I will provide a few points for further research (what else can be done).

The actual objectives of this research are listed in the Introduction (Section 1). The first objective was to evaluate the robustness of the water vapor profile derived from a Raman lidar with water vapor capabilities. The water vapor provides critical information on the hydration rate of the atmospheric particles and therefore the process of cloud formation, as well as, to height-resolved radiative-transfer calculations. Water vapor information is also desired in meteorology and applications therein. As presented in Paper I, accurate water vapor retrievals are subject to the calibration factor. The evaluation of the various calibration methods showed that robust retrievals are possible through an alternative reference system, in case operational on-site radiosondes are not available. On-site radiosondes are the best option for the calibration of the lidar water vapor but water vapor information from the nearest radiosonde site or modelled data were swimmingly suitable for the studied area. Satellite-derived water vapor profiles performed the poorest, but through our proposed methodology they could also serve as an option. The lidar-derived water vapor is a useful parameter as shown in applications of Paper III which include cloud seeding techniques.

The second objective was to investigate aerosol optical properties of understudied aerosol particle types. Through two intensive campaigns in Finland and the United Arab Emirates we were able to characterize the intensive and extensive aerosol optical properties of pollen and Arabian dust particles. In Paper II, we demonstrated that ground-based elastic and Raman lidars are adequate for the observation and identification of pollen particles in the atmosphere. The geometrical properties of pollen layers can be used to validate atmospheric pollen models and increase their spatial accuracy of both forecast (indirect) and reanalysis products (directly). Moreover, the polarization capabilities in elastic lidars have proven to be a powerful tool 
for the recognition of different pollen types when these exhibit distinct shapes. Although the study is currently on going and more observations are performed expanding to different locations and more pollen types, in Paper II we have concluded that the classification of various pollen types although challenging, is possible. This translates in multiple lidar optical parameters such as the linear particle depolarization ratios in at least two wavelengths as well as, external information such as backward airmass trajectories and the reassurance that other non-spherical aerosol particles such as dust are not present over the measurement site. Currently, pollen particles are misclassified in aerosol classification schemes and there is no separate aerosol category due to the lack of extensive research. Pristine environments as the ones in high latitudes, including our measurement site, create ideal conditions for such research. Properly classified pollen would raise near-real-time detection of pollen applications from ground-based lidars and provide useful information for allergy-related events. Pollen forecasts could also be improved using the robust lidar classification to evaluate corresponding pollen dispersion models. The results in this thesis are somewhat limited since there is a great variety of vegetation hence different kind of pollen types. Nevertheless, the results presented here are a step closer to the characterization of this understudied aerosol type.

Regarding the same objective, a yearlong field campaign was held in the United Arab Emirates under the wider frame of a project which aimed to improve cloud seeding techniques in this arid region. For this purpose, in Paper III we have characterized the mean aerosol optical and geometrical properties using a multi-wavelength Raman lidar. The monthly averaged aerosol layers showed height-depended aerosol optical and geometrical properties. This information can be used, for example, to evaluate climate model parametrizations in the region. We further retrieved Arabian dust optical properties, an aerosol type that its properties are not well defined. This year long dataset derives comprehensive results compared to previous studies which have focused only on case studies. The Arabian dust properties exhibit different lidar ratios than that of dust particles originating from the Saharan region. Currently a universal lidar ratio of $55 \mathrm{sr}$ is used in lidar applications which is not valid for dust originating from the Arabian region. Implications of this can affect extinction retrievals in the case of elastic lidars and further complicate aerosol separation techniques (Tesche et al., 2009). At the very end, separation techniques are the basic input of CCN/INP retrievals from lidar measurements propagating the lidar retrieval errors. Thus, the correct classification of dust types will eventually lead to more accurate techniques for remote observations of this climatically relevant aerosol type. 
The third (and final) objective was to explore how the different aerosol types affect cloud formation. In Paper IV, we used a synergy of collocated satellite-based elastic lidar and cloud radar observations to retrieve aerosol and cloud properties. We showed that in the pristine environment of Arctic the aerosol load exhibits strong correlation to mixed-phase clouds where higher aerosol load was associated with higher occurrence of the mixed cloud phase. We assume that higher aerosol load corresponds to higher $\mathrm{CCN}$ concentrations through which mixed-phase clouds have shown to persist in the Arctic environment. On the contrary, moderate association was found with varying the aerosol type. The effect of dynamical atmospheric processes can disturb the aforementioned associations. In fact, meteorology outweighed the aerosol load importance over less stable atmospheric conditions, for example, over open ocean with lower tropospheric stability and probably less stratified clouds. The results although valuable, need to be confirmed through more observations and instrument synergies focussing of more robust aerosol type characterization. This study also showed that combination of multiple instruments proves to be a powerful tool to bypass limitations of individual sensors providing a robust frame for the study of aerosol-cloud interactions. This kind of information is extremely valuable when climate and weather forecast models are validated as it is shown that the phase of clouds is one of the bottlenecks towards more accurate climate predictions.

With relation to the objectives of this thesis, there are several areas that require further attention. Firstly, the identification of aerosol types is critical due to implications in health, visibility, biological processes, aviation safety, and climate change. When aerosol optical properties are adequately characterized, their sources can be precisely determined, and actions can be better targeted to reduce aerosol emissions. To this end, there are still understudied aerosol particles and their climatic impact is underdetermined. Consequently, improved characterization as well as accurate aerosol classification methods should be investigated further. Therefore, more measurements of vertically-resolved aerosol optical properties should be performed in parallel to size distribution measurements. Also, combination of observations from multiple sensors could significantly minimize the misclassification rate of aerosol particle types and provide more detailed characterization of the aerosol properties.

Secondly, the relationship of atmospheric pollen and ambient conditions should be studied further with longer timeseries. As pollination periods will be longer, and the tree line will extend northwards in the warming climate, Finland can be a pioneer in ground-based and airborne observations of pollen particles. Having already acquired the intensive optical properties of different pollen types, their vertical profiles from lidar observations should be used to evaluate dispersion models and improve pollen forecasts. Applications of pollen particles can extend to satellite-based sensors 
for global identification of pollen particles, for example in CALIPSO observations. Then, validation of dispersion models will not be bounded to a specific measurement site but would be globally feasible.

Thirdly, observations of the chemical and physical transformation of dust and pollen in the atmosphere (aging) are needed. It has been observed that dust particles can be chemically and physically modified in the atmosphere altering their measured optical properties. For example, light absorption by mineral dust particles is less than previously believed. Nevertheless, dust particles coated with soot enhance their light absorption efficiency. This information could be utilized by computational aerosol modelling through empirical-based models for aged particles.

Fourthly, the development of light scattering models suited for non-spherical particles is still missing. Pollen-specific scattering simulations for ambient relative humidity will close the gap between field observations and laboratory measurements and build up the extensive pollen optical properties. Towards the same direction, non-spherical dust particles and their angle-dependent scattering properties with polarized electromagnetic radiation will set the base for more detailed optical properties. For example, a more realistic dust shape would determine surface roughness of the dust particles more accurately, therefore the thickness of the coating material on the optical properties of these irregular particles could be determined.

Lastly, the retrieval of aerosol microphysics will add valuable information to aerosol-cloud relations. Profiles of CCN/INP proxies are currently missing. To this end, climate models determine the fraction of ice and mixed-phase clouds using temperature and proxies for INP. These proxies are not linked with real aerosol properties introducing large uncertainties to simulated cloud microphysics and eventually to precipitation events and the lifetime of the cloud. Retrievals of CCN/INP concentrations in the vicinity of the cloud using lidar observations is promising and could provide the necessary missing information. Application of these methodologies to satellite-based lidars will deliver a powerful global product. 


\section{Bibliography}

Abo, M. (2005). Resonance Scattering Lidar. In C. Weitkamp (Ed.), Lidar: RangeResolved Optical Remote Sensing of the Atmosphere (pp. 307-323). New York, NY: Springer New York. https://doi.org/10.1007/0-387-25101-4_11

Adebiyi, A. A., \& Kok, J. F. (2020). Climate models miss most of the coarse dust in the atmosphere. Science Advances, 6(15), eaaz9507. https://doi.org/10.1126/sciadv.aaz9507

Althausen, D., Engelmann, R., Baars, H., Heese, B., Ansmann, A., Müller, D., \& Komppula, M. (2009). Portable raman lidar pollyxt for automated profiling of aerosol backscatter, extinction, and depolarization. Journal of Atmospheric and Oceanic Technology, 26(11), 2366-2378. https://doi.org/10.1175/2009JTECHA1304.1

Andreae, M. O. (2009). Correlation between cloud condensation nuclei concentration and aerosol optical thickness in remote and polluted regions. Atmospheric Chemistry and Physics, 9(2), 543-556. https://doi.org/10.5194/acp-9-543-2009

Ångström, A. (1929). On the Atmospheric Transmission of Sun Radiation and on Dust in the Air. Geografiska Annaler, 11, 156-166. https://doi.org/10.2307/519399

Ansmann, A., Riebesell, M., Wandinger, U., Weitkamp, C., Voss, E., Lahmann, W., \& Michaelis, W. (1992). Combined raman elastic-backscatter LIDAR for vertical profiling of moisture, aerosol extinction, backscatter, and LIDAR ratio. Applied Physics B Photophysics and Laser Chemistry, 55(1), 18-28. https://doi.org/10.1007/BF00348608

Ansmann, A., Tesche, M., Seifert, P., Althausen, D., Engelmann, R., Fruntke, J., et al. (2009). Evolution of the ice phase in tropical altocumulus: SAMUM lidar observations over Cape Verde. Journal of Geophysical Research, 114(D17), D17208. https://doi.org/10.1029/2008JD011659

Ansmann, A, Mamouri, R.-E., Hofer, J., Baars, H., Althausen, D., \& Abdullaev, S. F. (2019). Dust mass, cloud condensation nuclei, and ice-nucleating particle profiling with polarization lidar: updated POLIPHON conversion factors from global AERONET analysis. Atmospheric Measurement Techniques, 12(9), 4849-4865. https://doi.org/10.5194/amt-12-4849-2019

Ansmann, Albert, \& Müller, D. (2005). Lidar and Atmospheric Aerosol Particles BT Lidar: Range-Resolved Optical Remote Sensing of the Atmosphere. In C. Weitkamp (Ed.) (pp. 105-141). New York, NY: Springer New York. https://doi.org/10.1007/0-387-25101-4_4

Ansmann, Albert, Riebesell, M., \& Weitkamp, C. (1990). Measurement of atmospheric aerosol extinction profiles with a Raman lidar. Optics Letters, 15(13), 746. https://doi.org/10.1364/ol.15.000746

Arola, A., Eck, T. F., Huttunen, J., Lehtinen, K. E. J., Lindfors, A. V, Myhre, G., et al. 
(2013). Influence of observed diurnal cycles of aerosol optical depth on aerosol direct radiative effect. Atmospheric Chemistry and Physics, 13(15), 7895-7901. https://doi.org/10.5194/acp-13-7895-2013

Atkinson, J. D., Murray, B. J., Woodhouse, M. T., Whale, T. F., Baustian, K. J., Carslaw, K. S., et al. (2013). The importance of feldspar for ice nucleation by mineral dust in mixed-phase clouds. Nature, 498(7454), 355-358. https://doi.org/10.1038/nature12278

Augustin-Bauditz, S., Wex, H., Kanter, S., Ebert, M., Niedermeier, D., Stolz, F., et al. (2014). The immersion mode ice nucleation behavior of mineral dusts: A comparison of different pure and surface modified dusts. Geophysical Research Letters, 41(20), 7375-7382. https://doi.org/doi:10.1002/2014GL061317

Baars, H. (2011). Aerosol profiling with lidar in the Amazon Basin during the wet and dry season 2008. Univeristy of Leipzig.

Baars, H., Ansmann, A., Ohneiser, K., Haarig, M., Engelmann, R., Althausen, D., et al. (2019). The unprecedented 2017--2018 stratospheric smoke event: decay phase and aerosol properties observed with the EARLINET. Atmospheric Chemistry and Physics, 19(23), 15183-15198. https://doi.org/10.5194/acp-1915183-2019

Balis, D., Giannakaki, E., Müller, D., Amiridis, V., Kelektsoglou, K., Rapsomanikis, S., \& Bais, A. (2010). Estimation of the microphysical aerosol properties over Thessaloniki, Greece, during the SCOUT-O3 campaign with the synergy of Raman lidar and Sun photometer data. Journal of Geophysical Research: Atmospheres, 115(D8). https://doi.org/10.1029/2009JD013088

Battan, L. J. (1973). Radar observation of the atmosphere. Chicago: University of Chicago Press.

Behrendt, A. (2005). Temperature Measurements with Lidar. In C. Weitkamp (Ed.), Lidar: Range-Resolved Optical Remote Sensing of the Atmosphere (pp. 273305). New York, NY: Springer New York. https://doi.org/10.1007/0-387-251014_10

Behrendt, A., Nakamura, T., Onishi, M., Baumgart, R., \& Tsuda, T. (2002). Combined Raman lidar for the measurement of atmospheric temperature, water vapor, particle extinction coefficient, and particle backscatter coefficient. Appl. Opt., 41(36), 7657-7666. https://doi.org/10.1364/AO.41.007657

Belegante, L., Bravo-Aranda, J. A., Freudenthaler, V., Nicolae, D., Nemuc, A., Ene, D., et al. (2018). Experimental techniques for the calibration of lidar depolarization channels in EARLINET. Atmospheric Measurement Techniques, 11(2), 1119-1141. https://doi.org/10.5194/amt-11-1119-2018

Bennett, K. D. (1990). Textbook of pollen analysis. K. FAEGRI, J. IVERSEN (4th edn by K. FAEGRI, P. E. KALAND, K. KRZYWINSKI), Publisher John Wiley and Sons, Chichester 1989 (328 pp) £51.00 ISBN 047192178 5. Journal of Quaternary Science, 5(3), 254-255. https://doi.org/10.1002/jqs.3390050310

Bergeron, T. (1935). On the physics of clouds and precipitation. Proces Verbaux de 
l'Association de Météorologie, International Union of Geodesy and Geophysics, 156-178.

Di Biagio, C., Pelon, J., Ancellet, G., Bazureau, A., \& Mariage, V. (2018). Sources, Load, Vertical Distribution, and Fate of Wintertime Aerosols North of Svalbard From Combined V4 CALIOP Data, Ground-Based IAOOS Lidar Observations and Trajectory Analysis. Journal of Geophysical Research: Atmospheres, 123(2), 1363-1383. https://doi.org/10.1002/2017JD027530

Di Biagio, Claudia, Formenti, P., Balkanski, Y., Caponi, L., Cazaunau, M., Pangui, E., et al. (2017). Global scale variability of the mineral dust long-wave refractive index: a new dataset of in situ measurements for climate modeling and remote sensing. Atmospheric Chemistry and Physics, 17(3), 1901-1929. https://doi.org/10.5194/acp-17-1901-2017

Böckmann, C., Wandinger, U., Ansmann, A., Bösenberg, J., Amiridis, V., Boselli, A., et al. (2004). Aerosol lidar intercomparison in the framework of the EARLINET project. 2.Aerosol backscatter algorithms. Appl. Opt., 43(4), 977-989. https://doi.org/10.1364/AO.43.000977

Bond, T. C., \& Bergstrom, R. W. (2006). Light Absorption by Carbonaceous Particles: An Investigative Review. Aerosol Science and Technology, 40(1), 27-67. https://doi.org/10.1080/02786820500421521

Boonman, A., Bumrungsri, S., \& Yovel, Y. (2014). Nonecholocating Fruit Bats Produce Biosonar Clicks with Their Wings. Current Biology, 24(24), 2962-2967. https://doi.org/10.1016/J.CUB.2014.10.077

Bösenberg, J. (2005). Differential-Absorption Lidar for Water Vapor and Temperature Profiling. In C. Weitkamp (Ed.), Lidar: Range-Resolved Optical Remote Sensing of the Atmosphere (pp. 213-239). New York, NY: Springer New York. https://doi.org/10.1007/0-387-25101-4_8

Boucher, O., Randall, D., Artaxo, P., Bretherton, C., Feingold, G., Forster, P., et al. (2013). Clouds and Aerosols. In Intergovernmental Panel on Climate Change (Ed.), Climate Change 2013 - The Physical Science Basis (pp. 571-658). Cambridge: Cambridge University Press. https://doi.org/10.1017/CBO9781107415324.016

Bravo-Aranda, J. A., Belegante, L., Freudenthaler, V., Alados-Arboledas, L., Nicolae, D., Granados-Muñoz, M. J., et al. (2016). Assessment of lidar depolarization uncertainty by means of $\backslash$ hack $\{$ nnewline $\}$ a polarimetric lidar simulator. Atmospheric Measurement Techniques, 9(10), 4935-4953. https://doi.org/10.5194/amt-9-4935-2016

Bucholtz, A. (1995). Rayleigh-scattering calculations for the terrestrial atmosphere. Appl. Opt., 34(15), 2765-2773. https://doi.org/10.1364/AO.34.002765

Bufton, J. L., Garvin, J. B., Cavanaugh, J. F., Ramos-Izquierdo, L. A., Clem, T. D., \& Krabill, W. B. (1991). Airborne lidar for profiling of surface topography. Optical Engineering, 30(1), 72-78. https://doi.org/10.1117/12.55770

Cachier, H., Liousse, C., Buat-Menard, P., \& Gaudichet, A. (1995). Particulate 
content of savanna fire emissions. Journal of Atmospheric Chemistry, 22(1), 123-148. https://doi.org/10.1007/BF00708185

Cantrell, W., \& Heymsfield, A. (2005). Production of Ice in Tropospheric Clouds: A Review. Bulletin of the American Meteorological Society, 86(6), 795-808. https://doi.org/10.1175/BAMS-86-6-795

Cao, X., Roy, G. A., \& Bernier, R. (2010). Lidar polarization discrimination of bioaerosols. Optical Engineering, 49(11), 1-12. Retrieved from https://doi.org/10.1117/1.3505877

Carslaw, K. S., Lee, L. A., Reddington, C. L., Pringle, K. J., Rap, A., Forster, P. M., et al. (2013). Large contribution of natural aerosols to uncertainty in indirect forcing. Nature, 503(7474), 67-71. https://doi.org/10.1038/nature12674

Cavalli, F., Facchini, M. C., Decesari, S., Mircea, M., Emblico, L., Fuzzi, S., et al. (2004). Advances in characterization of size-resolved organic matter in marine aerosol over the North Atlantic. Journal of Geophysical Research: Atmospheres, 109(D24). https://doi.org/10.1029/2004JD005137

Chanin, M.-L., \& Hauchecorne, A. (1981). Lidar observation of gravity and tidal waves in the stratosphere and mesosphere. Journal of Geophysical Research: Oceans, 86(C10), 9715-9721. https://doi.org/10.1029/JC086iC10p09715

Cober, S., \& Isaac, G. (2002). Aircraft icing environments observed in mixed-phase clouds. In 40th AIAA Aerospace Sciences Meeting \& Exhibit. American Institute of Aeronautics and Astronautics. https://doi.org/doi:10.2514/6.2002-675

Comerón, A., Muñoz-Porcar, C., Rocadenbosch, F., Rodríguez-Gómez, A., \& Sicard, M. (2017). Current Research in Lidar Technology Used for the Remote Sensing of Atmospheric Aerosols. Sensors (Basel, Switzerland), 17(6), 1450. https://doi.org/10.3390/s17061450

Cronin, T. W., \& Tziperman, E. (2015). Low clouds suppress Arctic air formation and amplify high-latitude continental winter warming. Proceedings of the National Academy of Sciences of the United States of America, 112(37), 11490-5. https://doi.org/10.1073/pnas.1510937112

Dadashazar, H., Wang, Z., Crosbie, E., Brunke, M., Zeng, X., Jonsson, H., et al. (2017). Relationships between giant sea salt particles and clouds inferred from aircraft physicochemical data. Journal of Geophysical Research: Atmospheres, 122(6), 3421-3434. https://doi.org/10.1002/2016JD026019

DeMott, P. J., Sassen, K., Poellot, M. R., Baumgardner, D., Rogers, D. C., Brooks, S. D., et al. (2003). African dust aerosols as atmospheric ice nuclei. Geophysical Research Letters, 30(14). https://doi.org/10.1029/2003GL017410

Dubayah, R. O., \& Drake, J. B. (2000). Lidar Remote Sensing for Forestry. Journal of Forestry, 98(6), 44-46. https://doi.org/10.1093/jof/98.6.44

Dubovik, O., Sinyuk, A., Lapyonok, T., Holben, B. N., Mishchenko, M., Yang, P., et al. (2006). Application of spheroid models to account for aerosol particle nonsphericity in remote sensing of desert dust. Journal of Geophysical 
Research, 111(D11), D11208. https://doi.org/10.1029/2005JD006619

Eck, T. F., Holben, B. N., Reid, J. S., Dubovik, O., Smirnov, A., O'Neill, N. T., et al. (1999). Wavelength dependence of the optical depth of biomass burning, urban, and desert dust aerosols. Journal of Geophysical Research: Atmospheres, 104(D24), 31333-31349. https://doi.org/10.1029/1999JD900923

Eck, T. F., Holben, B. N., Reid, J. S., Sinyuk, A., Dubovik, O., Smirnov, A., et al. (2008). Spatial and temporal variability of column-integrated aerosol optical properties in the southern Arabian Gulf and United Arab Emirates in summer. Journal of Geophysical Research, 113(D1), D01204. https://doi.org/10.1029/2007JD008944

Egan G. Walter, \& Theodore, H. W. (1979). Optical Properties of Inhomogeneous Materials. Optical Properties of Inhomogeneous Materials. Elsevier. https://doi.org/10.1016/b978-0-12-232650-9.x5001-2

Elterman, L. (1951). The measurement of stratospheric density distribution with the searchlight technique. Journal of Geophysical Research (1896-1977), 56(4), 509-520. https://doi.org/10.1029/JZ056i004p00509

Elterman, L. (1954). Seasonal trends of temperature, density, and pressure to 67.6 $\mathrm{km}$ obtained with the searchlight probing technique. Journal of Geophysical Research (1896-1977), 59(3), 351-358. https://doi.org/10.1029/JZ059i003p00351

Emberlin, J. (2008, July 25). Grass, Tree, and Weed Pollen. Allergy and Allergic Diseases. https://doi.org/doi:10.1002/9781444300918.ch45

Engelmann, R., Kanitz, T., Baars, H., Heese, B., Althausen, D., Skupin, A., et al. (2016). The automated multiwavelength Raman polarization and water-vapor lidar Polly XT: the neXT generation. Atmospheric Measurement Techniques, 9(4), 1767-1784. https://doi.org/10.5194/amt-9-1767-2016

England, M. N., Ferrare, R. A., Melfi, S. H., Whiteman, D. N., \& Clark, T. A. (1992). Atmospheric water vapor measurements: Comparison of microwave radiometry and lidar. Journal of Geophysical Research: Atmospheres, 97(D1), 899-916. https://doi.org/10.1029/91JD02384

Evan, A. T., Flamant, C., Fiedler, S., \& Doherty, O. (2014). An analysis of aeolian dust in climate models. Geophysical Research Letters, 41(16), 5996-6001. https://doi.org/10.1002/2014GL060545

Fernald, F. G. (1984). Analysis of atmospheric lidar observations: some comments. Appl. Opt., 23(5), 652-653. https://doi.org/10.1364/AO.23.000652

Fierce, L., Bond, T. C., Bauer, S. E., Mena, F., \& Riemer, N. (2016). Black carbon absorption at the global scale is affected by particle-scale diversity in $\begin{array}{llll}\text { composition. Nature } \quad \text { Communications, } & 7, & 12361 .\end{array}$ https://doi.org/10.1038/ncomms12361

Findeisen, W. (1942). Results of cloud and precipitation observations in weather reconnaissance flights over sea. Forsch. Erfahr. Reichsamt Wetterdienst, 8(B), 
$1-12$.

Finlayson-Pitts, B. J., \& Pitts, J. N. (2000). CHAPTER 9 - Particles in the Troposphere. In B. J. Finlayson-Pitts \& J. N. B. T.-C. of the U. and L. A. Pitts (Eds.) (pp. 349-435). San Diego: Academic Press. https://doi.org/https://doi.org/10.1016/B978-012257060-5/50011-3

Fiocco, G., \& Smullin, L. D. (1963). Detection of Scattering Layers in the Upper Atmosphere (60-140 km) by Optical Radar. Nature, 199(4900), 1275-1276. https://doi.org/10.1038/1991275a0

Foth, A., Baars, H., Di Girolamo, P., \& Pospichal, B. (2015). Water vapour profiles from Raman lidar automatically calibrated by microwave radiometer data during HOPE. Atmospheric Chemistry and Physics, 15(14), 7753-7763. https://doi.org/10.5194/acp-15-7753-2015

Freudenthaler, V. (2016). About the effects of polarising optics on lidar signals and the $\$ \Delta \$ 90 \sim$ calibration. Atmospheric Measurement Techniques, 9(9), 41814255. https://doi.org/10.5194/amt-9-4181-2016

Fuzzi, S., Baltensperger, U., Carslaw, K., Decesari, S., van der Gon, H., Facchini, M. C., et al. (2015). Particulate matter, air quality and climate: lessons learned and future needs. Atmospheric Chemistry and Physics, 15(14), 8217-8299. https://doi.org/10.5194/acp-15-8217-2015

Gantt, B., \& Meskhidze, N. (2013). The physical and chemical characteristics of marine primary organic aerosol: a review. Atmospheric Chemistry and Physics, 13(8), 3979-3996. https://doi.org/10.5194/acp-13-3979-2013

Gasteiger, J., Wiegner, M., Groß, S., Freudenthaler, V., Toledano, C., Tesche, M., \& Kandler, K. (2011). Modelling lidar-relevant optical properties of complex mineral dust aerosols. Tellus B, 63(4), 725-741. https://doi.org/10.1111/j.16000889.2011.00559.x

Ghan, S. J., Rissman, T. A., Elleman, R., Ferrare, R. A., Turner, D., Flynn, C., et al. (2006). Use of in situ cloud condensation nuclei, extinction, and aerosol size distribution measurements to test a method for retrieving cloud condensation nuclei profiles from surface measurements. Journal of Geophysical Research: Atmospheres, 111(D5). https://doi.org/10.1029/2004JD005752

Gialitaki, A., Tsekeri, A., Amiridis, V., Ceolato, R., Paulien, L., Kampouri, A., et al. (2020). Is the near-spherical shape the "new black" for smoke? Atmospheric Chemistry and Physics Discussions, 2020, 1-29. https://doi.org/10.5194/acp2020-22

Gimmestad, G. G. (2005). Differential-Absorption Lidar for Ozone and Industrial Emissions. In C. Weitkamp (Ed.), Lidar: Range-Resolved Optical Remote Sensing of the Atmosphere (pp. 187-212). New York, NY: Springer New York. https://doi.org/10.1007/0-387-25101-4_7

Ginoux, P., Prospero, J. M., Gill, T. E., Hsu, N. C., \& Zhao, M. (2012). Global-scale attribution of anthropogenic and natural dust sources and their emission rates based on MODIS Deep Blue aerosol products. Reviews of Geophysics, 50(3). 
https://doi.org/10.1029/2012RG000388

Girard, E., Dueymes, G., Du, P., \& Bertram, A. K. (2013). Assessment of the effects of acid-coated ice nuclei on the Arctic cloud microstructure, atmospheric dehydration, radiation and temperature during winter. International Journal of Climatology, 33(3), 599-614. https://doi.org/10.1002/joc.3454

Girolamo, P. Di, Ambrico, P. F., Amodeo, A., Boselli, A., Pappalardo, G., \& Spinelli, N. (1999). Aerosol observations by lidar in the nocturnal boundary layer. Appl. Opt., 38(21), 4585-4595. https://doi.org/10.1364/AO.38.004585

Granados-Muñoz, M. J., Navas-Guzmán, F., Bravo-Aranda, J. A., GuerreroRascado, J. L., Lyamani, H., Valenzuela, A., et al. (2015). Hygroscopic growth of atmospheric aerosol particles based on active remote sensing and radiosounding measurements: selected cases in southeastern Spain. Atmospheric Measurement Techniques, 8(2), 705-718. https://doi.org/10.5194/amt-8-705-2015

Groß, S., Freudenthaler, V., Schepanski, K., Toledano, C., Schäfler, A., Ansmann, A., \& Weinzierl, B. (2015). Optical properties of long-range transported Saharan dust over Barbados as measured by dual-wavelength depolarization Raman lidar measurements. Atmospheric Chemistry and Physics, 15(19), 1106711080. https://doi.org/10.5194/acp-15-11067-2015

Groß, Silke, Tesche, M., Freudenthaler, V., Toledano, C., Wiegner, M., Ansmann, A., et al. (2011). Characterization of Saharan dust, marine aerosols and mixtures of biomass-burning aerosols and dust by means of multi-wavelength depolarization and Raman lidar measurements during SAMUM 2. Tellus B: Chemical and Physical Meteorology, 63(4), 706-724. https://doi.org/10.1111/j.1600-0889.2011.00556.x

Guerrero-Rascado, J. L., Landulfo, E., Antuña, J. C., de Melo Jorge Barbosa, H., Barja, B., Bastidas, Á. E., et al. (2016). Latin American Lidar Network (LALINET) for aerosol research: Diagnosis on network instrumentation. Journal of Atmospheric and Solar-Terrestrial Physics, 138-139, 112-120. https://doi.org/10.1016/J.JASTP.2016.01.001

Haarig, M., Ansmann, A., Gasteiger, J., Kandler, K., Althausen, D., Baars, H., et al. (2017). Dry versus wet marine particle optical properties: $\mathrm{RH}$ dependence of depolarization ratio, backscatter, and extinction from multiwavelength lidar measurements during SALTRACE. Atmospheric Chemistry and Physics, 17(23), 14199-14217. https://doi.org/10.5194/acp-17-14199-2017

Hansen, J., Nazarenko, L., Ruedy, R., Sato, M., Willis, J., Del Genio, A., et al. (2005). Earth's energy imbalance: confirmation and implications. Science (New York, N.Y.), 308(5727), 1431-5. https://doi.org/10.1126/science.1110252

Hartmann, D. L., Ockert-Bell, M. E., \& Michelsen, M. L. (1992). The Effect of Cloud Type on Earth's Energy Balance: Global Analysis. Journal of Climate, 5(11), 1281-1304.

0442(1992)005<1281:teocto $>2.0 . c 0 ; 2$ https://doi.org/10.1175/1520- 
Hinds, W. . (1998). Aerosol Technology: Properties, Behavior, and Measurement of Airborne Particles, 2nd Edition. John Wiley \& Sons.

Hisrt, J. M. (1952). AN AUTOMATIC VOLUMETRIC SPORE TRAP. Annals of Applied Biology, 39(2), 257-265. https://doi.org/10.1111/j.17447348.1952.tb00904.x

Hofer, J., Althausen, D., Abdullaev, S. F., Makhmudov, A. N., Nazarov, B. I., Schettler, G., et al. (2017). Long-term profiling of mineral dust and pollution aerosol with multiwavelength polarization Raman lidar at the Central Asian site of Dushanbe, Tajikistan: Case studies. Atmospheric Chemistry and Physics, 17(23), 14559-14577. https://doi.org/10.5194/acp-17-14559-2017

Hulburt, E. O. (1937). Observations of a Searchlight Beam to an Altitude of 28 Kilometers. J. Opt. Soc. Am., 27(11), 377-382. https://doi.org/10.1364/JOSA.27.000377

Hulley, G. C., \& Pavlis, E. C. (2007). A ray-tracing technique for improving Satellite Laser Ranging atmospheric delay corrections, including the effects of horizontal refractivity gradients. Journal of Geophysical Research: Solid Earth, 112(B6). https://doi.org/10.1029/2006JB004834

Huneeus, N., Schulz, M., Balkanski, Y., Griesfeller, J., Prospero, J., Kinne, S., et al. (2011). Global dust model intercomparison in AeroCom phase i. Atmospheric Chemistry and Physics, 11(15), 7781-7816. https://doi.org/10.5194/acp-117781-2011

Hunt, W. H., Winker, D. M., Vaughan, M. A., Powell, K. A., Lucker, P. L., \& Weimer, C. (2009). CALIPSO Lidar Description and Performance Assessment. Journal of Atmospheric and Oceanic Technology, 26(7), 1214-1228. https://doi.org/10.1175/2009JTECHA1223.1

Intrieri, J. M., Fairall, C. W., Shupe, M. D., Persson, P. O. G., Andreas, E. L., Guest, P. S., \& Moritz, R. E. (2002). An annual cycle of Arctic surface cloud forcing at SHEBA. Journal of Geophysical Research, 107(C10), 8039. https://doi.org/10.1029/2000JC000439

Janhäll, S., Andreae, M. O., \& Pöschl, U. (2010). Biomass burning aerosol emissions from vegetation fires: particle number and mass emission factors and size distributions. Atmospheric Chemistry and Physics, 10(3), 1427-1439. https://doi.org/10.5194/acp-10-1427-2010

Järvinen, E., Kemppinen, O., Nousiainen, T., Kociok, T., Möhler, O., Leisner, T., \& Schnaiter, M. (2016). Laboratory investigations of mineral dust nearbackscattering depolarization ratios. Journal of Quantitative Spectroscopy and Radiative Transfer, 178, 192-208. https://doi.org/10.1016/J.JQSRT.2016.02.003

Johnson, E. A., Meyer, R. C., Hopkins, R. E., \& Mock, W. H. (1939). The Measurement of Light Scattered by the Upper Atmosphere from a Search-Light Beam. J. Opt. Soc. Am., 29(12), 512-517. https://doi.org/10.1364/JOSA.29.000512 
Jordan, G., Meijninger, B. M. L., Hinsbergen, D. J. J. van, Meulenkamp, J. E., \& Dijk, P. M. van. (2005). Extraction of morphotectonic features from DEMs: Development and applications for study areas in Hungary and NW Greece. International Journal of Applied Earth Observation and Geoinformation, 7(3), 163-182. https://doi.org/10.1016/J.JAG.2005.03.003

Kacenelenbogen, M., Redemann, J., Vaughan, M. A., Omar, A. H., Russell, P. B., Burton, S., et al. (2014). An evaluation of CALIOP/CALIPSO's aerosol-abovecloud detection and retrieval capability over North America. Journal of Geophysical Research: Atmospheres, 119(1), 230-244. https://doi.org/10.1002/2013JD020178

Kahnert, M., Nousiainen, T., \& Markkanen, J. (2016). Morphological Models for Inhomogeneous Particles: Light Scattering by Aerosols, Cometary Dust, and Living Cells BT - Light Scattering Reviews, Volume 11: Light Scattering and Radiative Transfer. In A. Kokhanovsky (Ed.) (pp. 299-337). Berlin, Heidelberg: Springer Berlin Heidelberg. https://doi.org/10.1007/978-3-662-49538-4_6

Kanakidou, M., Seinfeld, J. H., Pandis, S. N., Barnes, I., Dentener, F. J., Facchini, M. C., et al. (2005). Organic aerosol and global climate modelling: a review. Atmospheric Chemistry and Physics, 5(4), 1053-1123. https://doi.org/10.5194/acp-5-1053-2005

Kanji, Z. A., Ladino, L. A., Wex, H., Boose, Y., Burkert-Kohn, M., Cziczo, D. J., et al. (2017). Overview of Ice Nucleating Particles. Meteorological Monographs, 58, 1.1-1.33. https://doi.org/10.1175/AMSMONOGRAPHS-D-16-0006.1

Kim, K. H., Späh, A., Pathak, H., Perakis, F., Mariedahl, D., Amann-Winkel, K., et al. (2017). Maxima in the thermodynamic response and correlation functions of deeply supercooled water. Science, 358(6370), 1589-1593. https://doi.org/10.1126/science.aap8269

Kim, M.-H., Omar, A. H., Tackett, J. L., Vaughan, M. A., Winker, D. M., Trepte, C. R., et al. (2018). The CALIPSO Version 4 Automated Aerosol Classification and Lidar Ratio Selection Algorithm. Atmospheric Measurement Techniques Discussions, 1-43. https://doi.org/10.5194/amt-2018-166

Klett, J. D. (1981). Stable analytical inversion solution for processing lidar returns. Appl. Opt., 20(2), 211-220. https://doi.org/10.1364/AO.20.000211

Klimont, Z., Kupiainen, K., Heyes, C., Purohit, P., Cofala, J., Rafaj, P., et al. (2017). Global anthropogenic emissions of particulate matter including black carbon. Atmospheric Chemistry and Physics, 17(14), 8681-8723. https://doi.org/10.5194/acp-17-8681-2017

Kok, J. F., Ridley, D. A., Zhou, Q., Miller, R. L., Zhao, C., Heald, C. L., et al. (2017). Smaller desert dust cooling effect estimated from analysis of dust size and abundance. Nature Geoscience, 10(4), 274-278. https://doi.org/10.1038/ngeo2912

Korolev, A., \& Isaac, G. (2003). Phase transformation of mixed-phase clouds. Quarterly Journal of the Royal Meteorological Society, 129(587), 19-38. 
https://doi.org/10.1256/qj.01.203

Kovalev, V. A., \& Eichinger, W. E. (2004, April 13). Analytical Solutions of the Lidar Equation. Elastic Lidar. https://doi.org/doi:10.1002/0471643173.ch5

Kylling, A., Kahnert, M., Lindqvist, H., \& Nousiainen, T. (2014). Volcanic ash infrared signature: porous non-spherical ash particle shapes compared to homogeneous spherical ash particles. Atmospheric Measurement Techniques, 7(4), 919-929. https://doi.org/10.5194/amt-7-919-2014

Laurent, B., Marticorena, B., Bergametti, G., Léon, J. F., \& Mahowald, N. M. (2008). Modeling mineral dust emissions from the Sahara desert using new surface properties and soil database. Journal of Geophysical Research Atmospheres, 113(14). https://doi.org/10.1029/2007JD009484

Lefsky, M. A., Cohen, W. B., Parker, G. G., \& Harding, D. J. (2002). Lidar Remote Sensing for Ecosystem Studies: Lidar, an emerging remote sensing technology that directly measures the three-dimensional distribution of plant canopies, can accurately estimate vegetation structural attributes and should be of particular inte. BioScience, 52(1), 19-30. https://doi.org/10.1641/00063568(2002)052[0019:LRSFES]2.0.CO;2

Li, J., Lv, Q., Zhang, M., Wang, T., Kawamoto, K., Chen, S., \& Zhang, B. (2017). Effects of atmospheric dynamics and aerosols on the fraction of supercooled water clouds. Atmospheric Chemistry and Physics, 17(3), 1847-1863. https://doi.org/10.5194/acp-17-1847-2017

Ligda, M. G. H. (1963). Proceedings of the first conference on laser technology (pp. 63-72). U.S. Navy, ONR.

Liou, K. N. (2002). An Introduction to Atmospheric Radiation. Academic Press.

Little, C. G. (1969). Acoustic methods for the remote probing of the lower atmosphere. Proceedings of the IEEE, 57(4), 571-578. https://doi.org/10.1109/PROC.1969.7010

Lohmann, U., \& Feichter, J. (2005). Global indirect aerosol effects: a review. Atmospheric Chemistry and Physics, 5(3), 715-737. https://doi.org/10.5194/acp-5-715-2005

Luo, J., Zhang, Y., Wang, F., \& Zhang, Q. (2018). Effects of brown coatings on the absorption enhancement of black carbon: a numerical investigation. Atmospheric Chemistry and Physics, 18(23), 16897-16914. https://doi.org/10.5194/acp-18-16897-2018

Lynch, D. K. (1996). Cirrus clouds: Their role in climate and global change. Acta Astronautica, 38(11), 859-863.https://doi.org/10.1016/S0094-5765(96)00098-7

MAIMAN, T. H. (1960). Stimulated Optical Radiation in Ruby. Nature, 187(4736), 493-494. https://doi.org/10.1038/187493a0

Mamouri, R.-E., \& Ansmann, A. (2017). Potential of polarization/Raman lidar to separate fine dust, coarse dust, maritime, and anthropogenic aerosol profiles. Atmospheric Measurement Techniques, 10(9), 3403-3427. 
https://doi.org/10.5194/amt-10-3403-2017

Mamouri, R. E., \& Ansmann, A. (2015). Estimated desert-dust ice nuclei profiles from polarization lidar: methodology and case studies. Atmospheric Chemistry and Physics, 15(6), 3463-3477. https://doi.org/10.5194/acp-15-3463-2015

Mamouri, R. E., Ansmann, A., Nisantzi, A., Kokkalis, P., Schwarz, A., \& Hadjimitsis, D. (2013). Low Arabian dust extinction-to-backscatter ratio. Geophysical Research Letters, 40(17), 4762-4766. https://doi.org/10.1002/grl.50898

Mamouri, Rodanthi-Elisavet, \& Ansmann, A. (2016). Potential of polarization lidar to provide profiles of CCN- and INP-relevant aerosol parameters. Atmospheric Chemistry and Physics, 16(9), 5905-5931. https://doi.org/10.5194/acp-165905-2016

Mandava, M., Gammenthaler, R. S., \& Hocker, S. F. (2018). Vehicle Speed Enforcement Using Absolute Speed Handheld Lidar. In IEEE 88th Vehicular Technology Conference (VTC-Fall) (pp. 1-5). Chicago, USA.

Martin, C. (2015). The invention of atmosphere. Studies in History and Philosophy of Science Part A, 52, 44-54. https://doi.org/10.1016/j.shpsa.2015.05.007

Masini, N., \& Lasaponara, R. (2013). Airborne Lidar in Archaeology: Overview and a Case Study. In B. Murgante, S. Misra, M. Carlini, C. M. Torre, H.-Q. Nguyen, D. Taniar, et al. (Eds.), Computational Science and Its Applications -- ICCSA 2013 (pp. 663-676). Berlin, Heidelberg: Springer Berlin Heidelberg.

Mattis, I., Ansmann, A., Althausen, D., Jaenisch, V., Wandinger, U., Müller, M., et al. (2002). Relative-humidity profiling in the troposphere with a Raman lidar. Applied Optics, 41(30), 6451-6462. https://doi.org/https://doi.org/10.1364/AO.41.006451

Mattis, Ina, Tesche, M., Grein, M., Freudenthaler, V., \& Müller, D. (2009). Systematic error of lidar profiles caused by a polarization-dependent receiver transmission: quantification and error correction scheme. Appl. Opt., 48(14), 2742-2751. https://doi.org/10.1364/AO.48.002742

McClung, F. J., \& Hellwarth, R. W. (1962). Giant Optical Pulsations from Ruby. Journal of Applied Physics, 33(3), 828-829. https://doi.org/10.1063/1.1777174

McCormack, J., Prine, J., Trowbridge, B., Rodriguez, A. C., \& Integlia, R. (2015). 2D LIDAR as a distributed interaction tool for virtual and augmented reality video games. In IEEE Games Entertainment Media Conference (GEM) (pp. 1-5). Toronto.

McCormick, R. A., \& Ludwig, J. H. (1967). Climate Modification by Atmospheric Aerosols. Science, 156(3780), 1358-1359. https://doi.org/10.1126/science.156.3780.1358

Middleton, W. E. K., \& Spilhaus, A. F. (1953). Meteorological Instruments. Quarterly Journal of the Royal Meteorological Society, 80(345), 484-484. https://doi.org/10.1002/qj.49708034532

Mie, G. (1908). Beiträge zur Optik trüber Medien, speziell kolloidaler Metallösungen. 


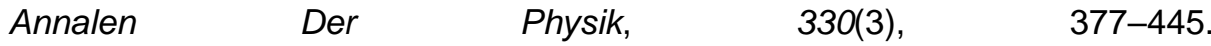
https://doi.org/10.1002/andp.19083300302

Müller, D., Ansmann, A., Mattis, I., Tesche, M., Wandinger, U., Althausen, D., \& Pisani, G. (2007). Aerosol-type-dependent lidar ratios observed with Raman lidar. Journal of Geophysical Research, 112(D16), D16202. https://doi.org/10.1029/2006JD008292

Müller, D., Ansmann, A., Freudenthaler, V., Kandler, K., Toledano, C., Hiebsch, A., et al. (2010). Mineral dust observed with AERONET Sun photometer, Raman lidar, and in situ instruments during SAMUM 2006: Shape-dependent particle properties. Journal of Geophysical Research: Atmospheres, 115(D11). https://doi.org/10.1029/2009JD012523

Müller, D., Lee, K.-H., Gasteiger, J., Tesche, M., Weinzierl, B., Kandler, K., et al. (2012). Comparison of optical and microphysical properties of pure Saharan mineral dust observed with AERONET Sun photometer, Raman lidar, and in situ instruments during SAMUM 2006. Journal of Geophysical Research: Atmospheres, 117(D7), n/a-n/a. https://doi.org/10.1029/2011JD016825

Müller, D., Böckmann, C., Kolgotin, A., Schneidenbach, L., Chemyakin, E., Rosemann, J., et al. (2016). Microphysical particle properties derived from inversion algorithms developed in the framework of EARLINET. Atmospheric Measurement Techniques, 9(10), 5007-5035. https://doi.org/10.5194/amt-95007-2016

Müller, M., Wandinger, U., \& Ansmann, A. (1999). Microphysical particle parameters from extinction and backscatter lidar data by inversion with regularization: simulation. Applied Optics, 38(12), 2358-2368.

Murayama, T., Okamoto, H., Kaneyasu, N., Kamataki, H., \& Miura, K. (1999). Application of lidar depolarization measurement in the atmospheric boundary layer: Effects of dust and sea-salt particles. Journal of Geophysical Research: Atmospheres, 104(D24), 31781-31792. https://doi.org/10.1029/1999JD900503

Navas-Guzmán, F., Fernández-Gálvez, J., Granados-Muñoz, M. J., GuerreroRascado, J. L., Bravo-Aranda, J. A., \& Alados-Arboledas, L. (2014). Tropospheric water vapour and relative humidity profiles from lidar and microwave radiometry. Atmospheric Measurement Techniques, 7(5), 12011211. https://doi.org/10.5194/amt-7-1201-2014

Navas-Guzmán, F., Martucci, G., Collaud Coen, M., Granados-Muñoz, M. J., Hervo, M., Sicard, M., \& Haefele, A. (2019). Characterization of aerosol hygroscopicity using Raman lidar measurements at the EARLINET station of Payerne. Atmospheric Chemistry and Physics, 19(18), 11651-11668. https://doi.org/10.5194/acp-19-11651-2019

Neff, T. (2018). The Laser That's Changing the World: The Amazing Stories behind Lidar, from 3D Mapping to Self-Driving Cars. Prometheus books.

Nicolae, D., Nemuc, A., Müller, D., Talianu, C., Vasilescu, J., Belegante, L., \& Kolgotin, A. (2013). Characterization of fresh and aged biomass burning events 
using multiwavelength Raman lidar and mass spectrometry. Journal of Geophysical Research: Atmospheres, 118(7), 2956-2965. https://doi.org/10.1002/jgrd.50324

Nicolae, D, Vasilescu, J., Talianu, C., Binietoglou, I., Nicolae, V., Andrei, S., \& Antonescu, B. (2018). A neural network aerosol-typing algorithm based on lidar data. Atmospheric Chemistry and Physics, 18(19), 14511-14537. https://doi.org/10.5194/acp-18-14511-2018

Nicolae, Doina, Talianu, C., Nemuc, A., \& Cârstea, E. (2008). Benefits and drawbacks of laser remote sensing in atmospheric research. UPB Scientific Bulletin, Series A: Applied Mathematics and Physics, 70.

Nisantzi, A., Mamouri, R. E., Ansmann, A., Schuster, G. L., \& Hadjimitsis, D. G. (2015). Middle East versus Saharan dust extinction-to-backscatter ratios. Atmospheric Chemistry and Physics, 15(12), 7071-7084. https://doi.org/10.5194/acp-15-7071-2015

Norgren, M. S., de Boer, G., \& Shupe, M. D. (2018). Observed aerosol suppression of cloud ice in low-level Arctic mixed-phase clouds. Atmospheric Chemistry and Physics, 18(18), 13345-13361. https://doi.org/10.5194/acp-18-13345-2018

Nousiainen, T., \& Kandler, K. (2015). Light scattering by atmospheric mineral dust particles BT - Light Scattering Reviews 9: Light Scattering and Radiative Transfer. In A. A. Kokhanovsky (Ed.) (pp. 3-52). Berlin, Heidelberg: Springer Berlin Heidelberg. https://doi.org/10.1007/978-3-642-37985-7_1

Nowak, S., Lafon, S., Caquineau, S., Journet, E., \& Laurent, B. (2018). Quantitative study of the mineralogical composition of mineral dust aerosols by $\mathrm{X}$-ray diffraction. Talanta, 186, 133-139. https://doi.org/10.1016/j.talanta.2018.03.059

O'Dowd, C. D., \& de Leeuw, G. (2007). Marine aerosol production: a review of the current knowledge. Philosophical Transactions of the Royal Society A: Mathematical, Physical and Engineering Sciences, 365(1856), 1753-1774. https://doi.org/10.1098/rsta.2007.2043

Omar, A. H., Winker, D. M., Vaughan, M. A., Hu, Y., Trepte, C. R., Ferrare, R. A., et al. (2009). The CALIPSO Automated Aerosol Classification and Lidar Ratio Selection Algorithm. Journal of Atmospheric and Oceanic Technology, 26(10), 1994-2014. https://doi.org/10.1175/2009JTECHA1231.1

Osterloh, L., Böckmann, C., Nicolae, D., \& Nemuc, A. (2013). Regularized inversion of microphysical atmospheric particle parameters: Theory and application. Journal of Computational Physics, 237, 79-94. https://doi.org/10.1016/J.JCP.2012.11.040

Pal, S. R., \& Carswell, A. I. (1973). Polarization Properties of Lidar Backscattering from Clouds. Appl. Opt., 12(7), 1530-1535. https://doi.org/10.1364/AO.12.001530

Pantazis, A., Papayannis, A., \& Georgoussis, G. (2018). LIDAR ALGORITHMS FOR ATMOSPHERIC SLANT-RANGE VISIBILITY, PLANETARY BOUNDARY 
LAYER HEIGHT, METEOROLOGICAL PHENOMENA AND ATMOSPHERIC LAYERING MEASUREMENTS.

Papagiannopoulos, N., Mona, L., Amodeo, A., D'Amico, G., Gumà Claramunt, P., Pappalardo, G., et al. (2018). An automatic observation-based aerosol typing method for EARLINET. Atmospheric Chemistry and Physics, 18(21), 1587915901. https://doi.org/10.5194/acp-18-15879-2018

Papayannis, A., Mamouri, R. E., Amiridis, V., Remoundaki, E., Tsaknakis, G., Kokkalis, P., et al. (2012). Optical-microphysical properties of Saharan dust aerosols and composition relationship using a multi-wavelength Raman lidar, in situ sensors and modelling: a case study analysis. Atmospheric Chemistry and Physics, 12(9), 4011-4032. https://doi.org/10.5194/acp-12-4011-2012

Pappalardo, G., Amodeo, A., Apituley, A., Comeron, A., Freudenthaler, V., Linné, H., et al. (2014). EARLINET: towards an advanced sustainable European aerosol lidar network. Atmospheric Measurement Techniques, 7(8), 2389-2409. https://doi.org/10.5194/amt-7-2389-2014

Patrick McCormick, M. (2005). Airborne and Spaceborne Lidar. In C. Weitkamp (Ed.), Lidar: Range-Resolved Optical Remote Sensing of the Atmosphere (pp. 355397). New York, NY: Springer New York. https://doi.org/10.1007/0-387-251014_13

Pérez-Raml'lirez, D., Whiteman, D. N., Veselovskii, I., Kolgotin, A., Korenskiy, M., \& Alados-Arboledas, L. (2013). Effects of systematic and random errors on the retrieval of particle microphysical properties from multiwavelength lidar measurements using inversion with regularization. Atmospheric Measurement Techniques, 6(11), 3039-3054. https://doi.org/10.5194/amt-6-3039-2013

Phillips, V. T. J., DeMott, P. J., \& Andronache, C. (2008). An Empirical Parameterization of Heterogeneous Ice Nucleation for Multiple Chemical Species of Aerosol. Journal of the Atmospheric Sciences, 65(9), 2757-2783. https://doi.org/10.1175/2007JAS2546.1

Powell, K. A., Hostetler, C. A., Vaughan, M. A., Lee, K.-P., Trepte, C. R., Rogers, R. R., et al. (2009). CALIPSO Lidar Calibration Algorithms. Part I: Nighttime 532$\mathrm{nm}$ Parallel Channel and 532-nm Perpendicular Channel. Journal of Atmospheric and Oceanic Technology, 26(10), 2015-2033. https://doi.org/10.1175/2009JTECHA1242.1

Prospero, J. M., \& Mayol-Bracero, O. L. (2013). Understanding the transport and impact of African dust on the Caribbean Basin. Bulletin of the American Meteorological Society, 94(9), 1329-1337. https://doi.org/10.1175/BAMS-D-1200142.1

Prospero, J. M., Ginoux, P., Torres, O., Nicholson, S. E., \& Gill, T. E. (2002). ENVIRONMENTAL CHARACTERIZATION OF GLOBAL SOURCES OF ATMOSPHERIC SOIL DUST IDENTIFIED WITH THE NIMBUS 7 TOTAL OZONE MAPPING SPECTROMETER (TOMS) ABSORBING AEROSOL PRODUCT. Reviews of Geophysics, 40(1), 2-31. https://doi.org/10.1029/2000RG000095 
Pruppacher, H. R., \& Klett, J. D. (2010). Microphysics of Clouds and Precipitation. https://doi.org/10.1007/978-0-306-48100-0_14

Querry, M. (1987). Optical constants of minerals and other materials from the millimeter to the ultraviolet. Aberdeen Proving Ground Md.: US Army Armament Munitions \& Chemical Research Development \& Engineering Center.

Raman, C. V, \& Krishnan, K. S. (1928). A New Type of Secondary Radiation. Nature, 121(3048), 501-502. https://doi.org/10.1038/121501c0

Ramanathan, V., Cess, R. D., Harrison, E. F., Minnis, P., Barkstrom, B. R., Ahmad, E., \& Hartmann, D. (1989). Cloud-radiative forcing and climate: Results from the earth radiation budget experiment. Science, 243(4887), 57-63. https://doi.org/10.1126/science.243.4887.57

Randles, C. A., Russell, L. M., \& Ramaswamy, V. (2004). Hygroscopic and optical properties of organic sea salt aerosol and consequences for climate forcing. Geophysical Research Letters, 31(16). https://doi.org/10.1029/2004GL020628

Redmond, H. E., Dial, K. D., \& Thompson, J. E. (2010). Light scattering and absorption by wind blown dust: Theory, measurement, and recent data. Aeolian Research, 2(1), 5-26. https://doi.org/10.1016/J.AEOLIA.2009.09.002

Reid, J S, Koppmann, R., Eck, T. F., \& Eleuterio, D. P. (2005). A review of biomass burning emissions part II: intensive physical properties of biomass burning particles. Atmospheric Chemistry and Physics, 5(3), 799-825. https://doi.org/10.5194/acp-5-799-2005

Reid, Jeffrey S., Jonsson, H. H., Maring, H. B., Smirnov, A., Savoie, D. L., Cliff, S. S., et al. (2003). Comparison of size and morphological measurements of coarse mode dust particles from Africa. Journal of Geophysical Research D: Atmospheres, 108(19). https://doi.org/10.1029/2002jd002485

Renaut, D., Pourny, J. C., \& Capitini, R. (1980). Daytime Raman-lidar measurements of water vapor. Opt. Lett., 5(6), 233-235. https://doi.org/10.1364/OL.5.000233

Ristori, P., Froidevaux, M., Dinoev, T., Serikov, I., Simeonov, V., Parlange, M., \& Bergh, H. Van den. (2005). Development of a temperature and water vapor Raman lidar for turbulent observations. In Proc.SPIE (Vol. 5984). Retrieved from https://doi.org/10.1117/12.629376

Rodriguez, S., Alastuey, A., Alonso-Pérez, S., Querol, X., Cuevas, E., Abreu-Afonso, J., et al. (2011). Transport of desert dust mixed with North African industrial pollutants in the subtropical Saharan Air Layer. Atmospheric Chemistry and Physics, 11(13), 6663-6685. https://doi.org/10.5194/acp-11-6663-2011

Salerno, M., Rondinella, D., Crispino, M., Costantini, G., Carota, M., \& Casali, D. (2008). Sky-scanner: an innovative LIDAR technology for air traffic management (pp. 46-53).

Sasano, Y., \& Nakane, H. (1984). Significance of the extinction/backscatter ratio and the boundary value term in the solution for the two-component lidar equation. Appl. Opt., 23(1), 11_1--13. https://doi.org/10.1364/AO.23.0011_1 
Sasano, Y., Browell, E. V, \& Ismail, S. (1985). Error caused by using a constant extinction/backscattering ratio in the lidar solution. Appl. Opt., 24(22), 39293932. https://doi.org/10.1364/AO.24.003929

Sassen, K. (2005). Polarization in Lidar BT - Lidar: Range-Resolved Optical Remote Sensing of the Atmosphere. In C. Weitkamp (Ed.) (pp. 19-42). New York, NY: Springer New York. https://doi.org/10.1007/0-387-25101-4_2

Schawlow, A. L., \& Townes, C. H. (1958). Infrared and Optical Masers. Physical Review, 112(6), 1940-1949. https://doi.org/10.1103/PhysRev.112.1940

Schotland, R. M., Sassen, K., \& Stone, R. (1971). Observations by Lidar of Linear Depolarization Ratios for Hydrometeors. Journal of Applied Meteorology, 10(5), 1011-1017. 0450(1971)010<1011:OBLOLD>2.0.CO;2 https://doi.org/10.1175/1520-

Schuster, G. L., Vaughan, M., MacDonnell, D., Su, W., Winker, D., Dubovik, O., et al. (2012). Comparison of CALIPSO aerosol optical depth retrievals to AERONET measurements, and a climatology for the lidar ratio of dust. Atmospheric Chemistry and Physics, 12(16), 7431-7452. https://doi.org/10.5194/acp-127431-2012

Schuster, Gregory L, Dubovik, O., \& Holben, B. N. (2006). Angstrom exponent and bimodal aerosol size distributions. Journal of Geophysical Research: Atmospheres, 111(D7). https://doi.org/10.1029/2005JD006328

Seinfeld, J H., \& Pandis, S. (2016). Atmospheric Chemistry and Physics: From Air Pollution to Climate Change, Atmospheric Chemistry and Physics: From Air Pollution to Climate Change (3rd Editio). Wiley.

Seinfeld, John H, Bretherton, C., Carslaw, K. S., Coe, H., DeMott, P. J., Dunlea, E. J., et al. (2016). Improving our fundamental understanding of the role of aerosolcloud interactions in the climate system. Proceedings of the National Academy of Sciences, 113(21), 5781-5790. https://doi.org/10.1073/pnas.1514043113

Sénéchal, H., Visez, N., Charpin, D., Shahali, Y., Peltre, G., Biolley, J.-P., et al. (2015). A Review of the Effects of Major Atmospheric Pollutants on Pollen Grains, Pollen Content, and Allergenicity. The Scientific World Journal, 2015, 940243. https://doi.org/10.1155/2015/940243

Shin, S.-K., Tesche, M., Kim, K., Kezoudi, M., Tatarov, B., Müller, D., \& Noh, Y. (2018). On the spectral depolarisation and lidar ratio of mineral dust provided in the AERONET version 3 inversion product. Atmospheric Chemistry and Physics, 18(17), 12735-12746. https://doi.org/10.5194/acp-18-12735-2018

Shupe, M. D., \& Intrieri, J. M. (2004). Cloud Radiative Forcing of the Arctic Surface: The Influence of Cloud Properties, Surface Albedo, and Solar Zenith Angle. Journal of Climate, 17(3), 616-628. https://doi.org/10.1175/15200442(2004)017<0616:CRFOTA>2.0.CO;2

Shupe, M. D., Uttal, T., \& Matrosov, S. Y. (2005). Arctic Cloud Microphysics Retrievals from Surface-Based Remote Sensors at SHEBA. Journal of Applied Meteorology, 44(10), 1544-1562. https://doi.org/10.1175/JAM2297.1 
Sofiev, M. (2017). On impact of transport conditions on variability of the seasonal pollen index. Aerobiologia, 33(1), 167-179. https://doi.org/10.1007/s10453016-9459-x

Sofiev, M., Siljamo, P., Ranta, H., \& Rantio-Lehtimäki, A. (2006). Towards numerical forecasting of long-range air transport of birch pollen: theoretical considerations and a feasibility study. International Journal of Biometeorology, 50(6), 392. https://doi.org/10.1007/s00484-006-0027-x

Sokolik, I. N., \& Toon, O. B. (1999). Incorporation of mineralogical composition into models of the radiative properties of mineral aerosol from UV to IR wavelengths. Journal of Geophysical Research: Atmospheres, 104(D8), 9423-9444. https://doi.org/10.1029/1998JD200048

Stevens, B., \& Feingold, G. (2009, October 1). Untangling aerosol effects on clouds and precipitation in a buffered system. Nature. https://doi.org/10.1038/nature08281

Stevens, R. G., Loewe, K., Dearden, C., Dimitrelos, A., Possner, A., Eirund, G. K., et al. (2018). A model intercomparison of CCN-limited tenuous clouds in the high Arctic. Atmospheric Chemistry and Physics, 18(15), 11041-11071. https://doi.org/10.5194/acp-18-11041-2018

Strutt, J. W. (1871). LVIII. On the scattering of light by small particles. The London, Edinburgh, and Dublin Philosophical Magazine and Journal of Science, 41(275), 447-454. https://doi.org/10.1080/14786447108640507

Sugimoto, N., Matsui, I., Shimizu, A., Uno, I., Asai, K., Endoh, T., \& Nakajima, T. (2002). Observation of dust and anthropogenic aerosol plumes in the Northwest Pacific with a two-wavelength polarization lidar on board the research vessel Mirai. Geophysical Research Letters, 29(19), 4-7. https://doi.org/10.1029/2002GL015112

Sullivan, R. C., Petters, M. D., DeMott, P. J., Kreidenweis, S. M., Wex, H., Niedermeier, D., et al. (2010). Irreversible loss of ice nucleation active sites in mineral dust particles caused by sulphuric acid condensation. Atmospheric Chemistry and Physics Discussions, 10(7), 16901-16940. https://doi.org/10.5194/acpd-10-16901-2010

Suomalainen, K., Wang, V., \& Sharp, B. (2017). Rooftop solar potential based on LiDAR data: Bottom-up assessment at neighbourhood level. Renewable Energy, 111, 463-475. https://doi.org/10.1016/J.RENENE.2017.04.025

Synge, E. H. (1930). XCl. A method of investigating the higher atmosphere. The London, Edinburgh, and Dublin Philosophical Magazine and Journal of Science, 9(60), 1014-1020. https://doi.org/10.1080/14786443008565070

Tan, W., Zhao, G., Yu, Y., Li, C., Li, J., Kang, L., et al. (2019). Method to retrieve cloud condensation nuclei number concentrations using lidar measurements. Atmospheric Measurement Techniques, 12(7), 3825-3839. https://doi.org/10.5194/amt-12-3825-2019

Terpstra, T., Dickinson, J., Hashemian, A., \& Fenton, S. (2019). Reconstruction of 3D 
Accident Sites Using USGS LiDAR, Aerial Images, and Photogrammetry. In SAE Technical Paper. SAE International. https://doi.org/10.4271/2019-01-0423

Tesche, M, Kolgotin, A., Haarig, M., Burton, S. P., Ferrare, R. A., Hostetler, C. A., \& Müller, D. (2019). $\$ 3+2+X \$$ : what is the most useful depolarization input for retrieving microphysical properties of non-spherical particles from lidar measurements using the spheroid model of Dubovik et al. (2006)? Atmospheric Measurement Techniques, 12(8), 4421-4437. https://doi.org/10.5194/amt-124421-2019

Tesche, Matthias, Ansmann, A., MüLLER, D., Althausen, D., Mattis, I., Heese, B., et al. (2009). Vertical profiling of Saharan dust with Raman lidars and airborne HSRL in southern Morocco during SAMUM. Tellus B: Chemical and Physical Meteorology, 61(1), 144-164. https://doi.org/10.1111/j.16000889.2008.00390.x

Tesche, Matthias, Gross, S., Ansmann, A., Müller, D., Althausen, D., Freudenthaler, V., \& Esselborn, M. (2011). Profiling of Saharan dust and biomass-burning smoke with multiwavelength polarization Raman lidar at Cape Verde. Tellus B: Chemical and Physical Meteorology, 63(4), 649-676. https://doi.org/10.1111/j.1600-0889.2011.00548.x

Textor, C., Schulz, M., Guibert, S., Kinne, S., Balkanski, Y., Bauer, S., et al. (2006). Analysis and quantification of the diversities of aerosol life cycles within AeroCom. Atmospheric Chemistry and Physics, 6(7), 1777-1813. https://doi.org/10.5194/acp-6-1777-2006

Thorsen, T. J., Ferrare, R. A., Hostetler, C. A., Vaughan, M. A., \& Fu, Q. (2017). The impact of lidar detection sensitivity on assessing aerosol direct radiative effects. Geophysical Research Letters, 44(17), 9059-9067. https://doi.org/10.1002/2017GL074521

de Tomasi, F., Torsello, G., Diso, D., Protopapa, M. L., \& Perrone, M. R. (1999). Daytime Raman lidar for vertical profiling of water vapor and ozone. In J. E. Russell (Ed.), Satellite Remote Sensing of Clouds and the Atmosphere IV (Vol. 3867, pp. 228-233). SPIE. https://doi.org/10.1117/12.373076

Toth, T. D., Campbell, J. R., Reid, J. S., Tackett, J. L., Vaughan, M. A., Zhang, J., \& Marquis, J. W. (2018). Minimum aerosol layer detection sensitivities and their subsequent impacts on aerosol optical thickness retrievals in CALIPSO level 2 data products. Atmospheric Measurement Techniques, 11(1), 499-514. https://doi.org/10.5194/amt-11-499-2018

Tredinnick, R., Smith, S., \& Ponto, K. (2019). A cost-benefit analysis of 3D scanning technology for crime scene investigation. Forensic Science International: Reports, 1, 100025. https://doi.org/10.1016/J.FSIR.2019.100025

Tsagkogeorga, G., Parker, J., Stupka, E., Cotton, J. A., \& Rossiter, S. J. (2013). Phylogenomic analyses elucidate the evolutionary relationships of bats. Current Biology: CB, 23(22), 2262-2267. https://doi.org/10.1016/j.cub.2013.09.014

Tsekeri, A., Freudenthaler, V., Gasteiger, J., Doxastakis, G., Binietoglou, I., 
Georgoussis, G., et al. (2019). Detecting dust particle orientation with a novel polarization lidar. In EGU General Assembly Conference Abstracts (p. 15655).

Tuve, M. A., Johnson, E. A., \& Wolf, O. R. (1935). A new experimental method for study of the upper atmosphere. Terr. Mag., 40(452).

Twomey, S. (1974). Pollution and the planetary albedo. Atmospheric Environment (1967), 8(12), 1251-1256. https://doi.org/10.1016/0004-6981(74)90004-3

Ullrich, R., Hoose, C., Möhler, O., Niemand, M., Wagner, R., Höhler, K., et al. (2017). A New Ice Nucleation Active Site Parameterization for Desert Dust and Soot. Journal of the Atmospheric Sciences, 74(3), 699-717. https://doi.org/10.1175/JAS-D-16-0074.1

Vavrus, S. (2004). The Impact of Cloud Feedbacks on Arctic Climate under Greenhouse Forcing. Journal of Climate, 17(3), 603-615. https://doi.org/10.1175/1520-0442(2004)017<0603:TIOCFO>2.0.CO;2

Vergara-Temprado, J., Holden, M. A., Orton, T. R., O’Sullivan, D., Umo, N. S., Browse, J., et al. (2018). Is Black Carbon an Unimportant Ice-Nucleating Particle in Mixed-Phase Clouds? Journal of Geophysical Research: Atmospheres, 123(8), 4273-4283. https://doi.org/10.1002/2017JD027831

Veselovskii, I., Kolgotin, A., Griaznov, V., Müller, D., Wandinger, U., \& Whiteman, D. N. (2002). Inversion with regularization for the retrieval of tropospheric aerosol parameters from multiwavelength lidar sounding. Applied Optics, 41(18), 36853699.

Veselovskii, I., Kolgotin, A., Griaznov, V., Müller, D., Franke, K., \& Whiteman, D. N. (2004). Inversion of multiwavelength Raman lidar data for retrieval of bimodal aerosol size distribution. Applied Optics, 43(5), 1180-1195.

Veselovskii, I., Dubovik, O., Kolgotin, A., Lapyonok, T., Di Girolamo, P., Summa, D., et al. (2010). Application of randomly oriented spheroids for retrieval of dust particle parameters from multiwavelength lidar measurements. Journal of Geophysical Research: Atmospheres, 115(D21). https://doi.org/10.1029/2010JD014139

Voudouri, K. A., Giannakaki, E., Komppula, M., \& Balis, D. (2019). Variability of cirrus cloud properties using a Polly^|mathrm\{XT\}\$ Raman Lidar over high and tropical latitudes. Atmospheric Chemistry and Physics Discussions, 2019, 126. https://doi.org/10.5194/acp-2019-565

Wagner, R., Ajtai, T., Kandler, K., Lieke, K., Linke, C., Müller, T., et al. (2012). Complex refractive indices of Saharan dust samples at visible and near UV wavelengths: a laboratory study. Atmospheric Chemistry and Physics, 12(5), 2491-2512. https://doi.org/10.5194/acp-12-2491-2012

Wandinger, U, Tesche, M., Seifert, P., Ansmann, A., Müller, D., \& Althausen, D. (2010). Size matters: Influence of multiple scattering on CALIPSO lightextinction profiling in desert dust. Geophysical Research Letters, 37(10). https://doi.org/10.1029/2010GL042815 
Wandinger, Ulla. (1998). Multiple-scattering influence on extinction- and backscattercoefficient measurements with Raman and high-spectral-resolution lidars. Appl. Opt., 37(3), 417-427. https://doi.org/10.1364/AO.37.000417

Wandinger, Ulla. (2005). Introduction to Lidar BT - Lidar: Range-Resolved Optical Remote Sensing of the Atmosphere. In C. Weitkamp (Ed.) (pp. 1-18). New York, NY: Springer New York. https://doi.org/10.1007/0-387-25101-4_1

Wandinger, Ulla, \& Ansmann, A. (2002). Experimental determination of the lidar overlap profile with Raman lidar. Applied Optics, 41(3), 511. https://doi.org/10.1364/AO.41.000511

Wang, X., Boselli, A., Bruscaglioni, P., D’Avino, L., Gambacorta, A., Ismaelli, A., et al. (2004). Evaluation of multiple-scattering influence on lidar measurement by iterative Monte Carlo method. In Proc.SPIE (Vol. 5240). Retrieved from https://doi.org/10.1117/12.514233

Webb, N. P., \& Pierre, C. (2018, February 1). Quantifying Anthropogenic Dust Emissions. Earth's Future. John Wiley and Sons Inc. https://doi.org/10.1002/2017EF000766

Weber, R. W. (2003). Patterns of pollen cross-allergenicity. Journal of Allergy and Clinical Immunology, 112(2), 229-239. https://doi.org/10.1067/mai.2003.1683

Wegener, A. (1912). Thermodynamik der Atmosphäre. Nature, 90(2237), 31. https://doi.org/10.1038/090031a0

Wehbe, Y., Ghebreyesus, D., Temimi, M., Milewski, A., \& Al Mandous, A. (2017). Assessment of the consistency among global precipitation products over the United Arab Emirates. Journal of Hydrology: Regional Studies, 12, 122-135. https://doi.org/10.1016/J.EJRH.2017.05.002

Weiss, U., \& Biber, P. (2011). Plant detection and mapping for agricultural robots using a 3D LIDAR sensor. Robotics and Autonomous Systems, 59(5), 265-273. https://doi.org/10.1016/J.ROBOT.2011.02.011

Weitkamp, C. (2005). Lidar Range-Resolved Optical Remote Sensing of the Atmosphere. Springer, New York, NY. https://doi.org/https://doi.org/10.1007/b106786

Werner, C. (2005). Doppler Wind Lidar. In C. Weitkamp (Ed.), Lidar: Range-Resolved Optical Remote Sensing of the Atmosphere (pp. 325-354). New York, NY: Springer New York. https://doi.org/10.1007/0-387-25101-4_12

Wex, H., Dieckmann, K., Roberts, G. C., Conrath, T., Izaguirre, M. A., Hartmann, S., et al. (2016). Aerosol arriving on the Caribbean island of Barbados: physical properties and origin. Atmospheric Chemistry and Physics, 16(22), 1410714130. https://doi.org/10.5194/acp-16-14107-2016

Whiteman, D N, Melfi, S. H., \& Ferrare, R. A. (1992). Raman lidar system for the measurement of water vapor and aerosols in the Earth's atmosphere. Appl. Opt., 31(16), 3068-3082. https://doi.org/10.1364/AO.31.003068

Whiteman, David N. (2003). Examination of the traditional Raman lidar technique I 
Evaluating the temperature-dependent lidar equations. Applied Optics, 42(15), 2571. https://doi.org/10.1364/ao.42.002571

Wiegner, M., Gasteiger, J., Kandler, K., Weinzierl, B., Rasp, K., Esselborn, M., et al. (2009). Numerical simulations of optical properties of Saharan dust aerosols with emphasis on lidar applications. Tellus B: Chemical and Physical Meteorology, 61(1), 180-194. https://doi.org/10.1111/j.16000889.2008.00381.x

Winker, D. M., Pelon, J., Coakley, J. A., Ackerman, S. A., Charlson, R. J., Colarco, P. R., et al. (2010). The CALIPSO Mission. Bulletin of the American Meteorological Society, 91(9), 1211-1230. https://doi.org/10.1175/2010BAMS3009.1

Wise, M. E., Biskos, G., Martin, S. T., Russell, L. M., \& Buseck, P. R. (2005). Phase Transitions of Single Salt Particles Studied Using a Transmission Electron Microscope with an Environmental Cell. Aerosol Science and Technology, 39(9), 849-856. https://doi.org/10.1080/02786820500295263

Xu, F., Chen, L., Lou, J., \& Ren, M. (2019). A real-time road detection method based on reorganized lidar data. PloS One. https://doi.org/10.1371/journal.pone.0215159

Yorks, J. E., Hlavka, D. L., Hart, W. D., \& McGill, M. J. (2011). Statistics of Cloud Optical Properties from Airborne Lidar Measurements. Journal of Atmospheric and Oceanic Technology, 28(7), 869-883. https://doi.org/10.1175/2011JTECHA1507.1

Yu, Y., Notaro, M., Liu, Z., Wang, F., Alkolibi, F., Fadda, E., \& Bakhrjy, F. (2015). Climatic controls on the interannual to decadal variability in Saudi Arabian dust activity: Toward the development of a seasonal dust prediction model. Journal of Geophysical Research, 120(5), 1739-1758. https://doi.org/10.1002/2014JD022611

Zamora, L. M., Kahn, R. A., Cubison, M. J., Diskin, G. S., Jimenez, J. L., Kondo, Y., et al. (2016). Aircraft-measured indirect cloud effects from biomass burning smoke in the Arctic and subarctic. Atmospheric Chemistry and Physics, 16(2), 715-738. https://doi.org/10.5194/acp-16-715-2016

Zamora, Lauren M., Kahn, R. A., Huebert, K. B., Stohl, A., \& Eckhardt, S. (2018). A satellite-based estimate of combustion aerosol cloud microphysical effects over the Arctic Ocean. Atmospheric Chemistry and Physics, 18(20), 14949-14964. https://doi.org/10.5194/acp-18-14949-2018

Zhang, D., Liu, D., Luo, T., Wang, Z., \& Yin, Y. (2015). Aerosol impacts on cloud thermodynamic phase change over East Asia observed with CALIPSO and CloudSat measurements. Journal of Geophysical Research: Atmospheres, 120(4), 1490-1501. https://doi.org/10.1002/2014JD022630 



\section{Paper I}

Profiling water vapor mixing ratios in Finland by means of a Raman lidar, a satellite and a model.

Filioglou, M., Nikandrova, A., Niemelä, S., Baars, H., Mielonen, T., Leskinen, A., Brus, D., Romakkaniemi, S., Giannakaki, E., and Komppula, M.

Atmospheric Measurement Techniques, 10: 4303-4316, 2017.

Reproduced under the Creative Commons Attribution 4.0 License (CC BY4.0). 


\title{
Profiling water vapor mixing ratios in Finland by means of a Raman lidar, a satellite and a model
}

\author{
Maria Filioglou $^{1}$, Anna Nikandrova ${ }^{2}$, Sami Niemelä $^{3}$, Holger Baars ${ }^{4}$, Tero Mielonen ${ }^{1}$, Ari Leskinen ${ }^{1,5}$, David Brus $^{3}$, \\ Sami Romakkaniemi ${ }^{1}$, Elina Giannakaki ${ }^{1,6}$, and Mika Komppula ${ }^{1}$ \\ ${ }^{1}$ Finnish Meteorological Institute, Atmospheric Research Centre of Eastern Finland, Kuopio, Finland \\ ${ }^{2}$ Department of Physics, University of Helsinki, Helsinki, Finland \\ ${ }^{3}$ Finnish Meteorological Institute, Helsinki, Finland \\ ${ }^{4}$ Leibniz Institute for Tropospheric Research (TROPOS), Leipzig, Germany \\ ${ }^{5}$ Department of Applied Physics, University of Eastern Finland, Kuopio, Finland \\ ${ }^{6}$ Department of Environmental Physics and Meteorology, University of Athens, Athens, Greece
}

Correspondence to: Maria Filioglou (maria.filioglou@ fmi.fi)

Received: 12 June 2017 - Discussion started: 24 July 2017

Revised: 27 September 2017 - Accepted: 5 October 2017 - Published: 10 November 2017

\begin{abstract}
We present tropospheric water vapor profiles measured with a Raman lidar during three field campaigns held in Finland. Co-located radio soundings are available throughout the period for the calibration of the lidar signals. We investigate the possibility of calibrating the lidar water vapor profiles in the absence of co-existing on-site soundings using water vapor profiles from the combined Advanced InfraRed Sounder (AIRS) and the Advanced Microwave Sounding Unit (AMSU) satellite product; the Aire Limitée Adaptation dynamique Développement INternational and High Resolution Limited Area Model (ALADIN/HIRLAM) numerical weather prediction (NWP) system, and the nearest radio sounding station located $100 \mathrm{~km}$ away from the lidar site (only for the permanent location of the lidar). The uncertainties of the calibration factor derived from the soundings, the satellite and the model data are $<2.8,7.4$ and $3.9 \%$, respectively. We also include water vapor mixing ratio intercomparisons between the radio soundings and the various instruments/model for the period of the campaigns. A good agreement is observed for all comparisons with relative errors that do not exceed $50 \%$ up to $8 \mathrm{~km}$ altitude in most cases. A 4year seasonal analysis of vertical water vapor is also presented for the Kuopio site in Finland. During winter months, the air in Kuopio is dry $\left(1.15 \pm 0.40 \mathrm{~g} \mathrm{~kg}^{-1}\right)$; during summer it is wet $\left(5.54 \pm 1.02 \mathrm{~g} \mathrm{~kg}^{-1}\right)$; and at other times, the air is in an intermediate state. These are averaged values over the lowest $2 \mathrm{~km}$ in the atmosphere. Above that height a quick de-
\end{abstract}

crease in water vapor mixing ratios is observed, except during summer months where favorable atmospheric conditions enable higher mixing ratio values at higher altitudes. Lastly, the seasonal change in disagreement between the lidar and the model has been studied. The analysis showed that, on average, the model underestimates water vapor mixing ratios at high altitudes during spring and summer.

\section{Introduction}

The radiative balance between incoming solar radiation and outgoing longwave radiation is the primary regulator of Earth's climate. Changes in atmospheric components, such as aerosols and greenhouse gases which affect the radiative balance, have an impact on climate (McCormic and Ludwig, 1967; Twomey, 1974; Lohmann and Feichter, 2005; Boucher et al., 2013). As the dominant greenhouse gas, water vapor is considered to be the main feedback agent of the atmosphere's state (Held and Soden, 2000; Dessler et al., 2008). As its concentration mostly depends on the air temperature, climate models suggest an amplified initial warming effect in global warming scenarios (Boucher et al., 2013). This important feedback roughly doubles the amount of warming caused by carbon dioxide (Held and Soden, 2000; Soden et al., 2002, 2005). In addition it is also involved in most of the atmospheric processes, such as frontal generation sys- 
tems (Van Baelen et al., 2011), cloud formation, atmospheric mixing, photochemical processes (McCormack et al., 2008) and aerosol hydration (Feingold et al., 2003; Estillore et al., 2016).

The validation of numerical weather forecast and climate models usually falls to the low spatial and temporal resolution of the observational parameters. Unlike other greenhouse gases, water vapor can be highly variable both in space and time, making it hard to simulate. To help address this issue more accurate and nested observational data are needed. Retrievals from space-borne passive sensors can provide some information but their vertical resolution is insufficient given the frequent occurrence of strong vertical gradients.

Based on the measuring technique, water vapor mixing ratios (WVMR) can be separated into two major categories. The first category considers in situ measurements of temperature and relative humidity which can be converted into WVMR. A plethora of weather stations provide groundbased WVMR over the globe. Nevertheless, such measurements are not representative for the whole atmosphere since their spatial availability is poor over remote areas (e.g., over oceans) and no vertical information is provided. Vertical mixing ratio profiles with high accuracy are delivered by means of radiosondes. Radiosondes (RSs) are a common and reliable in situ technique but they also lack temporal and spatial coverage as the number of sites is rather low and most of them perform very few soundings per day. Furthermore, the wind-driven drifting of the device can be misleading in terms of geographical location of the vertical information. In contrast, remote sensing techniques such as microwave radiometers (England et al., 1992; Reagan et al., 1995), differential absorption lidars (DIALs) (Bösenberg, 1998), photometers (Barreto et al., 2013) and Raman lidars (Whiteman et al., 1992; Ferrare et al., 1995; Turner et al., 2002; Whiteman, 2003; Leblanc et al., 2012; Navas-Guzmán et al., 2014; Foth et al., 2015) have been successfully adopted in water vapor studies. While microwave radiometers and photometers can accurately deliver the total precipitable water vapor (TPW), lidars (DIAL and Raman) are the only instruments available for high temporal and vertical resolution of continuous WVMR measurements. DIALs are able to provide accurate high-resolution profiles of water vapor, but their complex laser transmitter setup makes their WVMR automatization a difficult task. Raman lidars use a simpler setup than DIALs, although the majority of them are limited to nighttime performance due to collection of the intense daytime background light by the weak Raman-shifted channels. Nonetheless, Foth et al. (2017) proposed a methodology to retrieve water vapor mixing ratios during daytime by using a microwave radiometer and the Raman lidar profiles.

In the present paper, we calibrate Raman lidar WVMR profiles using in situ, satellite and model data. We have used RSs, retrievals from AIRS/AMSU instruments on board of Aqua satellite (Parkinson, 2003) and modeled WVMR from
ALADIN/HIRLAM NWP model (Seity et al., 2011; Bengtsson et al., 2017). Our dataset concentrates on three field campaigns conducted during 2014 and 2015. Within this time frame, 723 radio soundings were performed in total, but not all of them were suitable for direct comparison with the lidar due to the daytime limitation or occurrence of lowlevel clouds. Furthermore, we derive the seasonal variation of WVMR at Kuopio site where the lidar instrument is permanently located, both from the lidar and model, thereby validating the accuracy of the model and the capabilities of the lidar under the demanding low-water-content conditions of Finland.

The outline of the paper is as follows. First, we give a short description of the instruments/model (Sect. 2) followed by the methodology used to calculate/extract the WVMR profiles from the various sources (Sect. 3). An overview of the existing calibration methods for the lidar is also given in Sect. 3. The calibration factors from the various reference instruments are calculated in Sect. 4. Section 4 also includes comparisons between the RSs and the various instruments and the model, under cloud-free conditions. Furthermore, Sect. 5 presents the seasonal variability of the WVMR at the Kuopio site in Finland and the seasonal discrepancies between the lidar and the model based on a 4-year period of lidar and model data. Our summary and concluding remarks are given in Sect. 6.

\section{Instrumentation}

The site locations where the three field campaigns took place cover Finland from the southwest to the north: Hyytiälä $\left(61.84^{\circ} \mathrm{N}, 24.29^{\circ} \mathrm{E}\right.$; $179 \mathrm{~m}$ a.s.l.) from 1 April to 29 September 2014, Kuopio $\left(62.73^{\circ} \mathrm{N}, 27.54^{\circ} \mathrm{E}\right.$; $190 \mathrm{~m}$ a.s.l.) from 11 to 29 May 2015 , and Pallas $\left(67.99^{\circ} \mathrm{N}, 24.24^{\circ} \mathrm{E}\right.$; $345 \mathrm{~m}$ a.s.1.) from 22 September to 5 December 2015. Further information on the site locations and available instrumentation can be found in Hatakka et al. (2003) and Hirsikko et al. (2014).

\subsection{Remote sensing data}

\subsubsection{The Polly ${ }^{\mathrm{XT}}$-FMI}

The lidar data were obtained with the fully automated and portable multi-wavelength Raman lidar Polly ${ }^{\mathrm{XT}}$ (Althausen et al., 2009; Engelmann et al., 2016) operated by the Finnish Meteorological Institute (FMI). The system is a Raman polarization lidar with water vapor capabilities. The detection is performed at the three emitted elastic wavelengths $(355,532$ and $1064 \mathrm{~nm}$ ) and the three inelastic Raman-shifted wavelengths $(387,407$ and $607 \mathrm{~nm})$. Information on the polarization of the signal is available at $532 \mathrm{~nm}$ - cross-polarization with respect to the initial emitted polarization plane. The biaxial system attains full overlap at $800-900 \mathrm{~m}$ (Engelmann et al., 2016). Below that height, signals are corrected with an overlap function introduced in Wandinger and Ans- 
mann (2002). The instrument operates with a spatial resolution of $30 \mathrm{~m}$ and a temporal resolution of $30 \mathrm{~s}$. Near-real-time measurements are visualized through the lidar network PollyNET (Althausen et al., 2013; Baars et al., 2016) and can be accessed at http://polly.tropos.de/.

\subsubsection{Satellite data - AIRS/AMSU}

Both AIRS (Aumann et al., 2003) and AMSU are instruments on board the Aqua satellite (Parkinson, 2003). AIRS is a thermal IR grating spectrometer which allows measurements of temperature and humidity as a function of altitude. It has 2378 detectors in four wavelength bands: 3.74 , $4.61,6.20$ to $8.22 \mu \mathrm{m}$, and 8.80 to $15.40 \mu \mathrm{m}$. AMSU is a $15-$ channel microwave sounder providing temperature and humidity information along the track. In this study, we used the combined level two (L2) version 6 support products (AIRS + AMSU) (AIRS Science Team, 2013; Manning et al., 2012) provided publicly by NASA (http://disc.sci.gsfc. nasa.gov/uui/datasets?keywords $=\% 22$ AIRS $\% 22$ ) to surpass the limitation of AIRS and deliver usable water vapor profiles under cloudy conditions. Hearty et al. (2014) report on instrumental biases of AIRS/AMSU concluding to up to $2 \mathrm{~K}$ for the temperature measurements and $10 \%$ wet for the water vapor, where the bias is largest within the boundary layer. A detailed description of the uncertainties in the retrievals can be found in Hearty et al. (2014) and the AIRS version 6 performance and test report. The combined AIRS/AMSU product is reported in a $50 \mathrm{~km}$ spatial resolution at nadir and covers 100 vertical pressure levels.

\subsection{In situ data - radiosondes}

During the intensive campaign periods 630, 66 and 27 radio soundings were performed at the Hyytiälä, Kuopio and Pallas sites, respectively. For the Hyytiälä campaign soundings were performed four times a day at 05:20, 11:20, 17:20 and 23:20 UTC. During the Kuopio campaign, RSs were performed 3 times a day at 13:00, 19:30 and 22:00 UTC, increasing their launching frequency during the last two days of the campaign. Lastly, during the Pallas campaign the soundings were performed less frequently and in a non-standardized way in terms of time, focusing on special events. In the first two campaigns the RS was launched from a location not more than $100 \mathrm{~m}$ away from the lidar whereas in Pallas the launching site was $5 \mathrm{~km}$ away from the lidar site. The radiosondes used are of Vaisala type RS41 (Kuopio) and RS92 (Hyytiälä and Pallas). RS data from Jyväskylä airport (RS92), the nearest RS station located about $100 \mathrm{~km}$ away from Kuopio, were also used in this study. For temperature and relative humidity measurements, RS41 has associated instrumental uncertainties of $0.3^{\circ} \mathrm{C}$ and $4 \%$ in the first $16 \mathrm{~km}$ in the atmosphere, respectively. According to the manufacturer's specifications, the difference between RS41 and RS91 are within $0.1^{\circ} \mathrm{C}$ and $2 \%$ for the same height range.

\subsection{Model data - ALADIN/HIRLAM NWP system}

The ALADIN-HIRLAM cooperation is an international effort of 26 countries (mainly from Europe) to develop a mesoscale weather forecasting system. One configuration of the common ALADIN/HIRLAM NWP system, HARMONIE/AROME (Bengtsson et al., 2017), has been used operationally at FMI since 2006. HARMONIE/AROME is a non-hydrostatic model based on fully compressible Euler equations, where the time integration of the equation set is handled with a two-time-level semi-implicit semiLagrangian advection scheme. The model's physical parameterization package includes treatment of sub-grid scale processes related to cloud microphysics, turbulence, radiation transfer, shallow convection, surface and soil. All the parameterization schemes are described in detail by Bengtsson et al. (2017) and Seity et al. (2011).

In this study we have used data from FMI's operational HARMONIE/AROME setup. During the study period, two development versions of the model have been in use: (i) cy38h1.1 (January 2014 to March 2015; Niemelä, 2015) and (ii) cy38h1.2 (March 2015 onwards). The main difference between these two versions is related to cloud processes, where the fast liquid water process is rigorously separated from slower ice water process in cy38h1.2 (Ivarsson, 2015). The new model version has maximum WVMR bias up to $<0.12 \mathrm{~g} \mathrm{~kg}^{-1}$ compared to the older version where biases up to $0.20 \mathrm{~g} \mathrm{~kg}^{-1}$ were observed in the first $4 \mathrm{~km}$ in the atmosphere. The horizontal grid size is $2.5 \mathrm{~km} \times 2.5 \mathrm{~km}$ with 65 levels in vertical. In both versions, 49 vertical levels are located within the lowest $8 \mathrm{~km}$. The model is initialized every $3 \mathrm{~h}$ by using three-dimensional variational algorithm (3DVar) with conventional observations from TEMP (upper air soundings), SYNOP (surface synoptic observations), AMDAR (aircraft meteorological data relay), SHIP (ship synoptic code) and DRIBU (drifting buoys).

The hourly profiles of specific humidity, temperature and pressure were extracted from the model data for the locations: Hyytiälä, Kuopio and Pallas sites. The dataset included short forecasts $(+3 \mathrm{~h}$ to $+8 \mathrm{~h}$ ) from subsequent model runs initiated at 00:00, 06:00, 12:00 and 18:00 UTC. The data were interpolated bilinearly in the horizontal, whereas full resolution was used in the vertical.

\section{Methodology}

The WVMR is defined as the ratio of the mass of water vapor to the mass of dry air in a given volume, calculated as

$w(r)=\frac{\mathrm{MW}_{\mathrm{H}_{2} \mathrm{O}}}{\mathrm{MW}_{\text {DryAir }}} \frac{N_{\mathrm{H}_{2} \mathrm{O}}(r)}{N_{\text {DryAir }}(r)} \sim 0.78 \frac{\mathrm{MW}_{\mathrm{H}_{2} \mathrm{O}}}{\mathrm{MW}_{\text {DryAir }}} \frac{N_{\mathrm{H}_{2} \mathrm{O}}(r)}{N_{\mathrm{N}_{2}}(r)}$,

where $\mathrm{MW}_{\text {DryAir }}$ and $\mathrm{MW}_{\mathrm{N}_{2}}$ are the molecular weights of water vapor and nitrogen. $N_{\mathrm{H}_{2} \mathrm{O}}(r), N_{\mathrm{N}_{2}}(r)$ and $N_{\text {DryAir }}(r)$ denote the molecular number densities of the two atmospheric gases and dry air at altitude $r$. The 0.78 value stands 
for the fractional volume of nitrogen in the atmosphere. The latter expression is utilized in the water vapor Raman lidar technique, and is proportional to the water vapor mixing ratio.

\subsection{WVMR profiles from Raman lidar signals}

The Raman lidar WVMR technique has been extensively discussed in the literature (e.g., Whiteman, 2003). The approach is based on collecting the vibrational Raman backscattered signals from water vapor at $407 \mathrm{~nm}$ and nitrogen molecules at $387 \mathrm{~nm}$, both excited from $355 \mathrm{~nm}$ wavelength light. We calculate the WVMR from the lidar signals as

$w(r)=$

$K \frac{P\left(r, \lambda_{\mathrm{H}_{2} \mathrm{O}}\right)}{P\left(r, \lambda_{\mathrm{N}_{2}}\right)} \exp \left(\int_{0}^{r}\left[\alpha\left(r^{\prime}, \lambda_{\mathrm{H}_{2} \mathrm{O}}\right)-\alpha\left(r^{\prime}, \lambda_{\mathrm{N}_{2}}\right)\right] \mathrm{d} r^{\prime}\right)$,

where $P\left(r, \lambda_{\mathrm{N}_{2} / \mathrm{H}_{2} \mathrm{O}}\right)$ is the measured range-dependent backscatter signal, $K$ is the lidar system calibration factor

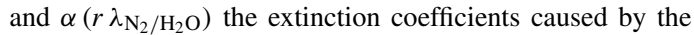
two gases. The exponential component accounts for the dif-

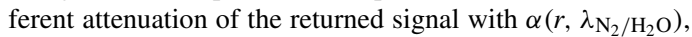
including both the molecular and the particle contribution. In this paper the particle extinction contribution is neglected as the resulting error is less than $1.3 \%$ at $2 \mathrm{~km}$ altitude as calculated by Foth et al. (2015). Whiteman (2003) concluded that such assumption can introduce an error of approximately $2 \%$ for every 0.5 of aerosol optical depth change below $2 \mathrm{~km}$ altitude. The lidar system calibration factor $(K)$ includes the range-independent lidar constants for the two Raman-shifted wavelengths, the Raman backscatter cross sections of $\mathrm{N}_{2}$ and $\mathrm{H}_{2} \mathrm{O}$, the ratio of the molecular masses and the fractional volume of nitrogen (0.78). For the calculation of the molecular density, a priori knowledge of vertical profiles of temperature and pressure are needed. We have calculated all lidar-derived WVMR using information provided by the radiosondes. The use of different input data, such as from the satellite or the model, can introduce $<0.10$ and $<0.32 \%$ maximum averaged discrepancies valid for the whole atmospheric column up to $8 \mathrm{~km}$ compared to that of the RS, respectively.

\subsection{Lidar water vapor calibration methods}

The calibration factor can be derived in two different ways. The first requires precise knowledge of the ratio of the lidar channel transmission coefficients and the Raman cross sections for the two active channels. Previous studies using this approach (Vaughan et al., 1988; Leblanc et al., 2012) computed the calibration constant with a 10-12\% accuracy. The second approach determines the calibration factor using simultaneous measurements from a collocated reference instrument. Approaches on this second technique include water vapor comparisons with radiosondes, satellites and microwave radiometers (Ferrare et al., 1995; Mattis et al., 2002;
Miloshevich et al., 2004; Madonna et al., 2011; Leblanc et al., 2012; Reichardt et al., 2012; Navas-Guzmán et al., 2014; Foth et al., 2015). The accuracy of the calibration factor derived using these techniques fluctuates between 5 and $10 \%$. Since it is rather challenging to decrease the uncertainties in the Raman cross-section calculations and define the optical transmission characteristics, we adopted the second approach.

There are several methods to calculate the calibration factor with this second approach. The principle of the first method is to perform a linear regression between the uncalibrated WVMR lidar signal and the known WVMR from the RS or any other reference instrument (England et al., 1992). The calculated slope is the unknown calibration factor (regression method). In general, a set of such comparisons is performed to increase the statistical significance of the derived factor. However, small changes in the lidar setup such as change of neutral density filters requires the calculation of a new factor. A second method falling into the same calibration category is to take into account the simultaneous total precipitate water (TPW) from a microwave radiometer (Madonna et al., 2011; Foth et al., 2015) or any other instrument capable of delivering an equivalent information. By integrating the lidar's WVMR profiles, the two quantities become comparable and it is then possible to compute the calibration factor. Lastly, the profile method (Reichardt et al., 2012) estimates the calibration factor by matching the mixing ratio profiles from the lidar and the reference instrument in a certain height range. The factor fulfilling this requirement is the optimum one. In this study we used the regression method since it is the method introducing the best accuracy and can be applicable in most days assuming that the calibration area is cloud-free.

\section{Lidar calibration}

For the calibration of the lidar signal, cloud-free nighttime atmosphere is considered. The lidar data were averaged over 30 min centered on the RS launch time. The RS vertical resolution was interpolated to the lidar's grid, where a $90 \mathrm{~m}$ unweighted sliding average was applied to smooth the signal. Only lidar signals between 0.5 and $3.5 \mathrm{~km}$ were retained for the calibration. This height limitation was used to minimize the inaccuracies in the WVMR values due to possibly different overlaps between the channels used for the water vapor calculation (see Sect. 4.1) and major drifts in the RS at higher altitudes. In unstable atmospheric conditions these two could result in measuring very different atmospheric layers showing temporal and spatial mismatching (Brocard et al., 2013) (see also Sect. 4.1). However, the upper height limit was lowered from $3.5 \mathrm{~km}$ when lidar signal-to-noise ratio (SNR) values were lower than 2 . For the satellite data we performed a trajectory analysis, forward or backward depending on the overpass and the RS launch time, for each of the satellite 
footprints selecting the profile whose trajectory endpoint was closest to the site. This method was used because it produced better agreement between the satellite data and the radio soundings than the usage of the closest satellite pixel to the site. The trajectory analysis was performed using the HYSPLIT model (HYbrid Single Particle Lagrangian Integrated Trajectory; Draxler and Hess, 1998; Stein et al., 2015). Satellite data marked with quality assurance flag 2 are omitted (AIRS version 6, level 2; Kahn et al., 2012) while the maximum overpass difference between the on-site RS and the satellite was set to $6 \mathrm{~h}$. For NWP model data the profile closest in time was used. In each campaign model's grid box was centered on the lidar site. A fixed intercept of 0 was used in the regression analysis in order not to introduce positive WVMR at heights where none should exist.

An example case (23 May 2015) demonstrating the calibration method with all the available reference instruments and the model is shown in Fig. 1. The satellite overpass is from 00:28 UTC on 24 May 2015. The closest satellite footprint was $14 \mathrm{~km}$ away from the site (white dot) and the selected WVMR for this case was based on the trajectory analysis which originated at the green dot shown in Fig. 1a. Figure $1 \mathrm{~b}$ shows the range corrected signals at $1064 \mathrm{~nm}$ along with the RS launch times marked as vertical red lines. The RS was launched at 22:00 UTC, and averaged lidar signals between 21:45 and 22:15 UTC were used (white rectangle). Applying the slope method, we obtained calibration factors of $17.87 \pm 0.17,17.43 \pm 0.13$ and $17.44 \pm 0.16 \mathrm{~g} \mathrm{~kg}^{-1}$ for RS, AIRS/AMSU and ALADIN/HIRLAM, respectively (Fig. 1c). The uncertainty reported here indicates the standard error of the slope.

From the 630 soundings in Hyytiälä, 66 in Kuopio and 27 in Pallas, 23, 10 and 5 RSs are suitable for the calibration procedure based on background light and cloud conditions. Due to the high geographical latitude and the time of the campaigns in Hyytiälä and Kuopio (between May and September), Finland's background sky light is too intense for this technique to retrieve water vapor profiles from lidar observations. For example, over the 18-day campaign in Kuopio, daytime increased by $2 \mathrm{~h}$. For all suitable aforementioned calibration cases factors from the various instruments/model were calculated and are summarized in Table 1 for Hyytiälä and Pallas and in Table 2 for Kuopio. The overall calibration factor computed has an associated uncertainty of $<1 \%$ for the RS launched on site and $2.8 \%$ for the nearest RS (only for Kuopio) corresponding to a mean factor of $17.46 \pm 0.13$ and $16.94 \pm 0.48 \mathrm{~g} \mathrm{~kg}^{-1}$, respectively. The uncertainty for the satellite and the model fluctuated at 7.4 and $3.9 \%$ with a mean factor of $18.53 \pm 1.37$ and $17.78 \pm 0.69 \mathrm{~g} \mathrm{~kg}^{-1}$, respectively. These accuracies comply with previous observational studies (Ferrare et al., 1995; Navas-Guzmán et al., 2011) yet we are aware of none publications regarding the calibration of lidar WVMR signals with the use of a model. We observe that the satellite-derived calibration factor diverges from the RS-derived one by about $6 \%$. This deviation is in- terpreted, depending on the water vapor amount, to as high as $0.4 \mathrm{~g} \mathrm{~kg}^{-1}$ offset for mixing ratios of about 8 and $0.1 \mathrm{~g} \mathrm{~kg}^{-1}$ offset for drier conditions when calibrating with the satellite. Such bias can have a large impact, for example in changing environments such as the tropopause, where the radiative forcing of surface climate is being calculated (Leblanc et al., 2012; Müller et al., 2016).

It can be seen in Tables 1 and 2 that there are a couple of cases where the satellite or/and the model have underestimated/overestimated the mixing ratios - hence the calibration factor. Consequently, individual cases can have a large effect on the calculated calibration factor. A more robust factor was retrieved by applying the regression method to all cases together (Fig. 2). Discrepancies are much lower when using this method as all techniques converge to the value calculated with the on-site RS, which is presumably the closest one to the true factor. If available, we suggest using this technique when calibrating lidar WVMR signals. We should mention here that the calculation of an overall factor is possible since in all three campaigns the lidar setup had the same configuration for the channels relating to water vapor.

\subsection{Intercomparisons}

A statistical analysis between on-site RS and the rest (lidar, satellite, model and nearest RS) is presented here by calculating absolute and relative differences from the on-site RS (Fig. 3a-h). Cases during daytime are excluded when RS profiles are compared with the lidar. For the satellite comparisons, a suitable WVMR profile was selected based on the trajectory analysis. For the ALADIN/HIRLAM comparisons, the profile from the time point closest to the RS launch time was selected. All cases presented here are cloud cleared. Furthermore, the RS from Jyväskylä airport at 18:00 UTC is compared with the on-site RS during the Kuopio campaign to evaluate the nearest available RS. For the lidar data, a 90, 270 and $390 \mathrm{~m}$ vertical smoothing is considered up to $3 \mathrm{~km}$, 3 to $5 \mathrm{~km}$ and above $5 \mathrm{~km}$, respectively, while signals with SNR less than 2 are discarded.

Absolute deviations between the RS and Polly XT observations are below $0.2 \mathrm{~g} \mathrm{~kg}^{-1}$ at altitudes above $0.5 \mathrm{~km}$ (Fig. 3a). The largest absolute discrepancies are observed in the lowermost part of the atmosphere between the surface and $0.5 \mathrm{~km}$. Although in relative error terms these discrepancies are not of major importance, they show possible instrumental limitations which result from the optical alignment region of the water-vapor-related channels which are focussing on the far range. For the seasonal analysis (see Sect. 5), we assumed well mixed conditions for the first $0.5 \mathrm{~km}$ keeping a constant value down to surface. We have also found that there is a better agreement between the lidar and the RS in the first $4 \mathrm{~km}$. Above that the relative error is bigger which is mainly attributed to a combination of low water vapor content and drifting of the RS device (Brocard et al., 2013). In all cases the relative error stayed well below $35 \%$ (Fig. 3b). 

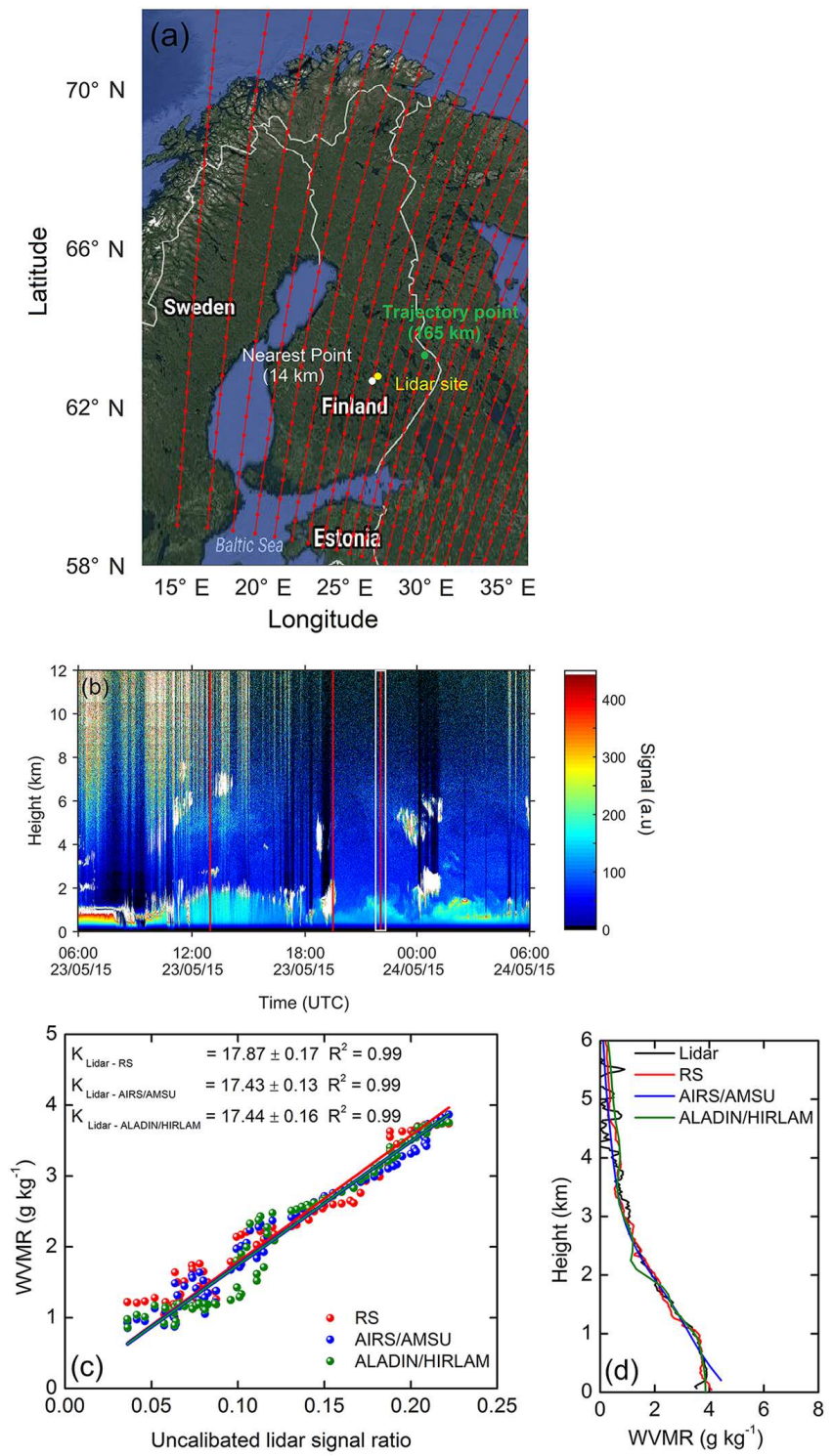

Figure 1. (a) Aqua overpass on 23 May 2015. The red dotted lines indicate the flight pattern in the area of interest. The nearest grid point ( $14 \mathrm{~km}$ away from the lidar site) and the selected point (165 km away from the lidar site) at 00:28 UTC are marked with white and green dots, respectively while the lidar site location is marked with a yellow dot. (b) Range-corrected lidar signals at $1064 \mathrm{~nm}$ wavelength between 06:00 UTC on 23 and 06:00 UTC on 24 May 2015. The radio soundings performed throughout this period are marked with red lines while the white rectangle shows the period over which the lidar signal is averaged. The night RS at 22:00 UTC is considered for this case. (c) Linear regression between the uncalibrated lidar signal ratio and the WVMR from the RS (red), AIRS-AMSU (blue) and ALADIN/HIRLAM (green). The calibration factor K and the standard error of the slope are reported. The ALADIN/HIRLAM WV profile at 22:00 UTC 23 May 2014 was chosen. (d) Respective lidar-calibrated water vapor mixing ratios (black), RS (red), AIRS/AMSU (blue) and ALADIN/HIRLAM (green) for the same day. 
Table 1. Lidar calibration factors and errors derived from RS, satellite and model data during Hyytiälä and Pallas campaign. For satellite overpasses the distance between the lidar site and the selected footprint along with the time difference from the RS launch time is available. Sunrise/sunset times are also shown.

\begin{tabular}{|c|c|c|c|c|c|c|c|}
\hline \multirow[b]{2}{*}{$\begin{array}{l}\text { Date/time of RS } \\
\text { on site (UTC) }\end{array}$} & \multirow[b]{2}{*}{$\begin{array}{l}\text { Sunset } \\
\text { (UTC) }\end{array}$} & \multirow[b]{2}{*}{$\begin{array}{r}\text { Sunrise } \\
\text { (UTC) }\end{array}$} & \multicolumn{5}{|c|}{ Calibration factors } \\
\hline & & & $\begin{array}{r}\text { RS } \\
\text { on site }\end{array}$ & Model & Satellite & $\begin{array}{r}\text { Time difference } \\
\text { in satellite } \\
\text { overpass }(\mathrm{h})\end{array}$ & $\begin{array}{r}\text { Satellite selected } \\
\text { overpass distance } \\
\text { from site }(\mathrm{km})\end{array}$ \\
\hline \multicolumn{8}{|c|}{ Hyytiälä campaign } \\
\hline 1 Apr 2014 23:17 & $17: 08$ & $03: 43^{+}$ & $17.43 \pm 0.07$ & $17.01 \pm 0.29$ & $19.80 \pm 1.93$ & 2 & 136.2 \\
\hline 2 Apr 2014 23:18 & $17: 11$ & $03: 40^{+}$ & $17.14 \pm 0.05$ & $18.08 \pm 0.47$ & $18.16 \pm 0.80$ & 3 & 75.7 \\
\hline 3 Apr $201423: 25$ & $17: 14$ & $03: 37^{+}$ & $16.71 \pm 0.12$ & $18.76 \pm 0.60$ & $15.38 \pm 1.22$ & 2 & 92.6 \\
\hline 4 Apr 2014 23:19 & $17: 16$ & $03: 33^{+}$ & $17.14 \pm 0.09$ & $16.75 \pm 0.74$ & $28.25 \pm 2.82$ & 2.5 & 122.5 \\
\hline 8 Apr 2014 23:22 & $17: 27$ & $03: 20^{+}$ & $16.59 \pm 0.08$ & $17.95 \pm 0.73$ & $24.86 \pm 1.66$ & 2 & 31.4 \\
\hline 9 Apr 201423.20 & $17: 30$ & $03: 17^{+}$ & $16.67 \pm 0.10$ & $20.95 \pm 1.04$ & $26.99 \pm 1.48$ & 1 & 51.1 \\
\hline 15 Apr 2014 23:30 & $17: 46$ & $02: 58^{+}$ & $17.94 \pm 0.09$ & $23.58 \pm 1.27$ & $20.31 \pm 0.57$ & 2 & 22.4 \\
\hline 22 Apr 2014 23:22 & 18:05 & $02: 36^{+}$ & $17.68 \pm 0.13$ & $15.61 \pm 1.20$ & $23.90 \pm 1.32$ & 2.5 & 158.4 \\
\hline 23 Apr 2014 23:22 & $18: 08$ & $02: 33^{+}$ & $17.53 \pm 0.14$ & $21.57 \pm 0.92$ & $25.91 \pm 3.13$ & 1.5 & 53.3 \\
\hline 24 Apr 2014 23:24 & $18: 10$ & $02: 30^{+}$ & $17.64 \pm 0.14$ & $10.35 \pm 0.83$ & $19.37 \pm 0.96$ & 0.5 & 86.2 \\
\hline 25 Apr 2014 23:21 & $18: 13$ & $02: 27^{+}$ & $17.91 \pm 0.11$ & $31.76 \pm 0.45$ & $17.31 \pm 0.72$ & 1 & 55.6 \\
\hline 26 Apr 2014 23:22 & $18: 16$ & $02: 24^{+}$ & $17.66 \pm 0.12$ & $18.94 \pm 1.94$ & $19.22 \pm 0.98$ & 2 & 32.0 \\
\hline 27 Apr 2014 23:18 & $18: 19$ & $02: 21^{+}$ & $17.47 \pm 0.09$ & $17.38 \pm 0.41$ & $17.66 \pm 0.81$ & 1 & 65.9 \\
\hline 29 Apr 2014 23:21 & $18: 24$ & $02: 14^{+}$ & $17.40 \pm 0.08$ & $17.51 \pm 0.34$ & $17.12 \pm 0.75$ & 1 & 89.2 \\
\hline 1 May 2014 23:27 & $18: 30$ & $02: 09^{+}$ & $17.06 \pm 0.11$ & $17.14 \pm 0.30$ & $18.60 \pm 0.90$ & 2 & 99.1 \\
\hline 2 May 2014 23:22 & $18: 33$ & $02: 06^{+}$ & $17.40 \pm 0.16$ & $21.46 \pm 0.75$ & $18.76 \pm 0.82$ & 1 & 22.2 \\
\hline 12 May 2014 23:25 & $19: 00$ & $01: 37^{+}$ & $17.74 \pm 0.07$ & $16.31 \pm 0.21$ & $17.76 \pm 0.33$ & 1 & 16.9 \\
\hline 14 May 2014 23:21 & $19: 06$ & $01: 32^{+}$ & $17.23 \pm 0.11$ & $15.98 \pm 1.14$ & $25.20 \pm 1.50$ & 1.5 & 65.9 \\
\hline 20 May 2014 23:20 & $19: 22$ & $01: 16^{+}$ & $17.65 \pm 0.06$ & $17.06 \pm 0.10$ & $17.19 \pm 0.41$ & 1 & 89.4 \\
\hline 22 May 2014 23:19 & $19: 27$ & $01: 12^{+}$ & $17.91 \pm 0.10$ & $18.22 \pm 1.78$ & $20.23 \pm 0.48$ & 2.5 & 126.1 \\
\hline 14 Jun 2014 23:20 & $20: 11$ & $00: 36^{+}$ & $17.51 \pm 0.41$ & $17.74 \pm 0.99$ & $18.41 \pm 0.90$ & 2.5 & 78.6 \\
\hline 4 Aug 2014 23:26 & 19:01 & $02: 01^{+}$ & $17.81 \pm 0.15$ & $14.55 \pm 1.54$ & $17.15 \pm 1.62$ & 1.5 & 40.2 \\
\hline \multicolumn{8}{|c|}{ Pallas campaign } \\
\hline 2 Dec 2015 14:31 & $11: 25$ & 09:03 & $16.96 \pm 0.14$ & $16.55 \pm 0.29$ & $12.52 \pm 0.65$ & 4.5 & 117.6 \\
\hline 2 Dec 2015 18:49 & $11: 25$ & 09:03 & $18.85 \pm 0.19$ & $16.49 \pm 0.13$ & $19.46 \pm 0.05$ & 6 & 238.6 \\
\hline 3 Dec 2015 17:12 & $11: 20$ & $09: 10$ & $16.91 \pm 0.14$ & $16.92 \pm 0.30$ & - & - & - \\
\hline 4 Dec 2015 13:54 & $11: 14$ & $09: 16$ & $16.93 \pm 0.13$ & $16.16 \pm 1.08$ & $18.30 \pm 0.83$ & 4 & 226.2 \\
\hline 4 Dec 2015 18:19 & $11: 14$ & $09: 16$ & $17.58 \pm 0.13$ & $17.96 \pm 0.51$ & $17.73 \pm 1.15$ & 6 & 224.2 \\
\hline
\end{tabular}

+ Plus 1 day.

The comparison between RS and satellite observations is shown in Fig. 3c and d. While absolute deviations are well below $0.85 \mathrm{~g} \mathrm{~kg}^{-1}$, relative fluctuations of up to $200 \%$ were observed. These large relative values are most likely caused by the larger spatial resolution in satellite data compared to that of RS measurements. On top of that, the sparser vertical resolution in satellite data cannot accurately attribute the geometrical boundaries of the layers as seen by the lidar. Accounting for these two factors, in the presence of strong vertical gradients one should expect WVMR inconsistencies between these two instruments. Mamouri et al. (2008) found that the differences between the lidar and the satellite are larger between 1.0 and $5.0 \mathrm{~km}$, a feature which we have also observed. This behavior is most likely the effect of the geometrical boundaries of the water vapor layers which cannot be precisely defined in the satellite. We should note here that the trajectory analysis for the overpass selection introduces smaller deviations when comparing with the RS and/or the lidar, and should be preferred over the closest overpass when there is sufficient time difference. However, since orographic lifts can modify air mass properties it should be used with care.

The relative difference between RS and the model is less than $36 \%$ for the lowest $2 \mathrm{~km}$ (Fig. $3 \mathrm{e}$ and f). Above $2.5 \mathrm{~km}$, deviations of up to $55 \%$ were found. There is a constant positive bias above $5 \mathrm{~km}$ between the model and RS during the Hyytiälä campaign, which is not present in the other two campaigns, indicating a possible model-version dependence, as an older model version is used for the Hyytiälä campaign. Averaged specific humidity biases over Scandinavia showed 
Table 2. Lidar calibration factors and errors derived from RS, model and satellite data during Kuopio campaign. Calibration factors from the nearest radio sounding site located in Jyväskylä airport $(\sim 100 \mathrm{~km}$ away) are also shown. For satellite overpasses the distance between the lidar site and the selected footprint along with the time difference from the RS launch time is available. Note: the same satellite overpass has been used on 27 May 2015, where multiple RSs were launched in a $1 \mathrm{~h}$ interval.

\begin{tabular}{|c|c|c|c|c|c|c|c|c|}
\hline \multirow[b]{2}{*}{$\begin{array}{l}\text { Date/time of RS } \\
\text { on site (UTC) }\end{array}$} & \multirow[b]{2}{*}{$\begin{array}{l}\text { Sunset } \\
\text { (UTC) }\end{array}$} & \multirow[b]{2}{*}{$\begin{array}{r}\text { Sunrise }^{+} \\
\text {(UTC) }\end{array}$} & \multicolumn{6}{|c|}{ Calibration factors } \\
\hline & & & $\begin{array}{r}\text { RS } \\
\text { on site }\end{array}$ & $\begin{array}{r}\text { RS } \\
\text { Jyväskylä } \\
(18: 00 \text { UTC })\end{array}$ & Model & Satellite & $\begin{array}{r}\text { Time difference } \\
\text { in satellite } \\
\text { overpass (h) }\end{array}$ & $\begin{array}{r}\text { Satellite selected } \\
\text { overpass distance } \\
\text { from site }(\mathrm{km})\end{array}$ \\
\hline \multicolumn{9}{|c|}{ Kuopio campaign } \\
\hline 15 May 2015 22:00 & $19: 04$ & 01:09 & $17.53 \pm 0.13$ & $16.47 \pm 0.19$ & $18.13 \pm 0.31$ & $17.41 \pm 0.57$ & 3 & 64.5 \\
\hline 20 May 2015 21:59 & $19: 19$ & $00: 55$ & $17.70 \pm 0.12$ & $18.74 \pm 0.41$ & $19.32 \pm 0.46$ & $16.54 \pm 0.89$ & 2 & 165.0 \\
\hline 21 May 2015 21:58 & $19: 22$ & $00: 52$ & $17.99 \pm 0.10$ & $19.03 \pm 0.34$ & $17.04 \pm 0.45$ & $17.38 \pm 0.71$ & 3 & 114.9 \\
\hline 22 May 2015 22:01 & $19: 24$ & $00: 50$ & $17.04 \pm 0.22$ & $16.08 \pm 0.89$ & $17.13 \pm 0.54$ & $19.77 \pm 0.69$ & 2 & 114.3 \\
\hline 23 May 2015 22:00 & $19: 27$ & $00: 47$ & $17.87 \pm 0.17$ & $16.94 \pm 0.35$ & $17.44 \pm 0.13$ & $17.43 \pm 0.16$ & 2.5 & 164.7 \\
\hline 25 May 2015 22:15 & $19: 33$ & $00: 42$ & $17.38 \pm 0.13$ & $17.18 \pm 0.92$ & $17.73 \pm 0.31$ & $17.76 \pm 0.93$ & 4 & 131.5 \\
\hline 27 May 2015 21:10 & $19: 38$ & $00: 37$ & $17.53 \pm 0.08$ & $17.23 \pm 0.34$ & $17.49 \pm 0.10$ & $15.08 \pm 0.70$ & 3 & 48.4 \\
\hline 27 May 2015 22:08 & $19: 38$ & $00: 37$ & $17.58 \pm 0.09$ & $16.39 \pm 0.15$ & $16.87 \pm 0.29$ & $14.15 \pm 0.77$ & 2 & 48.4 \\
\hline 27 May 2015 23:13 & $19: 38$ & $00: 37$ & $17.52 \pm 0.07$ & $16.43 \pm 0.17$ & $17.27 \pm 0.13$ & $14.19 \pm 0.72$ & 1 & 48.4 \\
\hline 28 May 2015 22:03 & $19: 41$ & $00: 34$ & $17.42 \pm 0.09$ & $14.92 \pm 0.19$ & $16.34 \pm 0.59$ & $21.42 \pm 1.36$ & 3 & 80.2 \\
\hline
\end{tabular}

+ Plus one day
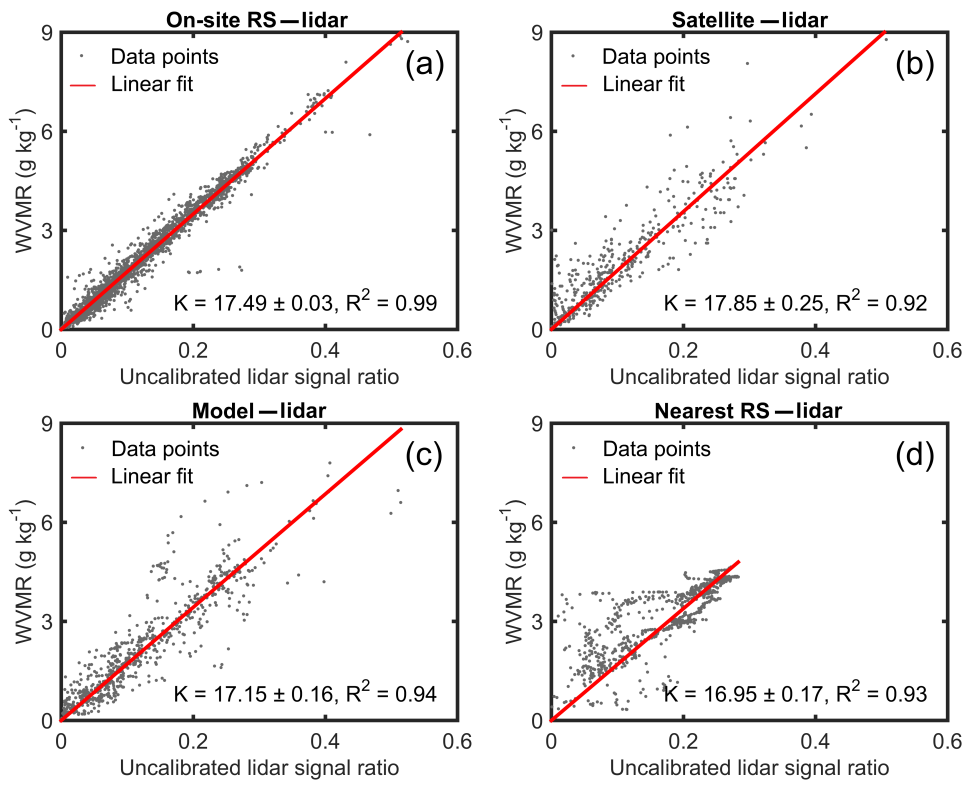

Figure 2. Overall calculation of the calibration factor including all available cases between the lidar and (a) on-site RS (b) the satellite, (c) the model and (d) the nearest RS (for Kuopio site only). Data points are marked as gray dots and the regression as red line. The calibration factor is also shown for each method.

a dry bias in the older version which has been reduced in the new one and could be the source of this behavior.

Lastly, the nearest available radio soundings from Jyväskylä and the RS launched at Kuopio site are compared in Fig. $3 \mathrm{~g}$ and h. The data consider only the Kuopio cam- paign since the Polly $\mathrm{XT}$ is permanently located there. Onsite soundings at 13:00, 19:30 and 22:00 UTC are compared with the 18:00 UTC RS launched in Jyväskylä. The discrepancies between the local RS and the on-site one are smaller in the evening or at night compared with those at 13:00 UTC. 

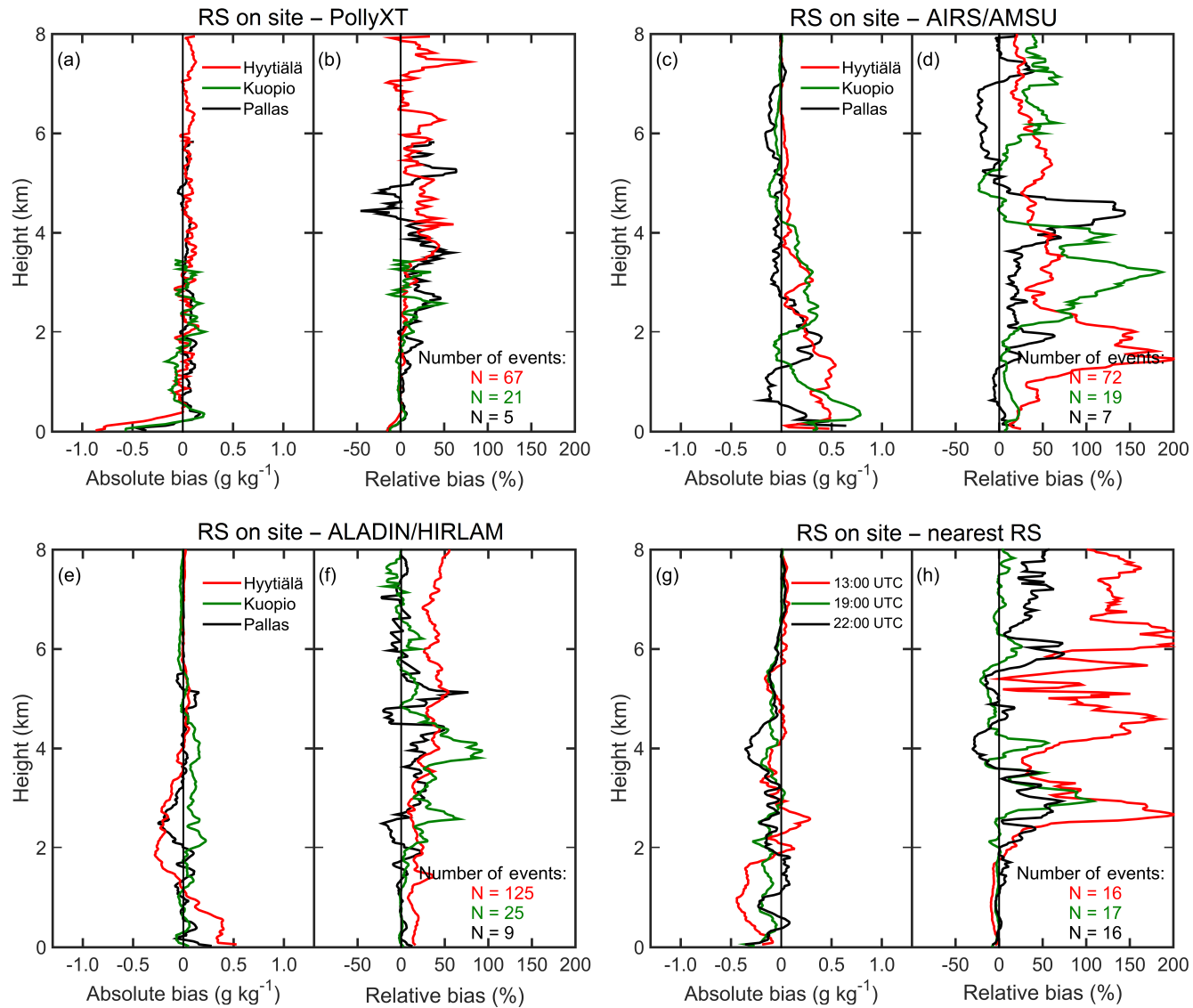

Figure 3. Comparisons between the on-site radio soundings and Polly ${ }^{X T}$, AIRS/AMSU, ALADIN/HIRLAM and nearest available radio soundings (for Kuopio site only). The various campaigns are indicated with different colors: red for Hyytiälä, green for Kuopio and black for Pallas. For the comparison between on-site RS and the nearest RS ( $\mathbf{g}$ and $\mathbf{h}$ ), the different colors indicate the three different on-site RS launch times compared to that of the nearest RS at 18:00 UTC. A 30 min average of the lidar signals is used. The trajectory method is used to select an appropriate WVMR profile from satellite data. The WV profile from ALADIN/HIRLAM model was selected from the nearest time point. Panels (a, $\mathbf{c}, \mathbf{e}, \mathbf{g})$ show the mean absolute bias from the on-site RS. Panels $(\mathbf{b}, \mathbf{d}, \mathbf{f}, \mathbf{h})$ indicate the corresponding mean relative bias. Height is above ground level.

Most probably the mesoscale meteorology along with planetary boundary layer (PBL) growth/collapse times resulted in these discrepancies and should be taken into consideration when using distant RS for further use (e.g., in WV lidar calibration or calculation of molecular coefficients in lidar retrievals).

\section{Seasonal variation of water vapor mixing ratio in Kuopio}

\subsection{Seasonal water vapor from Polly ${ }^{\mathrm{XT}}$ lidar data}

Since 16 November 2012, the Polly ${ }^{\mathrm{XT}}$ lidar has been located at Kuopio site operating automatically 24/7. For the seasonal analysis, measurements from a 4-year period between November 2012 and August 2016 were selected (campaigns outside of Kuopio were excluded). One WVMR profile was calculated per day, preferably during the darkest hour. For the Kuopio region this is around 22:30 UTC throughout the year. 
Table 3. Seasonal mean values of WVMR for different atmospheric layers and their SD as calculated from the lidar.

\begin{tabular}{|c|c|c|c|c|c|c|c|c|}
\hline \multirow{2}{*}{$\begin{array}{l}\text { Height } \\
(\mathrm{km})\end{array}$} & \multicolumn{2}{|c|}{ Winter (DJF) } & \multicolumn{2}{|c|}{ Spring (MAM) } & \multicolumn{2}{|c|}{ Summer (JJA) } & \multicolumn{2}{|c|}{ Autumn (SON) } \\
\hline & $\begin{array}{r}\text { Mean } \\
\left(\mathrm{g} \mathrm{kg}^{-1}\right)\end{array}$ & $\begin{array}{r}\text { SD } \\
\left(\mathrm{gkg}^{-1}\right)\end{array}$ & $\begin{array}{r}\text { Mean } \\
\left(\mathrm{g} \mathrm{kg}^{-1}\right)\end{array}$ & $\begin{array}{r}\mathrm{SD} \\
\left(\mathrm{gkg}^{-1}\right)\end{array}$ & $\begin{array}{r}\text { Mean } \\
\left(\mathrm{gkg}^{-1}\right)\end{array}$ & $\begin{array}{r}\text { SD } \\
\left(\mathrm{gkg}^{-1}\right)\end{array}$ & $\begin{array}{r}\text { Mean } \\
\left(\mathrm{gkg}^{-1}\right)\end{array}$ & $\begin{array}{r}\mathrm{SD} \\
\left(\mathrm{g} \mathrm{kg}^{-1}\right)\end{array}$ \\
\hline $0-2$ & 1.15 & 0.40 & 2.47 & 0.49 & 5.54 & 1.02 & 2.55 & 0.88 \\
\hline $2-4$ & 0.41 & 0.06 & 0.91 & 0.23 & 2.34 & 0.71 & 0.97 & 0.22 \\
\hline $4-6$ & 0.24 & 0.05 & 0.48 & 0.09 & 1.19 & 0.25 & 0.62 & 0.16 \\
\hline $6-8$ & 0.11 & 0.03 & 0.25 & 0.07 & 0.67 & 0.21 & 0.28 & 0.06 \\
\hline
\end{tabular}

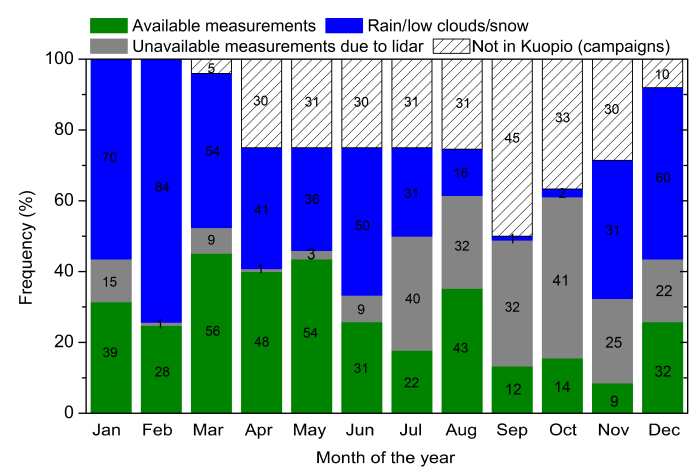

Figure 4. Monthly percentages of nighttime profiles for the period between 15 November 2012 and 31 August 2016. The measurements have been categorized depending on their availability as: available, unavailable measurements due to lidar, not in Kuopio (campaigns) and unavailable due to rain/low clouds/snow. The numbers on top of the color bars indicate the number of profiles for each category.

Profiles were averaged over $30 \mathrm{~min}$ in time and the applied vertical smoothing is the same as that described in Sect. 4.1. As indicated in Sect. 4.1, lidar profiles from $0.5 \mathrm{~km}$ down to the surface were kept constant based on the WVMR value at $0.5 \mathrm{~km}$. Furthermore, when necessary the lidar was calibrated using the closest RS from the Jyväskylä site. Figure 4 shows the number of available monthly nighttime profiles for the chosen period and their percentage share in each month. A total of 388 available measurements, indicated with the green color in Fig. 4, were further analyzed to extract the seasonal variability. Vertical mean profiles were calculated for each month while the seasonal value was retrieved by averaging the corresponding three months. The results are shown in Fig. 5a-d.

In Table 3, seasonal means were calculated for $2 \mathrm{~km}$ segments of atmosphere up to $8 \mathrm{~km}$. During summertime (JJA), the highest concentration of $\mathrm{WV}$ is observed with a mean value of $5.54 \pm 1.02 \mathrm{~g} \mathrm{~kg}^{-1}$ for the lowest $2 \mathrm{~km}$. While September's WVMR are comparable to those of July and August, the mean value for autumn (SON) decreases rapidly up to the driest period in winter (DJF), with $1.15 \pm 0.40 \mathrm{~g} \mathrm{~kg}^{-1}$ for the first $2 \mathrm{~km}$ and rapid drying above that. This follows the annual trend in temperature where the lowest values are observed at that period, especially during January, indicating absence of moisture. Spring and autumn have about the same mean amount of WV at all attitudes although individual months show a variety of mixing ratios.

\subsection{Discrepancies between the lidar and the model}

Following identical procedures to those described in Sect. 5.1, we derived the seasonal variability of WV using ALADIN/HIRLAM data including only the lidar-suitable dataset used in the previous section. In Fig. 6a we present seasonal mean WVMR between the lidar and the modellimited dataset. Figure $6 \mathrm{~b}$ and $\mathrm{c}$ show the absolute and relative biases. Both the lidar and the model are in reasonable agreement, although small discrepancies can be observed. At high altitudes, the humidity is rather low, meaning that the relative difference can fluctuate a lot, yet very few discrepancies greater than $50 \%$ were found. Nonetheless, there seems to be a negative bias between the model and the lidar at those high altitudes. The higher discrepancies between the lidar and the model during autumn is most likely caused by the use of the older model version as the available data for these months are based on the years 2012-2014. A dry bias of $0.02-0.08 \mathrm{~g} \mathrm{~kg}^{-1}$ has been found between the two model versions, with a higher bias at lower altitudes.

\section{Conclusions}

In this study we employed water vapor profiles from radio soundings, retrievals from AIRS/AMSU instruments on board of Aqua satellite and for the first time the ALADIN/HIRLAM model to calibrate a Raman lidar with water vapor capabilities. The uncertainty of the calibration factor from the radio soundings is $<1$ and $2.8 \%$ for the on-site and nearest RS, respectively. The calibration factor derived from the satellite had a discrepancy of $7.4 \%$, and from the model a $3.9 \%$. These results lay well within previous studies using the most common calibration technique - that of the regression method. If possible, we urge future lidar users to calculate the calibration factor applying a combined regres- 

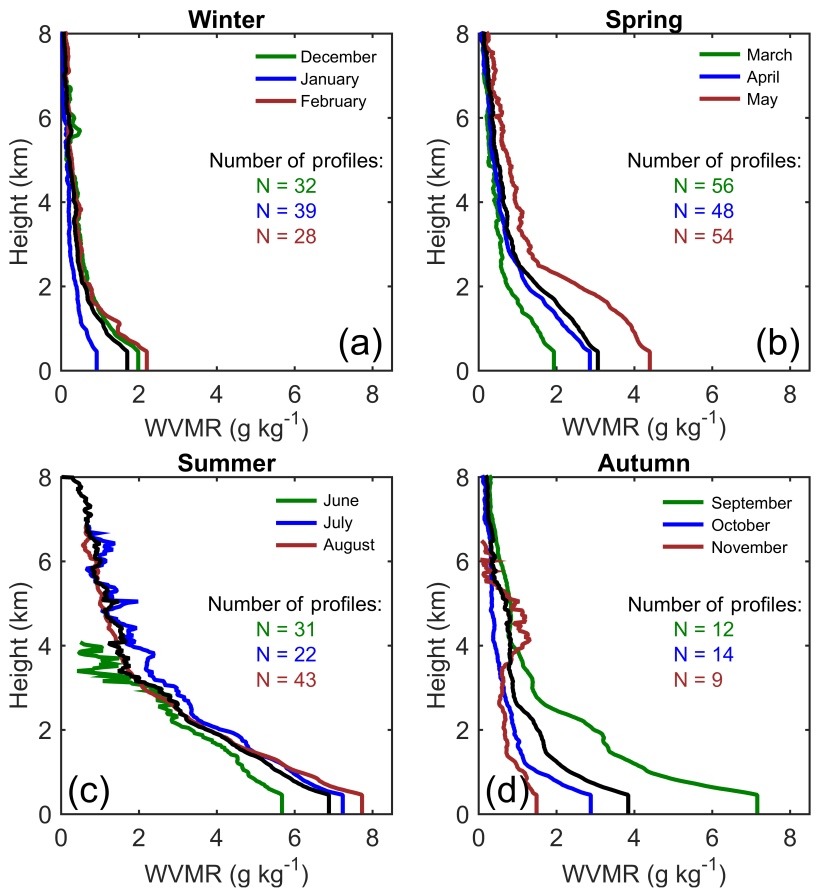

Figure 5. (a-d) Seasonal mean vertical profile of WVMR (black lines) as seen by the lidar and monthly mean WVMR (colored lines) for the aforementioned period. Some profiles stop below $8 \mathrm{~km}$ due to the SNR limitation.

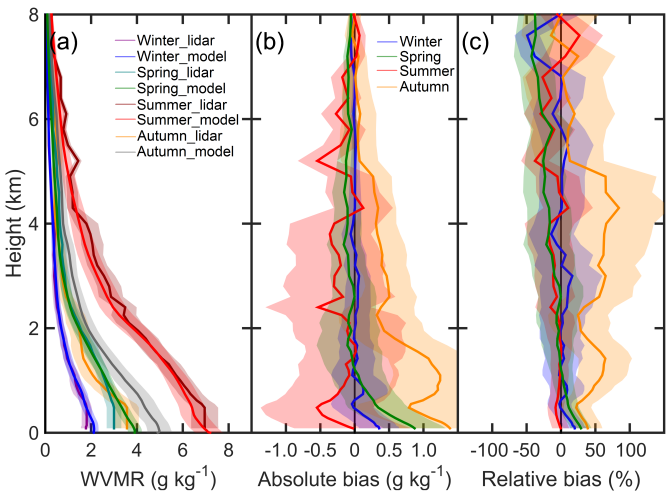

Figure 6. (a) Seasonal water vapor mixing ratios retrieved by the Raman lidar and the model between November 2012 and $\mathrm{Au}-$ gust 2016. (b) Respective seasonal absolute and (c) relative biases. Colored lines show the mean profile and shaded areas the SD.

sion line to all their cases simultaneously, since individual cases can have an impact on the derived calibration factor. In our study, this impact was translated into the aforementioned averaged percentages, yet the goal of the lidar calibration is to determine a proper factor as close as possible to the real factor (assuming that of the RS) and this is better obtained with the proposed method.

For the period being studied, intercomparisons between the on-site RS and the rest showed that the model and the nearest available soundings are an effective alternative when no soundings are on site, resulting in the smallest deviations after the lidar. We should note here that the model represents the shape of atmospheric WVMR profiles more accurately in the lowest few kilometers than the nearest RS which is located $100 \mathrm{~km}$ away from the lidar site. However, care should be taken when using the nearest RS, as non-stable atmospheric conditions between the two sites may lead to inadequate vertical representation of water vapor; for example, when there is sufficient time lag between the RS and the lidar measurement, especially when PBL activity is not constant - e.g., between day and night. The highest discrepancies were observed when comparing on-site RS and satellite WVMR. These discrepancies resulted from the larger spatial and poorer vertical resolution of the satellite data. A maximum $6 \mathrm{~h}$ overpass difference between the on-site measurements and the satellite was allowed in this study. This time limit is usually valid for the nearest RS where the 18:00 UTC 
RS is used, for example, with the 00:00 UTC lidar measurements. As has been shown in Sect. 4.1, the $6 \mathrm{~h}$ delay is acceptable for nighttime comparisons but not when one of the observations is during the day. We also encourage future users to apply the trajectory method when selecting satellite WVMR profiles and not the closest footprint to that of the site of interest. We found better agreement between the RS, the lidar and the satellite when applying this technique.

In addition, 4-year water vapor data from the lidar and the model were adopted to study the water vapor mixing ratio seasonality at the Kuopio site in eastern Finland. The analysis showed that three humidity states exist in Kuopio: a wet one during summer months where water vapor values of $5.52 \pm 1.01 \mathrm{~g} \mathrm{~kg}^{-1}$ were observed within the lowest $2 \mathrm{~km}$, a dry state during winter months with concentrations of $1.17 \pm 0.42 \mathrm{~g} \mathrm{~kg}^{-1}$ and a transition state during spring and autumn with intermediate values. Similar WV vertical structure to that of lidar was found when using modeled WVMR from ALADIN/HIRLAM. In general, the model simulates correctly WVMR for each season although some discrepancies were observed which are attributed partly to a combination of sparser vertical modeled bins and larger averaged area than that of the lidar. There seems to be a negative bias between the model and the lidar at higher altitudes.

Data availability. The data are available upon request (contact mail: maria.filioglou@fmi.fi).

Competing interests. The authors declare that they have no conflict of interest.

Acknowledgements. This project has received funding from the Kone Foundation and the European Union's Horizon 2020 research and innovation programme under grant agreement no. 654109 . Elina Giannakaki acknowledges the support of the Academy of Finland (project no. 270108). We also acknowledge the use of radiosonde data in collaboration with the US Department of Energy as part of the Atmospheric Radiation Measurement (ARM) Climate Research Facility during BAECC (AMF campaign in Hyytiälä, Finland). The authors gratefully acknowledge the support of ACTRIS-TNA during the BAECC campaign held in Hyytiälä and the NOAA Air Resources Laboratory (ARL) for the provision of the HYSPLIT transport and dispersion model used in this publication. We would also like to thank Eimear M. Dunne for her valuable contribution.

Edited by: Vassilis Amiridis

Reviewed by: Michael Kottas and one anonymous referee

\section{References}

AIRS Science Team/Texeira, J.: AIRS/Aqua L2 Support Retrieval (AIRS+AMSU) V006, version 006, Greenbelt, MD, USA, Goddard Earth Sciences Data and Information Services Center (GES DISC), https://doi.org/10.5067/AQUA/AIRS/DATA207, last access: July 2016, 2013.

Althausen, D., Engelmann, R., Baars, H., Heese, B., Ansmann, A., Müller, D., and Komppula, M.: Portable Raman lidar PollyXT for automated profiling of aerosol backscatter, extinction, and depolarization, J. Atmos. Ocean. Tech., 26, 2366-2378, https://doi.org/10.1175/2009JTECHA1304.1, 2009.

Althausen, D., Engelmann, E., Baars, H., Heese, B., Kanitz, T., Komppula, M., Giannakaki, E., Pfüller, A., Silva, A. M., Preißler, J., Wagner, F., Rascado, J. L., Pereira, S., Lim, J. H., Ahn, J. Y., Tesche, M., and Stachlewska, I. S.: PollyNET - a network of multiwavelength polarization Raman lidars, in: Proc. SPIE 8894, Lidar Technologies, Techniques, and Measurements for Atmospheric Remote Sensing IX, 88940I, 22 October 2013, Dresden, Germany, 8894, https://doi.org/10.1117/12.2028921, 2013.

Aumann, H. H., Chahine, M. T., Gautier, C., Goldberg, M. D., Kalnay, E., McMillin, L. M., Revercomb, H., Rosenkranz, P. W., Smith, W. L., Staelin, D. H., Strow, L. L., and Susskind, J.: AIRS/AMSU/HSB on the Aqua mission: design, science objectives, data products and processing system, IEEE T. Geosci. Remote, 41, 253-264, https://doi.org/10.1109/TGRS.2002.808356, 2003.

Baars, H., Kanitz, T., Engelmann, R., Althausen, D., Heese, B., Komppula, M., Preißler, J., Tesche, M., Ansmann, A., Wandinger, U., Lim, J.-H., Ahn, J. Y., Stachlewska, I. S., Amiridis, V., Marinou, E., Seifert, P., Hofer, J., Skupin, A., Schneider, F., Bohlmann, S., Foth, A., Bley, S., Pfüller, A., Giannakaki, E., Lihavainen, H., Viisanen, Y., Hooda, R. K., Pereira, S. N., Bortoli, D., Wagner, F., Mattis, I., Janicka, L., Markowicz, K. M., Achtert, P., Artaxo, P., Pauliquevis, T., Souza, R. A. F., Sharma, V. P., van Zyl, P. G., Beukes, J. P., Sun, J., Rohwer, E. G., Deng, R., Mamouri, R.-E., and Zamorano, F.: An overview of the first decade of Polly ${ }^{N E T}$ : an emerging network of automated Raman-polarization lidars for continuous aerosol profiling, Atmos. Chem. Phys., 16, 5111-5137, https://doi.org/10.5194/acp16-5111-2016, 2016.

Barreto, A., Cuevas, E., Damiri, B., Romero, P. M., and Almansa, F.: Column water vapor determination in night period with a lunar photometer prototype, Atmos. Meas. Tech., 6, 2159-2167, https://doi.org/10.5194/amt-6-2159-2013, 2013.

Bengtsson, L., Andrae, U., Aspelien, T., Batrak, Y., Calvo, J., de Rooy, W., Gleeson, E., Sass, B., Homleid, M., Hortal, M., Ivarsson, K.-I., Lenderink, G., Niemelä S., Nielsen, K., Onvlee, J., Rontu, L., Samuelsson, P., Santos-Munoz, D., Subias, A., Tijm, S., Toll, V., Yang, X., and Koltzow, M.: The HARMONIEAROME model configuration in the ALADIN-HIRLAM NWP system, accepted to Mon. Weather Rev., 145, 1919-1935, https://doi.org/10.1175/MWR-D-16-0417.1, 2017.

Boucher, O., Randall, D., Artaxo, P., Bretherton, C., Feingold, G., Forster, P., Kerminen, V. M., Kondo, Y., Liao, H., Lohmann, U., Rasch, P., Satheesh, S. K., Sherwood, S., Stevens, B., and Zhang, X. Y.: Clouds and aerosols, in: Climate Change 2013: The Physical Science Basis. Contribution of Working Group I to the Fifth Assessment Report of the Intergovernmental Panel 
on Climate Change, edited by: Stocker, T. F., Qin, D., Plattner, G. K., Tignor, M., Allen, S. K., Boschung, J., Nauels, A., Xia, Y., Bex, V., and Midgley, P. M., Cambridge University Press, Cambridge, UK and New York, NY, USA, 2013.

Bösenberg J.: Ground-based differential absorption lidar for watervapor and temperature profiling: methodology, Appl. Optics, 37, 3845-3860, https://doi.org/10.1364/AO.37.003845, 1998.

Brocard, E., Philipona, R., Haefele, A., Romanens, G., Mueller, A., Ruffieux, D., Simeonov, V., and Calpini, B.: Raman Lidar for Meteorological Observations, RALMO - Part 2: Validation of water vapor measurements, Atmos. Meas. Tech., 6, 1347-1358, https://doi.org/10.5194/amt-6-1347-2013, 2013.

Dessler, A. E., Zhang, Z., and Yang, P.: Water-vapor climate feedback inferred from climate fluctuations, 2003-2008, Geophys. Res. Lett., 35, L20704, https://doi.org/10.1029/2008GL035333, 2008.

Draxler, R. R. and Hess, G. D.: An overview of the HYSPLIT_4 modeling system of trajectories, dispersion, and deposition, Aust. Meteorol. Mag., 47, 295-308, 1998

Engelmann, R., Kanitz, T., Baars, H., Heese, B., Althausen, D., Skupin, A., Wandinger, U., Komppula, M., Stachlewska, I. S., Amiridis, V., Marinou, E., Mattis, I., Linné, H., and Ansmann, A.: The automated multiwavelength Raman polarization and water-vapor lidar Polly XT: the neXT generation, Atmos. Meas. Tech., 9, 1767-1784, https://doi.org/10.5194/amt-9-1767-2016, 2016.

England, M. N., Ferrare, R. A., Melfi, S. H., Whiteman, D. N., and Clark, T. A.: Atmospheric water vapor measurements: comparison of microwave radiometry and lidar, J. Geophys. Res.-Atmos., 97, 899-916, https://doi.org/10.1029/91JD02384, 1992.

Estillore, A. D., Hettiyadura, A. P., Qin, Z., Leckrone, E., Wombacher, B., Humphry, T., Stone, E. A., and Grassian, V. H.: Water uptake and hygroscopic growth of organosulfate aerosol, Environ. Sci. Technol., 50, 4259-4268, https://doi.org/10.1021/acs.est.5b05014, 2016.

Feingold, G. and Morley, B.: Aerosol hygroscopic properties as measured by lidar and comparison with in situ measurements, J. Geophys. Res.-Atmos., 108, 4327, https://doi.org/10.1029/2002JD002842, 2003.

Ferrare, R. A., Melfi, S. H., Whiteman, D. N., Evans, K. D., Schmidlin, F. J., and Starr, D. O.: A comparison of water vapor measurements made by raman lidar and radiosondes, J. Atmos. Ocean. Tech., 12, 1177-1195, https://doi.org/10.1175/15200426(1995)012<1177:ACOWVM>2.0.CO;2, 1995.

Foth, A. and Pospichal, B.: Optimal estimation of water vapour profiles using a combination of Raman lidar and microwave radiometer, Atmos. Meas. Tech., 10, 3325-3344, https://doi.org/10.5194/amt-10-3325-2017, 2017.

Foth, A., Baars, H., Di Girolamo, P., and Pospichal, B.: Water vapour profiles from Raman lidar automatically calibrated by microwave radiometer data during HOPE, Atmos. Chem. Phys., 15, 7753-7763, https://doi.org/10.5194/acp-15-7753-2015, 2015.

Hatakka, J., Aalto, T., Aaltonen, V., Aurela, M., Hakola, H., Komppula, M., Laurila, T., Lihavainen, H., Paatero, J., Salminen, K., and Viisanen, Y.: Overview of the atmospheric research activities and results at Pallas GAW station, Boreal Environ. Res., 8, 365-383, 2003.

Hearty, T. J., Savtchenko, A., Tian, B., Fetzer, E., Yung, Y. L., Theobald, M., Vollmer, B., Fishbein, E., and Won, Y. I.: Es- timating sampling biases and measurement uncertainties of AIRS/AMSU-A temperature and water vapor observations using MERRA reanalysis, J. Geophys. Res.-Atmos., 119, 2725-2741, https://doi.org/10.1002/2013JD021205, 2014.

Held, I. M. and Soden, B. J.: Water vapor feedback and global warming, Annu. Rev. Energ. Env., 25, 441-475, https://doi.org/10.1146/annurev.energy.25.1.441, 2000.

Hirsikko, A., O'Connor, E. J., Komppula, M., Korhonen, K., Pfüller, A., Giannakaki, E., Wood, C. R., Bauer-Pfundstein, M., Poikonen, A., Karppinen, T., Lonka, H., Kurri, M., Heinonen, J., Moisseev, D., Asmi, E., Aaltonen, V., Nordbo, A., Rodriguez, E., Lihavainen, H., Laaksonen, A., Lehtinen, K. E. J., Laurila, T., Petäjä, T., Kulmala, M., and Viisanen, Y.: Observing wind, aerosol particles, cloud and precipitation: Finland's new groundbased remote-sensing network, Atmos. Meas. Tech., 7, 13511375, https://doi.org/10.5194/amt-7-1351-2014, 2014.

Ivarsson, K. I.: Decription of the OCND2-option in the ICE3 clouds and stratiform condensation scheme in AROME, ALADINHIRLAM Newslett., 5, 83-87, 2015.

Kahn, B., Manning, E., Blaisdell, J., Iredell, L., and Susskind, J.: GSFCAIRS/AMSU/HSB Version 6 Level 2 Quality Control and Error Estimation, [Edited by Edward, T. Olsen] Jet Propulsion Laboratory California Institute of Technology Pasadena, C A. Version 1.0, Available at http://disc.sci.gsfc. nasa.gov/AIRS/documentation/v6_docs/v6releasedocs-1/V6_ L2_Quality_Control_and_Error_Estimation.pdf, last access: 29 November 2016, 2012.

Leblanc, T., McDermid, I. S., and Walsh, T. D.: Ground-based water vapor raman lidar measurements up to the upper troposphere and lower stratosphere for long-term monitoring, Atmos. Meas. Tech., 5, 17-36, https://doi.org/10.5194/amt-5-17-2012, 2012.

Lohmann, U. and Feichter, J.: Global indirect aerosol effects: a review, Atmos. Chem. Phys., 5, 715-737, https://doi.org/10.5194/acp-5-715-2005, 2005.

Madonna, F., Amodeo, A., Boselli, A., Cornacchia, C., Cuomo, V., D’Amico, G., Giunta, A., Mona, L., and Pappalardo, G.: CIAO: the CNR-IMAA advanced observatory for atmospheric research, Atmos. Meas. Tech., 4, 1191-1208, https://doi.org/10.5194/amt4-1191-2011, 2011.

Mamouri, R. E., Papayannis, A., Tsaknakis, G., Amiridis, V., and Koukouli, M.: First water vapor measurements over Athens, Greece, obtained by a combined Raman-elastic backscatter lidar system, Opt. Pura Apl., 41, 109-116, 2008.

Manning, E., Wong, S., Irion, F., Van, T. Dang, H., Hulley, G., Susskind, J., Iredell, L. F., Blaisdell, J. M., Molnar, G., Lambrigtsen, B. H., Kahn, B. H., Xiong, X., Warner, J., Tian, B., Strow, L., and Teixeira, J.: Version 6 Performance and Test Report: AIRS/AMSU/HSB Version 6 Level 2 Performance and Test Report, edited by: Van, T. Dang, H., Lambrigtsen, B., and Manning, E., Jet Propulsion Laboratory, California Institute of Technology, version 1.2, available at: http://disc.sci.gsfc.nasa.gov/AIRS/documentation/v6_docs/ v6releasedocs-1/V6_L2_Performance_and_Test_Report.pdf, last access: 29 November 2016, 2012.

Mattis, I., Ansmann, A., Althausen, D., Jaenisch, V., Wandinger, U., Müller, D., Arshinov, Y. F., Bobrovnikov, S. M., and Serikov, I. B.: Relative-humidity profiling in the troposphere with a Raman lidar, Appl. Optics, 41, 6451-6462, https://doi.org/10.1364/AO.41.006451, 2002. 
McCormack, J. P., Hoppel, K. W., and Siskind, D. E.: Parameterization of middle atmospheric water vapor photochemistry for high-altitude NWP and data assimilation, Atmos. Chem. Phys., 8, 7519-7532, https://doi.org/10.5194/acp-8-7519-2008, 2008.

McCormic, R. A. and Ludwig, J. H.: Climate modifications by atmospheric aerosols, Science, 156, 1358-1359, https://doi.org/10.1126/science.156.3780.1358, 1967.

Miloshevich, L. M., Paukkunen, A., Vömel, H., and Oltmans, S. J.: Development and validation of a time-lag correction for Vaisala radiosonde humidity measurements, J. Atmos. Ocean. Tech., 21, 1305-1327, https://doi.org/10.1175/15200426(2004)021<1305:DAVOAT>2.0.CO;2, 2004.

Müller, R., Kunz, A., Hurst, D. F., Rolf, C., Krämer, M., and Riese, M.: The need for accurate long-term measurements of water vapor in the upper troposphere and lower stratosphere with global coverage, Earth's Future, 4, 25-32, https://doi.org/10.1002/2015EF000321, 2016.

Navas-Guzmán, F., Fernández-Gálvez, J., Granados-Muñoz, M. J., Guerrero-Rascado, J. L., Bravo-Aranda, J. A., and AladosArboledas, L.: Tropospheric water vapour and relative humidity profiles from lidar and microwave radiometry, Atmos. Meas. Tech., 7, 1201-1211, https://doi.org/10.5194/amt-7-1201-2014, 2014.

Niemelä, S.: Highlights of NWP activities at FMI in 2014, ALADIN-HIRLAM Newslett., 4, 36-38, 2015, available at: http: //www.umr-cnrm.fr/aladin/spip.php?article260.

Parkinson, C. L.: Aqua: an Earth-observing satellite mission to examine water and other climate variables, IEEE T. Geosci. Remote, 41, 173-183, https://doi.org/10.1109/TGRS.2002.808319, 2003.

Reagan, J., Thome, K., Herman, B., Stone, R., Deluisi, J., and Snider, J.: A comparison of columnar water vapor retrievals obtained with near- IR solar radiometer and microwave radiometer measurements, J. Appl. Meteorol., 34, 1384-1391, https://doi.org/10.1175/15200450(1995)034<1384:ACOCWV>2.0.CO;2, 1995.

Reichardt, J., Wandinger, U., Klein, V., Mattis, I., Hilber, B., and Begbie, R.: RAMSES: German Meteorological Service autonomous Raman lidar for water vapor, temperature, aerosol, and cloud measurements, Appl. Opt., 51, 8111-8131, https://doi.org/10.1364/AO.51.008111, 2012.

Seity, Y., Brousseu, P., Malardel, S., Hello, G., Benard, P., Bouttier, F., Lac, C., and Masson, V.: The AROME-France convective scale operational model, Mon. Weather Rev., 139, 976-991, https://doi.org/10.1175/2010MWR3425.1, 2011.
Soden, B. J., Wetherald, R. T., Stenchikov, G. L., and Robock, A.: Global cooling after the eruption of mount Pinatubo: a test of climate feedback by water vapor, Science, 296, 727-730, https://doi.org/10.1126/science.296.5568.727, 2002.

Soden, B. J., Jackson, D L., Ramaswamy, V., Schwarzkopf, M. D., and Huang, X.: The radiative signature of upper tropospheric moistening, Science, 310, 841-844, https://doi.org/10.1126/science.1115602, 2005.

Stein, A. F., Draxler, R. R., Rolph, G. D., Stunder, B. J. B., Cohen, M. D., and Ngan, F.: NOAA's HYSPLIT atmospheric transport and dispersion modeling system, B. Am. Meteorol. Soc., 96, 2059-2077, https://doi.org/10.1175/BAMS-D-14$00110.1,2015$.

Turner, D. D., Ferrare, R. A., Brasseur, L. A. H., Feltz, W. F., and Tooman, T. P.: Automated retrievals of water vapor and aerosol profiles from an operational Raman lidar, J. Atmos. Ocean. Tech., 19, 37-50, https://doi.org/10.1175/1520-0426, 2002.

Twomey, S.: Pollution and the planetary albedo, Atmos. Environ., 8, 1251-1256, https://doi.org/10.1016/0004-6981(74)90004-3, 1974.

Van Baelen, J., Reverdy, M., Tridon, F., Labbouz, L., Dick, G., Bender, M., and Hagen, M.: On the relationship between water vapour field evolution and the life cycle of precipitation systems, Q. J. Roy. Meteor. Soc., 137, 204-223, https://doi.org/10.1002/qj.785, 2011.

Vaughan, G., Wareing, D. P., Thomas, L., and Mitev, V.: Humidity measurements in the free troposphere using Raman backscatter, Q. J. Roy. Meteor. Soc., 114, 1471-1484, https://doi.org/10.1002/qj.49711448406, 1988.

Wandinger, U. and Ansmann, A.: Experimental determination of the lidar overlap profile with Raman lidar, Appl. Optics, 41, 511514, https://doi.org/10.1364/AO.41.000511, 2002.

Whiteman, D. N.: Examination of the traditional Raman lidar technique. I I. Evaluating the ratios for water vapor and aerosols, Appl. Optics, 42, 2593-2608, https://doi.org/10.1364/AO.42.002593, 2003.

Whiteman, D., Melfi, S., and Ferrare, R.: Raman lidar system for the measurement of water vapor and aerosols in the Earth's atmosphere, Appl. Optics, 31, 3068-3082, https://doi.org/10.1364/AO.31.003068, 1992. 



\section{Paper II}

Detection and characterization of birch pollen in the atmosphere using a multiwavelength Raman polarization lidar and Hirst-type pollen sampler in Finland.

Bohlmann, S., Shang, X., Giannakaki, E., Filioglou, M., Saarto, A., Romakkaniemi, S. and Komppula M.

Atmospheric Chemistry and Physics, 19, 14559-14569, 2019.

Reproduced under the Creative Commons Attribution 4.0 License (CC BY4.0). 
Atmos. Chem. Phys., 19, 14559-14569, 2019

https://doi.org/10.5194/acp-19-14559-2019

(C) Author(s) 2019. This work is distributed under

the Creative Commons Attribution 4.0 License.

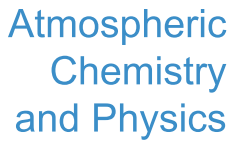

(1)

\title{
Detection and characterization of birch pollen in the atmosphere using a multiwavelength Raman polarization lidar and Hirst-type pollen sampler in Finland
}

\author{
Stephanie Bohlmann ${ }^{1}$, Xiaoxia Shang ${ }^{1}$, Elina Giannakaki ${ }^{1,2}$, Maria Filioglou ${ }^{1}$, Annika Saarto ${ }^{3}$, \\ Sami Romakkaniemi ${ }^{1}$, and Mika Komppula ${ }^{1}$ \\ ${ }^{1}$ Finnish Meteorological Institute, Atmospheric Research Centre of Eastern Finland, 70211 Kuopio, Finland \\ ${ }^{2}$ Department of Environmental Physics and Meteorology, University of Athens, 15784 Athens, Greece \\ ${ }^{3}$ Biodiversity Unit, University of Turku, 20014 Turku, Finland
}

Correspondence: Stephanie Bohlmann (stephanie.bohlmann@fmi.fi)

Received: 9 July 2019 - Discussion started: 22 July 2019

Revised: 14 October 2019 - Accepted: 29 October 2019 - Published: 2 December 2019

\begin{abstract}
We present the results of birch pollen characterization using lidar and in situ measurements based on a $11 \mathrm{~d}$ pollination period from 5 to 15 May 2016 at the $\mathrm{Eu}-$ ropean Aerosol Research Lidar Network (EARLINET) station in Vehmasmäki (Kuopio; 62 ${ }^{\circ} 44^{\prime} \mathrm{N}, 27^{\circ} 33^{\prime} \mathrm{E}$ ), Finland. The ground-based multiwavelength Raman polarization lidar Polly ${ }^{\mathrm{XT}}$ performed continuous measurements at this rural forest site and has been combined with a Hirst-type volumetric air sampler, which measured the pollen type and concentration at roof level $(4 \mathrm{~m})$. The period was separated into two parts due to different atmospheric conditions and detected pollen types. During the first period, high concentrations of birch pollen were measured with a maximum $2 \mathrm{~h}$ average pollen concentration of 3700 grains $\mathrm{m}^{-3}$. Other pollen types represented less than $3 \%$ of the total pollen count. In observed pollen layers, the mean particle depolarization ratio at $532 \mathrm{~nm}$ was $10 \pm 6 \%$ during the intense birch pollination period. Mean lidar ratios were found to be $45 \pm 7$ and $55 \pm 16 \mathrm{sr}$ at 355 and $532 \mathrm{~nm}$, respectively. During the second period, birch pollen was still dominant, but a significant contribution of spruce pollen was observed as well. Spruce pollen grains are highly nonspherical, leading to a larger mean depolarization ratio of $26 \pm 7 \%$ for the birch-spruce pollen mixture. Furthermore, higher lidar ratios were observed during this period with mean values of $60 \pm 3$ and $62 \pm 10 \mathrm{sr}$ at 355 and $532 \mathrm{~nm}$, respectively. The presented study shows the potential of the particle depolarization ratio to track pollen grains in the atmosphere.
\end{abstract}

\section{Introduction}

Atmospheric pollen is a well-known health threat as it can irritate the respiratory system and cause asthmatic symptoms (Bousquet et al., 2008). The number of people suffering from pollen-triggered diseases is rising (Schmidt, 2016), and the prevalence of pollen allergies is likely to further increase due to climate change as the pollination season becomes longer and pollen production increases (Lake et al., 2018). In addition to the well-known allergenic impacts, pollen also affects the climate (IPCC, 2013; WHO, 2003). Steiner et al. (2015) suggested that fragments of pollen act as cloud condensation nuclei $(\mathrm{CCN})$ and therefore influence cloud optical properties. Pollen can furthermore change ice cloud formation processes by acting as ice nuclei (IN) (von Blohn et al., 2005; Diehl et al., 2001, 2002).

Worldwide, 879 active stations have continuously monitored pollen type and concentration near ground level in 2016 (Buters et al., 2018). The majority of these stations operate with Hirst-type volumetric air samplers. These traditional pollen traps are operated manually, which requires human resources and is time consuming. In recent years, novel techniques have been developed to enable automated pollen monitoring and reduce workload. Those techniques use, for example, automated image recognition (Oteros et al., 2015) or fluorescence spectra (Crouzy et al., 2016; Richardson et al., 2019; Saito et al., 2018) to identify pollen types, and they could enable a systematic pollen monitoring at ground level in near-real-time. Systematic information on the vertical dis- 
tribution, however, is missing. Models are using phenological and meteorological data to forecast concentration and dispersion of pollen in the atmosphere. But observations, especially in the vertical direction, to evaluate the model results are rare or missing. Light detection and ranging (lidar) is an effective method to investigate the vertical distribution of aerosols, as it enables measurements with high vertical and temporal resolutions under ambient conditions. Recently, the signature of pollen grains has been observed in lidar measurements (Noh et al., 2013a, b; Sassen, 2008; Sicard et al., 2016). It has been revealed that nonspherical pollen generates strong laser depolarization, and thus information on particle shape can be retrieved. For example, Sassen (2008) measured a linear depolarization ratio at $694 \mathrm{~nm}$ up to $30 \%$ for paper birch in Alaska. In controlled laboratory experiments, Cao et al. (2010) measured the linear depolarization ratio of different pollen types and determined a linear depolarization ratio at $532 \mathrm{~nm}$ for paper birch of $33 \%$. In the absence of other depolarizing particles, the depolarization ratio could therefore be used to track pollen grains. Lidar-derived depolarization ratio profiles thus can provide information about the vertical distribution of pollen, which could result in an improvement in the model input parameters and serve as validation for model results.

Within our study, we aim to improve and deepen the knowledge of optical properties of pollen in the atmosphere by using a multiwavelength Raman polarization lidar. Finland provides suitable conditions for the observation of pollen as $78 \%$ of Finland's total area is forestland and sources of other highly depolarizing particles like dust are absent. Hence the contamination with other aerosols is considered to be small. During a 4-month measurement campaign in 2016, the multiwavelength Raman polarization lidar Polly ${ }^{X T}$ (Engelmann et al., 2016) performed continuous measurements at the rural forest station in Vehmasmäki (Kuopio), which is part of the European Aerosol Research Lidar Network (EARLINET). Simultaneously, a Hirst-type volumetric air sampler was operated to obtain pollen type and concentration at roof level. Twenty-one different pollen types were detected from May to August 2016. In this study, we focus on the description of birch pollen and the mixture of birch and spruce pollen as birch is one of the most allergenic pollen types and the most allergenic tree pollen in northern, central and eastern Europe (D'Amato et al., 2007).

\section{Measurement site and instrumentation}

Our measurement campaign took place from the beginning of May to the end of August 2016 at Vehmasmäki, Finland $\left(62^{\circ} 44^{\prime} \mathrm{N}, 27^{\circ} 33^{\prime} \mathrm{E} ; 190 \mathrm{~m}\right.$ a.s.l. $)$; a rural forest site $18 \mathrm{~km}$ from the city center of Kuopio, Eastern Finland. The measurement site was equipped with the multiwavelength Raman polarization lidar Polly ${ }^{\mathrm{XT}}$ (Sect. 2.1) and a Hirst-type pollen sampler (Sect. 2.2). With this setup it is possible to combine vertical profiles of the aerosol properties above the site and the pollen concentration on the ground. Due to the location of the site, far from major aerosol sources like dust or anthropogenic aerosol and mainly surrounded by forest, the atmosphere is relatively clean and suitable for pollen studies.

\subsection{Lidar: Polly $\mathrm{XT}$}

Lidar measurements were conducted with the multiwavelength Raman polarization lidar Polly ${ }^{\mathrm{XT}}$ (Althausen et al., 2009; Baars et al., 2016; Engelmann et al., 2016). Polly XT has three emission wavelengths $(355,532$ and $1064 \mathrm{~nm})$ and seven detection channels. In addition to the three emitted wavelengths, the backscattered signals at the inelastic Raman-shifted wavelengths (387, 407 and $607 \mathrm{~nm}$ ) and the cross-polarized signal at $532 \mathrm{~nm}$ are detected. During nighttime, extinction and backscatter coefficient profiles at 355 and $532 \mathrm{~nm}$ can be determined independently using the Raman method (Ansmann et al., 1992). During daytime, the Klett-Fernald method (Fernald, 1984; Klett, 1981) is applied using the elastic signals due to the low signal-to-noise ratio for the Raman channels. The signal at the $407 \mathrm{~nm}$ Ramanshifted wavelength is used to determine water vapor mixing ratio profiles during dark hours (Filioglou et al., 2017). The simultaneous measurement of the cross-polarized and total backscattered light at $532 \mathrm{~nm}$ enables the determination of the linear particle depolarization ratio (PDR; Freudenthaler et al., 2009), which allows for the characterization of particle shape (Sassen, 2005). The measurement of multiple wavelengths allows for the retrieval of Angström exponents $(\AA)$, which are related to the particle size. The ratio of extinction to backscatter coefficient is called lidar ratio (LR). It is considered an important criterion for particle characterization, as it depends on single scattering albedo and backscatter phase function and therefore on the size distribution and the chemical composition of the aerosol particle. The LR is therefore considered to be aerosol-type dependent.

The operated lidar system has an initial spatial resolution of $30 \mathrm{~m}$ and a temporal resolution of $30 \mathrm{~s}$. Due to the biaxial setup of emission and detection units, the height of complete overlap between the laser and the receiver field of view is reached at about 800-900 m (Engelmann et al., 2016). An overlap correction can be applied on the basis of a simple technique proposed by Wandinger and Ansmann (2002), which allows operators to extend profiles down to around $500 \mathrm{~m}$. In this study, the lower limit of reliable profiles of vertically smoothed and temporally averaged optical properties is at around $800 \mathrm{~m}$. Uncertainties in nighttime lidar products are mainly determined by signal noise and the correction of Rayleigh scattering. The overall relative errors of the lidar-derived optical properties retrieved with the Raman method are in the range of 5\%-10\% for backscatter coefficients and depolarization ratios and $10 \%-20 \%$ for extinction coefficients (Ansmann et al., 1992; Baars et al., 2012). These 
uncertainties propagate to the retrieved Ångström exponents and LRs.

Further details on the setup, principle and error propagation of Polly XT can be found in Althausen et al. (2009) and Engelmann et al. (2016). Near-real-time measurements and Polly ${ }^{\mathrm{XT}}$ data can be accessed at the PollyNET website (http://polly.tropos.de/, last access: 22 November 2019).

\subsection{Pollen collector: Hirst-type volumetric air sampler}

A Hirst-type volumetric air sampler located next to the lidar, $4 \mathrm{~m}$ above ground, monitored the pollen concentration and type. This type of spore sampler enables continuous $7 \mathrm{~d}$ collection of pollen grains with $2 \mathrm{~h}$ time resolution. The sampling principle is based on the design described by Hirst (1952). With a flow rate of $10 \mathrm{~L} \mathrm{~min}^{-1}$, air is drawn into the sampling device through a $14 \mathrm{~mm} \times 2 \mathrm{~mm}$ orifice. A large wind vane on a rotatable sampler head makes the sampler sensitive to changes in wind direction and ensures that the orifice is always oriented towards the wind. Particles impact on an adhesive-coated plastic tape beneath the orifice. For this study, the tape, fixed on a rotating drum, was changed every $7 \mathrm{~d}$ and the pollen grains impacted on the tape were further analyzed under the microscope. The pollen type was determined using characteristic features of the examined pollen grains. By converting the counted spores on the sample tape surface in relation to the inlet air flow, the pollen concentration was obtained.

\section{Methodology}

Figure 1 shows the temporal variation in the pollen concentration (Fig. 1a), the range-corrected signal at $1064 \mathrm{~nm}$ (Fig. 1b) and the volume depolarization ratio at $532 \mathrm{~nm}$ (Fig. 1c) during the period 5-15 May 2016. This period represents the main birch pollination season of 2016 as $83 \%$ of the annual birch pollen had been collected during that time. A relatively large aerosol load was observed within the planetary boundary layer up to $\sim 3.5 \mathrm{~km}$. As shown in Fig. $1 \mathrm{c}$, the volume depolarization ratio ranges between $4 \%$ and $10 \%$ suggesting the presence of nonspherical particles. A detailed examination of the air masses arriving during this period along with modeled dust load using the BSCDREAM8b model (Basart et al., 2012) confirms the absence of dust in middle and northern Europe. Additionally, MODIS data (MODIS, 2019) were synergistically used to exclude smoke aerosol layers from biomass burning. Hence, the highly depolarizing aerosol layers were likely attributed to pollen, keeping in mind that some contamination with local anthropogenic aerosol is always possible.

Ground-level pollen concentration values presented in Fig. 1a were used to verify the strong pollination event in the beginning of May, which provides $50 \%$ of the annual birch pollen concentration. The event started in the evening (17:00 UTC) of 5 May and lasted until noon on 9 May (hereafter called period 1). During period 1 , the $2 \mathrm{~h}$ average pollen concentration exceeded 1000 grains $\mathrm{m}^{-3}$ for $53 \%$ of the time. The majority of pollen identified was birch $(97 \%)$ with a very small contribution from willow $(2 \%)$ and other pollen types (1\%). From 12 to 15 May (period 2), the mean pollen concentration was significantly lower. Only $8 \%$ of the time, the total pollen concentration was higher than 1000 grains $\mathrm{m}^{-3}$. In addition to birch $(82 \%)$, spruce pollen $(14 \%)$ and other pollen types (4\%) were detected. This variation can be explained by the different meteorological conditions during the two periods. A different predominant wind direction during the two periods was observed, which probably caused the different mixtures of pollen types. The most frequent wind direction in period 1 was northwest, whereas in period 2 the air masses were mainly advected from the southeast. When comparing the diurnal cycle of temperature and relative humidity measured at ground level, we found higher temperature values and lower relative humidity during period 1 compared with period 2 . Temperature and pollen concentration have been shown to be positively correlated, whereas pollen concentration and relative humidity show a negative correlation (Bartková-Ščevková, 2003). The different pollen concentrations could therefore be partly explained by variations in temperature and humidity.

The near-ground aerosol layers are assumed to contain the highest concentration of local pollen, and they are defined as pollen layers in this study. The gradient method was applied to determine the bottom and top layer heights of the pollen layers (Bösenberg and Matthias, 2003; Flamant et al., 1997; Mattis et al., 2008). The local maximum in the first derivative of the $1064 \mathrm{~nm}$ backscatter coefficient was considered to be the bottom of the layer. The local minimum was considered to be the layer top. To verify the determined layers, the layer boundaries identified by the gradient method were compared with the bottom and top heights of coherent structures in the height-time illustration of the range-corrected signal (Giannakaki et al., 2015). The layer identification was based on the assumption that the optical properties should be relatively homogeneous, which means that within one layer the variability of the optical properties should be lower than the statistical uncertainty of the individual data points. Two layers with a vertical distance less than $100 \mathrm{~m}$ apart from each other were combined into one layer. All layers detected during the $11 \mathrm{~d}$ period are shown in Fig. 2. Black, magenta, blue and yellow bars show the first, second, third and fourth layers, respectively. Triangles mark the part of the layer which was used for calculations of the mean optical properties of the layer. The lower limit for reliable profiles during our measurement period was at around $800 \mathrm{~m}$. Since the closest layer to the ground is assumed to contain the highest pollen concentration and share, we only consider the lowest layers (black) in the following analysis. 

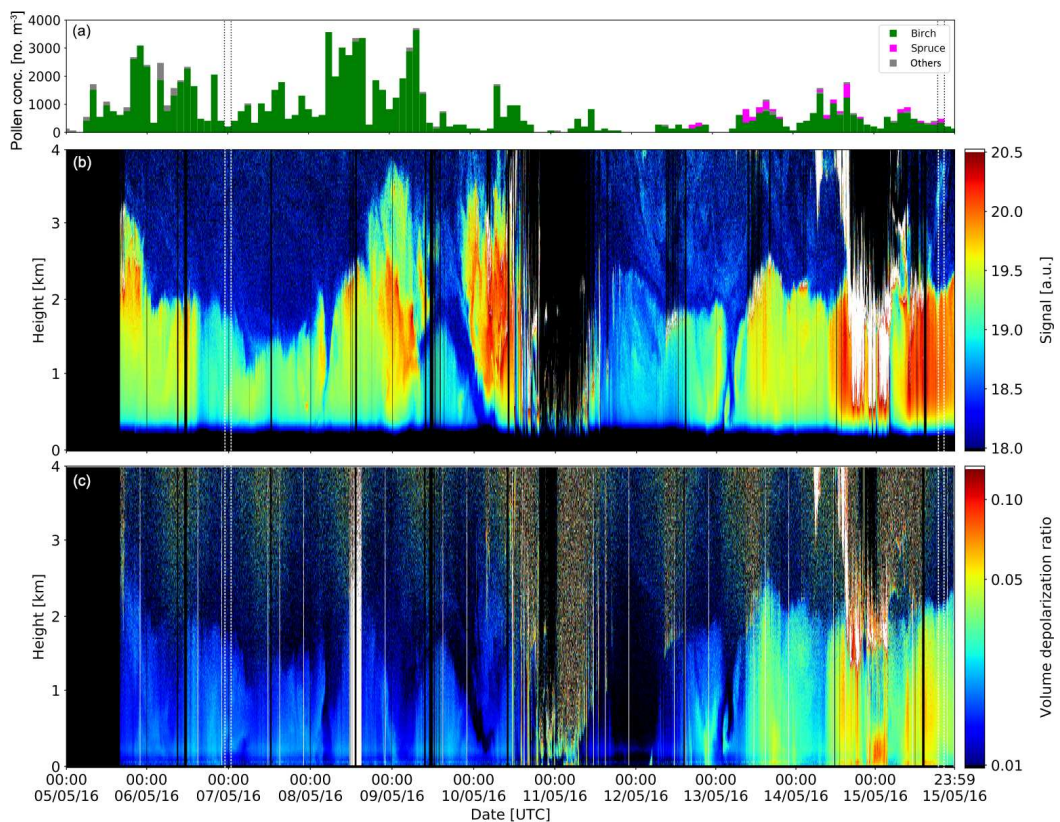

Figure 1. Overview of the $11 \mathrm{~d}$ birch pollen period. (a) Pollen concentration obtained from the Hirst-type pollen sampler, (b) range-corrected signal at $1064 \mathrm{~nm}$ and (c) volume depolarization ratio at $532 \mathrm{~nm}$. Dashed vertical lines mark the period of the case studies.

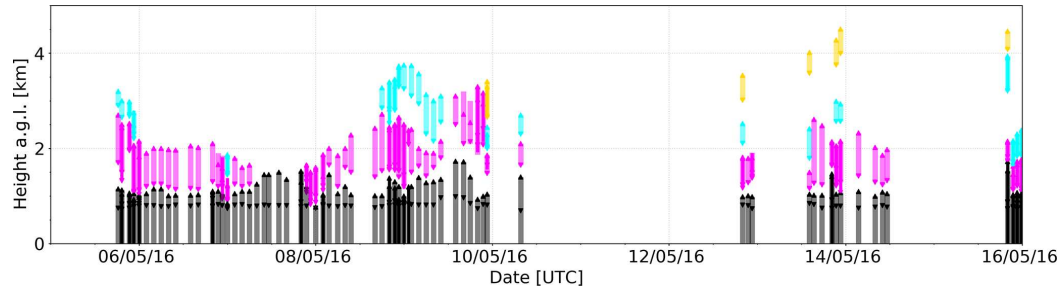

Figure 2. Layer definition during the measurement period 5-15 May 2016. The definition of layers is explained in Sect. 3. Colors mark the upper layers, which were not used for further analysis. Triangles mark the lower and upper limits of the area used for calculation.

\section{Results and discussion}

\subsection{Case studies}

We present two case studies representative for different pollen mixtures: in the first case study only birch pollen had been detected by the Hirst-type sampler, and in the second case study spruce pollen was detected in addition to birch. In the choice of case studies, backward trajectories have been considered to select cases with minimal contamination with of other aerosol. Furthermore, nighttime Raman measurements were chosen to present all lidar-derived parameters including the retrieved LR profile. Figure 3 shows, from left to right, the particle backscatter coefficient at
355 (blue), 532 (green) and $1064 \mathrm{~nm}$ (red); the particle extinction coefficient at 355 (dashed blue) and $532 \mathrm{~nm}$ (dashed green); the LR at 355 (blue) and $532 \mathrm{~nm}$ (green); the PDR at $532 \mathrm{~nm}$ (light green); the Ångström exponents calculated both from the backscatter coefficient at $355-532 \mathrm{~nm}$ (blue) and $532-1064 \mathrm{~nm}$ (red) and from extinction coefficients at $355-532 \mathrm{~nm}$ (black); and the relative humidity from lidarderived water vapor profiles (black) and temperature profiles from a radiosonde launched at 18:00 UTC (orange). Lidarderived optical properties were vertically smoothed using a sliding average of 25 bins $(750 \mathrm{~m})$. Four-day backward trajectories ending at the height of the layers and the middle of the time period are shown as well. 


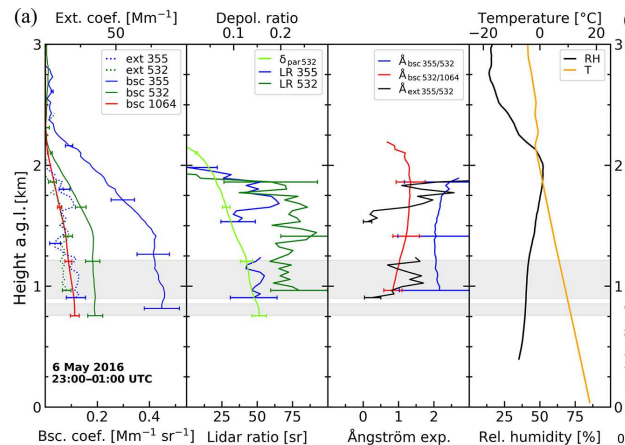

$4 \mathrm{~d}$ backward trajectories ending at
$62.738^{\circ} \mathrm{N}, 27.543^{\circ} \mathrm{E}$ on $07 / 05 / 16$ 00:00

(c) Ext. coef. $\left[\mathrm{Mm}^{-1}\right]$ Depol ratio
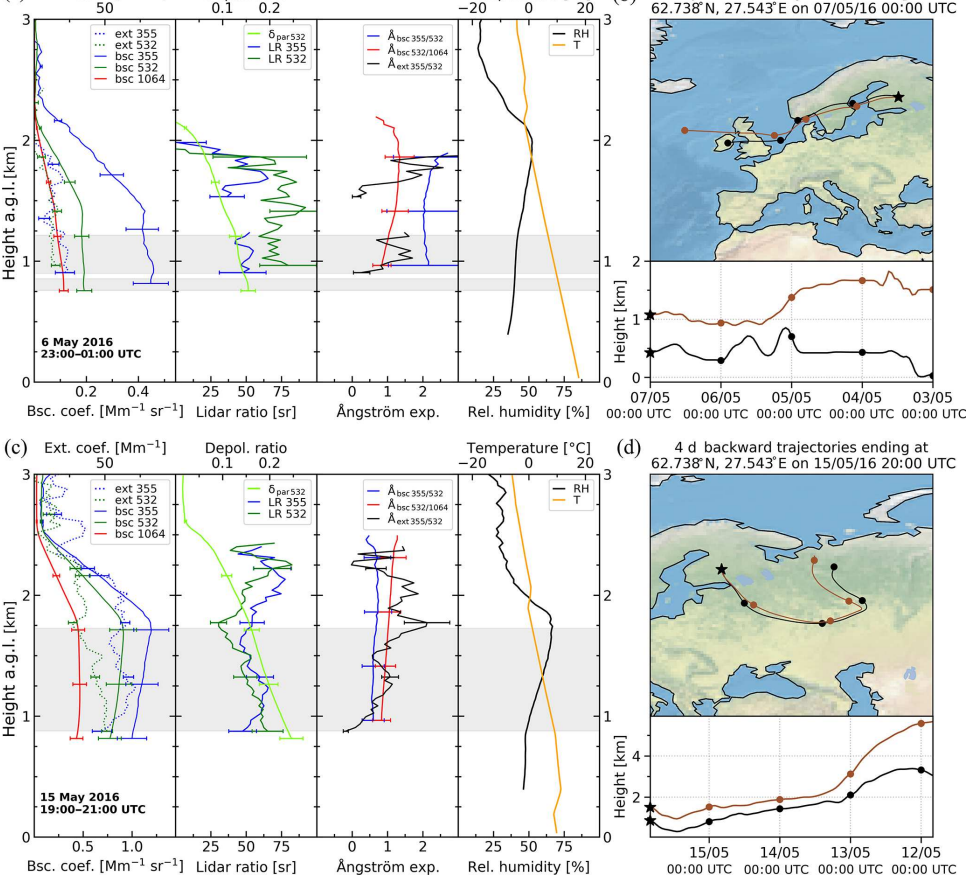

$4 \mathrm{~d}$ backward trajectories ending at
$62.738^{\circ} \mathrm{N}, 27.543^{\circ} \mathrm{E}$ on $15 / 05 / 1620: 00$ UTC

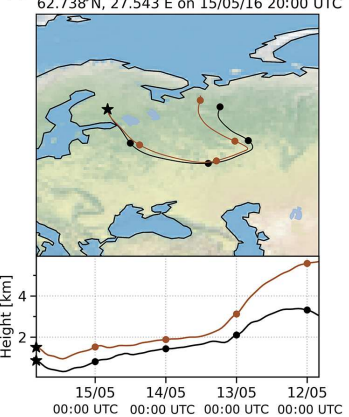

Figure 3. Two case studies of different pollen mixtures. (a, b) Period 1, 6 May 2016 23:00-01:00 UTC, only birch pollen was collected by the Hirst-type volumetric air sampler. (c, d) Period 2, 15 May 2016 19:00-21:00 UTC, birch and spruce pollen were collected. (a, c) Profiles of backscatter and extinction coefficients, particle depolarization and lidar ratio, Ångström exponents, relative humidity (derived from lidar measurements) and temperature profiles (18:00 UTC radio sounding). (b, d) Four-day HYSPLIT backward trajectories. Defined pollen layers are marked in gray.

The first case study was selected during the intense birch pollination event (period 1). On 6 May 2016 between 23:00 and 01:00 UTC only birch pollen was detected. Using the layer definition methodology (Sect. 3), three layers were determined, and the two lowest ones have been combined to one pollen layer for this analysis since the distance was less than $100 \mathrm{~m}$.

Four-day HYSPLIT (Hybrid Single Particle Lagrangian Integrated Trajectory) backward trajectories (Stein et al., 2015) ending at $450 \mathrm{~m}$ and $1.1 \mathrm{~km}$ on 7 May 00:00 UTC show that the air masses are advected from western directions and have traveled over the British Isles, the North Sea and southern Sweden. The contamination with depolarizing aerosol like dust is therefore considered to be negligible; however, the mixture with other anthropogenic aerosol cannot be ruled out. The presumed birch pollen layer was observed up to $1.2 \mathrm{~km}$. Extinction coefficient at $355 \mathrm{~nm}$ is about $22 \pm 2$ and is $13 \pm 1 \mathrm{Mm}^{-1}$ at $532 \mathrm{~nm}$. The mean LR for the observed layer is $49 \pm 4$ and $70 \pm 7 \mathrm{sr}$ at 355 and $532 \mathrm{~nm}$, respectively. Mean backscatter and extinction-related Ångström exponents at $355-532 \mathrm{~nm}$ are $2.1 \pm 0.04$ and $1.1 \pm 0.5$, respec- tively. The backscatter-related Ångström exponent between 532 and $1064 \mathrm{~nm}$ is $0.9 \pm 0.1$. The mean PDR at $532 \mathrm{~nm}$ within the layer is $14 \pm 1 \%$. Note that it can be even higher close to the ground, below the height of complete overlap. The PDR decreases with increasing height, while the LR remains constant. Thus the measured LR may not be a good indicator for characterizing the observed birch pollen in these cases as the contribution of pollen is assumed to decrease with increasing distance to the pollen source.

During our second case study on 15 May 2016 between 19:00 and 21:00 UTC, spruce pollen had been measured simultaneously with the birch pollen. Profiles and backward trajectories are shown in the lower row of Fig. 3 (Fig. 3c and d). The pollen layer reaches up to $1.7 \mathrm{~km}$.

The extinction coefficients at 355 and $532 \mathrm{~nm}$ are higher than in the previous case, being $61 \pm 5 \mathrm{Mm}^{-1}$ at $355 \mathrm{~nm}$ and $44 \pm 6 \mathrm{Mm}^{-1}$ at $532 \mathrm{~nm}$. The mean LR is $55 \pm 6 \mathrm{sr}$ at $355 \mathrm{~nm}$ and $51 \pm 9 \mathrm{sr}$ at $532 \mathrm{~nm}$. The backscatter and extinctionrelated Ångström exponents at $355-532 \mathrm{~nm}$ are lower than in the first case with values of 0.5 to 0.7 and 0.1 to 1.7 , 
(a)

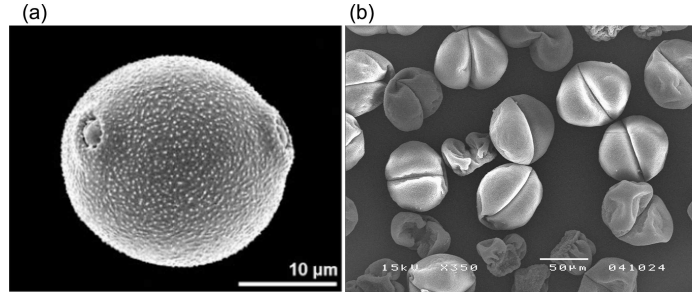

Figure 4. Pollen micrographs are shown. (a) Birch (Betula pendula) pollen grain (source: Halbritter and Diethart, 2016). (b) Spruce (Picea abies) pollen grains (source: the Biodiversity Unit of the University of Turku, Kari Kaunisto).

respectively. The backscatter-related Ångström exponent at $532-1064 \mathrm{~nm}$ is 0.8 to 1.0 .

The PDR at $532 \mathrm{~nm}$ is on average $19 \pm 2 \%, 24 \%$ at its maximum, and is clearly higher than in the case when only birch pollen was observed (period 1). The air masses arriving at the height of the layers on 15 May 20:00 UTC have been advected from Russia and remained close to the ground only for the last $12 \mathrm{~h}$ before reaching the site. The contamination with depolarizing dust can therefore be neglected. An explanation for the higher depolarization of the backscattered light is the nonspherical shape of the spruce pollen grains which have been detected in addition to birch pollen.

Figure 4 shows micrographs of birch and spruce pollen grains. Birch pollen (Fig. 4a) has a diameter around 20$30 \mu \mathrm{m}$, is almost spherical and possess three pores on the edge of the grain. Spruce pollen grains, on the other hand, possess two air bladders and are clearly nonspherical. Furthermore, those pollen grains are significantly larger, with their longest-axis diameter ranging between 90 and $110 \mu \mathrm{m}$ (including air bladders).

Pollen grains are low-density particles, which make them more sensitive to air currents, reduces the settling velocity and allows them to be lifted by turbulent air flows. Birch pollen, for example, has a gravitational settling velocity of around $1 \mathrm{~cm} \mathrm{~s}^{-1}$ (Sofiev et al., 2006). This settling velocity is similar to anthropogenic aerosol smaller than $10 \mu \mathrm{m}\left(\mathrm{PM}_{10}\right)$ although birch pollen grains are more than twice the size. The air bladders on the bigger spruce pollen grains increase the surface area of the grain without adding much mass and therefore decrease the settling velocity. Hence, even those big pollen grains can be lifted up to several kilometers and be dispersed by wind over thousands of kilometers as has been shown by several studies on the long-distance transport of pollen (Rousseau et al., 2008; Skjøth et al., 2007; Szczepanek et al., 2017).

\subsection{Lidar-derived optical parameters}

All pollen layers between 5 and 15 May have been identified and analyzed to determine the relationship between pollen type and the lidar-derived optical properties of the aerosol layer. Figure $5 \mathrm{a}$ shows the LR at $532 \mathrm{~nm}$ against the PDR at the same wavelength for all Raman measurements during nighttime. Measurements during the first intense birch pollination period are shown in green, while measurements during the second period, when spruce pollen was detected simultaneous to birch pollen, are shown in black. The size of the dots represents the measured pollen concentration by the Hirst-type sampler at ground level. The standard deviation is shown by the error bars. Lidar ratio values range from 31 to $74 \mathrm{sr}$. This wide range of LRs suggest that the LR alone is not a suitable parameter for the characterization of pollen as other aerosol types also show characteristic values in this range. However, the mean PDR within the pollen layers during the first period is $10 \pm 6 \%$, which is significantly higher than that of anthropogenic pollution. In the absence of other depolarizing aerosol, e.g., dust, pollen is likely the dominant aerosol causing this depolarization. Depolarization ratios higher than $15 \%$ are only observed during the second period (12-15 May) in which spruce pollen was present. The mean LR and PDR at $532 \mathrm{~nm}$ during this period are $62 \pm 10 \mathrm{sr}$ and $21 \pm 3 \%$, respectively. The significantly higher PDR is caused by the nonspherical shape of spruce pollen in those layers. In Fig. 5b, the backscatter-related Angström exponent between 532 and $1064 \mathrm{~nm}$ is shown against the PDR at $532 \mathrm{~nm}$ for all measurements between 5 and 15 May, including Klett retrievals for daytime measurements (dotted markers). A clear tendency towards smaller Ångström exponents with increasing depolarization ratios in both periods can be seen. This correlation indicates that the influence of nonspherical particles on the backscattered signal increases with decreasing Ångström exponent, i.e., bigger particles. The Ångström exponent in the second period is around 0.8 , whereas it is around 1 in the first period, demonstrating the effect of the larger spruce pollen $(\sim 90-110 \mu \mathrm{m})$, even with a small contribution $(\sim 14 \%)$ to the total pollen number concentration. But considering the different volumes of birch and spruce pollen grains, the contribution of spruce to the total volume concentration exceeds $75 \%$ in the second period, which may explain the large effect of spruce pollen on the measured optical properties even with a small number concentration.

However, the effect of the background particles has to be considered. Lidar measurements during the winter months of 2015 and 2016 and during pollen-free periods in spring and summer 2016 have been analyzed to determine the effect of background aerosol at our measurement site. During winter time the absence of pollen can be ensured but there is a possibility that pollen also had been present in the atmosphere during spring and summer when no pollen was detected by the Hirst-type sampler on the ground. Nevertheless, values of mean PDR at $532 \mathrm{~nm}$ are below $4 \%$ during all analyzed periods with no observed pollen. Since the PDR during the pollination period is significantly higher than the PDR of the background aerosol, the depolarization ratio can 


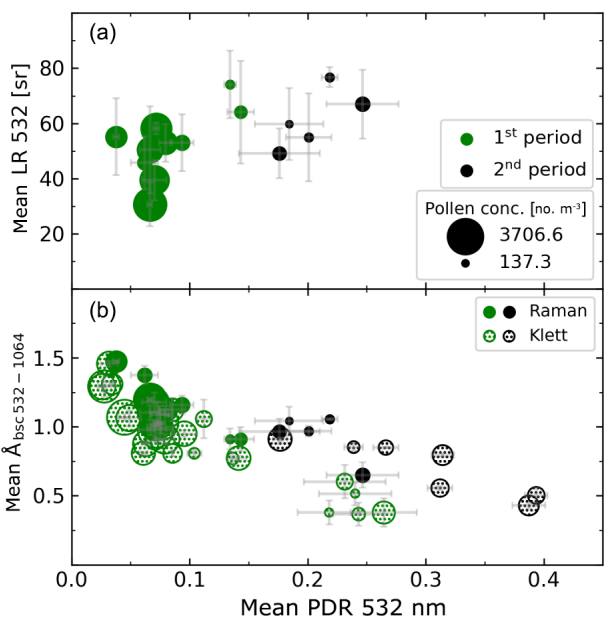

Figure 5. Mean values of optical properties of the detected pollen layers during the period 5 to 15 May. Error bars denote the standard deviation, and marker size denotes the pollen concentration. Marker color denotes the measurement period. Green dots are measured from 5 to 10 May and black dots from 12 to 15 May. Solid dots indicate Raman retrievals and dotted markers the Klett solution. Panel (a) shows lidar ratio at $532 \mathrm{~nm}$ vs. particle depolarization ratio at $532 \mathrm{~nm}$. Panel (b) shows backscatter-related Ångström exponent at $532-1064 \mathrm{~nm}$ vs. particle depolarization ratio at $532 \mathrm{~nm}$.

be used as an indicator for detecting the presence of pollen. The Ångström exponent, on the other hand, can be also related to the amount and type of background aerosol and is therefore less representative here.

Earlier studies show that relative humidity can affect the size and shape of pollen grains, which leads to different optical properties (Franchi et al., 1984; Griffiths et al., 2012; Katifori et al., 2010). When pollen grains dehydrate, the pollen wall can fold onto itself to prevent further dehydration, and this phenomena is known as harmomegathy (Katifori et al., 2010). The shape of the pollen grain changes, which could lead to significantly higher depolarization of the backscattered light. At humid conditions, pollen grains swell by taking up water internally and after reaching a relative humidity over $89 \%$ external wetting of the pollen surface can occur (Griffiths et al., 2012). To check whether the ambient relative humidity affects our measurements, the Ångström exponent $(532-1064 \mathrm{~nm})$ and the PDR at $532 \mathrm{~nm}$ are presented against the relative humidity in Fig. 6 . In the selected measurement periods, the relative humidity ranged between $40 \%$ and $65 \%$. In this humidity range, Ångström exponent (Fig. 6a) and depolarization ratio (Fig. 6b) do not show any correlation with the relative humidity. Thus, our measurements were not affected by extreme humidity events and represent values for pollen under ambient atmospheric conditions in the spring season in Finland. However, lidar measurements of relative

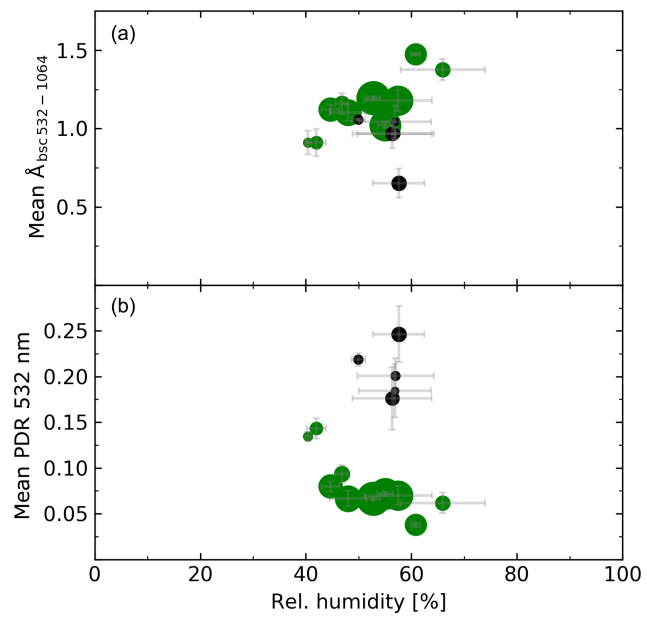

Figure 6. Dependence of the backscatter-related Ångström exponent at $532-1064 \mathrm{~nm}$ (a) and the particle depolarization ratio at $532 \mathrm{~nm}$ (b) on the relative humidity for all Raman measurements of pure and mixed birch cases during the first period (5-10 May, green) and the second period (12-15 May, black).

humidity profiles are only available during nighttime. The relative humidity in the observed pollen layers during daytime could be smaller. This could result in occasional folding of the pollen grains and higher depolarization ratios. This hypothesis could also explain the higher depolarization ratios of about $25 \%$ of a few Klett measurements of birch pollen during the first period.

Table 1 summarizes the mean intensive properties together with the associated standard derivation (SD), range and median in the first (birch) period of our campaign. The contribution of other pollen types in this period was small. Those values, therefore, can be considered to be characteristic for birch-pollen-dominated aerosol conditions. Table 2 shows the same properties for the spruce-contaminated period. $\mathrm{Li}$ dar ratio and PDR are higher when spruce is detected simultaneously with birch. The PDR values for birch pollen are considerably lower than previously determined in lidar studies. A linear depolarization ratio up to $30 \%$ at $694 \mathrm{~nm}$ was detected by Sassen (2008) for paper birch in Alaska. And under controlled laboratory environment, Cao et al. (2010) measured a linear depolarization ratio at $532 \mathrm{~nm}$ of $33 \%$ for dried paper birch pollen. We assume that those high depolarization values can be caused by dry birch pollen grains, which fold and change their shape when dehydrating. Under ambient conditions the pollen grains are more spherical and therefore less depolarizing. Also, the orientation of the pollen grains in the atmosphere has to be considered. Pollen with air bladders, e.g., spruce pollen, is known to align with its air bladders upwards when drifting in the air (Schwendemann 
Table 1. Mean values, range and median of optical properties of the detected pollen layers in the first measurement period: 5-10 May, intense birch pollination period.

\begin{tabular}{lrrrr}
\hline \multicolumn{1}{c}{ Parameter } & & Mean $\pm \mathrm{SD}$ & Range & Median \\
\hline Layer top height $(\mathrm{km})$ & & $1.3 \pm 0.3$ & $1.0-2.2$ & 1.2 \\
\hline Backscatter coefficient & $355 \mathrm{~nm}$ & $0.7 \pm 0.5$ & $0.1-2.4$ & 0.7 \\
$\left(\mathrm{Mm}^{-1} \mathrm{sr}^{-1}\right)$ & $532 \mathrm{~nm}$ & $0.3 \pm 0.2$ & $0.1-1.0$ & 0.3 \\
& $1064 \mathrm{~nm}$ & $0.2 \pm 0.1$ & $0.1-0.4$ & 0.2 \\
\hline Extinction coefficient & $355 \mathrm{~nm}$ & $33.0 \pm 13.3$ & $20.0-68.2$ & 30.9 \\
$\left(\mathrm{Mm}^{-1}\right)$ & $532 \mathrm{~nm}$ & $19.0 \pm 6.5$ & $11.0-34.4$ & 19.1 \\
\hline Lidar ratio $(\mathrm{sr})$ & $355 \mathrm{~nm}$ & $46 \pm 8$ & $34-60$ & 46 \\
& $532 \mathrm{~nm}$ & $52 \pm 12$ & $31-74$ & 53 \\
\hline PDR & $532 \mathrm{~nm}$ & $0.10 \pm 0.06$ & $0.03-0.26$ & 0.08 \\
\hline Number of pollen layers & & all: 41 & Raman: 10 & \\
\hline
\end{tabular}

Table 2. Mean values, range and median of optical properties of the detected pollen layers in the second measurement period: 12-15 May, spruce-contaminated period.

\begin{tabular}{llrrr}
\hline \multicolumn{1}{c}{ Parameter } & & Mean $\pm \mathrm{SD}$ & Range & Median \\
\hline Layer top height $(\mathrm{km})$ & & $1.3 \pm 0.4$ & $1-2.2$ & 1.1 \\
\hline Backscatter coefficient & $355 \mathrm{~nm}$ & $0.7 \pm 0.2$ & $0.3-1.1$ & 0.6 \\
$\left(\mathrm{Mm}^{-1} \mathrm{sr}^{-1}\right)$ & $532 \mathrm{~nm}$ & $0.5 \pm 0.2$ & $0.3-0.8$ & 0.4 \\
& $1064 \mathrm{~nm}$ & $0.3 \pm 0.1$ & $0.2-0.4$ & 0.2 \\
\hline Extinction coefficient & $355 \mathrm{~nm}$ & $52.9 \pm 13.1$ & $26.9-60.9$ & 58.5 \\
$\left(\mathrm{Mm}^{-1}\right)$ & $532 \mathrm{~nm}$ & $40.0 \pm 9.5$ & $24.6-54.6$ & 40.2 \\
\hline Lidar ratio $(\mathrm{sr})$ & $355 \mathrm{~nm}$ & $60 \pm 3$ & $55-64$ & 59 \\
& $532 \mathrm{~nm}$ & $62 \pm 10$ & $49-77$ & 60 \\
\hline PDR & $532 \mathrm{~nm}$ & $0.26 \pm 0.07$ & $0.18-0.39$ & 0.24 \\
\hline Number of pollen layers & & all: 12 & Raman: 5 & \\
\hline
\end{tabular}

et al., 2007), and also an orientation of the almost spherical birch pollen grains was observed (Sassen, 2011; Tränkle and Mielke, 1994). This could cause differences in the measured optical properties if the orientation of the particles in laboratory experiments is not considered, or the irregularly shaped particles are observed from different angles.

\section{Conclusion}

Particle depolarization ratios of about $10 \%$ have been observed during a birch pollination event in Vehmasmäki, Finland. When more nonspherical pollen, e.g., spruce, is present, the particle depolarization ratio can be as high as $26 \%$. Those depolarization ratios are similar to dust and biomass-burning aerosol mixtures (Tesche et al., 2011) or dust mixtures with marine aerosol (Groß et al., 2011), thus pollen could easily be misclassified as dusty mixtures. The mean LRs show a wide range of values depending on the mixing of differ- ent pollen types in the atmosphere. The mean LR at $355 \mathrm{~nm}$ varies between $46 \pm 8 \mathrm{sr}$ (first period) and $60 \pm 3 \mathrm{sr}$ (second period) and at $532 \mathrm{~nm}$ between $52 \pm 12 \mathrm{sr}$ (first period) and $62 \pm 10 \mathrm{sr}$ (second period). Those LRs are characteristic for dust or dust-smoke mixtures (Tesche et al., 2011), which complicates the characterization of pollen using the LR. Also the backscatter-related Ångström exponents at 532$1064 \mathrm{~nm}$, which is around 1.0 for the intense birch pollination period and around 0.8 for the spruce-contaminated period, are similar to characteristic values for smoke and dustsmoke mixtures, respectively. Thus, in order to distinguish between pollen and other aerosol types, all three parameters and backward trajectories as well as possible dust and biomass-burning aerosol sources have to be considered.

The presented data show the potential of lidar measurements to detect pollen in the atmosphere. Nevertheless, there are challenges which need to be addressed in order to improve the characterization of optical properties of airborne 
pollen. First, the minimum height of the usable lidar signal needs to be as low as possible. By operating a lidar system with a low full-overlap height or additional near-field channels, the coverage of lower heights can be significantly improved. Second, the contribution of other aerosol types like anthropogenic pollution has to be determined. Therefore, more multiwavelength lidar studies with depolarization characterization on atmospheric pollen are necessary.

Data availability. Lidar data are available upon request from the authors and data "quicklooks" are available on the PollyNET website (http://polly.tropos.de/, last access: 22 November 2019). Trajectories are calculated with the NOAA (National Oceanic and Atmospheric Administration) HYSPLIT (HYbrid Single-Particle Lagrangian Integrated Trajectory) model (https://ready.arl.noaa.gov/ HYSPLIT.php, last access: 30 April 2019). Fire data are available at the NASA Worldview application (https://worldview.earthdata. nasa.gov, last access: 30 April 2019). BSC-DREAM8b model simulations are operated by the Barcelona Supercomputing Center and are available at https://ess.bsc.es/bsc-dust-daily-forecast/ (last access: 30 April 2019).

Author contributions. SB, XS and MF performed the lidar data analysis. AS analyzed the pollen samples. MK and EG initiated the measurement campaign. All authors contributed to the scientific discussion and the article preparation.

Competing interests. The authors declare that they have no conflict of interest.

Special issue statement. This article is part of the special issue "EARLINET aerosol profiling: contributions to atmospheric and climate research". It is not associated with a conference.

Acknowledgements. We acknowledge the use of data and imagery of BSC-DREAM8b simulations performed by the Barcelona Supercomputing Center and from the NASA Worldview application (https://worldview.earthdata.nasa.gov), part of the NASA Earth Observing System Data and Information System (EOSDIS). We thank the NOAA Air Resources Laboratory (ARL) for the provision of the HYSPLIT transport and dispersion model used in this publication.

Financial support. This project was supported by the Academy of Finland (project no. 310312).

Review statement. This paper was edited by Albert Ansmann and reviewed by two anonymous referees.

\section{References}

Althausen, D., Engelmann, R., Baars, H., Heese, B., Ansmann, A., Müller, D., and Komppula, M.: Portable Raman lidar Polly ${ }^{X T}$ for automated profiling of aerosol backscatter, extinction, and depolarization, J. Atmos. Ocean. Tech., 26, 2366-2378, https://doi.org/10.1175/2009JTECHA1304.1, 2009.

Ansmann, A., Wandinger, U., Riebesell, M., Weitkamp, C., and Michaelis, W.: Independent measurement of extinction and backscatter profiles in cirrus clouds by using a combined Raman elastic-backscatter lidar, Appl. Opt., 31, 7113-7131, 1992.

Baars, H., Ansmann, A., Althausen, D., Engelmann, R., Heese, B., Müller, D., Artaxo, P., Paixao, M., Pauliquevis, T. and Souza, R.: Aerosol profiling with lidar in the Amazon Basin during the wet and dry season, J. Geophys. Res.-Atmos., 117, D21201, https://doi.org/10.1029/2012JD018338, 2012.

Baars, H., Kanitz, T., Engelmann, R., Althausen, D., Heese, B., Komppula, M., Preißler, J., Tesche, M., Ansmann, A., Wandinger, U., Lim, J.-H., Ahn, J. Y., Stachlewska, I. S., Amiridis, V., Marinou, E., Seifert, P., Hofer, J., Skupin, A., Schneider, F., Bohlmann, S., Foth, A., Bley, S., Pfüller, A., Giannakaki, E., Lihavainen, H., Viisanen, Y., Hooda, R. K., Pereira, S. N., Bortoli, D., Wagner, F., Mattis, I., Janicka, L., Markowicz, K. M., Achtert, P., Artaxo, P., Pauliquevis, T., Souza, R. A. F., Sharma, V. P., van Zyl, P. G., Beukes, J. P., Sun, J., Rohwer, E. G., Deng, R., Mamouri, R.-E., and Zamorano, F.: An overview of the first decade of PollyNET: an emerging network of automated Raman-polarization lidars for continuous aerosol profiling, Atmos. Chem. Phys., 16, 5111-5137, https://doi.org/10.5194/acp16-5111-2016, 2016.

Bartková-Ščevková, J.: The influence of temperature, relative humidity and rainfall on the occurrence of pollen allergens (Betula, Poaceae, Ambrosia artemisiifolia) in the atmosphere of Bratislava (Slovakia), Int. J. Biometeorol., 48, 1-5, https://doi.org/10.1007/s00484-003-0166-2, 2003.

Basart, S., Pérez, C., Nickovic, S., Cuevas, E., and Baldasano, J. M.: Development and evaluation of the BSCDREAM8b dust regional model over Northern Africa, the Mediterranean and the Middle East, Tellus B, 64, 18539, https://doi.org/10.3402/tellusb.v64i0.18539, 2012.

Bösenberg, J. and Matthias, V.: EARLINET: A European Aerosol Research Lidar Network to Establish an Aerosol Climatology, MPI Rep., 348, 6-31, 2003.

Bousquet, J., Khaltaev, N., Cruz, A. A., Denburg, J., Fokkens, W. J., Togias, A., Zuberbier, T., Baena-Cagnani, C. E., Canonica, G. W., Van Weel, C., Agache, I., Aït-Khaled, N., Bachert, C., Blaiss, M. S., Bonini, S., Boulet, L.-P., Bousquet, P.-J., Camargos, P., Carlsen, K.-H., Chen, Y., Custovic, A., Dahl, R., Demoly, P., Douagui, H., Durham, S. R., Van Wijk, R. G., Kalayci, O., Kaliner, M. A., Kim, Y.-Y., Kowalski, M. L., Kuna, P., Le, L. T. T., Lemiere, C., Li, J., Lockey, R. F., MavaleManuel, S., Meltzer, E. O., Mohammad, Y., Mullol, J., Naclerio, R., O’Hehir, R. E., Ohta, K., Ouedraogo, S., Palkonen, S., Papadopoulos, N., Passalacqua, G., Pawankar, R., Popov, T. A., Rabe, K. F., Rosado-Pinto, J., Scadding, G. K., Simons, F. E. R., Toskala, E., Valovirta, E., Van Cauwenberge, P., Wang, D.-Y., Wickman, M., Yawn, B. P., Yorgancioglu, A., Yusuf, O. M., Zar, H., Annesi-Maesano, I., Bateman, E. D., Kheder, A. Ben, Boakye, D. A., Bouchard, J., Burney, P., Busse, W. W., Chan-Yeung, M., Chavannes, N. H., Chuchalin, A., Dolen, 
W. K., Emuzyte, R., Grouse, L., Humbert, M., Jackson, C., Johnston, S. L., Keith, P. K., Kemp, J. P., Klossek, J.-M., Larenas-Linnemann, D., Lipworth, B., Malo, J.-L., Marshall, G. D., Naspitz, C., Nekam, K., Niggemann, B., NizankowskaMogilnicka, E., Okamoto, Y., Orru, M. P., Potter, P., Price, D., Stoloff, S. W., Vandenplas, O., Viegi, G., and Williams, D.: Allergic Rhinitis and its Impact on Asthma (ARIA) 2008, Allergy, 63, 8-160, https://doi.org/10.1111/j.1398-9995.2007.01620.x, 2008.

Buters, J. T. M., Antunes, C., Galveias, A., Bergmann, K. C., Thibaudon, M., Galán, C., Schmidt-Weber, C., and Oteros, J.: Pollen and spore monitoring in the world, Clin. Transl. Allergy, 8, 9, https://doi.org/10.1186/s13601-018-0197-8, 2018.

Cao, X., Roy, G., and Bernier, R.: Lidar polarization discrimination of bioaerosols, Opt. Eng., 49, 116201, https://doi.org/10.1117/1.3505877, 2010.

Crouzy, B., Stella, M., Konzelmann, T., Calpini, B., and Clot, B.: All-optical automatic pollen identification: Towards an operational system, Atmos. Environ., 140, 202-212, https://doi.org/10.1016/J.ATMOSENV.2016.05.062, 2016.

D'Amato, G., Cecchi, L., Bonini, S., Nunes, C., AnnesiMaesano, I., Behrendt, H., Liccardi, G., Popov, T., and van Cauwenberge, P.: Allergenic pollen and pollen allergy in Europe, Allergy, 62, 976-990, https://doi.org/10.1111/j.13989995.2007.01393.x, 2007.

Diehl, K., Quick, C., Matthias-Maser, S., Mitra, S. K., and Jaenicke, R.: The ice nucleating ability of pollen Part I: Laboratory studies in deposition and condensation freezing modes, Atmos. Res., 58, 75-87, https://doi.org/10.1016/S0169-8095(01)00091-6, 2001.

Diehl, K., Matthias-Maser, S., Jaenicke, R., and Mitra, S. K.: The ice nucleating ability of pollen: Part II. Laboratory studies in immersion and contact freezing modes, Atmos. Res., 61, 125-133, https://doi.org/10.1016/S0169-8095(01)00132-6, 2002.

Engelmann, R., Kanitz, T., Baars, H., Heese, B., Althausen, D., Skupin, A., Wandinger, U., Komppula, M., Stachlewska, I. S., Amiridis, V., Marinou, E., Mattis, I., Linné, H., and Ansmann, A.: The automated multiwavelength Raman polarization and water-vapor lidar Polly XT: the neXT generation, Atmos. Meas. Tech., 9, 1767-1784, https://doi.org/10.5194/amt-9-1767-2016, 2016.

Fernald, F. G.: Analysis of atmospheric lidar observations: some comments, Appl. Opt., 23, 652-653, 1984.

Filioglou, M., Nikandrova, A., Niemelä, S., Baars, H., Mielonen, T., Leskinen, A., Brus, D., Romakkaniemi, S., Giannakaki, E., and Komppula, M.: Profiling water vapor mixing ratios in Finland by means of a Raman lidar, a satellite and a model, Atmos. Meas. Tech., 10, 4303-4316, https://doi.org/10.5194/amt10-4303-2017, 2017.

Flamant, C., Pelon, J., Flamant, P. H., and Durand, P.: Lidar determination of the entrainment zone thickness at the top of the unstable marine atmospheric boundary layer, Bound.-Lay. Meteorol., 83, 247-284, https://doi.org/10.1023/A:1000258318944, 1997.

Franchi, G. G., Pacini, E., and Rottoli, P.: Pollen grain viability in Parietaria judaica L. during the long blooming period and correlation with meteorological conditions and allergic diseases, G. Bot. Ital., 118, 163-178, https://doi.org/10.1080/11263508409426670, 1984.

Freudenthaler, V., Esselborn, M., Wiegner, M., Heese, B., Tesche, M., Ansmann, A., Müller, D., Althausen, D., Wirth, M., Fix, A.,
Ehret, G., Knippertz, P., Toledano, C., Gasteiger, J., Garhammer, M., and Seefeldner, M.: Depolarization ratio profiling at several wavelengths in pure Saharan dust during SAMUM 2006, Tellus B, 61, 165-179, 2009.

Giannakaki, E., Pfüller, A., Korhonen, K., Mielonen, T., Laakso, L., Vakkari, V., Baars, H., Engelmann, R., Beukes, J. P., Van Zyl, P. G., Josipovic, M., Tiitta, P., Chiloane, K., Piketh, S., Lihavainen, H., Lehtinen, K. E. J., and Komppula, M.: One year of Raman lidar observations of free-tropospheric aerosol layers over South Africa, Atmos. Chem. Phys., 15, 5429-5442, https://doi.org/10.5194/acp-15-5429-2015, 2015.

Griffiths, P. T., Borlace, J.-S., Gallimore, P. J., Kalberer, M., Herzog, M., and Pope, F. D.: Hygroscopic growth and cloud activation of pollen: a laboratory and modelling study, Atmos. Sci. Lett., 13, 289-295, https://doi.org/10.1002/asl.397, 2012.

Groß, S., Tesche, M., Freudenthaler, V., Toledano, C., Wiegner, M., Ansmann, A., Althausen, D. and Seefeldner, M.: Characterization of Saharan dust, marine aerosols and mixtures of biomassburning aerosols and dust by means of multi-wavelength depolarization and Raman lidar measurements during SAMUM 2, Tellus B, 63, 706-724, https://doi.org/10.1111/j.16000889.2011.00556.x, 2011.

Halbritter, H. and Diethart, B.: Betula pendula, in: PalDat - A palynological database, available at: https://www.paldat.org/pub/ Betula_pendula/300732 (last access: 22 November 2019), 2016.

Hirst, J. M.: An automatic volumetric spore trap, Ann. Appl. Biol., 39, 257-265, https://doi.org/10.1111/j.17447348.1952.tb00904.x, 1952.

IPCC: Climate Change 2013: The Physical Science Basis. Contribution of Working Group I to the Fifth Assessment Report of the Intergovernmental Panel on Climate Change, edited by: Stocker, T. F., Qin, D., Plattner, G.-K., Tignor, M., Allen, S. K., Boschung, J., Nauels, A., Xia, Y., Bex, V., and Midgley, P. M., Cambridge University Press, 2013.

Katifori, E., Alben, S., Cerda, E., Nelson, D. R., and Dumais, J.: Foldable structures and the natural design of pollen grains, P. Natl. Acad. Sci. USA, 107, 7635-7639, https://doi.org/10.1073/pnas.0911223107, 2010.

Klett, J. D.: Stable analytical solution for processing lidar returns, Appl. Opt., 20, 211-220, 1981.

Lake, I. R., Jones, N. R., Agnew, M., Goodess, C. M., Giorgi, F., Hamaoui-Laguel, L., Semenov, M. A., Solmon, F., Storkey, J., Vautard, R., and Epstein, M. M.: Erratum: "Climate Change and Future Pollen Allergy in Europe,” Environ. Health Persp., 126, 079002, https://doi.org/10.1289/EHP2073, 2018.

Mattis, I., Müller, D., Ansmann, A., Wandinger, U., Preißler, J., Seifert, P., and Tesche, M.: Ten years of multiwavelength Raman lidar observations of free-tropospheric aerosol layers over central Europe: Geometrical properties and annual cycle, J. Geophys. Res., 113, D20202, https://doi.org/10.1029/2007JD009636, 2008 .

MODIS: $\quad$ MODIS $\quad$ Collection $6 \quad$ NRT Hotspot/Active Fire Detections MCD14DL, https://doi.org/10.5067/FIRMS/MODIS/MCD14DL.NRT.006, 2019.

Noh, M. Y., Müller, D., Lee, H., and Choi, T.: Influence of biogenic pollen on optical properties of atmospheric aerosols observed by lidar over Gwangju, South Korea, Atmos. Environ., 69, 139-147, https://doi.org/10.1016/j.atmosenv.2012.12.018, 2013a. 
Noh, Y. M., Lee, H., Mueller, D., Lee, K., Shin, D., Shin, S., Choi, T. J., Choi, Y. J., and Kim, K. R.: Investigation of the diurnal pattern of the vertical distribution of pollen in the lower troposphere using LIDAR, Atmos. Chem. Phys., 13, 7619-7629, https://doi.org/10.5194/acp-13-7619-2013, 2013b.

Oteros, J., Pusch, G., Weichenmeier, I., Heimann, U., Möller, R., Röseler, S., Traidl-Hoffmann, C., SchmidtWeber, C., and Buters, J. T. M.: Automatic and Online Pollen Monitoring, Int. Arch. A. Imm., 167, 158-166, https://doi.org/10.1159/000436968, 2015.

Richardson, S. C., Mytilinaios, M., Foskinis, R., Kyrou, C., Papayannis, A., Pyrri, I., Giannoutsou, E., and Adamakis, I. D. S.: Bioaerosol detection over Athens, Greece using the laser induced fluorescence technique, Sci. Total Environ., 696, 133906, https://doi.org/10.1016/j.scitotenv.2019.133906, 2019.

Rousseau, D.-D., Schevin, P., Ferrier, J., Jolly, D., Andreasen, T., Ascanius, S. E., Hendriksen, S.-E., and Poulsen, U.: Long-distance pollen transport from North America to Greenland in spring, J. Geophys. Res.-Biogeo., 113, G02013, https://doi.org/10.1029/2007JG000456, 2008.

Saito, Y., Ichihara, K., Morishita, K., Uchiyama, K., Kobayashi, F., and Tomida, T.: Remote Detection of the Fluorescence Spectrum of Natural Pollens Floating in the Atmosphere Using a LaserInduced-Fluorescence Spectrum (LIFS) Lidar, Remote Sens., 10, 1533, https://doi.org/10.3390/rs10101533, 2018.

Sassen, K.: Polarization in lidar, in Lidar: Range-Resolved Optical Remote Sensing of the Atmosphere, edited by: Weitkamp, C., Springer, 19-42, 2005.

Sassen, K.: Boreal tree pollen sensed by polarization lidar: Depolarizing biogenic chaff, Geophys. Res. Lett., 35, L18810, https://doi.org/10.1029/2008GL035085, 2008.

Sassen, K.: Elliptical pollen corona from North American boreal paper birch trees (Betula papyrifera): strong fall orientations for near-spherical particles, Appl. Opt., 50, F1-F5, https://doi.org/10.1364/AO.50.0000F1, 2011.

Schmidt, C. W.: Pollen Overload: Seasonal Allergies in a Changing Climate, Environ. Health Persp., 124, A70-A75, https://doi.org/10.1289/ehp.124-A70, 2016.

Schwendemann, A. B., Wang, G., Mertz, M. L., McWilliams, R. T., Thatcher, S. L., and Osborn, J. M.: Aerodynamics of saccate pollen and its implications for wind pollination, Am. J. Bot., 94, 1371-1381, https://doi.org/10.3732/ajb.94.8.1371, 2007.

Sicard, M., Izquierdo, R., Alarcón, M., Belmonte, J., Comerón, A., and Baldasano, J. M.: Near-surface and columnar measurements with a micro pulse lidar of atmospheric pollen in Barcelona, Spain, Atmos. Chem. Phys., 16, 6805-6821, https://doi.org/10.5194/acp-16-6805-2016, 2016.
Skjøth, C. A., Sommer, J., Stach, A., Smith, M. and Brandt, J.: The long-range transport of birch (Betula) pollen from Poland and Germany causes significant pre-season concentrations in Denmark, Clin. Exp. Allergy, 37, 1204-1212, https://doi.org/10.1111/j.1365-2222.2007.02771.x, 2007.

Sofiev, M., Siljamo, P., Ranta, H., and Rantio-Lehtimäki, A.: Towards numerical forecasting of long-range air transport of birch pollen: theoretical considerations and a feasibility study, Int. J. Biometeorol., 50, 392-402, https://doi.org/10.1007/s00484-0060027-x, 2006.

Stein, A. F., Draxler, R. R., Rolph, G. D., Stunder, B. J. B., and Cohen, M. D.: NOAA's HYSPLIT Atmospheric Transport and Dispersion Modeling System, B. Am. Meteorol. Soc., 96, 20592077, https://doi.org/10.1175/BAMS-D-14-00110.1, 2015.

Steiner, A. L., Brooks, S. D., Deng, C., Thornton, D. C. O., Pendleton, M. W., and Bryant, V.: Pollen as atmospheric cloud condensation nuclei, Geophys. Res. Lett., 42, 3596-3602, https://doi.org/10.1002/2015GL064060, 2015.

Szczepanek, K., Myszkowska, D., Worobiec, E., Piotrowicz, K., Ziemianin, M., and Bielec-Bạkakowska, Z.: The longrange transport of Pinaceae pollen: an example in Kraków (southern Poland), Aerobiologia (Bologna), 33, 109-125, https://doi.org/10.1007/s10453-016-9454-2, 2017.

Tesche, M., Groß, S., Ansmann, A., Müller, D., Althausen, D., Freudenthaler, V. and Esselborn, M.: Profiling of Saharan dust and biomass-burning smoke with multiwavelength polarization Raman lidar at Cape Verde, Tellus B, 63, 649-676, 2011.

Tränkle, E. and Mielke, B.: Simulation and analysis of pollen coronas, Appl. Opt., 33, 4552-4562, https://doi.org/10.1364/AO.33.004552, 1994.

von Blohn, N., Mitra, S. K., Diehl, K., and Borrmann, S.: The ice nucleating ability of pollen: Part III: New laboratory studies in immersion and contact freezing modes including more pollen types, Atmos. Res., 78, 182-189, https://doi.org/10.1016/j.atmosres.2005.03.008, 2005.

Wandinger, U. and Ansmann, A.: Experimental determination of the lidar overlap profile with Raman lidar, Appl. Opt., 41, 511-514, 2002.

WHO: World Health Report 2003: A Vision for Global Health, Shaping the Future, World Heal. Organ., 2003. 


\section{Paper III}

Optical and geometrical aerosol particle properties over the United Arab Emirates.

Filioglou, M, Giannakaki, E., Backman, J., Kesti, J., Hirsikko, A., Engelmann, R., O'Connor, E, Leskinen, J. T. T., Shang, X., Korhonen H, Lihavainen, H., Romakkaniemi, S, and Komppula, M.

Atmospheric Chemistry and Physics Discussion, 2020, https://doi.org/10.5194/acp$\underline{2020-133}$

Reproduced under the Creative Commons Attribution 4.0 License (CC BY4.0). 


\section{Optical and geometrical aerosol particle properties over the United Arab Emirates}

Maria Filioglou ${ }^{1}$, Elina Giannakaki1 ${ }^{1,2}$, John Backman $^{3}$, Jutta Kesti ${ }^{3}$, Anne Hirsikko $^{3}$, Ronny Engelmann ${ }^{4}$, Ewan O'Connor ${ }^{3}$, Jari T.T Leskinen ${ }^{5}$, Xiaoxia Shang ${ }^{1}$, Hannele Korhonen ${ }^{3}$, Heikki Lihavainen ${ }^{3,6}$, Sami 5 Romakkaniemi ${ }^{1}$ and Mika Komppula ${ }^{1}$

\footnotetext{
${ }^{1}$ Finnish Meteorological Institute, Kuopio, FI70211, Finland 15784, Greece

${ }^{3}$ Finnish Meteorological Institute, Helsinki, FI00560, Finland

$10{ }^{4}$ Leibniz Institute for Tropospheric Research (TROPOS), Leipzig, DE04318, Germany

${ }^{5}$ University of Eastern Finland, Kuopio, FI70211, Finland

${ }^{6}$ Svalbard Integrated Arctic Earth Observing System, Longyearbyen, N-9170, Norway
}

${ }^{2}$ Environmental Physics and Meteorology, Faculty of Physics, National and Kapodistrian University of Athens, Athens, GR

Correspondence to: Maria Filioglou (maria.filioglou@fmi.fi)

Abstract. One-year of ground-based night-time Raman lidar observations have been analysed under the Optimization of Aerosol Seeding In rain enhancement Strategies (OASIS) project, in order to characterize the aerosol particle properties over a rural site in the United Arab Emirates. In total, 1130 aerosol particle layers were detected during the one-year measurement campaign which took place between March 2018 and February 2019. Several subsequent aerosol layers could be observed simultaneously in the atmosphere up to $11 \mathrm{~km}$. The observations indicate that the measurement site is a receptor of frequent dust events but predominantly the dust is mixed with aerosols of anthropogenic and/or marine origin. The mean aerosol optical depth over the measurement site ranged at $0.37 \pm 0.12$ and $0.21 \pm 0.11$ for the 355 and $532 \mathrm{~nm}$, respectively. Moreover, a mean lidar ratio of $43 \pm 11 \mathrm{sr}$ at a wavelength of $355 \mathrm{~nm}$ and $39 \pm 10 \mathrm{sr}$ at $532 \mathrm{~nm}$ was found. The average linear particle depolarization ratio measured over the course of the campaign was $15 \pm 6 \%$ and $19 \pm 7 \%$ at $355 \mathrm{~nm}$ and $532 \mathrm{~nm}$ wavelengths, respectively. Since the region is both a source and a receptor of mineral dust, we have also explored the properties of Arabian mineral dust of the greater area of United Arab of Emirates and the Arabian Peninsula. The observed Arabian dust particle properties were $45 \pm 5(42 \pm 5)$ sr at $355(532) \mathrm{nm}$ for the lidar ratio, $25 \pm 2 \%(31 \pm 2 \%)$ for the linear particle depolarization ratio at $355(532) \mathrm{nm}$, and $0.3 \pm 0.2(0.2 \pm 0.2)$ for the extinction-related Ångström exponent (backscatter-related Ångström exponent) between 355 and $532 \mathrm{~nm}$. This study is the first to report comprehensive optical properties of the Arabian dust particles based on long-term observations, using at the fullest the capabilities of a multi-wavelength Raman lidar instrument. The results suggest that the mineral dust properties over the Middle East and western Asia, including the observation site, are comparable to those of African mineral dust with regard to the particle depolarization ratios but not for lidar ratios. The smaller lidar ratio values in this study compared to the reference studies are attributed to the difference in the geochemical characteristics of the soil originating in the study region compared to Northern Africa. 


\section{Introduction}

The Earth's energy budget involves the exchange of energy between three levels: its surface, the top of the atmosphere and the atmosphere in between (Hansen et al., 2005). In this system, aerosol particles are an important, yet underdetermined, component introducing uncertainties in weather and climatic predictions (Boucher et al., 2013; Stevens and Feingold, 2009). Additionally, aerosol particles are tied to health (Davidson et al., 2005), biological processes (Kanakidou et al., 2018; Moore and Braucher, 2008) and aviation safety (Guffanti et al., 2010; Lechner et al., 2017). Mineral dust is one of the most mass abundant types of primary aerosol particles emitted into the atmosphere (Kok et al., 2017). It accounts for almost 30 to $50 \%$ of the total global aerosol mass burden and its physicochemical properties such as size distribution, composition, and shape vary substantially. Recent studies have shown that fine mode dust have a cooling effect on the global climate whereas coarse dust (particle diameter larger than $5 \mu \mathrm{m}$ ) likely has a warming impact (Kok et al., 2017; Miller et al., 2006). Mineral dust particles are characterized as nonspherical with irregular shapes and substantial surface heterogeneity (Wagner et al., 2012; Wiegner et al., 2009). Their optical properties, such as the linear particle depolarization ratio, is also subject to their chemical composition. Therefore, dust particles originating from different regions exhibit different scattering properties due to their different microphysical and chemical composition (Järvinen et al., 2016; Müller et al., 2007; Nisantzi et al., 2015; Shin et al., 2018).

Mineral dust and other aerosol particle types can affect clouds and their microphysical properties and precipitation patterns by acting as cloud condensation nuclei (CCN) and ice nuclei (IN) (DeMott et al., 2003; Karydis et al., 2011). To this end, numerous studies have identified the complex interplay of aerosols and clouds (Morrison et al., 2005; Rosenfeld, 2018). Li et al. (2017) report that dust-mixed ice clouds have warmer cloud top temperatures (CTTs) suggesting their efficiency to act as IN. Most recent studies, however, stress the complexity of dust to IN mechanism and its relative effectiveness in different geographic locations (Ansmann et al., 2009; Coopman et al., 2018; Filioglou et al., 2019; Zamora et al., 2017). The complexity of dust particles also becomes evident when comparing observations from remote sensing instruments with modelled dust properties (Binietoglou et al., 2015). Modelling the dust shape and further calculate its optical properties such as dust optical depth, rely among others on approximations on the sphericity of the dust particles and assumptions on the contribution of non-dust particles together with vertical dust height information (Dubovik et al., 2002; Hoshyaripour et al., 2019). Accurate knowledge of the dust optical properties and their spatial distribution in regional and vertical scale is, therefore, a step towards a more realistic understanding of the climatic forcing impact of this component.

60 The Middle East and the Arabian Peninsula are one of the major source areas of mineral dust particles, together with northern Africa. Although this region is key to improving the understanding of the climate impact of mineral dust, very few measurement campaigns have been conducted and continuous aerosol observations are scarce in the area. In addition of being one of the world's largest sources of mineral dust, the Arabian Peninsula is also a large emitter of anthropogenic pollution (Rushdi et al., 2017). The United Arab Emirates (UAE) is a crossroad for air masses originating from western and central 
65 Asia, or from North Africa (Wehbe et al., 2019). Local emission of mineral dust is also abundant in this area. Regarding anthropogenic pollution, ever growing energy demand have increased $\mathrm{CO}_{2}$ emissions and other pollutants of anthropogenic origin over the past decade (Betancourt-Torcat and Almansoori, 2015; Ukhov et al., 2018) with adverse health effects (Li et al., 2010). These varying aerosol sources make the UAE an interesting area to study aerosol particles, and in particular, dust properties. A few studies indicate that long-range transported dust from the Middle East exhibit different optical properties to that from Saharan origin (Hofer et al., 2017; Mamouri et al., 2013; Müller et al., 2007; Nisantzi et al., 2015).

To shed further light into atmospheric aerosol properties in the UAE region, a one-year field campaign was conducted from March 2018 to February 2019. The measurement campaign focused on the characterization of the geometrical and optical properties of atmospheric aerosol particles and their interaction with the regional/local meteorology and cloud precipitation patterns under different atmospheric conditions. With less than $100 \mathrm{~mm}$ of annual rainfall (Wehbe et al., 2017), precipitation enhancement techniques such as cloud seeding (French et al., 2018; Vonnegut and Chessin, 1971), have been implemented within UAE's strategy to tackling water shortages in the region. This approach requires accurate understanding of local/regional meteorology, detailed characterization of the background aerosol particles and their efficiency to act as CCN/IN, and the complex interplay between aerosol-cloud-meteorology. Therefore, the Optimization of Aerosol Seeding In rain enhancement Strategies (OASIS) project aimed towards a more robust knowledge of the efficiency of the aerosol particles to act as CCN/IN in a challenging environment. A multi-instrument approach was used for this purpose including both in-situ and remote sensing sensors along with model simulations. In this paper, we will focus on the characterization of the aerosol properties over the measurement site. Observations of a multi-wavelength Raman lidar with water vapor capability were used along with air mass back-trajectories calculated from the Hybrid Single Particle Lagrangian Integrated Trajectory (HySPLIT) model (Stein et al., 2015) in order to identify and classify the aerosol layers during the campaign period. Moreover, the optical properties of the Arabian have been characterized.

\section{Methodology}

\subsection{The measurement site}

Between March 2018 and February 2019 the OASIS campaign was established at a palm plantation located $10 \mathrm{~km}$ south-west of Al Dhaid city, in the emirate of Sharjah in the UAE $\left(25^{\circ} 14^{\prime} 7.8^{\prime \prime} \mathrm{N}, 55^{\circ} 58^{\prime} 39.97^{\prime \prime} \mathrm{E}, 165 \mathrm{~m}\right.$ a.s.l). This rural site is located at a desert area about $70 \mathrm{~km}$ north-east from Dubai and the Arabian Gulf, where oil extraction and shipping activities are situated. To the east, the site faces a mountainous area whose altitude ranges from 1 to $2.1 \mathrm{~km}$, and the sea (Gulf of Oman and Arabian Sea, respectively) (Fig. 1a). In principle, the measurement site receives dust from three different sources. To the North, including Iraq and the surrounding countries, is a region with several sources of dust and the sediment surface may contain sand deposits with particle sizes which are easily lofted by winds. In fact, it is the largest source of Aeolian dust in the Arabian Gulf. North-east in Iran and Pakistan are regions responsible for dust and sandstorms in Asia. Lastly, Saudi Arabia and the 
Arabian Peninsula provide the third major dust source with multiple terrain types. Towards the west side from the measurement location, mountains up to $2.5 \mathrm{~km}$ form a natural barrier between this region and the Red Sea. The region itself can be considered as a fourth dust source where dust can be emitted locally due to thermal lows, unstable conditions, or human activities. Anthropogenic pollution is also present in the greater area where oil and gas extraction activities add up to the man-made aerosol particulate burden from the cities. The Aerosol Optical Depth at $500 \mathrm{~nm}$ in the region varies between 0.4 and 0.5 (Eck et al., 2008) where the contribution of mineral dust particles can be 60 - $70 \%$ even in urban areas (Roshan et al., 2019). Figure $1 \mathrm{~b}$ shows the air mass backward trajectory cluster analysis, computed with HySPLIT (Stein et al., 2015, see Section 2.3), and their frequency over the course of the campaign period. The aforementioned aerosol sources can be viewed at the location of the backward trajectory paths.

\section{$105 \quad$ 2.2 The multi-wavelength Raman lidar FMI - Polly ${ }^{\mathrm{XT}}$}

The FMI-Polly ${ }^{\mathrm{XT}}$ lidar is a fully automated instrument capable of 24/7 operation (Engelmann et al., 2016). It is equipped with three elastic backscatter channels at $355 \mathrm{~nm}, 532 \mathrm{~nm}$ and $1064 \mathrm{~nm}$, two rotational-vibrational Raman channels at $387 \mathrm{~nm}$ and $607 \mathrm{~nm}$, two linear depolarization channels at $355 \mathrm{~nm}$ and $532 \mathrm{~nm}$ and one water vapor detection channel at $407 \mathrm{~nm}$. In addition to the far field capabilities, the system includes two near field elastic backscatter channels at $355 \mathrm{~nm}$ and $532 \mathrm{~nm}$ and two near

110 field rotational-vibrational Raman channels at $387 \mathrm{~nm}$ and $607 \mathrm{~nm}$. Due to the near field capability, full overlap is attained at around $120 \mathrm{~m}$. Data are acquired with a vertical resolution of $7.5 \mathrm{~m}$ in temporal steps of $30 \mathrm{~s}$.

The lidar has been employed under various campaigns and locations over the course of years. Among others, two long-term aerosol experimental campaigns at Gual Pahari, India (Komppula et al., 2012) and Elandsfontein, South Africa (Giannakaki et al., 2015, 2016; Korhonen et al., 2014) and at the permanent measurement site in Vehmasmäki, Finland (Bohlmann et al.,

115 2019; Filioglou et al., 2017) have been conducted. The system is also part of the Finnish lidar network (Hirsikko et al., 2014), the European Aerosol Research Lidar Network (EARLINET) (Bösenberg et al., 2003; Pappalardo et al., 2014) and PollyNET (Baars et al., 2016) which is an independent Raman and polarization lidar network where measurements from all member-stations are visualized through "quick looks", publicly available on the web page of PollyNET (http://polly.tropos.de).

\subsection{Processing of lidar observations}

120 For the analysis presented, two aerosol profiles were retrieved per day using the Raman method (Ansmann et al., 1990, 1992; Whiteman, 2003). The temporal averaging of each profile corresponded to two hours. In total, 380 profiles were retrieved at fixed times each day ( 01 and 20 UTC) in order to derive all possible optical properties minimizing the assumptions in the retrievals. The 2-hour average profiles were further analysed by detecting intensive aerosol layers and isolating them from air segments containing very low aerosol particle burden. For the automatic detection of the aerosol particle layers we used the second derivative of the backscatter profiles. In total 1130 high quality aerosol particle layers were detected during the campaign period. We considered as high quality aerosol layers the ones which were not affected by clouds and exhibited lidar 
ratios between 5 and $150 \mathrm{sr}$, linear particle depolarization ratio between 0 and $40 \%$ and Ångström exponents between -1.1 and 3. The geometrical boundaries of the aerosol particle layers were retrieved from a less vertically smoothed lidar profile (less than $400 \mathrm{~m}$ ) as opposed to the optical properties which were retrieved by applying higher smoothing (case depended). By applying less smoothing to the signals, we were able to appoint correct geometrical depth and boundaries of these layers while the higher smoothing assigned meaningful optical properties. Mean values of all the available optical properties, i.e backscatter $(\beta)$ and extinction $(\alpha)$ coefficients, lidar ratios (LR), Ångström exponents (AE for the extinction-related and BAE for the backscatter-related Ångströms), color ratios (CR), linear particle depolarization ratios ( $\left.\delta_{\mathrm{p}}\right)$ and aerosol optical depths (AOD), were then calculated for each of the layers, along with their geometrical properties (depth and centre mass). A 5-day backward trajectory analysis at the centre mass of each of the layers was also computed using HySPLIT in order to assess the origin of the detected aerosol particle layers. The timestamp used for the trajectories was the centred 2-hour lidar retrieval.

\subsection{Microanalysis of the collected dust particles}

To aid the findings in Section 3.3 where we retrieve the optical properties of the Arabian dust particles we have collected two dust samples. The samples were dry collected from two different locations around the measurement site where different macrophysical properties, e.g. color, were evident. Two particle distributions were studied to reveal physicochemical properties of gathered particles, i.e., size, morphology and composition. In order to analyse the chemical composition of the particles, energy dispersive X-ray spectroscopy (EDX, Thermo Pathfinder 1.4, Thermo Fisher Scientific, Madison, WI, USA) was used in synergy with a scanning electron microscope (SEM, Zeiss SigmaHD $\mid$ VP, Carl Zeiss NTS, Cambridge, UK) which was used to observe the morphology of the dust particles. For this, dust samples were attached on a standard $12 \mathrm{~mm}$ aluminium stub for SEM specimens using a piece of double sided carbon adhesive tape. The SEM imaging was executed without any sputter coating in low vacuum (Zeiss Variable Pressure mode), Nitrogen atmosphere at $30 \mathrm{~Pa}$ pressure using $15 \mathrm{kV}$ acceleration voltage and variable pressure secondary electron (VPSE) detector and a working distance of $15 \mathrm{~mm}$. The elemental composition for individual particles was obtained using EDX mapping. The chemical analysis and two SEM images can be found in Appendix A.

\section{Results}

\subsection{Geometrical properties and aerosol optical depths of aerosol particle layers}

Altogether 1130 night-time aerosol particle layers have been analysed throughout the campaign period in order to characterize the background aerosol properties over the measurement site. The time series of the geometrical extent of the retrieved aerosol particle layers showed up to 7 simultaneous layers (Fig. 2). Indeed, as observed in the dataset, frequent multiple aerosol particle layer structures were present most of the time, with single-layers mostly occurring during December and January. In fact, only $10 \%$ of the cases had a single aerosol layer present, with two (30\%), three (29\%) or even more simultaneous layers (31\%). 
The multiple aerosol particle layers result from gravitational waves generated by the sea breeze passing over the mountains, stratifying the atmosphere over the measurement site. The gaps in the dataset during May to August and between September and November were due to instrumental malfunction, mainly failure of the cooling unit of the system while performing under such demanding conditions where maximum ambient temperatures up to $51^{\circ} \mathrm{C}$ were measured.

Geometrical features of the aerosol particle layers are further characterized by frequency distributions (Fig. 3). Up to $61 \%$ of the layers identified were located below $2.5 \mathrm{~km}$ in altitude, with few layers reaching as high as $11 \mathrm{~km}$. The geometrical depth of the layers varied from a few hundred metres to several kilometres throughout the period. Most commonly $(58 \%$ of the cases) the geometrical depth varied between 0.4 and $0.8 \mathrm{~m}$.

In order to define the geometrical boundaries of the aerosol particle layers in the free-troposphere (FT) and the atmospheric boundary layer (BL), we determined the top height of BL using the methodology described at Baars et al. (2008). The night-time BL over the measurement site ranged between 0.65 and $1.2 \mathrm{~km}$ while the mean top of the mixed layer height during daytime was at $2.0 \pm 0.3 \mathrm{~km}$ (not shown here). The, rather low in altitude, PBL is suppressed by several limiting factors; 1) the frequent high pressure system in the region, 2) gravitational waves, 3) low wind speeds and 4) very dry air, which altogether limit convection. The gravitational waves define the horizontal transport of air and limit the growth of PBL to higher altitudes. In total, 844 FT aerosol particle layers were observed and 286 BL layers. To have a better insight of the time variation of the aerosol particle layers, Figure 4 presents the monthly geometrical and layer optical depth characteristics of BL and FT aerosol particles. Figure 4a corresponds to the centre of mass of the detected layers at the BL (red) and FT (green). While there is a very persistent and stable night-time $\mathrm{BL}$ at $1 \mathrm{~km}$ or so throughout the measurement year, the FT aerosol layers show seasonality. The FT particle layers extend to higher altitudes during the warmer months (April-August) and have a minimum height during November-December. Regarding their average geometrical depth (Fig. 4b), both BL and FT aerosol layers exhibit similar characteristics.

The optical depths of BL and FT layers at $355 \mathrm{~nm}$ wavelength and their contribution to the total layer AOD are shown 180 in Figures 4c-d. Similar conclusions are valid for AOD at $532 \mathbf{~ n m}$ wavelength, which is not shown here but discussed in the manuscript. The optical depths were determined by integrating the layer aerosol extinction coefficient at 355 and $532 \mathrm{~nm}$. For the first layer, where the overlap is incomplete, we assumed that the extinction coefficient value at the lowest trustworthy bin is representative for the values down to the surface to account for the incomplete overlap region. The highest layer AODs were measured during the summer months, and the lowest values during November and

185 December for FT and February for BL. The mean (max) value of the total layer AOD amounts to $0.37 \pm 0.12(1.11)$ and $0.21 \pm 0.11(1.04)$ at 355 and $532 \mathrm{~nm}$, respectively. These values are in line with previous studies, utilizing mainly sunphotometric observations at inland desert areas in the surrounding region (Ali et al., 2017; Eck et al., 2008). Moderate variations of the contribution of AOD in FT to the total layer AOD were observed for the investigated period (Fig. 4d). The contribution of the night-time FT layers to the total AOD was usually greater than that of the BL.

190 Nevertheless, this behaviour was reversed from November to February. The lower total layer AODs in these months may be attributable to the absence of multiple FT layers, or to the lower surface wind speeds (which drive dust particles), during those months. There is a mesoscale phenomenon referred to as shamal conditions where northern to north-westerly winds are more intense between March to August compared to the rest of the year (Kutiel and Furman, 2003; Yu et al., 2016). Although the aforementioned values refer to night-time observations, on average the intra-day 
variation in the region is moderate (Eck et al., 2008; Arola et al., 2013), and therefore comparable to this study.3.2 Intensive and extensive aerosol properties

So far, we have examined the monthly variation of the aerosol layers over the measurement site in terms of their geometrical and AOD properties. In this section, we investigate the intensive (lidar ratios, linear particle depolarization ratios and Ångström exponents) and extensive (backscatter and extinction coefficients) aerosol properties of the retrieved aerosol particle layers

(Fig. 5). The backscatter and extinction coefficient values indicate occasional strong dust events. The dust events take place mainly between March and August when enhanced shamal conditions cause an increase in the probability of dust suspension and dust storms (Yu et al., 2016). Average $\beta$-values of $2.5 \pm 1.9,2.1 \pm 1.9$ and $1.6 \pm 1.6 \mathrm{Mm}^{-1} \mathrm{sr}^{-1}$ for the 355,532 and $1064 \mathrm{~nm}$ were observed, respectively. During strong dust events $\beta$-values up to $19.7(18.5,16.4) \mathrm{Mm}^{-1} \mathrm{sr}^{-1}$ at $355(532,1064) \mathrm{nm}$ and $\alpha$-values of 800 (774) $\mathrm{Mm}^{-1}$ at 355 (532) nm, were measured (not shown in the Figure). In general, the intensive optical properties exhibit similar characteristics with little variation throughout the year apart from the period from mid-November to January. During the winter season increased LR values related to bigger Angström exponents and lower linear particle depolarization values indicate a greater share of anthropogenic pollution in the aerosol particle mixture compared to other seasons.

Histograms of the aforementioned optical properties are shown in Figure 6. In the same figure, the statistical distribution is also presented with box and whisker plots. For 40 (35) \% of the cases, the LR at 355 (532) nm ranged between 35-45 sr while the second most frequent LR range was 45-55 (25-35) sr for the 355 (532) nm representing 27 (25) \% of the cases. Furthermore, less than $12 \%$ of the cases exhibited $\delta_{p} \geq 27 \%$ indicating the complexity of the aerosol type over the site; frequently a mixture of mineral dust (dominant aerosol) with anthropogenic and/or marine aerosol presence. This is also consistent with the backscatter-related Ångström exponent staying well below 0.8 in $71 \%$ of the cases. In general, an average LR of $43 \pm 11$ sr

215 and $39 \pm 10 \mathrm{sr}$ was observed at 355 and 532, respectively. The mean $\delta_{\mathrm{p}}$ was $15 \pm 6 \%$ for the $355 \mathrm{~nm}$ wavelength and $19 \pm 7 \%$ at $532 \mathrm{~nm}$. A mean extinction-related Ångström exponent of $0.7 \pm 0.5$ between 355 and $532 \mathrm{~nm}$ was measured during the one-year period in UAE, similar to the value by Eck et al. (2008) based on sunphotometric observations in the greater area. Lastly, backscatter-related Ångström exponents at 355/532 and 532/1064 (not shown) were $0.6 \pm 0.4$ and $0.5 \pm 0.3$, respectively.

In order to reveal height-depended aerosol particle properties, we have further divided the atmosphere into 5 altitude ranges $(0-1,1-2,2-3,3-4$ and $>5 \mathrm{~km})$ and grouped the aerosol properties contained in each altitude segment (Fig. 7). As expected, the $\beta$ and $\alpha$-coefficients decreased with increasing altitude. In contrast, LRs showed rather constant behavior up to $5 \mathrm{~km}$ suggesting similar aerosol mixtures throughout these altitude ranges. Interestingly, $\delta_{\mathrm{p}}$ at $532 \mathrm{~nm}$ wavelength increased or remained constant with altitude except for aerosol layers above $5 \mathrm{~km}$. This behavior was seen at $355 \mathrm{~nm}$ wavelength up to $2 \mathrm{~km}$, but $\delta_{\mathrm{p}}$ then decreased with altitude above $2 \mathrm{~km}$. The most plausible explanation is that up to $2 \mathrm{~km}$ or so the night-time residual layers contain mixtures of mineral dust and anthropogenic pollution or/and marine aerosols resulting to lower linear particle 
depolarization values. The mean relative humidity of these aerosol layers is much less than $60 \%$ for $82 \%$ of the cases hence hygroscopicity effects can be excluded. Ångström exponents increasing with altitude show the height-dependent nature of the aerosol size distribution (the higher the altitude the smaller the particles).

\subsection{Optical properties of Arabian dust}

To characterize the properties of mineral dust over the region, we have selected the top decile of linear particle depolarization values in the dataset. We discarded cases when the path of backward air mass trajectory passed over regions other than the Arabian Peninsula and the minimum height of the air mass over these regions was less than $3 \mathrm{~km}$ in altitude. The backward trajectories of the selected 46 cases are shown in Figure 8a and the characteristic optical properties and the aerosol type depended optical properties in Figures 8b-d for both 355 and $532 \mathrm{~nm}$ wavelengths, including a $95 \%$ confidence ellipsoids. The mean values of all the aerosol particle optical properties are further reported in Table 1 along with literature values. The mean altitude of these layers was $1.8 \pm 0.9 \mathrm{~km}$; in $73 \%$ of the cases the centre mass of the layer was located above $1 \mathrm{~km}$ excluding the stable and often well-mixed with anthropogenic or/and marine pollution, night-time BL. The retrieved dust aerosol properties over the region concerning the lidar ratios fluctuated between 35(34) and 55(54) sr with a mean value of $45 \pm 5(42 \pm 5) \mathrm{sr}$ at $355(532) \mathrm{nm}$. The values ranged between 22 (29) and 32 (35) \% with an average value of $25 \pm 2$ $(31 \pm 2) \%$ for the linear particle depolarization ratio at $355(532) \mathrm{nm}$ and $0.3 \pm 0.2(0.2 \pm 0.2,0.3 \pm 0.1)$ for the extinction-related Ångström exponent (backscatter-related Ångström exponent at 355/532 and 532/1064). The ratio of LRs fluctuated between 1.0 and 1.2. Moreover, we report on the ratio of backscatter coefficients know as color ratio (CR) between 355/523, 355/1064 and 532/1064 wavelengths. This ratio is usually below 1 for aerosols and can be used in a simple aerosol/cloud detection scheme but dust particles show ratios above one which complicate this rather simple and straightforward relationship. Note that in the literature the $\mathrm{CR}$ is retrieved interchangeably either from smaller to bigger wavelength or the opposite. In this paper we calculated the CR as smaller to bigger wavelength.

To the authors' knowledge, four earlier studies have attempted to characterize the properties of dust originating from the Arabian Peninsula using the lidar technique, however, the full properties of dust were not characterised, particularly multi-wavelength optical properties and/or linear particle depolarization values have not been simultaneously defined. Müller et al. (2007), using lidar observations during INDOEX (Indian Ocean Experiment, Ramanathan et al., 2001) was first to stress the lower LR values of free-tropospheric dust when originating from the Arabian Peninsula compared to that from Northern Saharan. However, the long-range transported Arabian dust (aged) in their study suggest smaller LR values and greater Ångström exponents than the ones reported here (Table 1). Similar conclusions were found by Mamouri et al. (2013) and

255 Nisantzi et al. (2015) whose studies show lower LR for the Arabian dust over a Mediterranean site in Cyprus than dust originating from the Saharan area, based on study cases (Table 1). A recent study by Hofer et al. (2017) using lidar observations in Tajikistan, Central Asia also report on Middle East dust optical properties and comparisons of those to Asian dust. To the 
same direction, the study cases used over Dushanbe in Tajikistan show similar Arabian dust characteristics as in the present study (see Table 1).

260 A few limited studies are also available for the characterization of the Arabian dust properties using sunphotometric observations. Sunphotometric observations are column-integrated values which often include the contribution of BL aerosols and the contribution of non-dust aerosols (smoke, marine and anthropogenic aerosols). Nevertheless, Schuster et al. (2012) report a mean LR of 43 at $532 \mathrm{~nm}$ with a 39 to 43 range. On the contrary, Shin et al. (2018) result in higher LR values as $54 \pm 7$ at $440 \mathrm{~nm}$ and $37 \pm 4$ at $670 \mathrm{~nm}$. The reported linear particle depolarization ratios are $0.21 \pm 0.03 \%$ at $440 \mathrm{~nm}$ and $0.25 \pm 0.03 \%$ at $670 \mathrm{~nm}$ whereas the Ångström exponent $0.18 \pm 0.10$ at 440/870 $\mathrm{nm}$.

Examining the reasons behind the different LR values in Arabian compared to African dust, previous studies related the optical characteristics to the chemical composition of the dust particles themselves. Numerous studies have analysed samples from various regions exploring the mineralogical composition of dust (Di Biagio et al., 2017; Egan G. Walter and Theodore, 1979; Querry, 1987; Sokolik and Toon, 1999). Schuster et al. (2012) linked the LR behaviour of dust to the percentage of illite in the soil. The content of illite (K-rich argillaceous component of sedimentary rocks) in the dust defines the real refractive index which strongly influences LR. Since the real refractive index, which is determined by the mineralogical composition of dust defines the lidar ratio, an aerosol type parameter, it is expected that different dust types would exhibit different optical characteristics. Lower content of illite signifies lower LR compared to, for example, higher content illite in Saharan soils which result in the somewhat higher real refractive index. The refractive index of dust from Arabian peninsula is 1.48 and for Saharan dust the corresponding value is 1.54 (Kim et al., 2011; Schuster et al., 2012). Towards this direction, we have collected two different dust samples from the area around the measurement site and further retrieved SEM images and performed elemental analysis (see Appendix A). Comparable to previous studies mentioned above, the fraction of K-rich argillaceous component of sedimentary rocks was well below $5.5 \%$ in the collected dust samples.

\section{Summary and conclusions}

280 One-year of ground-based night-time lidar observations were analysed in synergy with backward air mass trajectories in order to characterize the seasonal variability of the background aerosol particle properties in a -heavy dust and anthropogenic polluted- region in the United Arab of Emirates (UAE). Our analysis suggests that aerosol particle populations over the UAE are sensitive to transport from Saudi Arabia, Iran, and Iraq but also from local sources. Two seasons exist in this area, summer and winter, where the main difference is the higher wind speeds between March-August compared to the rest of the year The AOD was positively correlated with the season with maximum values being observed in the warmest months, June to August, resulting from the increased probability of dust suspension and dust storms. Multiple aerosol layers were present in the majority of identified cases, except during November-December; for $58 \%$ of the cases the geometrical depth ranged between 0.4 and $0.8 \mathrm{~km}$. The geometrical properties are determined by large scale pressure systems over the region as well as gravitational 
waves introduced by local and regional topography. Regarding the optical properties, Ångström exponent values increased with altitude indicating the incapacity of bigger aerosols to reach higher up in the atmosphere. Lidar ratios were almost constant up to $5 \mathrm{~km}$ with a mean value of $43 \pm 11 \mathrm{sr}$ at $355 \mathrm{~nm}$ and $39 \pm 10 \mathrm{sr}$ at $532 \mathrm{~nm}$. The linear particle depolarization, $\delta_{\mathrm{p}}$, at $532 \mathrm{~nm}$ $(355 \mathrm{~nm})$, however, increased with altitude up to $3 \mathrm{~km}(2 \mathrm{~km})$. The most probable explanation is that up to $2 \mathrm{~km}$ or so, night-time residual layers contain mixtures of mineral dust and urban-marine aerosols resulting in lower linear particle depolarization values. Higher up the linear particle depolarization decreases; the aerosol particles at higher altitudes are usually long-range transported and while aging in the atmosphere they become more spherical.

The Arabian Peninsula is a major contributor of airborne dust, yet very few studies have been made in order to characterize the pure dust optical properties of the region. To our knowledge this study is the first long-term one reporting the complete lidar-based optical characteristics of the Arabian dust. The FMI-Polly ${ }^{\mathrm{XT}}$ Raman lidar enabled the provision of lidar ratios and linear particle depolarization ratios at two wavelengths $(355,532 \mathrm{~nm})$ giving us the possibility to answer to wavelengthdependent dust properties. The observed dust particle properties over the region regarding the lidar ratio amounted to $45 \pm 5 \mathrm{sr}$ at $355 \mathrm{~nm}$ and $42 \pm 5 \mathrm{sr}$ at $532 \mathrm{~nm}$ wavelength. Linear particle depolarization ratios of $25 \pm 2 \%(31 \pm 2 \%)$ was observed at $355(532) \mathrm{nm}$ and $0.3 \pm 0.2(0.2 \pm 0.2)$ values was retrieved for the extinction-related Ångström exponent (backscatter-related Ångström exponent) at 355/532. The findings of this study suggest that the pure dust properties over the Middle East and western Asia, including the observation site, are comparable to those of African mineral dust regarding the linear particle depolarization ratios but not for the lidar ratios. The lower lidar ratio values are attributed to the different geochemical characteristics of soil with Arabian dust having lower K-rich values in the dust mixture, a component which determines the real refractive index of the dust. Implications of these findings propose that a universal lidar ratio for dust aerosol particles will lead to biased results, for example in satellite or ground-based extinction or aerosol typing retrievals as well as separation methods of a lidar signal to its aerosol components. In turn, all the aforementioned products are usually the basic input for advanced methodologies such as the retrieval of IN/CCN concentrations from lidar observations.

\section{Data availability}

The data used in this work are available upon request.

\section{Author contribution}

MF, MK and EG conceptualized and finalized the methodology. MF and MK were responsible for the lidar data and collection 315 of the dust samples; RE and XS helped with the up keeping of the data and troubleshooting of instrument. JL analysed the dust samples. MF performed the data analysis and wrote the paper. All co-authors were involved in the paper editing, interpretation of the results and discussion of the manuscript. 


\section{Competing interests}

The authors declare that they have no conflict of interest.

\section{Acknowledgements}

This work was supported by the National Center of Meteorology, Abu Dhabi, UAE, under the UAE Research Program for Rain Enhancement Science. Hannele Korhonen received funding from the European Research Council (ERC) under the European Union's Horizon 2020 research and innovation programme under grant agreement No. 646857. Elina Giannakaki acknowledges the support of Academy of Finland (project no. 270108). The authors gratefully acknowledge the NOAA Air Resources Laboratory (ARL) for the provision of the HYSPLIT transport and dispersion model used in this publication. The EM facility of SIB Labs at University of Eastern Finland is greatly acknowledged for providing their SEM and EDX equipment to the study. We would also like to thank Timo Anttila and Siddharth Tampi for providing onsite technical support.

\section{References}

Ali, M. A., Assiri, M. and Dambul, R.: Seasonal aerosol optical depth (AOD) variability using satellite data and its comparison over Saudi Arabia for the period 2002-2013, Aerosol Air Qual. Res., 17(5), 1267-1280, doi:10.4209/aaqr.2016.11.0492, 2017. Ansmann, A., Riebesell, M. and Weitkamp, C.: Measurement of atmospheric aerosol extinction profiles with a Raman lidar, Opt. Lett., 15(13), 746, doi:10.1364/ol.15.000746, 1990.

Ansmann, A., Riebesell, M., Wandinger, U., Weitkamp, C., Voss, E., Lahmann, W. and Michaelis, W.: Combined raman elastic-backscatter LIDAR for vertical profiling of moisture, aerosol extinction, backscatter, and LIDAR ratio, Appl. Phys. B Photophysics Laser Chem., 55(1), 18-28, doi:10.1007/BF00348608, 1992.

Ansmann, A., Tesche, M., Seifert, P., Althausen, D., Engelmann, R., Fruntke, J., Wandinger, U., Mattis, I. and Müller, D.: Evolution of the ice phase in tropical altocumulus: SAMUM lidar observations over Cape Verde, J. Geophys. Res., 114(D17), D17208, doi:10.1029/2008JD011659, 2009.

Arola, A., Eck, T. F., Huttunen, J., Lehtinen, K. E. J., Lindfors, A. V., Myhre, G., Smirnov, A., Tripathi, S. N., and Yu, H.: Influence of observed diurnal cycles of aerosol optical depth on aerosol direct radiative effect, Atmos. Chem. Phys., 13, 78957901, https://doi.org/10.5194/acp-13-7895-2013, 2013.

Baars, H., Ansmann, A., Engelmann, R. and Althausen, D.: Continuous monitoring of the boundary-layer top with lidar, Atmos. Chem. Phys., 8(23), 7281-7296, doi:10.5194/acp-8-7281-2008, 2008.

Baars, H., Kanitz, T., Engelmann, R., Althausen, D., Heese, B., Komppula, M., Preißler, J., Tesche, M., Ansmann, A., 345 Wandinger, U., Lim, J.-H., Ahn, J. Y., Stachlewska, I. S., Amiridis, V., Marinou, E., Seifert, P., Hofer, J., Skupin, A., Schneider, F., Bohlmann, S., Foth, A., Bley, S., Pfüller, A., Giannakaki, E., Lihavainen, H., Viisanen, Y., Hooda, R. K., Pereira, S. N., Bortoli, D., Wagner, F., Mattis, I., Janicka, L., Markowicz, K. M., Achtert, P., Artaxo, P., Pauliquevis, T., Souza, R. A. 
F., Sharma, V. P., van Zyl, P. G., Beukes, J. P., Sun, J., Rohwer, E. G., Deng, R., Mamouri, R.-E. and Zamorano, F.: An overview of the first decade of Polly\&amp;lt;sup\&amp;gt;NET\&amp;lt;/sup\&amp;gt;: an emerging network of automated

Raman-polarization lidars for continuous aerosol profiling, Atmos. Chem. Phys., 16(8), 5111-5137, doi:10.5194/acp-16-51112016, 2016

Betancourt-Torcat, A. and Almansoori, A.: Design multiperiod optimization model for the electricity sector under uncertainty - A case study of the Emirate of Abu Dhabi, Energy Convers. Manag., 100, 177-190, doi:10.1016/j.enconman.2015.05.001, 2015.

355 Di Biagio, C., Formenti, P., Balkanski, Y., Caponi, L., Cazaunau, M., Pangui, E., Journet, E., Nowak, S., Caquineau, S., Andreae, M. O., Kandler, K., Saeed, T., Piketh, S., Seibert, D., Williams, E. and Doussin, J.-F.: Global scale variability of the mineral dust long-wave refractive index: a new dataset of in situ measurements for climate modeling and remote sensing, Atmos. Chem. Phys., 17(3), 1901-1929, doi:10.5194/acp-17-1901-2017, 2017.

Binietoglou, I., Basart, S., Alados-Arboledas, L., Amiridis, V., Argyrouli, A., Baars, H., Baldasano, J. M., Balis, D., Belegante, L., Bravo-Aranda, J. A., Burlizzi, P., Carrasco, V., Chaikovsky, A., Comerón, A., D\&amp;apos;Amico, G., Filioglou, M., Granados-Muñoz, M. J., Guerrero-Rascado, J. L., Ilic, L., Kokkalis, P., Maurizi, A., Mona, L., Monti, F., Muñoz-Porcar, C., Nicolae, D., Papayannis, A., Pappalardo, G., Pejanovic, G., Pereira, S. N., Perrone, M. R., Pietruczuk, A., Posyniak, M., Rocadenbosch, F., Rodríguez-Gómez, A., Sicard, M., Siomos, N., Szkop, A., Terradellas, E., Tsekeri, A., Vukovic, A., Wandinger, U. and Wagner, J.: A methodology for investigating dust model performance using synergistic

EARLINET/AERONET dust concentration retrievals, Atmos. Meas. Tech., 8(9), 3577-3600, doi:10.5194/amt-8-3577-2015, 2015.

Bohlmann, S., Shang, X., Giannakaki, E., Filioglou, M., Saarto, A., Romakkaniemi, S. and Komppula, M.: Detection and characterization of birch pollen in the atmosphere using a multiwavelength Raman polarization lidar and Hirst-type pollen sampler in Finland, Atmos. Chem. Phys., 19(23), 14559-14569, doi:10.5194/acp-19-14559-2019, 2019.

Boucher, O., Randall, D., Artaxo, P., Bretherton, C., Feingold, G., Forster, P., Kerminen, V. M., Kondo, Y., Liao, H., Lohmann, U., Rasch, P., Satheesh, S. K., Sherwood, S., Stevens, B. and Zhang, X. Y.: Clouds and Aerosols, in Climate Change 2013 The Physical Science Basis, edited by Intergovernmental Panel on Climate Change, pp. 571-658, Cambridge University Press, Cambridge., 2013.

Coopman, Q., Garrett, T. J., Finch, D. P. and Riedi, J.: High Sensitivity of Arctic Liquid Clouds to Long-Range Anthropogenic 375 Aerosol Transport, Geophys. Res. Lett., 45(1), 372-381, doi:10.1002/2017GL075795, 2018.

Davidson, C. I., Phalen, R. F. and Solomon, P. A.: Airborne Particulate Matter and Human Health: A Review, Aerosol Sci. Technol., 39(8), 737-749, doi:10.1080/02786820500191348, 2005.

DeMott, P. J., Sassen, K., Poellot, M. R., Baumgardner, D., Rogers, D. C., Brooks, S. D., Prenni, A. J. and Kreidenweis, S. M.: African dust aerosols as atmospheric ice nuclei, Geophys. Res. Lett., 30(14), doi:10.1029/2003GL017410, 2003.

380 Dubovik, O., Holben, B. N., Lapyonok, T., Sinyuk, A., Mishchenko, M. I., Yang, P. and Slutsker, I.: Non-spherical aerosol retrieval method employing light scattering by spheroids, Geophys. Res. Lett., 29(10), 54-1-54-4, 
doi:10.1029/2001GL014506, 2002.

Eck, T. F., Holben, B. N., Reid, J. S., Sinyuk, A., Dubovik, O., Smirnov, A., Giles, D., O’Neill, N. T., Tsay, S.-C., Ji, Q., Al Mandoos, A., Ramzan Khan, M., Reid, E. A., Schafer, J. S., Sorokine, M., Newcomb, W. and Slutsker, I.: Spatial and temporal variability of column-integrated aerosol optical properties in the southern Arabian Gulf and United Arab Emirates in summer, J. Geophys. Res., 113(D1), D01204, doi:10.1029/2007JD008944, 2008.

Egan G. Walter and Theodore, H. W.: Optical Properties of Inhomogeneous Materials, Elsevier., 1979.

Engelmann, R., Kanitz, T., Baars, H., Heese, B., Althausen, D., Skupin, A., Wandinger, U., Komppula, M., Stachlewska, I. S., Amiridis, V., Marinou, E., Mattis, I., Linné, H. and Ansmann, A.: The automated multiwavelength Raman polarization and water-vapor lidar Polly\&amp;1t;sup\&amp;gt;XT\&amp;lt;/sup\&amp;gt;: the neXT generation, Atmos. Meas. Tech., 9(4), 1767-1784, doi:10.5194/amt-9-1767-2016, 2016.

Filioglou, M., Nikandrova, A., Niemelä, S., Baars, H., Mielonen, T., Leskinen, A., Brus, D., Romakkaniemi, S., Giannakaki, E. and Komppula, M.: Profiling water vapor mixing ratios in Finland by means of a Raman lidar, a satellite and a model, Atmos. Meas. Tech., 10(11), 4303-4316, doi:10.5194/amt-10-4303-2017, 2017.

395 Filioglou, M., Mielonen, T., Balis, D., Giannakaki, E., Arola, A., Kokkola, H., Komppula, M. and Romakkaniemi, S.: Aerosol Effect on the Cloud Phase of Low-Level Clouds Over the Arctic, J. Geophys. Res. Atmos., 124(14), 7886-7899, doi:10.1029/2018JD030088, 2019.

French, J. R., Friedrich, K., Tessendorf, S. A., Rauber, R. M., Geerts, B., Rasmussen, R. M., Xue, L., Kunkel, M. L. and Blestrud, D. R.: Precipitation formation from orographic cloud seeding., Proc. Natl. Acad. Sci. U. S. A., 115(6), 1168-1173, doi:10.1073/pnas.1716995115, 2018.

Giannakaki, E., Pfüller, A., Korhonen, K., Mielonen, T., Laakso, L., Vakkari, V., Baars, H., Engelmann, R., Beukes, J. P., Van Zyl, P. G., Josipovic, M., Tiitta, P., Chiloane, K., Piketh, S., Lihavainen, H., Lehtinen, K. E. J. and Komppula, M.: One year of Raman lidar observations of free-tropospheric aerosol layers over South Africa, Atmos. Chem. Phys., 15(10), 5429-5442, doi:10.5194/acp-15-5429-2015, 2015.

405 Giannakaki, E., van Zyl, P. G., Müller, D., Balis, D. and Komppula, M.: Optical and microphysical characterization of aerosol layers over South Africa by means of multi-wavelength depolarization and Raman lidar measurements, Atmos. Chem. Phys., 16(13), 8109-8123, doi:10.5194/acp-16-8109-2016, 2016.

Guffanti, M., Schneider, D. J., Wallace, K. L., Hall, T., Bensimon, D. R. and Salinas, L. J.: Aviation response to a widely dispersed volcanic ash and gas cloud from the August 2008 eruption of Kasatochi, Alaska, USA, J. Geophys. Res., 115(D2), D00L19, doi:10.1029/2010JD013868, 2010.

Hansen, J., Nazarenko, L., Ruedy, R., Sato, M., Willis, J., Del Genio, A., Koch, D., Lacis, A., Lo, K., Menon, S., Novakov, T., Perlwitz, J., Russell, G., Schmidt, G. A. and Tausnev, N.: Earth's energy imbalance: confirmation and implications., Science, 308(5727), 1431-5, doi:10.1126/science.1110252, 2005.

Hirsikko, A., O\&amp;apos;Connor, E. J., Komppula, M., Korhonen, K., Pfüller, A., Giannakaki, E., Wood, C. R., Bauer-

Pfundstein, M., Poikonen, A., Karppinen, T., Lonka, H., Kurri, M., Heinonen, J., Moisseev, D., Asmi, E., Aaltonen, V., 
Nordbo, A., Rodriguez, E., Lihavainen, H., Laaksonen, A., Lehtinen, K. E. J., Laurila, T., Petäjä, T., Kulmala, M. and Viisanen, Y.: Observing wind, aerosol particles, cloud and precipitation: Finland's new ground-based remote-sensing network, Atmos. Meas. Tech., 7(5), 1351-1375, doi:10.5194/amt-7-1351-2014, 2014.

Hofer, J., Althausen, D., Abdullaev, S. F., Makhmudov, A. N., Nazarov, B. I., Schettler, G., Engelmann, R., Baars, H., Fomba, K. W., Müller, K., Heinold, B., Kandler, K. and Ansmann, A.: Long-term profiling of mineral dust and pollution aerosol with multiwavelength polarization Raman lidar at the Central Asian site of Dushanbe, Tajikistan: Case studies, Atmos. Chem. Phys., 17(23), 14559-14577, doi:10.5194/acp-17-14559-2017, 2017.

Hoshyaripour, G. A., Bachmann, V., Förstner, J., Steiner, A., Vogel, H., Wagner, F., Walter, C. and Vogel, B.: Effects of Particle Nonsphericity on Dust Optical Properties in a Forecast System: Implications for Model-Observation Comparison, J.

Geophys. Res. Atmos., 124(13), 2018JD030228, doi:10.1029/2018JD030228, 2019.

Järvinen, E., Kemppinen, O., Nousiainen, T., Kociok, T., Möhler, O., Leisner, T. and Schnaiter, M.: Laboratory investigations of mineral dust near-backscattering depolarization ratios, J. Quant. Spectrosc. Radiat. Transf., 178, 192-208, doi:10.1016/J.JQSRT.2016.02.003, 2016.

Kanakidou, M., Myriokefalitakis, S. and Tsigaridis, K.: Aerosols in atmospheric chemistry and biogeochemical cycles of nutrients, Environ. Res. Lett., 13(6), 063004, doi:10.1088/1748-9326/aabcdb, 2018.

Karydis, V. A., Kumar, P., Barahona, D., Sokolik, I. N. and Nenes, A.: On the effect of dust particles on global cloud condensation nuclei and cloud droplet number, J. Geophys. Res. Atmos., 116(D23), n/a-n/a, doi:10.1029/2011JD016283, 2011.

Kim, D., Chin, M., Yu, H., Eck, T. F., Sinyuk, A., Smirnov, A. and Holben, B. N.: Dust optical properties over North Africa and Arabian Peninsula derived from the AERONET dataset, Atmos. Chem. Phys., 11(20), 10733-10741, doi:10.5194/acp-1110733-2011, 2011.

Kok, J. F., Ridley, D. A., Zhou, Q., Miller, R. L., Zhao, C., Heald, C. L., Ward, D. S., Albani, S. and Haustein, K.: Smaller desert dust cooling effect estimated from analysis of dust size and abundance, Nat. Geosci., 10(4), 274-278, doi:10.1038/ngeo2912, 2017.

440 Komppula, M., Mielonen, T., Arola, A., Korhonen, K., Lihavainen, H., Hyvärinen, A.-P., Baars, H., Engelmann, R., Althausen, D., Ansmann, A., Müller, D., Panwar, T. S., Hooda, R. K., Sharma, V. P., Kerminen, V.-M., Lehtinen, K. E. J. and Viisanen, Y.: Technical Note: One year of Raman-lidar measurements in Gual Pahari EUCAARI site close to New Delhi in India Seasonal characteristics of the aerosol vertical structure, Atmos. Chem. Phys., 12(10), 4513-4524, doi:10.5194/acp-12-4513$2012,2012$.

445 Korhonen, K., Giannakaki, E., Mielonen, T., Pfüller, A., Laakso, L., Vakkari, V., Baars, H., Engelmann, R., Beukes, J. P., Van Zyl, P. G., Ramandh, A., Ntsangwane, L., Josipovic, M., Tiitta, P., Fourie, G., Ngwana, I., Chiloane, K. and Komppula, M.: Atmospheric boundary layer top height in South Africa: measurements with lidar and radiosonde compared to three atmospheric models, Atmos. Chem. Phys., 14(8), 4263-4278, doi:10.5194/acp-14-4263-2014, 2014.

Kutiel, H. and Furman, H.: Dust Storms in the Middle East: Sources of Origin and their Temporal Characteristics, in Indoor 
and Built Environment, vol. 12, pp. 419-426., 2003.

Lechner, P., Tupper, A., Guffanti, M., Loughlin, S. and Casadevall, T.: Volcanic Ash and Aviation-The Challenges of RealTime, Global Communication of a Natural Hazard, pp. 51-64, Springer, Cham., 2017.

Li, J., Lv, Q., Zhang, M., Wang, T., Kawamoto, K., Chen, S. and Zhang, B.: Effects of atmospheric dynamics and aerosols on the fraction of supercooled water clouds, Atmos. Chem. Phys., 17(3), 1847-1863, doi:10.5194/acp-17-1847-2017, 2017.

Li, Y., Gibson, J. M. D., Jat, P., Puggioni, G., Hasan, M., West, J. J., Vizuete, W., Sexton, K. and Serre, M.: Burden of disease attributed to anthropogenic air pollution in the United Arab Emirates: Estimates based on observed air quality data, Sci. Total Environ., 408(23), 5784-5793, doi:10.1016/j.scitotenv.2010.08.017, 2010.

Mamouri, R. E., Ansmann, A., Nisantzi, A., Kokkalis, P., Schwarz, A. and Hadjimitsis, D.: Low Arabian dust extinction-tobackscatter ratio, Geophys. Res. Lett., 40(17), 4762-4766, doi:10.1002/grl.50898, 2013a.

Mamouri, R. E., Ansmann, A., Nisantzi, A., Kokkalis, P., Schwarz, A. and Hadjimitsis, D.: Low Arabian dust extinction-tobackscatter ratio, Geophys. Res. Lett., 40(17), 4762-4766, doi:10.1002/grl.50898, $2013 \mathrm{~b}$.

Miller, R. L., Cakmur, R. V., Perlwitz, J., Geogdzhayev, I. V., Ginoux, P., Koch, D., Kohfeld, K. E., Prigent, C., Ruedy, R., Schmidt, G. A. and Tegen, I.: Mineral dust aerosols in the NASA Goddard Institute for Space Sciences ModelE atmospheric general circulation model, J. Geophys. Res., 111(D6), D06208, doi:10.1029/2005JD005796, 2006.

Moore, J. K. and Braucher, O.: Sedimentary and mineral dust sources of dissolved iron to the world ocean, Biogeosciences, 5(3), 631-656, doi:10.5194/bg-5-631-2008, 2008.

Morrison, H., Shupe, M. D., Pinto, J. O. and Curry, J. A.: Possible roles of ice nucleation mode and ice nuclei depletion in the extended lifetime of Arctic mixed-phase clouds, Geophys. Res. Lett., 32(18), n/a-n/a, doi:10.1029/2005GL023614, 2005.

Müller, D., Ansmann, A., Mattis, I., Tesche, M., Wandinger, U., Althausen, D. and Pisani, G.: Aerosol-type-dependent lidar ratios observed with Raman lidar, J. Geophys. Res., 112(D16), D16202, doi:10.1029/2006JD008292, 2007.

Nisantzi, A., Mamouri, R. E., Ansmann, A., Schuster, G. L. and Hadjimitsis, D. G.: Middle East versus Saharan dust extinctionto-backscatter ratios, Atmos. Chem. Phys., 15(12), 7071-7084, doi:10.5194/acp-15-7071-2015, 2015.

Pappalardo, G., Amodeo, A., Apituley, A., Comeron, A., Freudenthaler, V., Linné, H., Ansmann, A., Bösenberg, J., D\&amp;apos;Amico, G., Mattis, I., Mona, L., Wandinger, U., Amiridis, V., Alados-Arboledas, L., Nicolae, D. and Wiegner,

M.: EARLINET: towards an advanced sustainable European aerosol lidar network, Atmos. Meas. Tech., 7(8), 2389-2409, doi:10.5194/amt-7-2389-2014, 2014.

Querry, M.: Optical constants of minerals and other materials from the millimeter to the ultraviolet, US Army Armament Munitions \& Chemical Research Development \& Engineering Center, Aberdeen Proving Ground Md., 1987.

Ramanathan, V., Crutzen, P. J., Lelieveld, J., Mitra, A. P., Althausen, D., Anderson, J., Andreae, M. O., Cantrell, W., Cass, G.

R., Chung, C. E., Clarke, A. D., Coakley, J. A., Collins, W. D., Conant, W. C., Dulac, F., Heintzenberg, J., Heymsfield, A. J., Holben, B., Howell, S., Hudson, J., Jayaraman, A., Kiehl, J. T., Krishnamurti, T. N., Lubin, D., McFarquhar, G., Novakov, T., Ogren, J. A., Podgorny, I. A., Prather, K., Priestley, K., Prospero, J. M., Quinn, P. K., Rajeev, K., Rasch, P., Rupert, S., Sadourny, R., Satheesh, S. K., Shaw, G. E., Sheridan, P. and Valero, F. P. J.: Indian Ocean Experiment: An integrated analysis 
of the climate forcing and effects of the great Indo-Asian haze, J. Geophys. Res. Atmos., 106(D22), 28371-28398, doi:10.1029/2001JD900133, 2001.

Rosenfeld, D.: Cloud-Aerosol-Precipitation Interactions Based of Satellite Retrieved Vertical Profiles of Cloud Microstructure, Remote Sens. Aerosols, Clouds, Precip., 129-152, doi:10.1016/B978-0-12-810437-8.00006-2, 2018.

Roshan, D. R., Koc, M., Isaifan, R., Shahid, M. Z. and Fountoukis, C.: Aerosol Optical Thickness over Large Urban Environments of the Arabian Peninsula-Speciation, Variability, and Distributions, Atmosphere (Basel)., 10(5), 228, doi:10.3390/atmos10050228, 2019.

Rushdi, A. I., El-Mubarak, A. H., Lijotra, L., Al-Otaibi, M. T., Qurban, M. A., Al-Mutlaq, K. F. and Simoneit, B. R. T.: Characteristics of organic compounds in aerosol particulate matter from Dhahran city, Saudi Arabia, Arab. J. Chem., 10, S3532-S3547, doi:10.1016/j.arabjc.2014.03.001, 2017.

Schuster, G. L., Vaughan, M., MacDonnell, D., Su, W., Winker, D., Dubovik, O., Lapyonok, T. and Trepte, C.: Comparison of CALIPSO aerosol optical depth retrievals to AERONET measurements, and a climatology for the lidar ratio of dust, Atmos. Chem. Phys., 12(16), 7431-7452, doi:10.5194/acp-12-7431-2012, 2012.

Shin, S.-K., Tesche, M., Kim, K., Kezoudi, M., Tatarov, B., Müller, D. and Noh, Y.: On the spectral depolarisation and lidar ratio of mineral dust provided in the AERONET version 3 inversion product, Atmos. Chem. Phys., 18(17), 12735-12746, doi:10.5194/acp-18-12735-2018, 2018.

500 Sokolik, I. N. and Toon, O. B.: Incorporation of mineralogical composition into models of the radiative properties of mineral aerosol from UV to IR wavelengths, J. Geophys. Res. Atmos., 104(D8), 9423-9444, doi:10.1029/1998JD200048, 1999.

Stein, A. F., Draxler, R. R., Rolph, G. D., Stunder, B. J. B., Cohen, M. D. and Ngan, F.: NOAA’S HYSPLIT ATMOSPHERIC TRANSPORT AND DISPERSION MODELING SYSTEM, Bull. Am. Meteorol. Soc., 96, 2059-2078, doi:10.2307/26233118, 2015.

505 Stevens, B. and Feingold, G.: Untangling aerosol effects on clouds and precipitation in a buffered system, Nature, 461(7264), 607-613, doi:10.1038/nature08281, 2009.

Ukhov, A., Mostamandi, S., Anisimov, A. and Stenchikov, G.: Natural and anthropogenic air pollution in the Middle East., 2018.

Vonnegut, B. and Chessin, H.: Ice nucleation by coprecipitated silver iodide and silver bromide., Science, 174(4012), 945-6, 510 doi:10.1126/science.174.4012.945, 1971.

Wagner, R., Ajtai, T., Kandler, K., Lieke, K., Linke, C., Müller, T., Schnaiter, M. and Vragel, M.: Complex refractive indices of Saharan dust samples at visible and near UV wavelengths: a laboratory study, Atmos. Chem. Phys., 12(5), 2491-2512, doi:10.5194/acp-12-2491-2012, 2012.

Wehbe, Y., Ghebreyesus, D., Temimi, M., Milewski A. and Al Mandous A. Assessment of the consistency among global 515 precipitation products over the United Arab Emirates, J. Hydrol. Reg. Stud., 12, 122-135, https://doi.org/10.1016/j.ejrh.2017.05.002, 2017.

Wehbe, Y., Temimi, M., Weston, M., Chaouch, N., Branch, O., Schwitalla, T., Wulfmeyer, V., Zhan, X., Liu, J., and Al 
Mandous, A.: Analysis of an extreme weather event in a hyper-arid region using WRF-Hydro coupling, station, and satellite data, Nat. Hazards Earth Syst. Sci., 19, 1129-1149, https://doi.org/10.5194/nhess-19-1129-2019, 2019.

Whiteman, D. N.: Examination of the traditional Raman lidar technique I Evaluating the temperature-dependent lidar equations, Appl. Opt., 42(15), 2571, doi:10.1364/ao.42.002571, 2003.

Wiegner, M., Gasteiger, J., Kandler, K., Weinzierl, B., Rasp, K., Esselborn, M., Freudenthaler, V., Heese, B., Toledano, C., Tesche, M. and Althausen, D.: Numerical simulations of optical properties of Saharan dust aerosols with emphasis on lidar applications, Tellus B Chem. Phys. Meteorol., 61(1), 180-194, doi:10.1111/j.1600-0889.2008.00381.x, 2009.

525 Yu, Y., Notaro, M., Kalashnikova, O. V. and Garay, M. J.: Climatology of summer Shamal wind in the Middle East, J. Geophys. Res. Atmos., 121(1), 289-305, doi:10.1002/2015JD024063, 2016.

Zamora, L. M., Kahn, R. A., Eckhardt, S., McComiskey, A., Sawamura, P., Moore, R. and Stohl, A.: Aerosol indirect effects on the nighttime Arctic Ocean surface from thin, predominantly liquid clouds, Atmos. Chem. Phys., 17(12), 7311-7332, doi:10.5194/acp-17-7311-2017, 2017.
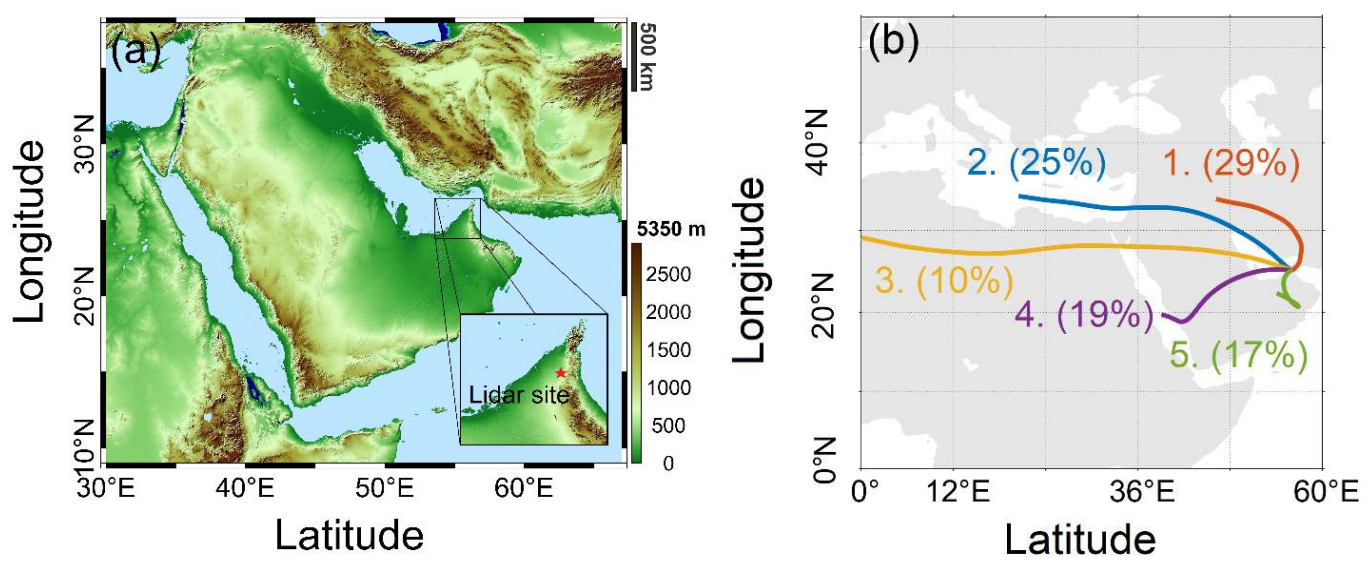

Figure 1. (a) Digital Elevation Map (DEM) from the NASA Shuttle Radar Topographic Mission (SRTM) for the greater area under study. The colorbar values correspond to the altitude above sea level. The site location is shown at the bottom-right of this figure with a red star. (b) Cluster analysis of sources of the detected night-time aerosol layer in the region computed with HySPLIT over the course of the campaign period. Colored lines indicate the trajectory path and the numbers show the percentage share of each trajectory path. 


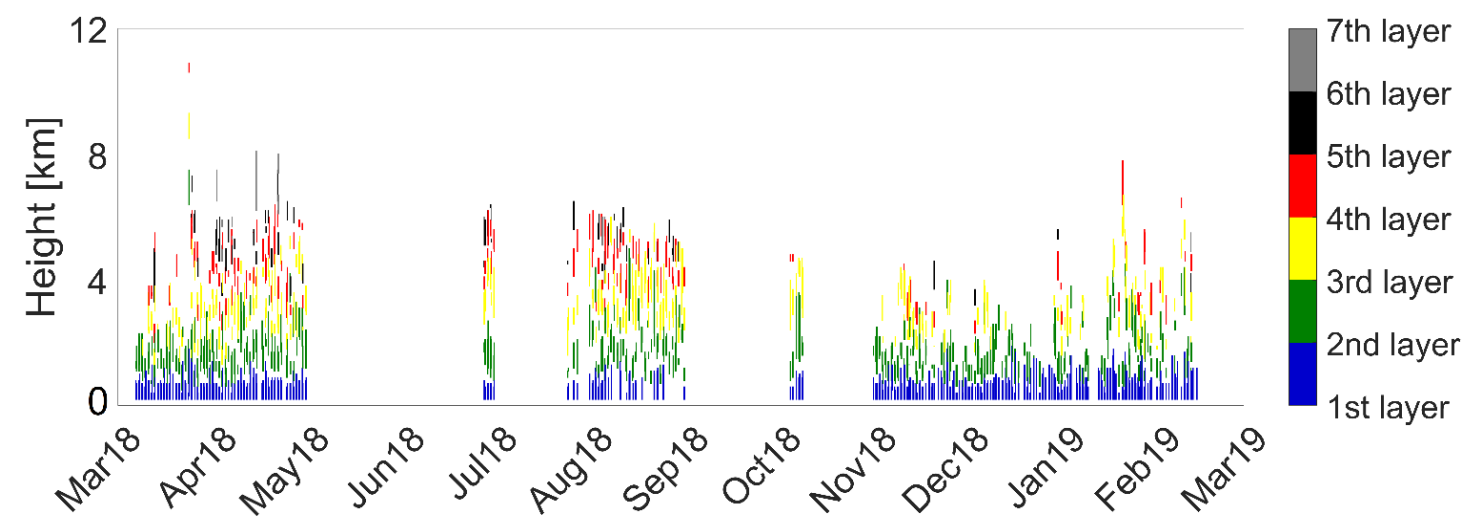

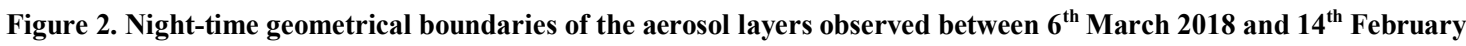
5452019 at the measurement site in UAE. The color indicates the number of aerosol layers in the atmosphere. The gaps in the dataset seen from May to August and between September and November were due to instrumental complications. 

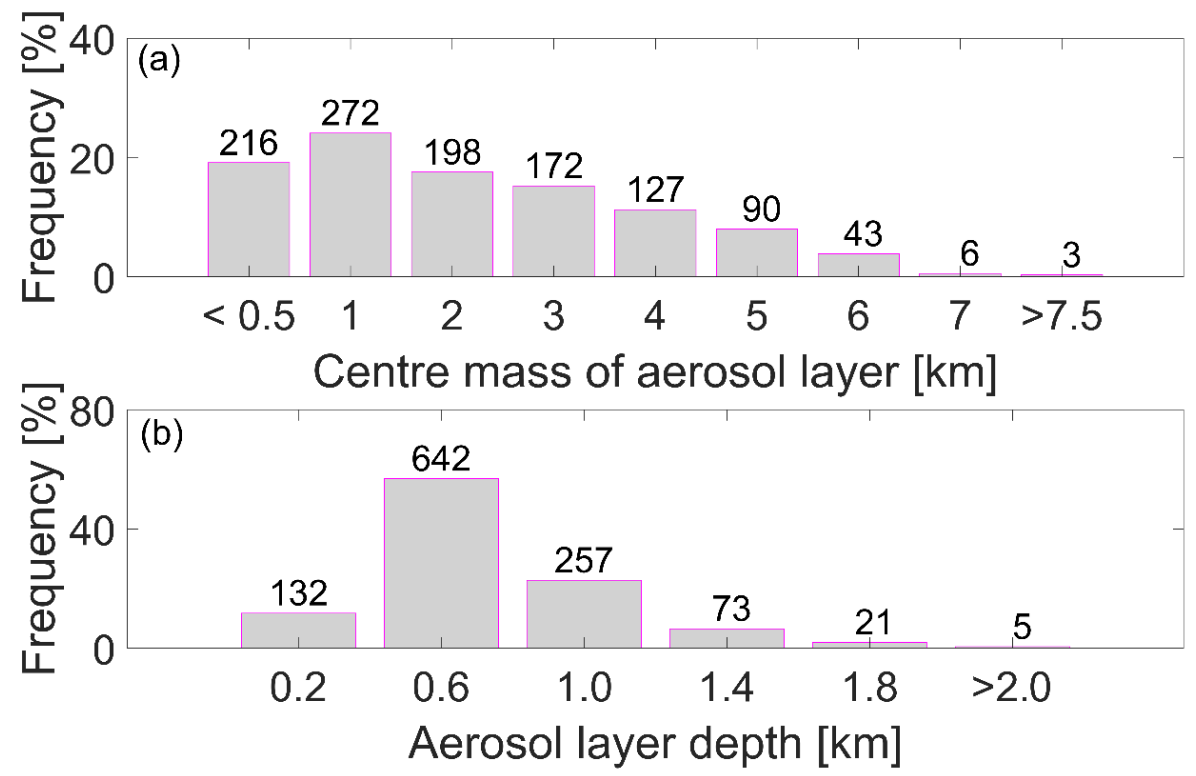

Figure 3. Geometrical characteristics of the aerosol layers during the campaign period. (a) Frequency of the altitude of the centre of mass of the aerosol layers. The width of each bin $1 \mathrm{~km}$ apart from the first and last bins. (b) Frequency of the geometrical depth of the aerosol layers. The width of each bin is $0.4 \mathrm{~km}$ apart from the last bin. The numbers on top of the bars indicates the amount of cases included in the bin. 

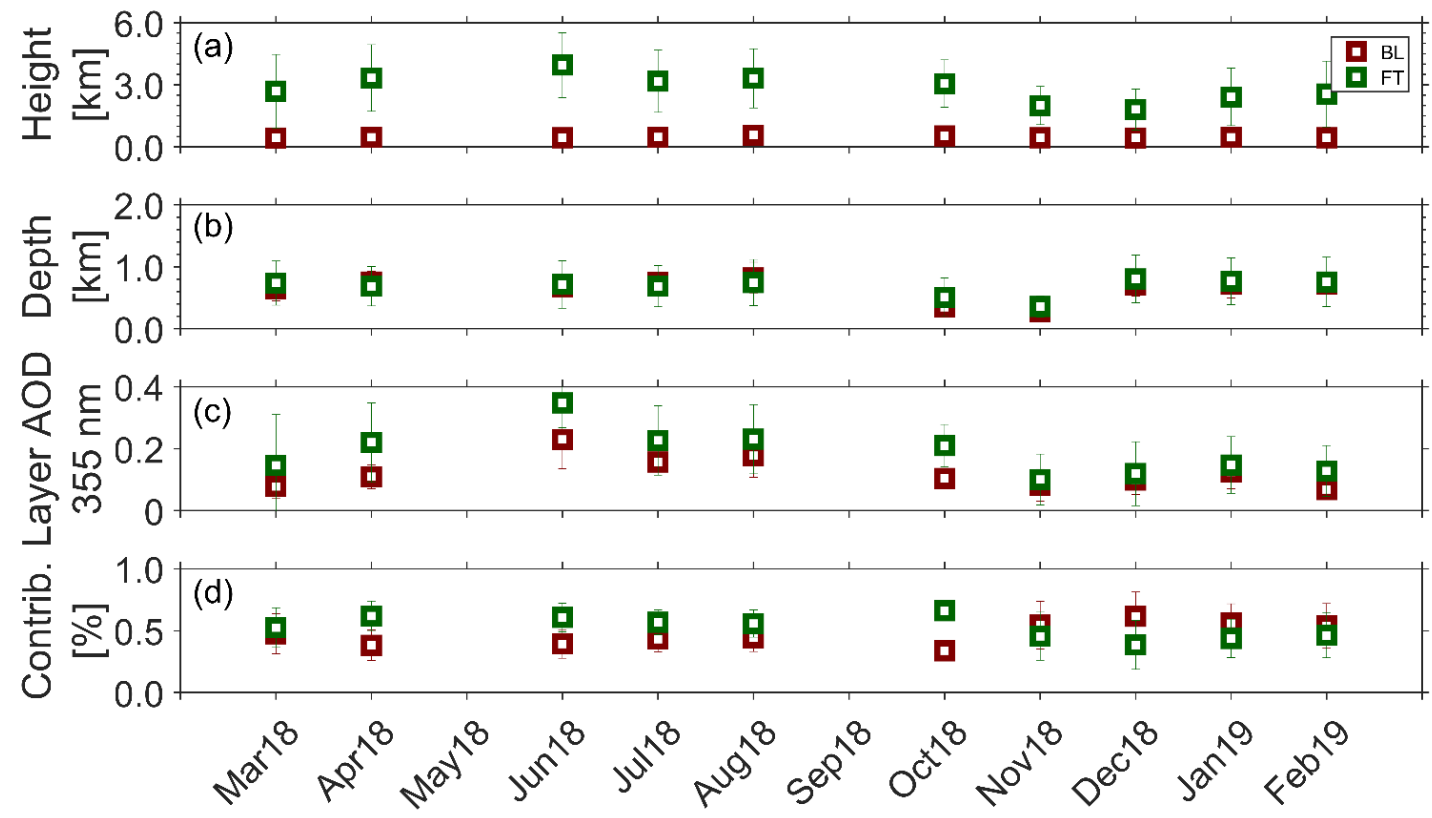

Figure 4. Geometrical characteristics and optical properties of the detected night-time aerosol layers in the boundary layer (BL; in red) and free-troposphere (FT; in green). (a) Centre of mass height of the aerosol layers. (b) Geometrical depth of the detected layers. (c) Layer aerosol optical depths (AOD) at 355. (d) Contribution of BL (red) and FT (green) aerosol layers to the total AOD. 

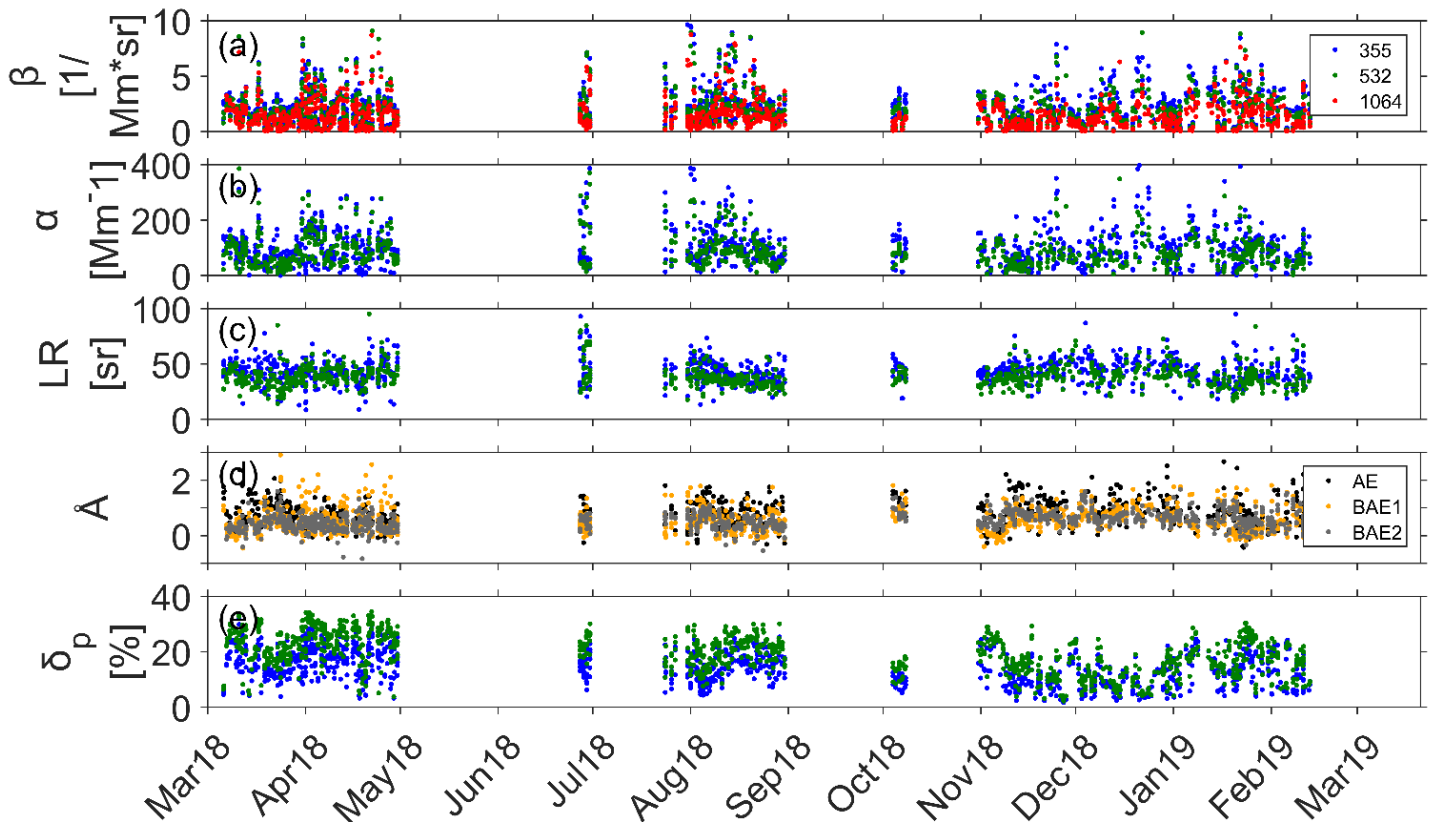

565 Figure 5. Intensive and extensive aerosol properties at different wavelengths $(355 \mathrm{~nm}$ in blue, $532 \mathrm{~nm}$ is green and $1064 \mathrm{~nm}$ in red). (a) Backscatter coefficient. (b) Extinction coefficient. (c) Lidar ratio. (d) Ångström exponents (Å) where the extinction-related Ångström exponent (AE) is marked with black dots, the backscatter -related Ångström exponent at 355/532 (BAE1) with orange and the backscatter-related Ångström exponent at 532/1064 (BAE2) with grey. (e) Linear particle depolarization ratio $\left(\delta_{\mathrm{p}}\right)$. 

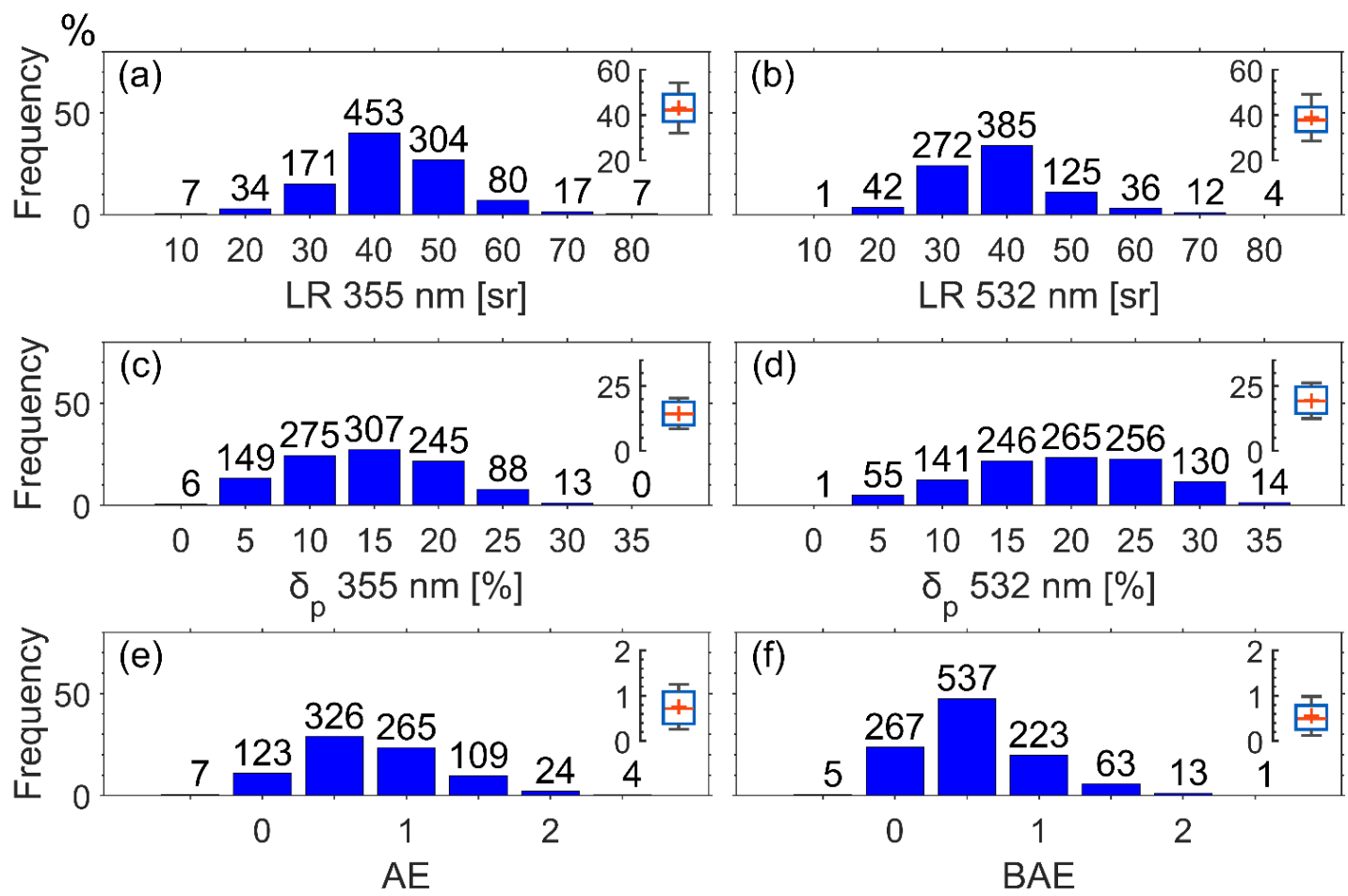

Figure 6. Frequency distribution of: (a) Lidar ratio at $355 \mathrm{~nm}$ with bin width of $10 \mathrm{sr}$. (b) Lidar ratio at $532 \mathrm{~nm}$ with bin width of $10 \mathrm{sr}$. (c) Linear particle depolarization ratio at $355 \mathrm{~nm}$ with bin width of $5 \%$. (d) Linear particle depolarization ratio at $532 \mathrm{~nm}$ with bin width of $5 \%$. (e) Extinction-related Ångström exponent (AE) at 355/532 with bin width of 0.5. (f) Backscatter-related Ångström exponent (BAE) at 355/532 with bin width of 0.5. Box and whisker plots are also presented where cross is the mean value, horizontal line is the median, boxes are the 25 and $75 \%$ percentiles respectively, and whiskers represent the one standard deviation. The numbers above the bars indicate the amount of cases fallen in the bin. 

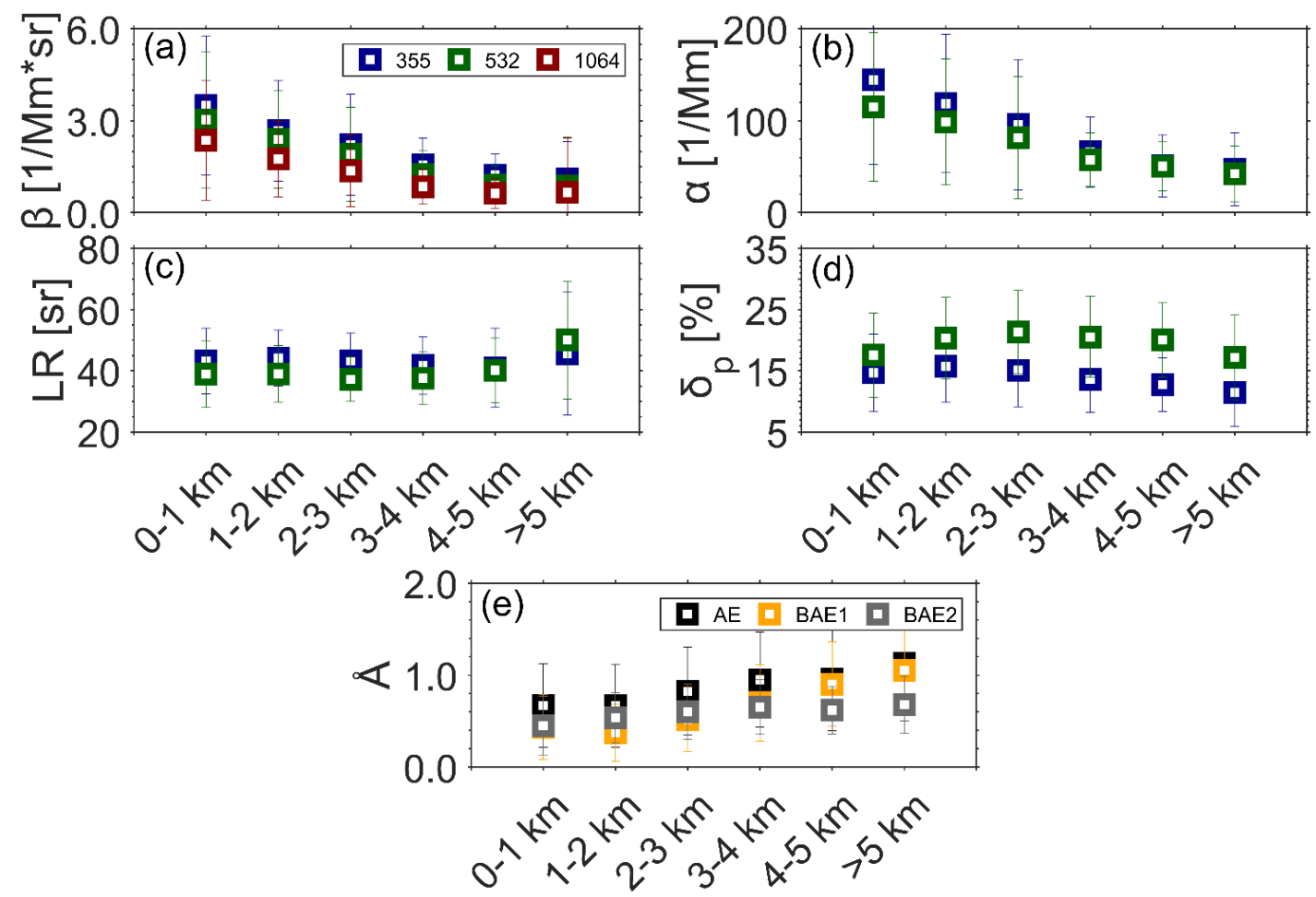

Figure 7. Height-dependent aerosol properties for 0-1, 1-2, 2-3, 3-4 and $>5 \mathrm{~km}$ altitude. (a) Backscatter coefficient at $355 \mathrm{~nm}$ (blue), $532 \mathrm{~nm}$ (green) and $1064 \mathrm{~nm}$ (red). (b) Extinction coefficient at $355 \mathrm{~nm}$ and $532 \mathrm{~nm}$. (c) Lidar ratio at

$355 \mathrm{~nm}$ and $532 \mathrm{~nm}$. (d) Linear particle depolarization ratio at $355 \mathrm{~nm}$ and $532 \mathrm{~nm}$. (e) Extinction-related Ångström exponent (AE) at 355/532, Backscatter-related Ångström exponent (BAE1) at 355/532 and Backscatter-related Ångström exponent (BAE2) at 532/1064. 

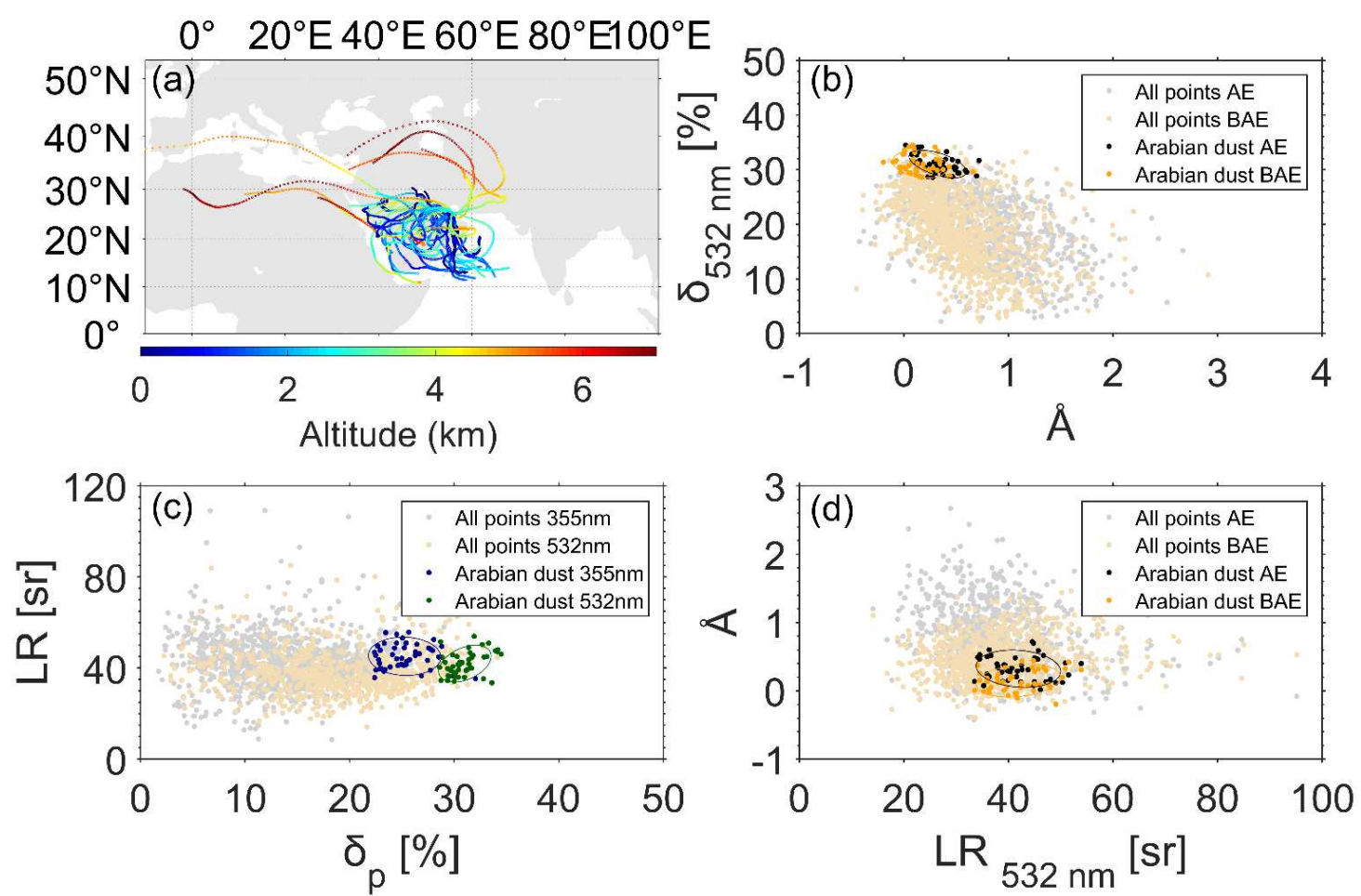

Figure 8. (a) Backward air mass trajectories of all the cases considered for the characterization of the Arabian dust properties. (b) Ångström exponent $(\AA ̊)$ versus linear particle depolarization $\left(\delta_{p}\right)$ at $532 \mathrm{~nm}$. (c) Linear particle depolarization $\left(\delta_{p}\right)$ versus lidar ratio (LR). (d) Lidar ratio (LR) at $532 \mathrm{~nm}$ versus Ångström exponents (Å). The Ångström exponent plots at $b$ and $d$ panels indicate the extinction-related (AE) and backscatter-related (BAE) exponents at $355 / 532$. The ellipsoids in panels b-d were drawn considering a $95 \%$ confidence for the set of data points. 
605 Table 1: Aerosol particle properties of the Arabian dust and comparison to previous studies. Both 355 and 532 nm wavelengths are reported in terms of their lidar ratio (LR), linear particle depolarization $\left(\delta_{p}\right)$ and the ratio of theirs lidar ratios. Combination of Ångström exponents both from the extinction (AE) and backscatter (BAE) coefficients along with the color ratios (CR) are shown due to the multi-wavelength capability of the lidar instrument. The numbers in the brackets show the range of values found for each optical property.

\begin{tabular}{|c|c|c|c|c|c|c|c|c|c|c|c|}
\hline Property & $\begin{array}{c}\mathrm{LR} \\
355 \mathrm{~nm} \\
{[\mathrm{sr}]}\end{array}$ & $\begin{array}{c}\mathrm{LR} \\
532 \mathrm{~nm} \\
{[\mathrm{sr}]}\end{array}$ & $\begin{array}{c}\delta_{\mathrm{p}} \\
355 \mathrm{~nm} \\
{[\%]}\end{array}$ & $\begin{array}{c}\delta_{\mathrm{p}} \\
532 \mathrm{~nm} \\
{[\%]}\end{array}$ & $\mathrm{AE}$ & $\begin{array}{c}\text { BAE } \\
355 / 532\end{array}$ & $\begin{array}{c}\text { BAE } \\
532 / 1064\end{array}$ & $\begin{array}{c}\text { CR } \\
355 / 1064\end{array}$ & $\begin{array}{c}\text { CR } \\
532 / 1064\end{array}$ & $\begin{array}{c}\text { CR } \\
355 / 532\end{array}$ & $\begin{array}{l}\text { LR355/ } \\
\text { LR532 }\end{array}$ \\
\hline $\begin{array}{l}\text { Müller et } \\
\text { al. } \\
(2007)\end{array}$ & $38 \pm 5$ & $38 \pm 5$ & - & - & $0.6 \pm 0.3$ & - & $1.1 \pm 0.4$ & - & - & - & $\sim 1$ \\
\hline $\begin{array}{c}\text { Mamouri } \\
\text { et al. } \\
(2013)\end{array}$ & - & $\begin{array}{c}34 \pm 7 \\
\text { to } \\
39 \pm 5\end{array}$ & - & $(28-35)$ & - & - & - & - & - & - & - \\
\hline $\begin{array}{l}\text { Nisantzi } \\
\text { et al. } \\
(2015)\end{array}$ & - & $\begin{array}{c}41 \pm 4 \\
(33-48)\end{array}$ & - & - & - & - & - & - & - & - & - \\
\hline $\begin{array}{c}\text { Hofer et } \\
\text { al. } \\
\text { (2017) }\end{array}$ & $42 \pm 3$ & $36 \pm 2$ & $18 \pm 2$ & $31 \pm 1$ & $0.4 \pm 0.2$ & $0.0 \pm 0.2$ & $0.1 \pm 0.0$ & - & - & - & - \\
\hline $\begin{array}{l}\text { This } \\
\text { study }\end{array}$ & $\begin{array}{c}45 \pm 5 \\
(35-55)\end{array}$ & $\begin{array}{c}42 \pm 5 \\
(34-54)\end{array}$ & $\begin{array}{c}25 \pm 2 \\
(22-32)\end{array}$ & $\begin{array}{c}31 \pm 2 \\
(28-35)\end{array}$ & $\begin{array}{l}0.3 \pm 0.2 \\
(0.0-0.7)\end{array}$ & $\begin{array}{c}0.2 \pm 0.2 \\
(-0.2-0.7)\end{array}$ & $\begin{array}{l}0.3 \pm 0.1 \\
(0.1-0.6)\end{array}$ & $\begin{array}{l}1.4 \pm 0.2 \\
(1.1-2.0)\end{array}$ & $\begin{array}{l}1.3 \pm 0.1 \\
(1.1-1.5)\end{array}$ & $\begin{array}{c}1.1 \pm 0.1 \\
(0.9-1.3)\end{array}$ & $\begin{array}{l}1.1 \pm 0.1 \\
(0.9-1.3)\end{array}$ \\
\hline
\end{tabular}


https://doi.org/10.5194/acp-2020-133

Preprint. Discussion started: 13 March 2020

(c) Author(s) 2020. CC BY 4.0 License.

\section{Atmospheric}

Chemistry

(c) (i)

\section{Appendix A}

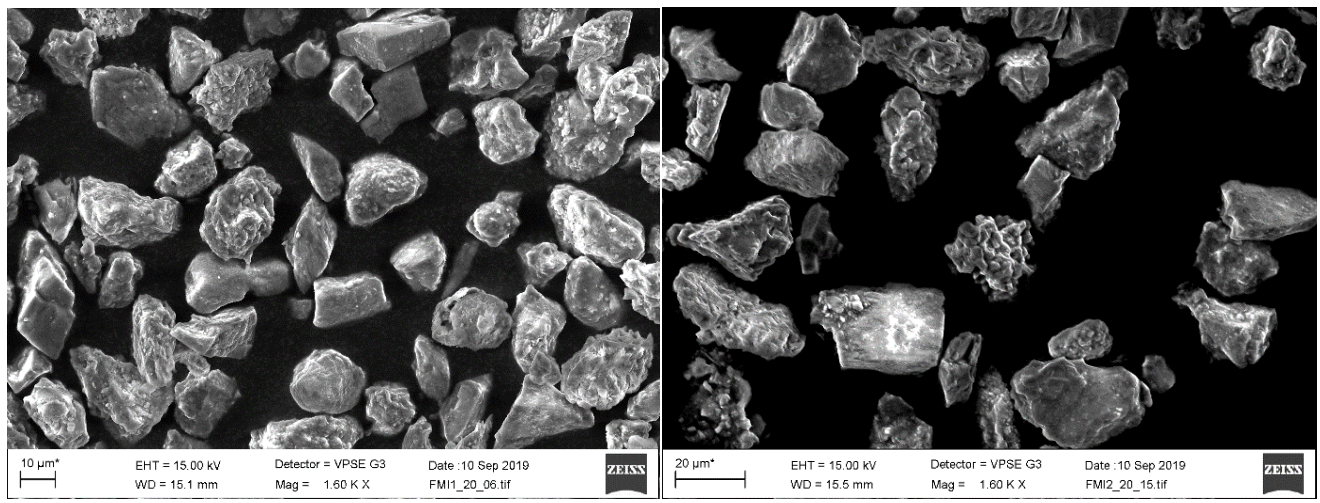

Figure B1: SEM pictures of the two dust samples. Sample 1 on the left and sample 2 on the right.

Table C1. Chemical composition of the two dust samples. The numbers show the minimum/maximum value of the elements found in the sample.

\begin{tabular}{ccc}
\hline Weight \% & Sample 1 & Sample 2 \\
$O$ & $45-82-64.49$ & $50.79-59.25$ \\
$F$ & - & 6.17 \\
$N a$ & $0.48-3.38$ & $0.55-2.10$ \\
$M g$ & $2.68-6.30$ & $2.66-10.04$ \\
$A l$ & $1.48-10.88$ & $1.79-3.38$ \\
$S i$ & $5.45-23.89$ & $6.09-35.87$ \\
$S$ & $0.30-15.87$ & $0.21-1.93$ \\
$K$ & $0.30-5.39$ & $0.21-0.74$ \\
$C a$ & $6.43-33.55$ & $4.04-32.33$ \\
$T i$ & - & $0.83-35.88$ \\
$F e$ & $1.20-12.33$ & $2.08-5.62$ \\
$B a$ & 0.90 & - \\
$C l$ & 0.20 & - \\
\hline
\end{tabular}





\section{Paper IV}

Aerosol effect on the cloud phase of low-level clouds over the Arctic.

Filioglou, M., Mielonen, T., Balis, D., Giannakaki, E., Arola, A., Kokkola, H., Komppula, M. and Romakkaniemi, S.

Journal of Geophysical Research: Atmospheres, 124: 7886-7899, 2019. 


\section{JGR Atmospheres}

\author{
RESEARCH ARTICLE \\ 10.1029/2018JD030088 \\ Key Points: \\ - Cloud thermodynamic phase of \\ low-level Arctic clouds is more \\ susceptible to aerosol concentration \\ changes than the type of the aeroso \\ - Both the aerosol type and aerosol \\ concentration effects are smaller \\ over open ocean than over land \\ or ice
}

Supporting Information:

- Supporting Information S1

Correspondence to:

M. Filioglou,

maria.filioglou@fmi.fi

Citation:

Filioglou, M., Mielonen, T., Balis, D., Giannakaki, E., Arola, A., Kokkola, H., et al. (2019). Aerosol effect on the cloud phase of low-level clouds over the Arctic. Journal of Geophysical Research: Atmospheres, 124. https://doi.org/ 10.1029/2018JD030088

Received 30 NOV 2018 Accepted 18 JUN 2019 Accepted article online 8 JUL 2019

(C)2019. American Geophysical Union. All Rights Reserved.

\section{Aerosol Effect on the Cloud Phase of Low-Level Clouds Over the Arctic}

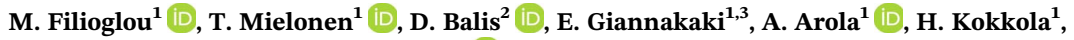 \\ M. Komppula ${ }^{1}$, and S. Romakkaniemi ${ }^{1}$ iD \\ ${ }^{1}$ Finnish Meteorological Institute, Kuopio, Finland, ${ }^{2}$ Laboratory of Atmospheric Physics, Physics Department, Aristotle \\ University of Thessaloniki, Thessaloniki, Greece, ${ }^{3}$ Environmental Physics and Meteorology, Faculty of Physics, National \\ and Kapodistrian University of Athens, Athens, Greece
}

Abstract Three years of nighttime Cloud-Aerosol Lidar and Infrared Pathfinder Satellite Observation data was used in synergy with CloudSat measurements to quantify how strongly aerosol type and aerosol load affect the cloud phase in low-level clouds over the Arctic. Supercooled liquid layers were present in the majority of observed low-level clouds $(0.75 \leq z \leq 3.5 \mathrm{~km})$ between -10 and $-25^{\circ} \mathrm{C}$. Furthermore, based on the subset (6\%) of data with high quality assurance for aerosol typing, ice formation is more common in the presence of dust or continental aerosols as opposed to marine or elevated smoke aerosols. With the first aerosol group, glaciated clouds were found at cloud top temperatures of 2 to $4{ }^{\circ} \mathrm{C}$ warmer than with the latter aerosol types. Further association of the aerosol concentration with the cloud phase showed that the aerosol concentration outweighs the aerosol type effect. Depending on the aerosol load, the temperature at which a cloud completely glaciates can vary by up to $6-10{ }^{\circ} \mathrm{C}$. However, this behavior was most pronounced in stable atmospheric conditions and absent over open ocean with lower tropospheric stability values and probably less stratified clouds. Finally, more mixed-phase clouds were associated with high aerosol load, suggesting that mixed-phase clouds have an extended lifetime in the Arctic under high cloud condensation nuclei concentrations. This implies that in a pristine environment, with few or no local aerosol sources, and under the investigated conditions the amount of aerosol particles affects the cloud phase more than the aerosol type does.

\section{Introduction}

Low-level clouds are very common in the Arctic (Bennartz et al., 2013; Wylie, 2001). In contrast to other regions on the Earth, these clouds have a positive net radiative effect (Cronin \& Tziperman, 2015; Shupe \& Intrieri, 2004), which is attributed to the long lasting polar nights and high surface albedo of the region. In practice, Arctic low-level clouds prevent the transfer of longwave radiation to space for most of the time except for the short summertime period when the albedo effect of the clouds outweighs their warming effect. This results in about $30-\mathrm{W} / \mathrm{m}^{2}$ warming over the annual cycle (Bintanja \& Krikken, 2016; Intrieri et al., 2002; Shupe \& Intrieri, 2004; Yeo et al., 2018). These clouds have also been associated with the Arctic sea ice loss (Kay \& Gettelman, 2009; Schweiger et al., 2008) and melting of the Greenland ice sheet (Bennartz et al., 2013).

Presently, local aerosol emission sources in the Arctic are small and the aerosols are mainly transported from lower latitudes (Law \& Stohl, 2007). Yet aerosol sources, both local and far away, are likely to change in the warming Arctic. Because the pristine environment in the Arctic is particularly susceptible to changes in aerosol concentrations (Quinn et al., 2007, 2008; Ritter et al., 2005), there is a need to better understand and quantify the aerosol effect on clouds (Boucher et al., 2013). This is especially important as the clouds in the Arctic are currently poorly represented in atmospheric models (Karlsson \& Svensson, 2013). In addition, the decline of the sea ice cover gives the opportunity to map new Trans-Arctic routes between Asia, Europe, and North America (Aksenov et al., 2017; Holland et al., 2006; Smith \& Stephenson, 2013; Stephenson et al., 2013), thus increasing local aerosol emissions. Estimating the effect of these increases in aerosol emissions would require better understanding of the link between the aerosol emissions and Arctic clouds. For example, open/closed cell clouds related to ship tracks have been linked with increased/decreased precipitation compared to aerosol free conditions (Christensen \& Stephens, 2012; Possner et al., 2017).

The thermodynamic phase of a cloud is driven both by the meteorology and the ability of the aerosols to act as ice nuclei particles (INPs) or cloud condensation nuclei (CCN). Comparison studies between modeled and 
observed fractions of liquid, mixed, and ice clouds have shown that models underestimate the fraction of liquid containing clouds due to simplified representation of the cloud phase (Tan et al., 2016). For example, in several models, droplets are not allowed to form at temperatures lower than about $-20^{\circ} \mathrm{C}$ although this is commonly observed (Bennartz et al., 2013; Cesana et al., 2012). In addition, global models tend to glaciate mixed-phase clouds too quickly through the Bergeron-Findeisen process followed by precipitation. Hence, an increase in INP is likely to decrease cloud lifetime by increasing precipitation release via the ice phase. Due to the complicated interplay between aerosols and clouds, the aerosol indirect effect is the most uncertain climate related process in atmospheric models (Boucher et al., 2013). A significant source of uncertainty originates from our limited knowledge on the various heterogeneous ice nucleation pathways at the subfreezing temperature region between -10 and $-38^{\circ} \mathrm{C}$, where liquid and ice particles coexist.

A plethora of studies suggest that certain aerosol types such as mineral dust particles are more efficient INPs than most other types (Atkinson et al., 2013; DeMott et al., 2003; Kanji et al., 2017; Prenni et al., 2009; Price et al., 2018; Seifert et al., 2010; Zhang et al., 2015). Li et al. (2017) found that dust-mixed ice clouds are linked with warmer cloud top temperatures (CTTs) suggesting the efficiency of such particles to act as INP. Using cloud model simulations to study the efficiency of ice nucleation mechanisms, Morrison et al. (2005) linked the extended lifetime of low-level mixed-phase clouds in the Arctic to rapid scavenging of deposition/condensation-freezing nuclei They also stated that contact freezing, as a self-regulated process, is unable to glaciate the cloud. Moreover, Zamora et al. (2017) used a limited subset of observations from Cloud-Aerosol Lidar and Infrared Pathfinder Satellite Observation (CALIPSO; Winker et al., 2010) and CloudSat (Stephens et al., 2002) over the Arctic and found that aerosol influenced clouds over the sea ice have smaller effective radii and are less likely to precipitate (cloud lifetime effect). On the other hand, in the same study it is concluded that open ocean clouds are less sensitive to aerosols than clouds over the sea ice due to greater boundary layer turbulent fluxes. Similarly, Ansmann et al. (2009) concluded that the effectiveness of, specifically, mineral dust to act as INP is not high compared to how efficiently changes in the meteorology or the aerosol load modify the properties of altocumulus clouds observed over Cape Verde. Later studies stress the complexity of this mechanism and its efficiency in different geographic locations. For example, Coopman, Garrett, et al. (2018) using multiyear satellite, meteorological, and tracer transport model data found that low-level Arctic cloud response to anthropogenic aerosols are 2 to 8 times higher than in lower latitudes and that the role of biomass aerosols to Arctic clouds response have been overstated in previous studies. Consequently, the relative contribution of aerosol to the radiative forcing of Arctic clouds is still highly uncertain (Coopman, Riedi, et al., 2018; Flanner, 2013; Garrett et al., 2002; Garrett et al., 2004; Norgren et al., 2018; Solomon et al., 2018; Wylie \& Hudson, 2002; Zamora et al., 2018; Zhao \& Garrett, 2015).

To enhance our understanding on the role of aerosols in the formation of Arctic clouds, we have investigated the relationship between low-level cloud properties, such as the cloud phase, associated with different aerosol types and load over the Arctic and studied how their relationship is linked to CTTs. Finally, we have isolated the meteorology effect on the aforementioned associations in order to extract robust conclusions. For this purpose, we used spaceborne active remote sensing observations from CALIPSO and CloudSat to extract the thermodynamic phase of the clouds and the type of the aerosols in their vicinity.

\section{Methods}

Satellite-based observations provide a unique opportunity to study remote locations, such as the Arctic, with great spatial and temporal resolution. Aerosols and clouds are ubiquitous, and their characteristics, either microphysical or geometrical, are highly variable over space and time. This fact makes them challenging to be addressed by a single sensor alone. In this study, we used a synergy of a cloud radar and a LiDAR (Light Detection And Ranging), in order to suppress the limitations of each instrument and have a more complete information of cloud characteristics. Regarding the aerosol properties, we have relied on the information provided by the LiDAR alone.

\subsection{Data Set}

Both the LiDAR and cloud radar were flying in the A Train formation with $17.5 \pm 2.5 \mathrm{~s}$ apart. CALIOP is a three-channel LiDAR system onboard CALIPSO satellite delivering optical properties with a vertical resolution of $30 \mathrm{~m}$ for heights up to $8.2 \mathrm{~km}$. CALIOP has a beam diameter of about $70 \mathrm{~m}$ at the Earth's surface. The 
Cloud Profiling Radar onboard CloudSat has a spatial resolution of $1.4 \mathrm{~km}$ (cross track) by $1.7 \mathrm{~km}$ (along track). Its vertical resolution is $240 \mathrm{~m}$.

Two data sets were used in this study employing the preceding instruments. The merged CloudSat CALIPSO 2B CLDCLASS LiDAR R04 product (hereafter combined CloudSat/CALIPSO) combined with the European Centre for Medium-range Weather Forecasts Auxiliary (ECMWF-AUX) product (Partain, 2007; Sassen et al., 2008; Wang et al., 2012) and the merged aerosol and cloud CALIPSO $5 \mathrm{~km}$ (level 2, v4.1) layer product (Kim et al., 2018; Winker, 2016).

The combined CloudSat/CALIPSO product provided cloud layer height boundaries, top/base temperatures, and the thermodynamic phase of each of the detected cloud layers (the thermodynamic phase corresponds to the whole cloud). The reported spatial resolution of this product is the same as in the standard CloudSat products $(1.4 \mathrm{~km}$ by $1.7 \mathrm{~km})$. Temperature information was retrieved from the ECMWF-AUX product. The combined CloudSat/CALIPSO data set is expected to overcome the limitations of the individual instruments and to provide a more complete cloud classification and their corresponding properties. To some extent, the performance and limitations of CloudSat have been addressed in previous studies (Candlish et al., 2013; Li et al., 2015; Li et al., 2018; Noh et al., 2011; Sassen et al., 2008) but no comprehensive study was found for the evaluation of the combined product. We should mention here that data from CALIPSO version 3 have been used to retrieve the combined CloudSat/CALIPSO data set (R04). This older version of CALIPSO algorithms have been improved since and evaluated, to some extent, against the newer one (v4.1; Kar et al., 2018; Kim et al., 2018). A notable difference from v3 is that all aerosol subtypes are allowed over polar region and the aerosol classification algorithm no longer uses snow, ice, and tundra as decision points. Thus, we used the merged aerosol and cloud CALIPSO $5 \mathrm{~km}$ (level 2, v4.1) layer product where all the above cloud layer parameters, including the equivalent aerosol layer parameters and aerosol typing, are available.

To describe the aerosol impact on low-level Arctic clouds (cloud layers with boundaries between 0.75 and 3.5 $\mathrm{km}$ ) with the highest possible confidence, it was essential to choose only a subset of these data fulfilling certain criteria. The cases presented concern single cloud ( $\mathrm{SiC}$ ) layer for single aerosol (SiA) layer with their vertical distance being within $1 \mathrm{~km}$ from each other. We should mention here that the aerosol layer can be found anywhere around the cloud. This SiC-SiA combination was chosen in order to minimize the attenuation of the LiDAR laser beam in multiply-layered cases and to simplify the relationship between the observed cloud and the aerosol layer in its vicinity. Nonetheless, we cannot distinguish with the selected satellite observations where the mixing between the aerosol and cloud really occurs. Another reason to limit our analysis to these cases was to avoid the seeding effect of the cloud formation in the presence of another cloud on top of it (e.g., Ansmann et al., 2009). However, such events cannot be completely ruled out. Cloud layers whose base were found to be below $0.75 \mathrm{~km}$ were omitted due to the limitation of CloudSat to correctly identify clouds within the boundary layer (Chan \& Comiso, 2013; Christensen et al., 2013; Mioche et al., 2015). Another restriction applied to the depolarization ratio of the aerosol layers at $532 \mathrm{~nm}$. Negative or values above $40 \%$ have been discarded as being unrealistic.

In addition, concerning the CALIOP observations, layers with cloud aerosol discrimination score lower than absolute 70 were removed from the data set to limit the analysis to observations with high confidence (Yang et al., 2012). Moreover, due to the strong background noise during daytime in the LiDAR signal, measurements were limited to nighttime observations for better confidence. Similarly, cloud layers from the combined CloudSat/CALIPSO product whose confidence level scored below 5 were omitted to use only the observations with high confidence. Thus, the selection of the SiC-SiA cases was made regarding the quality of the observations themselves and their relative distance. We aimed for the highest possible quality data assuring at the same time that the sample is sufficient to draw safe conclusions.

This data set is also limited to latitudes above $62^{\circ} \mathrm{N}$ and to observations between January 2008 and December 2010 to exclude the $3^{\circ}$ off nadir angle epoch of CALIOP, which enhances specular reflections originating from horizontally oriented ice crystals.

Overall, CALIPSO identified over $59 \cdot 10^{5}$ nighttime cloud signatures during the aforementioned period in the area. The low-level cloud share of those was $42 \%$ (tops $<3.5 \mathrm{~km}$ ). Low-level clouds where no other cloud was present in the whole atmospheric column decreased fraction to $18 \%$ (8\%) of all low-level (all nighttime) 
clouds. Finally, limiting further to cloud bases above $0.75 \mathrm{~km}$ resulted to $14 \%$ (6\%) of all low-level (all nighttime) clouds. This is our final data set in which further quality assurance was applied on as discussed above and used further on in this study. Although this cloud data set is a small fraction of the total observations of nighttime low-level clouds in the Arctic and may not be representative in general in the Arctic for such clouds, it was essential to ascertain high-quality observations for robust conclusions.

\subsection{Collocation}

In the CALIPSO 5-km layer product, cloud layers are usually reported at 5- or 20-km spatial resolution, while aerosol layers are provided with $5-, 20-$, or $80-\mathrm{km}$ spatial resolution depending on the strength of the returned signal. On the other hand, the combined CloudSat/CALIPSO cloud data set spatial resolution along the track is $1.7 \mathrm{~km}$. In order to match the $5-\mathrm{km}$ resolution of the CALIPSO cloud data set, we combined three footprints from the combined CloudSat/CALIPSO data set. First, the closest footprint to a CALIPSO footprint was identified in the combined CloudSat/CALIPSO data set and then three CloudSat/CALIPSO points centered on this middle point were averaged. Cloud cases with $20-\mathrm{km}$ resolution in CALIPSO data set are omitted. We should mention here that, in the end, we only considered cases where both data sets detected $\mathrm{SiC}$. The new spatial resolution of the combined CloudSat/CALIPSO cloud data set was $1.4 \mathrm{~km}$ (cross) by $5.1 \mathrm{~km}$ (along) although the CALIPSO cross footprint is around $70 \mathrm{~m}$ at the surface. The schematic (Figure 1) demonstrates the procedure for acquiring the final working data set.

Figure 2 shows the number of cloud cases for each season detected by the two data sets. For the SiC cases observed by the LiDAR (blue bars) only a part of them is found at CloudSat/CALIPSO data set (red bars), while more than one cloud layers (orange bars) were also present in the combined CloudSat/CALIPSO. In fact, we found a 22-28\% disagreement at SiC cases between the two cloud data sets, depending on the season, which is in agreement with previous studies (e.g., Chan et al., 2013). This includes both cases where the combined CloudSat/CALIPSO data set did not detected any cloud layer and cases where more than one layer has been observed as shown in Figure 2 (orange and purple bars). Since we have considered that CALIPSO v4.1 should contain the least misclassified cloud/aerosol layers, the aforementioned percentage shows only a part of their disagreement; nevertheless, we do not expect disagreement higher than that. This discrepancy originates from the fact that the combined product is using the CALIPSO v3 data set; hence, the classification is somewhat different from the newer version and the fact that the LiDAR attenuates in liquid layers and consequently neglects any clouds below such layers. As already mentioned, a small fraction of the combined data set does not contain any cloud layers (purple bars). We found that $40-50 \%$ of those cases are present in CALIPSO v3 but they are not found in the combined CloudSat/CALIPSO data set. Finally, the green bars show the final data set when the SiC cases are linked with SiA layers and have been quality controlled as described in section 2.1. The seasonal spatial distribution of this final data set is shown in Figure 3. Due to the restriction to nighttime data only, the final data set contains mainly cases from winter and autumn seasons. Additionally, the majority of the cases are found over ocean including sea ice.

\section{Results}

\subsection{Relative Cloud Phase Occurrence of Low-Level Arctic Clouds}

The temperature dependence of the thermodynamic cloud phases is required when calculating the cloud radiative forcing as cloud optical properties depend on the amount of liquid water and ice. Currently, the fraction of ice and mixed-phase clouds in climate models is determined primarily by the temperature and proxies for INP, which are not linked with real aerosol properties. This approach is rather simplified and uncertain.

Using 3 years of satellite data, we have calculated the relative cloud phase occurrence (RCPO) for each thermodynamic phase and their relationship with the CTT for low-level Arctic clouds (Figure 4). All low-level clouds with top boundaries below $3.5 \mathrm{~km}$ and bases above $0.75 \mathrm{~km}$ were considered. For this data set, no extra constrains were applied except those of cloud aerosol discrimination score (to CALIPSO observations) and confidence level (to the combined CloudSat/CALIPSO observations) as described in section 2.1. RCPO is derived as the ratio of the total amount of cloud layers of a specific thermodynamic phase over the total amount of cloud layers falling into a temperature bin with the width of $2{ }^{\circ} \mathrm{C}$, ranging from -40 to $0{ }^{\circ} \mathrm{C}$. Similar to results from Morrison et al. (2005) and de Boer et al. (2011), Arctic mixed-phase clouds dominate between -10 and $-25^{\circ} \mathrm{C}$. Only below $-27^{\circ} \mathrm{C}$ the frequency of ice-only clouds exceeds mixed-phase clouds 


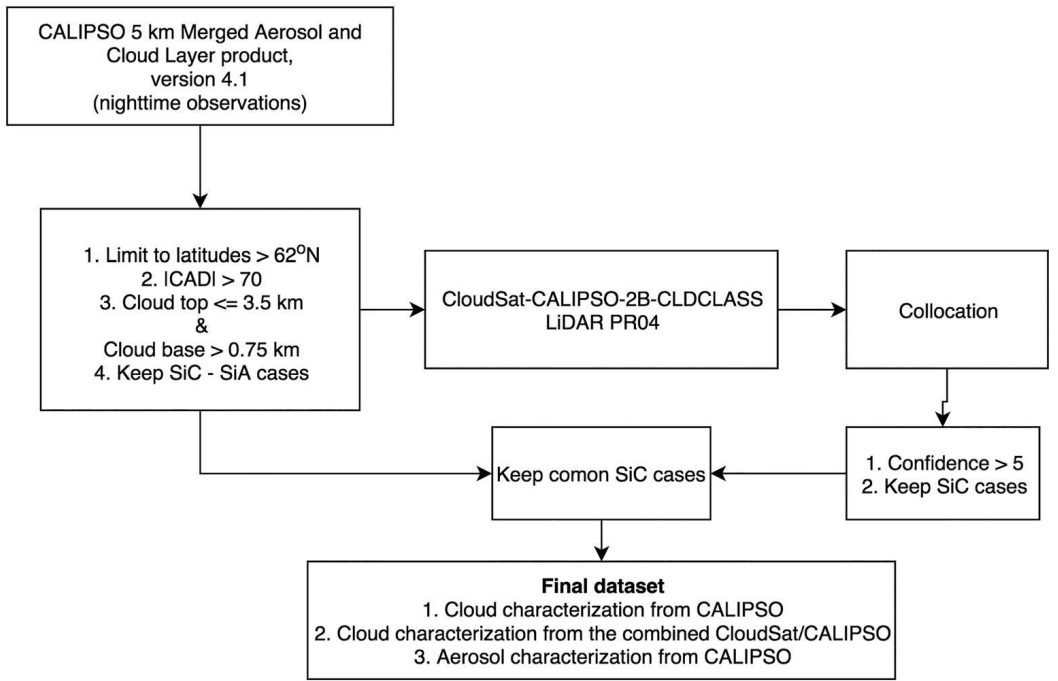

Figure 1. Schematic of the data selection procedure. $\mathrm{CAD}=$ cloud aerosol discrimination; CALIPSO $=$ Cloud-Aerosol Lidar and Infrared Pathfinder Satellite Observation; LiDAR = Light Detection And Ranging; SiA = single aerosol; $\mathrm{SiC}=$ single cloud

existence. At $-20^{\circ} \mathrm{C}$, the share of ice-only clouds amounts to $6 \%$, reinforcing the conclusions from previous studies on the limited efficiency of heterogeneous ice nucleation mechanisms at warmer temperatures. While the utilized data set cannot reveal the possible ice nucleation pathways, it appears that the number concentration of particles efficient as contact nucleation or immersion/condensation freezing nucleus is not high enough to glaciate the whole cloud.

The LiDAR cannot distinguish between mixed-phase and water clouds since the beam attenuates in the presence of a liquid layer; hence, mixed-phase and water clouds from the combined CloudSat/CALIPSO

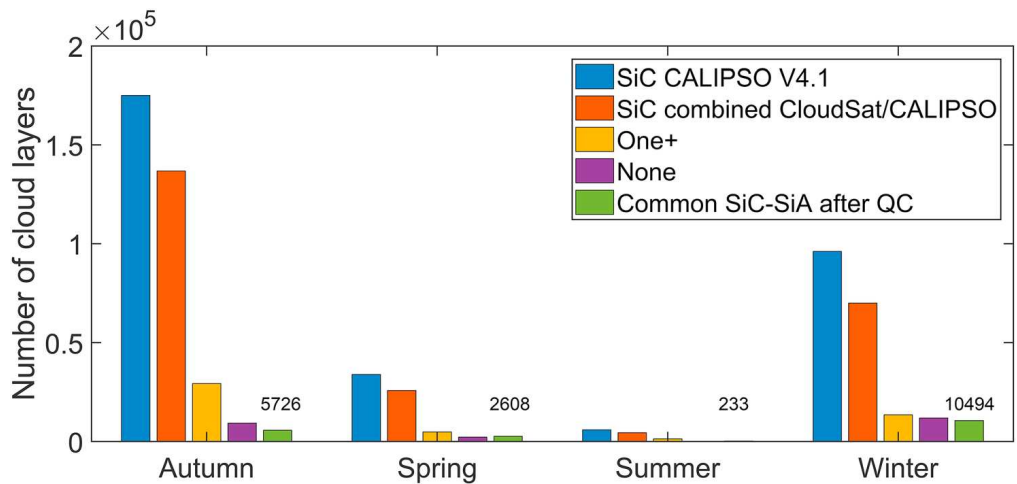

Figure 2. Seasonal differences in the detected $\mathrm{SiC}$ layer cases between the combined CloudSat/CALIPSO and CALIPSO v4.1. Blue: SiC layer cases detected with CALIPSO v4.1. Red: SiC cases in the combined CloudSat/CALIPSO data set for the blue $\mathrm{SiC}$ cases. Orange: More than one (one+) cloud layers detected in the combined CloudSat/CALIPSO product for the blue SiC cases. Purple: No cloud layers detected in the combined CloudSat/CALIPSO product for the blue $\mathrm{SiC}$ cases. The red, orange, and purple bars combined together result to the blue bar cases. Green: Final SiC-SiA data set after quality control. The number above the green bars indicate the number of the final cases used hereafter. Only nighttime observations are considered. CALIPSO = Cloud-Aerosol Lidar and Infrared Pathfinder Satellite Observation; $\mathrm{QC}=$ quality control; $\mathrm{SiA}=$ single aerosol; $\mathrm{SiC}=$ single cloud. 

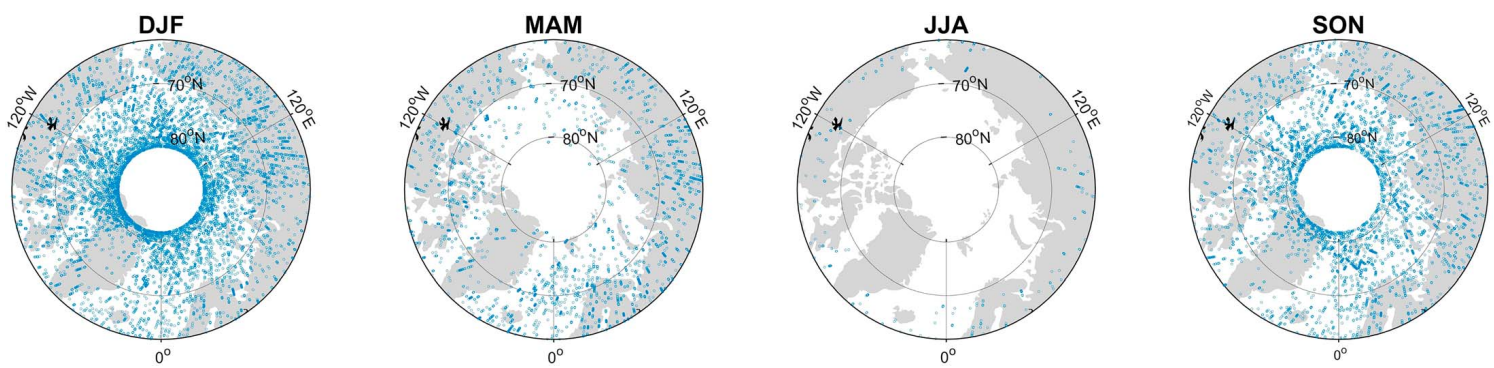

Figure 3. Seasonal and spatial distribution of the final nighttime low-level cloud $(0.75<z<3.5 \mathrm{~km})$ data set with aerosol collocation used in this study (single cloud-single aerosol cases). DJF = December-February; JJA = June-August; MAM = March-May; SON $=$ September-November.

product have been added up together for a more straightforward comparison (Figure 4, black line) between these two data sets. Good agreement between CALIPSO v4.1 and the combined CloudSat/CALIPSO data set is observed (Figure 4 dashed vs. solid lines). Any discrepancies can be justified by the difference in the CTT between these two data sets. The CTT difference was found to be $1.5^{\circ} \mathrm{C}$ and corresponds to the maximum value of $\pm 0.5 \mathrm{~km}$ for the cloud top height difference (not shown here). In addition, the radar can detect big sparse ice crystals, which are below the detection limit of the LiDAR, which can also explain the higher frequency of ice clouds found in the combined product.

Assessing an error bar to these results is rather challenging since the $y$ axis represents the occurrence (0-1) and the $x$ axis is binned every $2{ }^{\circ} \mathrm{C}$. Furthermore, the cloud phase determination itself is a qualitative measure, which is either true or false. Due to the nature of this problem, we have decided to use the bootstrapping approach without replacement in order to investigate the significance of the findings (Efron \& Tibshirani, 1994). This approach allows assigning measures of accuracy, such as standard deviation, by random selection of cases in a sample. Up to 200 random samples were selected allowing for an error estimation as shown in Figure 4 (the size of the random samples was chosen to be half of the amount of the original data set). The deviation of the lines in Figure 4 are small showing that robust conclusions can be made. This approach was used throughout this paper for the assessment of significance of the results.

\subsection{Aerosol Type Effect}

Following the procedure described in section 2, Figure 5 further links the CTT relationship of RCPOs with collocated marine, continental, dust, and elevated smoke (ES) aerosol particles. The aerosol type

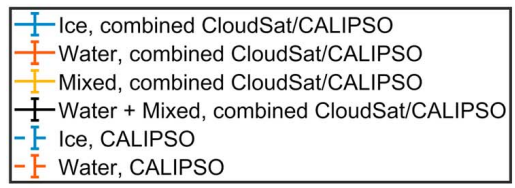

\begin{tabular}{|l|}
\hline I- Ice, combined CloudSat/CALIPSO \\
I-Water, combined CloudSat/CALIPSO \\
$\frac{1}{T}$ Mixed, combined CloudSat/CALIPSO \\
I Water + Mixed, combined CloudSat/CALIPSO \\
- - Ice, CALIPSO \\
- - Water, CALIPSO
\end{tabular}

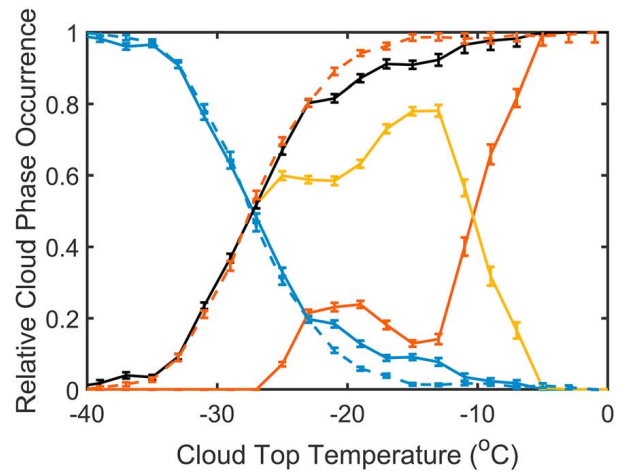

Figure 4. Relative cloud phase occurrence for each thermodynamic phase and their relationship with the cloud top temperature for low-level Arctic clouds. Low-level clouds are considered those with bases above $0.75 \mathrm{~km}$ and tops below $3.5 \mathrm{~km}$. The solid lines indicate data from the combined CloudSat/CALIPSO product, while the dashed lines are from CALIPSO observations only. The black solid line is the summation of the water and mixed phase as seen in the combined CloudSat/CALIPSO product as a reference to the liquid containing clouds derived from CALIPSO only. CALIPSO $=$ Cloud-Aerosol Lidar and Infrared Pathfinder Satellite Observation. 

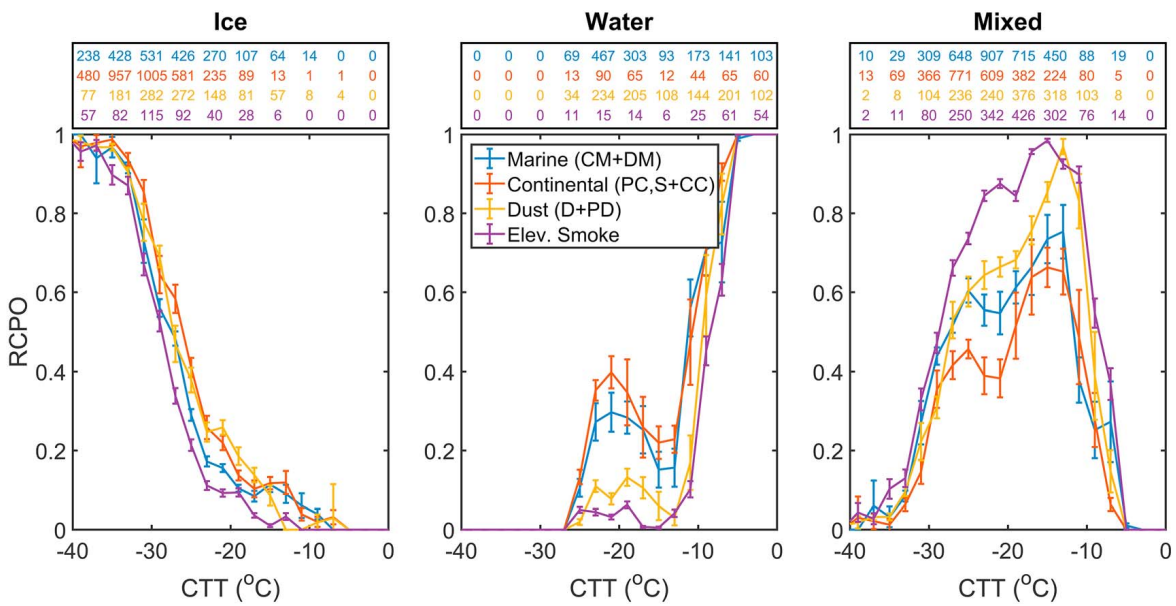

Figure 5. Relative cloud phase occurrence (RCPO) for each thermodynamic phase and their relationship with the cloud top temperature (CTT) associated with marine (clean marine [CM] and dusty marine [DM]), continental (polluted continental [PC], smoke [S], and clean continental [CC]), dust (dust [D] and polluted dust $[\mathrm{PD}]$ ) and elevated smoke (Elev. smoke) aerosol particles. Corresponding number of cases for each aerosol type summed every two temperature bins are located at the top of each thermodynamic phase panel.

information was taken from the CALIPSO v4.1 layer product and the cloud characterization from the combined CloudSat/CALIPSO product. The box on top of each cloud phase contains information on the number of cases of each aerosol type within 4 degree temperature bins (corresponding to two 2 degree bins used in the analysis. Similar to Figure 4, the bootstrapping technique was used for calculating the standard deviation.

Overall, the different aerosol types exhibit quite similar relationships between RCPO and CTT for the ice phase. However, there is a maximum of $4{ }^{\circ} \mathrm{C}$ discrepancy in CTT between ES and dust-related ice clouds at $50 \% \mathrm{RCPO}$, which suggests ice formation in warmer temperatures in the presence of dust particles. However, almost identical behavior to that of dust is observed for continental aerosol particles as well. To investigate if the sampling size among the aerosol types affects the robustness of our results, we performed a $t$ test and calculated $p$ values in each temperature bin for all six possible aerosol combinations assuming that the variables are independent from each other. The statistical testing refers to the ice phase only. The findings (see Figure S1 in the supporting information) support the aforementioned relationships where the null hypothesis (no differences among the aerosol types) is confirmed ( $p \geq 0.05$ ) for the marine versus continental/dust combinations, and statistically significant difference can be found only when ES is compared with any of the other three aerosol types. The same conclusion was found for the pair continental dust in the temperature region below $-23^{\circ} \mathrm{C}$. After exploring statistically the significance among the aerosol types, their similarities or differences can originate from the fact that continental aerosol mixtures already contain sufficient INPs for ice formation. In addition, the aerosol typing is not foolproof, since aerosol mixtures coexist within the aerosol types reported possibly narrowing the temperature gap among them. For example, Papagiannopoulos et al. (2016) compared CALIPSO level 3 aerosol type to ground-based LiDAR observations over Europe and found that CALIPSO overuses the polluted dust (PD) subtype, which normally should be classified as polluted continental (PC) or smoke. Moreover, marine aerosols are surface dependent and are not allowed over land. Another observational study by Di Biagio et al. (2018) north of Svalbard concluded that often diamond dust is misclassified as some dust type (e.g., dust or PD), while part of clean marine are actually polluted species. Additionally, after long-range transport and aging in the atmosphere, Arctic aerosols are likely coated with sulfuric acid (Girard et al., 2013) and studies suggest that aerosols coated with such material are less effective INPs (Eastwood et al., 2009; Ettner et al., 2004; Sullivan et al., 2010). Assigning a single factor from the list above resulting to this discrepancy among the different aerosol types is rather difficult. Finally, dissimilar to the average frequency of ice clouds at $-20{ }^{\circ} \mathrm{C}$ (Figure 4 ), those associated with dust aerosols showed approximately $25 \%$ higher fraction in the same temperature range. 
Regarding the water and mixed cloud phases, the discrepancies among the aerosol types are more profound. Below -15 and up to $-25^{\circ} \mathrm{C}$, water clouds related to marine and continental aerosols were more frequent than those related to dust and ES aerosols by about $20 \%$. Such behavior was present regardless the region and terrain (ocean/land) and may originate from the hygroscopicities of different aerosol types. Lastly, ES aerosols were mostly associated with mixed-phase clouds. This result is the opposite to the glaciation indirect effect in which black carbon provides more INPs and supports recent studies suggesting the limited role of black carbon as a source for INP (Ullrich et al., 2017; Vergara-Temprado et al., 2018). Airborne measurements over high latitudes indicate a reduction of $\sim 50 \%$ in the cloud droplet radii when these were in the presence of smoke aerosols (Zamora et al., 2016), supporting also less efficient glaciation due to higher droplet number concentration.

\subsection{Aerosol Load Effect}

So far, we have investigated the aerosol types association with the cloud phase occurrence. However, the temperature differences among the aerosol types in Figure 5 are within the temperature uncertainty range, and therefore, solid conclusion cannot be made. Since the CCN concentration can also affect the cloud microphysical properties and glaciation efficiency, we have investigated further the effect of aerosol load on the temperature dependence of the RCPOs. In order to do so, we have considered two aerosol categories, dust (D + PD) and the rest of the aerosol types grouped together (marine, continental, and ES). Then, these two aerosol categories were separated by setting a constraint for the aerosol optical depth (AOD). Aerosol layers with $\mathrm{AOD}<0.10$ were considered as low concentration and those with AOD $>0.25$ as high. The low AOD threshold is typical for Arctic aerosol conditions (Sand et al., 2017), while the high AOD limit is a compromise between the higher AODs, which were observed in this region and the amount of data points in our data set. Figure 6 a delivers the same information as Figure 5 but with the AOD constraint, and Figure $6 \mathrm{~b}$ shows the number of cases per aerosol type for each temperature bin for each aerosol category and load. Similarly to previous graphs, the bootstrapping technique using up to 200 randomly selected samples from the data set was used for calculating the standard deviation.

Figure 6a suggests that the aerosol concentration is more important than the aerosol type when it comes to cloud phase. From the figure, we observe that the ice RCPOs for both aerosol categories, dust and rest, show similar behavior under the same AOD constraint. Furthermore, compared to the aerosol-related water phase occurrences (Figure 5, middle panel), the separation by AOD (Figure 6a, middle panel) does not exhibit significant differences. Moreover, more mixed-phase clouds were associated with the high aerosol load, which supports recent studies associating the longevity of the Arctic mixed-phase clouds with higher CCN concentrations (Norgren et al., 2018; Stevens et al., 2018).

Figure $6 \mathrm{~b}$ shows the number of cases per aerosol type and load for the temperature range between -40 and 0 ${ }^{\circ} \mathrm{C}$. In both aerosol categories, dust and the rest, the majority of the cases fall under the low AOD conditions. Such result is expected in the Arctic since the mean AOD over the region fluctuates around 0.07 at $500 \mathrm{~nm}$ (Sand et al., 2017) with occasional pollution episodes from lower latitudes. Nevertheless, there is a rather equal fraction of mineral dust and PD cases over the dust category regardless the aerosol load. Regarding the rest category, as already mentioned the aerosol distribution is found mainly over ocean hence the majority of our cases are of marine origin. Calculated $p$ values for the Low Dust-Low Rest combination were larger than 0.05 indicating that there are no statistically significant differences between them. For the High/Low category combinations, $p$ values indicate clearly that they are statistically different. It has to be noted that although High Dust-High Rest values are overlapping in Figure 6a, some of the corresponding $p$ values were smaller than 0.05 indicating that this similarity is not statistically significant due to low number of events and large variability in $p$ values (see Figure S2 in the supporting information).

For the correct interpretation of Figure $6 \mathrm{a}$ it is fundamental to exclude sampling issues behind the significant high/low aerosol-independent difference. Di Pierro et al. (2013) examined the seasonal variation of the aerosol extinction coefficient at high latitudes for different regions by using 6 years of CALIPSO observations along with airborne measurements. They found that the mean extinction is highly variable during summer (June-August) and the month of May compared to the rest of the year and also that different regions exhibit different extinction values. Due to the nighttime restriction, our data set does not include or has only a small number of cases during those months. This means that the high and low AOD cases are mainly from the winter and autumn seasons and there is no seasonal difference between the groups. 
a)

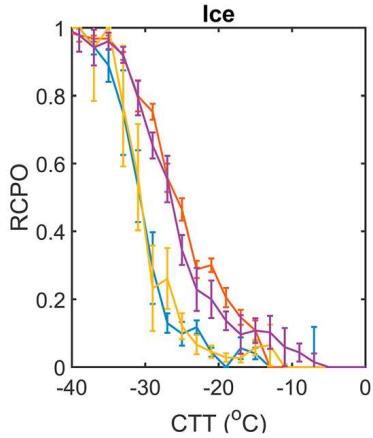

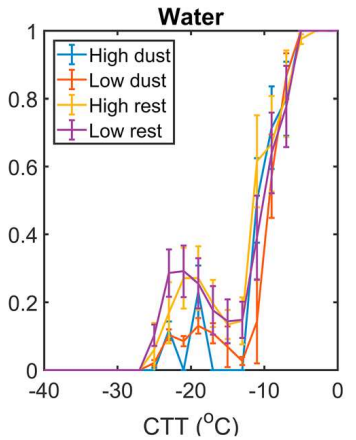

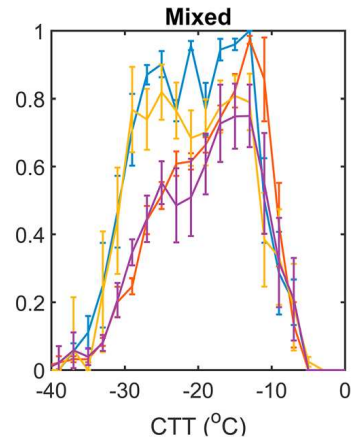

b)
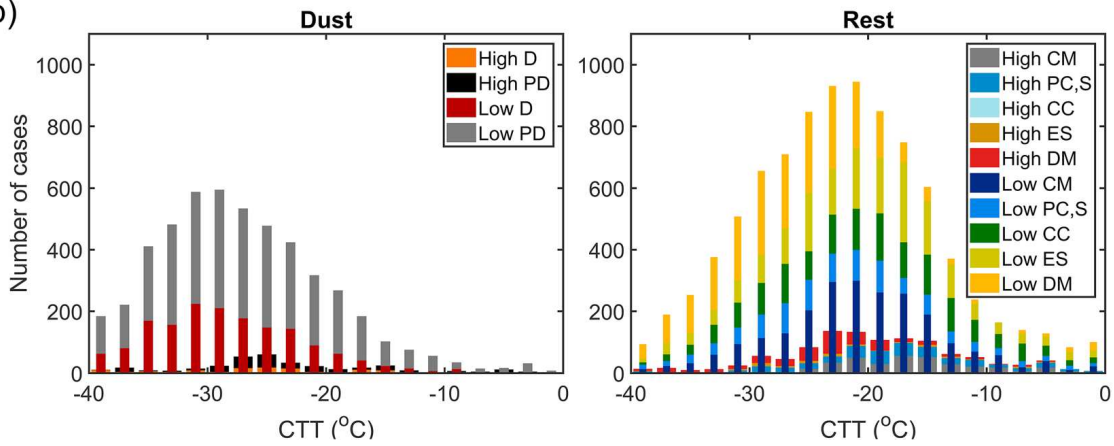

Figure 6. (a) Same as Figure 5 but here an aerosol optical depth (AOD) constrain has been applied to the data. Aerosol layers with AOD values higher that 0.25 were considered as high AOD cases and aerosol layers with AOD less than 0.1 were considered as low AOD cases, respectively. Two aerosol type categories are shown: Dust and Rest, where Rest includes marine, continental, and elevated smoke aerosols. (b) Number of cases falling in each of the two aerosol categories without cloud phase distinction. Left: dust, Right: rest. Abbreviations used: dust (D), polluted dust (PD), clean marine (CM), polluted continental/smoke (PC, S), clean continental (CC), elevated smoke (ES), and dusty marine (DM).

To confirm that the observed aerosol effect is not caused by different meteorological conditions with different aerosol typing, we have explored if atmospheric stability or aerosol relative humidity (RH) differ for different aerosol categories. Figure 7 shows the temperature dependence of the low tropospheric stability (LTS) and RH corresponding to Figures 5 and $6 \mathrm{a}$ (without cloud phase distinction). The CTT dependence of LTS (upper panels), regardless the aerosol type or aerosol load, is modest suggesting that the cloud phase is driven by the aerosol load. The same trend is observed for the RH values (lower panels in Figure 7). Regarding the spatial variability of the aerosols and whether the results are affected by regional differences, we have observed the same evident discrepancy between the high and low AOD categories when separating the data set regionally. There is an exception over North Atlantic, Barents Sea, and Greenland Sea up to the coast of Greenland (hereafter Region 1) where the differences were diminished, almost overlapping, compared to the rest regions (not shown). Looking deeper into this difference and whether it is a regional or a meteorology driven factor, we have isolated the meteorology effect over the aerosol load and type by separating the data set into high/low LTS and high/low RH values. The threshold for the LTS was below $11 \mathrm{~K}$ (Low) and above $22 \mathrm{~K}$ (High), while for the RH it was less than 65\% (Low) and above 85\% (High), respectively. Coincidentally enough, low LTS cases were gathered around Region 1 and high LTS over the rest Arctic Ocean. The difference between the two regions rely on the terrain where open ocean compared to snow/ice covered ocean is found. The region over North Atlantic is ice free most of the time allowing greater boundary layer turbulent fluxes due to open ocean driving the cloud phase. The LTS separation showed that meteorology effect dominated over the open ocean and the aerosol load effect prevails over snow/ice covered sea in the Arctic region. Higher aerosol type influence compared to aerosol load was found over the low LTS cases yet no concrete conclusions can be made due the low number of cases. Insignificant differences were observed for the RH separation regardless the case. 

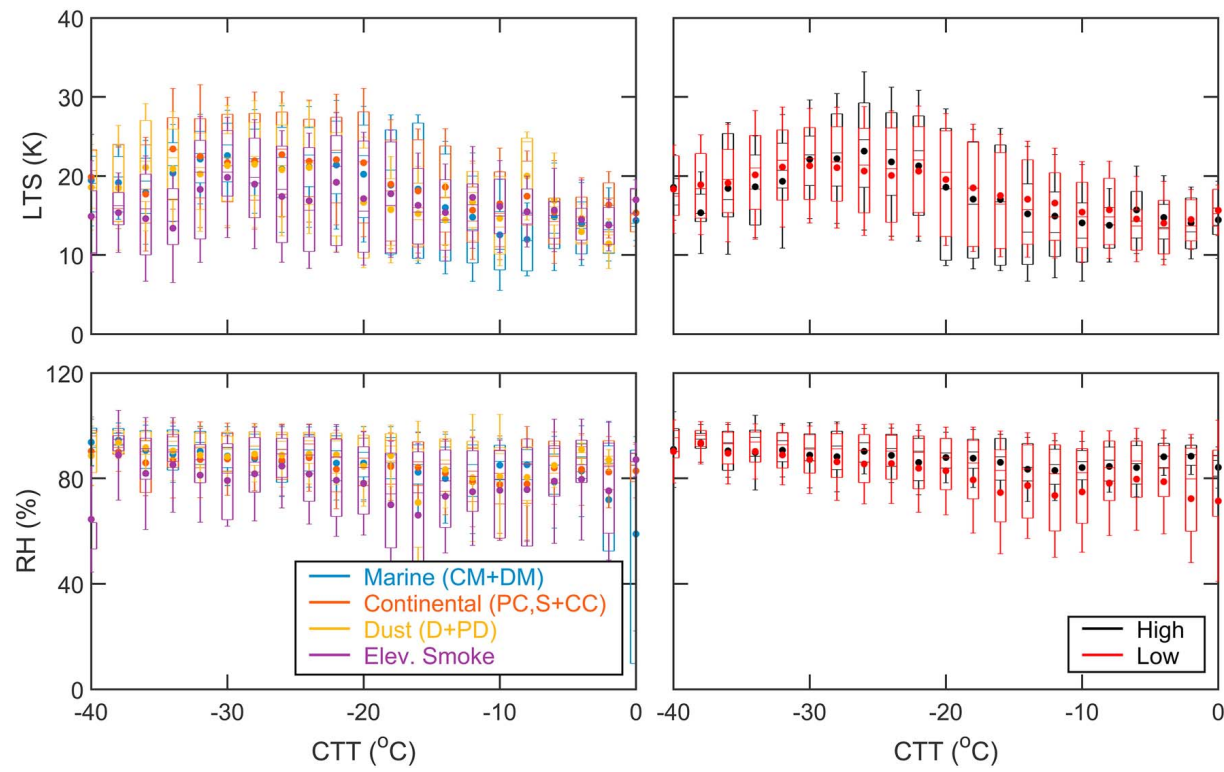

Figure 7. (upper panels) Box and whisker plots of LTS corresponding to Figure 5 (left) and Figure 6a (right). (lower panels) Box and whisker plots of RH corresponding to Figure 5 (left) and Figure 6a (right). LTS = low tropospheric stability; RH = relative humidity; $\mathrm{CM}=$ clean marine; $\mathrm{DM}=$ dusty marine; $\mathrm{PC}=$ polluted continental; $\mathrm{CC}=$ clean continental; $\mathrm{S}=$ smoke; $\mathrm{D}=$ dust $\mathrm{PD}=$ polluted dust $\mathrm{CTT}=$ cloud top temperature.

\section{Summary and Conclusions}

Three years data of nighttime CALIPSO LiDAR observations was used in synergy with CloudSat radar measurements to quantify the cloud phase dependence on aerosol type and load. The efficiency of different aerosol types to affect the heterogeneous ice nucleation and cloud glaciation at different temperatures is still highly uncertain. Satellite observations are able to narrow this knowledge gap since they offer great spatial and temporal sampling coverage over areas not accessible by continuous ground-based measurements. However, satellite data are bound with large uncertainties. In order to retrieve robust conclusions, it was necessary to limit the data set to high-quality observations only. This limited data set may not be representative for the majority of the low-level clouds since our data set was limited to low-level clouds with bases above $0.75 \mathrm{~km}$, yet it provides a robust link between the aerosol type and aerosol load to the cloud properties with the highest possible confidence. In this study, we have collocated cloud information from the combined radar-LiDAR data set and aerosol properties from the LiDAR observations.

Long-term observations over the Arctic show that mixed-phase low-level clouds occur far more frequently than ice-only or liquid-only clouds at temperatures between -25 and $-10{ }^{\circ} \mathrm{C}$. Their frequency reaches $80 \%$ in this temperature region, allowing less than $10 \%$ share for ice clouds. This result is in compliance with previous studies over other regions and supports the idea of ice formation in the supercooled liquid layer at the top of a cloud.

To get a better insight of the aerosol-related cloud characteristics, we have further linked the CTT, the aerosol type detected in the vicinity of the cloud, and the cloud thermodynamic phase (ice, water, and mixed). In general, the aerosol type dependence of ice clouds was found to be modest. Compared to the frequency of glaciated clouds at $-20^{\circ} \mathrm{C}$, those associated with dust aerosols had $\sim 25 \%$ higher frozen fraction at this temperature. Overall, the CTT discrepancy at $50 \%$ of ice cloud occurrence over the different aerosol types did not exceed $4{ }^{\circ} \mathrm{C}$. More specifically, there was no difference between dust and continental aerosol-related ice clouds. Both categories were separated from marine and ES related ice clouds by $2-4{ }^{\circ} \mathrm{C}$. The behavior behind this difference can be originated by instrumental limitations or physical effects. However, it has to be noted that the LiDAR can only distinguish between the dominant aerosol type; hence, mixtures can 
coexist. Presumably, INP concentrations in continental aerosol mixtures can be already sufficient for ice formation or the effectiveness of dust aerosols is limited due to sulfuric acid coating, thus narrowing their glaciation temperature gap.

Previous studies have also suggested that the cloud phase might also depend on the aerosol load through the number of INP or CCN. To investigate this, we have separated the data set into high/low aerosol load. We confirmed the significance of the concentration to the cloud phase since it outweighed the aerosol type CTT discrepancy. Such behavior was evident regardless the aerosol type. The CTT difference of ice clouds between the high/low aerosol load categories was more than $6{ }^{\circ} \mathrm{C}$. Moreover, the high aerosol load category was linked with higher mixed-phase cloud occurrences, which supports recent studies proposing that the high $\mathrm{CCN}$ concentration in mixed-phase clouds delays their dissipation time, assuming that higher aerosol load equals more $\mathrm{CCN}$.

We also acknowledge that the impacts of the dynamical atmospheric processes can equally contribute/modify the aforementioned associations (Morrison et al., 2011). The lower tropospheric stability (LTS) and RH were used in this study as a measure to address the meteorology effect. The findings suggest a complex interplay between meteorology, aerosol load, and aerosol type under certain conditions. For example, this was observed over North Atlantic and Barents Sea where the CTT discrepancies among the aerosol types and aerosol loads were diminished due to the open ocean and the lower atmospheric stability in this region (meteorology dominates cloud formation). Nonetheless, the aerosol load outweighed meteorology and aerosol type over the rest of Arctic regions. Constraining meteorology and aerosol driven effects on clouds is challenging, yet more effort should be put toward this direction. Neither should we forget that spaceborne observations retrieve the vertical information along their track and do not follow the formation of the cloud itself. Whether these findings are universal or they are only valid over high latitudes is an open question. But this paper, along with a plethora of recent studies, underlies the importance of aerosols, both their amount and their type, in the warming Arctic and gives an insight of possible future Arctic climate implications.

In the future, we will focus on the retrieval of the INP/CCN concentration profiles in order to have a straightforward association of the in-cloud properties. Advanced LiDAR methods developed recently (Mamouri \& Ansmann, 2016) give such opportunity, but they are yet to be applied into spaceborne observations. Regarding the used data set, we suggest that a new version of the combined CloudSat/CALIPSO product should be released employing the latest and significantly improved version of the CALIPSO algorithms since mixed-phase clouds are prevalent over the Arctic and as shown they could play a key role in aerosolcloud interactions.

\section{Acknowledgments}

The CALIPSO data used in this study are publicly available from the NASA Langley Research Center Atmospheric Science Data Center (https://search. earthdata.nasa.gov/search). We also acknowledge NASA CloudSat project for the provision of the publicly available CloudSat data (http://www. cloudsat.cira.colostate.edu/order-data). The codes for reproducing the results of this study can be found at the GitHub repository (https://github.com/TUTISI/Filioglou_et_al_2019_JGR (DOI: 10.5281/zenodo.3244067). The research was supported by the Academy of Finland (projects 285067, 283031, and 309127).

\section{References}

Aksenov, Y., Karcher, M., Proshutinsky, A., Gerdes, R., De Cuevas, B., Golubeva, E., et al. (2017). Arctic pathways of Pacific Water: Arctic Ocean Model Intercomparison experiments. Journal of Geophysical Research: Oceans, 121, 27-59. https://doi.org/10.1002/ 2015JC011299@10.1002/(ISSN)2169-9291.FAMOS1

Ansmann, A., Tesche, M., Seifert, P., Althausen, D., Engelmann, R., Fruntke, J., et al. (2009). Evolution of the ice phase in tropical altocumulus: SAMUM lidar observations over Cape Verde. Journal of Geophysical Research, 114, D17208. https://doi.org/10.1029/ 2008JD011659

Atkinson, J. D., Murray, B. J., Woodhouse, M. T., Whale, T. F., Baustian, K. J., Carslaw, K. S., et al. (2013). The importance of feldspar for ice nucleation by mineral dust in mixed-phase clouds. Nature, 498(7454), 355-358. https://doi.org/10.1038/nature12278

Bennartz, R., Shupe, M. D., Turner, D. D., Walden, V. P., Steffen, K., Cox, C. J., et al. (2013). July 2012 Greenland melt extent enhanced by low-level liquid clouds. Nature, 496(7443), 83-86. https://doi.org/10.1038/nature12002

Bintanja, R., \& Krikken, F. (2016). Magnitude and pattern of Arctic warming governed by the seasonality of radiative forcing. Scientific Reports, 6(1), 38287. https://doi.org/10.1038/srep38287

Boucher, O., Randall, D., Artaxo, P., Bretherton, C., Feingold, G., Forster, P., et al. (2013). Clouds and aerosols. In Intergovernmental Panel on Climate Change (Ed.), Climate Change 2013 - The Physical Science Basis (pp. 571-658). Cambridge: Cambridge University Press. https://doi.org/10.1017/CBO9781107415324.016

Candlish, L. M., Raddatz, R. L., Gunn, G. G., Asplin, M. G., \& Barber, D. G. (2013). A validation of CloudSat and CALIPSO's temperature, humidity, cloud detection, and cloud base height over the Arctic marine cryosphere. Atmosphere-Ocean, 51(3), 249-264. https://doi.org/ $10.1080 / 07055900.2013 .798582$

Cesana, G., Kay, J. E., Chepfer, H., English, J. M., \& de Boer, G. (2012). Ubiquitous low-level liquid-containing Arctic clouds: New observations and climate model constraints from CALIPSO-GOCCP. Geophysical Research Letters, 39, L20804. https://doi.org/10.1029/ 2012GL053385

Chan, M. A., \& Comiso, J. C. (2013). Arctic cloud characteristics as derived from MODIS, CALIPSO, and CloudSat. Journal of Climate, 26(10), 3285-3306. https://doi.org/10.1175/JCLI-D-12-00204.1

Chan, M. A., Comiso, J. C., Chan, M. A., \& Comiso, J. C. (2013). Arctic cloud characteristics as derived from MODIS, CALIPSO, and CloudSat. Journal of Climate, 26(10), 3285-3306. https://doi.org/10.1175/JCLI-D-12-00204.1 
Christensen, M. W., \& Stephens, G. L. (2012). Microphysical and macrophysical responses of marine stratocumulus polluted by underlying ships: 2. Impacts of haze on precipitating cloud. Journal of Geophysical Research, 117, D03201. https://doi.org/10.1029/2011JD017125

Christensen, M. W., Stephens, G. L., \& Lebsock, M. D. (2013). Exposing biases in retrieved low cloud properties from CloudSat: A guide for evaluating observations and climate data. Journal of Geophysical Research: Atmospheres, 118, 12,120-12,131. https://doi.org/10.1002/ 2013JD020224

Coopman, Q., Garrett, T. J., Finch, D. P., \& Riedi, J. (2018). High sensitivity of Arctic liquid clouds to long-range anthropogenic aerosol transport. Geophysical Research Letters, 45, 372-381. https://doi.org/10.1002/2017GL075795

Coopman, Q., Riedi, J., Finch, D. P., \& Garrett, T. J. (2018). Evidence for changes in Arctic cloud phase due to long-range pollution transport. Geophysical Research Letters, 45, 10,709-10,718. https://doi.org/10.1029/2018GL079873

Cronin, T. W., \& Tziperman, E. (2015). Low clouds suppress Arctic air formation and amplify high-latitude continental winter warming. Proceedings of the National Academy of Sciences of the United States of America, 112(37), 11,490-11,495. https://doi.org/10.1073/ pnas. 1510937112

de Boer, G., Morrison, H., Shupe, M. D., \& Hildner, R. (2011). Evidence of liquid dependent ice nucleation in high-latitude stratiform clouds from surface remote sensors. Geophysical Research Letters, 38, L01803. https://doi.org/10.1029/2010GL046016

DeMott, P. J., Sassen, K., Poellot, M. R., Baumgardner, D., Rogers, D. C., Brooks, S. D., et al. (2003). African dust aerosols as atmospheric ice nuclei. Geophysical Research Letters, 30(14), 1732. https://doi.org/10.1029/2003GL017410

Di Biagio, C., Pelon, J., Ancellet, G., Bazureau, A., \& Mariage, V. (2018). Sources, load, vertical distribution, and fate of wintertime aerosols north of Svalbard from combined V4 CALIOP data, ground-based IAOOS lidar observations and trajectory analysis. Journal of Geophysical Research: Atmospheres, 123, 1363-1383. https://doi.org/10.1002/2017JD027530

Di Pierro, M., Jaeglé, L., Eloranta, E. W., \& Sharma, S. (2013). Spatial and seasonal distribution of Arctic aerosols observed by the CALIOP satellite instrument (2006-2012). Atmospheric Chemistry and Physics, 13(14), 7075-7095. https://doi.org/10.5194/acp-13-7075-2013

Eastwood, M. L., Cremel, S., Wheeler, M., Murray, B. J., Girard, E., \& Bertram, A. K. (2009). Effects of sulfuric acid and ammonium sulfate coatings on the ice nucleation properties of kaolinite particles. Geophysical Research Letters, 36, L02811. https://doi.org/10.1029/ 2008GL035997

Efron, B., \& Tibshirani, R. (1994). An introduction to the bootstrap. London. Retrieved from: Chapman \& Hall. https://www.crcpress.com/ An-Introduction-to-the-Bootstrap/Efron-Tibshirani/p/book/9780412042317

Ettner, M., Mitra, S. K., \& Borrmann, S. (2004). Heterogeneous freezing of single sulfuric acid solution droplets: Laboratory experiments utilizing an acoustic levitator. Atmospheric Chemistry and Physics, 4(7), 1925-1932. https://doi.org/10.5194/acp-4-1925-2004

Flanner, M. G. (2013). Arctic climate sensitivity to local black carbon. Journal of Geophysical Research: Atmospheres, 118, 1840-1851. https://doi.org/10.1002/jgrd.50176

Garrett, T. J., Radke, L. F., Hobbs, P. V., Garrett, T. J., Radke, L. F., \& Hobbs, P. V. (2002). Aerosol effects on cloud emissivity and surface longwave heating in the Arctic. Journal of the Atmospheric Sciences, 59(3), 769-778. https://doi.org/10.1175/1520-0469(2002)059<0769: AEOCEA $>2.0 . \mathrm{CO} ; 2$

Garrett, T. J., Zhao, C., Dong, X., Mace, G. G., \& Hobbs, P. V. (2004). Effects of varying aerosol regimes on low-level Arctic stratus. Geophysical Research Letters, 31, L17105. https://doi.org/10.1029/2004GL019928

Girard, E., Dueymes, G., Du, P., \& Bertram, A. K. (2013). Assessment of the effects of acid-coated ice nuclei on the Arctic cloud microstructure, atmospheric dehydration, radiation and temperature during winter. International Journal of Climatology, 33(3), 599-614. https://doi.org/10.1002/joc.3454

Holland, M. M., Bitz, C. M., \& Tremblay, B. (2006). Future abrupt reductions in the summer Arctic sea ice. Geophysical Research Letters, 33 , L23503. https://doi.org/10.1029/2006GL028024

Intrieri, J. M., Fairall, C. W., Shupe, M. D., Persson, P. O. G., Andreas, E. L., Guest, P. S., \& Moritz, R. E. (2002). An annual cycle of Arctic surface cloud forcing at SHEBA. Journal of Geophysical Research, 107(C10), 8039. https://doi.org/10.1029/2000JC000439

Kanji, Z. A., Ladino, L. A., Wex, H., Boose, Y., Burkert-Kohn, M., Cziczo, D. J., \& Krämer, M. (2017). Overview of ice nucleating particles. Meteorological Monographs, 58, 1.1-1.33. https://doi.org/10.1175/AMSMONOGRAPHS-D-16-0006.1

Kar, J., Vaughan, M. A., Lee, K.-P., Tackett, J. L., Avery, M. A., Garnier, A., et al. (2018). CALIPSO lidar calibration at 532 nm: Version 4 nighttime algorithm. Atmospheric Measurement Techniques, 11(3), 1459-1479. https://doi.org/10.5194/amt-11-1459-2018

Karlsson, J., \& Svensson, G. (2013). Consequences of poor representation of Arctic sea-ice albedo and cloud-radiation interactions in the CMIP5 model ensemble. Geophysical Research Letters, 40, 4374-4379. https://doi.org/10.1002/grl.50768

Kay, J. E., \& Gettelman, A. (2009). Cloud influence on and response to seasonal Arctic sea ice loss. Journal of Geophysical Research, 114, D18204. https://doi.org/10.1029/2009JD011773

Kim, M.-H., Omar, A. H., Tackett, J. L., Vaughan, M. A., Winker, D. M., Trepte, C. R., et al. (2018). The CALIPSO version 4 automated aerosol classification and lidar ratio selection algorithm. Atmospheric Measurement Techniques Discussions. https://doi.org/10.5194/ amt-2018-166, 1, 43

Law, K. S., \& Stohl, A. (2007). Arctic air pollution: Origins and impacts. Science, 315(5818), 1537-1540. https://doi.org/10.1126/ science. 1137695

Li, J., Huang, J., Stamnes, K., Wang, T., Lv, Q., \& Jin, H. (2015). A global survey of cloud overlap based on CALIPSO and CloudSat measurements. Atmospheric Chemistry and Physics, 15(1), 519-536. https://doi.org/10.5194/acp-15-519-2015

Li, R., Dong, X., Guo, J., Fu, Y., Zhao, C., Wang, Y., \& Min, Q. (2017). The implications of dust ice nuclei effect on cloud top temperature in a complex mesoscale convective system. Scientific Reports, 7(1), 13826. https://doi.org/10.1038/s41598-017-12681-0

Li, X., Zheng, X., Zhang, D., Zhang, W., Wang, F., Deng, Y., \& Zhu, W. (2018). Clouds over East Asia observed with collocated CloudSat and CALIPSO measurements: Occurrence and macrophysical properties. Atmosphere, 9(5), 168. https://doi.org/10.3390/atmos9050168

Mamouri, R.-E., \& Ansmann, A. (2016). Potential of polarization lidar to provide profiles of CCN- and INP-relevant aerosol parameters. Atmospheric Chemistry and Physics, 16(9), 5905-5931. https://doi.org/10.5194/acp-16-5905-2016

Mioche, G., Jourdan, O., Ceccaldi, M., \& Delanoë, J. (2015). Variability of mixed-phase clouds in the Arctic with a focus on the Svalbard region: A study based on spaceborne active remote sensing. Atmospheric Chemistry and Physics, 15(5), 2445-2461. https://doi.org/ 10.5194/acp-15-2445-2015

Morrison, H., de Boer, G., Feingold, G., Harrington, J., Shupe, M. D., \& Sulia, K. (2011). Resilience of persistent Arctic mixed-phase clouds Nature Geoscience, 5(1), 11-17. https://doi.org/10.1038/ngeo1332

Morrison, H., Shupe, M. D., Pinto, J. O., \& Curry, J. A. (2005). Possible roles of ice nucleation mode and ice nuclei depletion in the extended lifetime of Arctic mixed-phase clouds. Geophysical Research Letters, 32, L18801. https://doi.org/10.1029/2005GL023614

Noh, Y.-J., Seaman, C. J., Vonder Haar, T. H., Hudak, D. R., \& Rodriguez, P. (2011). Comparisons and analyses of aircraft and satellite observations for wintertime mixed-phase clouds. Journal of Geophysical Research, 116, D18207. https://doi.org/10.1029/2010JD015420 
Norgren, M. S., de Boer, G., \& Shupe, M. D. (2018). Observed aerosol suppression of cloud ice in low-level Arctic mixed-phase clouds. Atmospheric Chemistry and Physics, 18(18), 13,345-13,361. https://doi.org/10.5194/acp-18-13345-2018

Papagiannopoulos, N., Mona, L., Alados-Arboledas, L., Amiridis, V., Baars, H., Binietoglou, I., et al. (2016). CALIPSO climatological products: Evaluation and suggestions from EARLINET. Atmospheric Chemistry and Physics, 16(4), 2341-2357. https://doi.org/10.5194/acp16-2341-2016

Partain, P. (2007). Cloudsat ECMWF-AUX auxiliary data process description and interface control document. Fort Collins, CO, USA: Cooperative Institute for Research in the Atmosphere, Colorado State University. 80523

Possner, A., Ekman, A. M. L., \& Lohmann, U. (2017). Cloud response and feedback processes in stratiform mixed-phase clouds perturbed by ship exhaust. Geophysical Research Letters, 44, 1964-1972. https://doi.org/10.1002/2016GL071358

Prenni, A. J., Petters, M. D., Kreidenweis, S. M., Heald, C. L., Martin, S. T., Artaxo, P., et al. (2009). Relative roles of biogenic emissions and Saharan dust as ice nuclei in the Amazon basin. Nature Geoscience, 2(6), 402-405. https://doi.org/10.1038/ngeo517

Price, H. C., Baustian, K. J., McQuaid, J. B., Blyth, A., Bower, K. N., Choularton, T., et al. (2018). Atmospheric ice-nucleating particles in the dusty tropical Atlantic. Journal of Geophysical Research: Atmospheres, 123, 2175-2193. https://doi.org/10.1002/2017JD027560

Quinn, P. K., Bates, T. S., Baum, E., Doubleday, N., Fiore, A. M., Flanner, M., et al. (2008). Short-lived pollutants in the Arctic: Their climate impact and possible mitigation strategies. Atmospheric Chemistry and Physics, 8(6), 1723-1735. https://doi.org/10.5194/acp-8-1723-2008

Quinn, P. K., Shaw, G., Andrews, E., Dutton, E. G., Ruoho-Airola, T., \& Gong, S. L. (2007). Arctic haze: Current trends and knowledge gaps. Tellus B, 59(1), 115-129. https://doi.org/10.1111/j.1600-0889.2006.00238.x

Ritter, C., Notholt, J., Fischer, J., \& Rathke, C. (2005). Direct thermal radiative forcing of tropospheric aerosol in the Arctic measured by ground based infrared spectrometry. Geophysical Research Letters, 32, L23816. https://doi.org/10.1029/2005GL024331

Sand, M., Samset, B. H., Balkanski, Y., Bauer, S., Bellouin, N., Berntsen, T. K., et al. (2017). Aerosols at the poles: an AeroCom Phase II multi-model evaluation. Atmospheric Chemistry and Physics, 17(19), 12,197-12,218. https://doi.org/10.5194/acp-17-12197-2017

Sassen, K., Wang, Z., \& Liu, D. (2008). Global distribution of cirrus clouds from CloudSat/Cloud-Aerosol Lidar and Infrared Pathfinder Satellite Observations (CALIPSO) measurements. Journal of Geophysical Research, 113, D00A12. https://doi.org/10.1029/2008JD009972

Schweiger, A. J., Lindsay, R. W., Vavrus, S., \& Francis, J. A. (2008). Relationships between Arctic sea ice and clouds during autumn. Journal of Climate, 21(18), 4799-4810. https://doi.org/10.1175/2008JCLI2156.1

Seifert, P., Ansmann, A., Mattis, I., Wandinger, U., Tesche, M., Engelmann, R., et al. (2010). Saharan dust and heterogeneous ice formation: Eleven years of cloud observations at a central European EARLINET site. Journal of Geophysical Research, 115, D20201. https://doi.org/ 10.1029/2009JD013222

Shupe, M. D., \& Intrieri, J. M. (2004). Cloud radiative forcing of the Arctic surface: The influence of cloud properties, surface albedo, and solar zenith angle. Journal of Climate, 17(3), 616-628. https://doi.org/10.1175/1520-0442(2004)017<0616:CRFOTA >2.0.CO;2

Smith, L. C., \& Stephenson, S. R. (2013). New Trans-Arctic shipping routes navigable by midcentury. Proceedings of the National Academy of Sciences of the United States of America, 110(13), E1191-E1195. https://doi.org/10.1073/pnas.1214212110

Solomon, A., de Boer, G., Creamean, J. M., McComiskey, A., Shupe, M. D., Maahn, M., \& Cox, C. (2018). The relative impact of cloud condensation nuclei and ice nucleating particle concentrations on phase partitioning in Arctic mixed-phase stratocumulus clouds. Atmospheric Chemistry and Physics, 18(23), 17,047-17,059. https://doi.org/10.5194/acp-18-17047-2018

Stephens, G. L., Vane, D. G., Boain, R. J., Mace, G. G., Sassen, K., Wang, Z., et al., \& the CloudSat Science Team (2002). THE CLOUDSAT MISSION AND THE A-TRAIN. Bulletin of the American Meteorological Society, 83(12), 1771-1790. https://doi.org/10.1175/BAMS-83-121771

Stephenson, S. R., Smith, L. C., Brigham, L. W., \& Agnew, J. A. (2013). Projected 21st-century changes to Arctic marine access. Climatic Change, 118(3-4), 885-899. https://doi.org/10.1007/s10584-012-0685-0

Stevens, R. G., Loewe, K., Dearden, C., Dimitrelos, A., Possner, A., Eirund, G. K., et al. (2018). A model intercomparison of CCNlimited tenuous clouds in the high Arctic. Atmospheric Chemistry and Physics, 18(15), 11,041-11,071. https://doi.org/10.5194/acp-1811041-2018

Sullivan, R. C., Petters, M. D., DeMott, P. J., Kreidenweis, S. M., Wex, H., Niedermeier, D., et al. (2010). Irreversible loss of ice nucleation active sites in mineral dust particles caused by sulphuric acid condensation. Atmospheric Chemistry and Physics Discussions, 10(7), 16,901-16,940. https://doi.org/10.5194/acpd-10-16901-2010

Tan, I., Storelvmo, T., \& Zelinka, M. D. (2016). Observational constraints on mixed-phase clouds imply higher climate sensitivity. Science (New York, N.Y.), 352(6282), 224-227. https://doi.org/10.1126/science.aad5300

Ullrich, R., Hoose, C., Möhler, O., Niemand, M., Wagner, R., Höhler, K., et al. (2017). A new ice nucleation active site parameterization for desert dust and soot. Journal of the Atmospheric Sciences, 74(3), 699-717. https://doi.org/10.1175/JAS-D-16-0074.1

Vergara-Temprado, J., Holden, M. A., Orton, T. R., O'Sullivan, D., Umo, N. S., Browse, J., et al. (2018). Is black carbon an unimportant icenucleating particle in mixed-phase clouds? Journal of Geophysical Research: Atmospheres, 123, 4273-4283. https://doi.org/10.1002/ 2017JD027831

Wang, Z., Vane, D., Stephens, G., \& Reinke, D. (2012). Level 2 combined radar and lidar cloud scenario classification product process description and interface control document. Retrieved May 22, 2018, from http://www.cloudsat.cira.colostate.edu/sites/default/files/\% 0Aproducts/files/2B-CLDCLASS-LIDAR_PDICD.P_R04.20120522.pdf

Winker, D. (2016). CALIPSO LID_L2_05kmMLay-Standard-V4-10 [2008 2010]. Retrieved from https://doi.org/10.5067/CALIOP/ CALIPSO/LID_L2_05kmMLay-Standard-V4-10\%0A\%0A

Winker, D. M., Pelon, J., Coakley, J. A. Jr., Ackerman, S. A., Charlson, R. J., Colarco, P. R., et al. (2010). The CALIPSO Mission. Bulletin of the American Meteorological Society, 91(9), 1211-1230. https://doi.org/10.1175/2010BAMS3009.1

Wylie, D. P. (2001). Arctic weather during the FIRE/ACE flights in 1998. Journal of Geophysical Research, 106(D14), 15,363-15,375. https:// doi.org/10.1029/2000JD900750

Wylie, D. P., \& Hudson, J. G. (2002). Effects of long-range transport and clouds on cloud condensation nuclei in the springtime Arctic. Journal of Geophysical Research, 107(D16), 4318. https://doi.org/10.1029/2001JD000759

Yang, W., Marshak, A., Várnai, T., \& Liu, Z. (2012). Effect of CALIPSO cloud-aerosol discrimination (CAD) confidence levels on observations of aerosol properties near clouds. Atmospheric Research, 116, 134-141. https://doi.org/10.1016/j.atmosres.2012.03.013

Yeo, H., Park, S.-J., Kim, B.-M., Shiobara, M., Kim, S.-W., Kwon, H., et al. (2018). The observed relationship of cloud to surface longwave radiation and air temperature at Ny-Ålesund, Svalbard. Tellus B: Chemical and Physical Meteorology, 70(1), 1-10. https://doi.org/ $10.1080 / 16000889.2018 .1450589$

Zamora, L. M., Kahn, R. A., Cubison, M. J., Diskin, G. S., Jimenez, J. L., Kondo, Y., et al. (2016). Aircraft-measured indirect cloud effects from biomass burning smoke in the Arctic and subarctic. Atmospheric Chemistry and Physics, 16(2), 715-738. https://doi.org/10.5194/ acp-16-715-2016 
Zamora, L. M., Kahn, R. A., Eckhardt, S., McComiskey, A., Sawamura, P., Moore, R., \& Stohl, A. (2017). Aerosol indirect effects on the nighttime Arctic Ocean surface from thin, predominantly liquid clouds. Atmospheric Chemistry and Physics, 17(12), 7311-7332. https://doi.org/10.5194/acp-17-7311-2017

Zamora, L. M., Kahn, R. A., Huebert, K. B., Stohl, A., \& Eckhardt, S. (2018). A satellite-based estimate of combustion aerosol cloud microphysical effects over the Arctic Ocean. Atmospheric Chemistry and Physics, 18(20), 14,949-14,964. https://doi.org/10.5194/acp-1814949-2018

Zhang, D., Liu, D., Luo, T., Wang, Z., \& Yin, Y. (2015). Aerosol impacts on cloud thermodynamic phase change over East Asia observed with CALIPSO and CloudSat measurements. Journal of Geophysical Research: Atmospheres, 120, 1490-1501. https://doi.org/10.1002/ 2014JD022630

Zhao, C., \& Garrett, T. J. (2015). Effects of Arctic haze on surface cloud radiative forcing. Geophysical Research Letters, 42, 557-564. https://doi.org/10.1002/2014GL062015 

FINNISH METEOROLOGICAL INSTITUTE

Erik Palménin aukio 1

P.O. Box 503

FI-00560 HELSINKI

tel. +358 295391000

\section{WWW.FMI.FI}

FINNISH METEOROLOGICAL INSTITUTE CONTRIBUTIONS No. 166

ISSN 0782-6117

ISBN 978-952-336-110-2 (pdf)

https://doi.org/10.35614/isbn.9789523361102
ISBN 978-952-336-109-6 (paperback)

$\because .8$
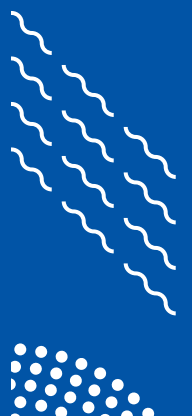